TaCtics at The Category LeVel of Purchasing AND Supply Management:

SOURCING LEVERs, CONTINGENCIES AND PERFORMANCE 

Frank Henrik Hesping

\section{TACTICS AT THE CATEgory LEVEL OF Purchasing AND Supply MaNagement:}

SOURCING LEVERs, CONTINGENCIES AND PERFoRMANCE 



\title{
TACTICS AT THE CATEgory LeVEl OF Purchasing ANd Supply Management:
}

\author{
SOURCING LEVERS, CONTINGENCIES AND PERFORMANCE
}

\author{
DISSERTATION
}

to obtain

the degree of doctor at the University of Twente, on the authority of the rector magnificus,

Prof.dr. H. Brinksma,

on account of the decision of the graduation committee,

to be publicly defended

on Thursday, $26^{\text {th }}$ November, 2015 at 12.45 hours

by

\section{Frank Henrik Hesping}

born on the $9^{\text {th }}$ April 1984

in Lingen, Germany 
This dissertation has been approved by:

Prof. Dr. habil. Holger Schiele

Frank Henrik Hesping: 2015

ISBN: 978-90-365-4002-5 



\section{Promotion Committee}

Chairman and Secretary:

Prof.dr. Th.A.J. Toonen

Promotor:

Prof. Dr. habil. H. Schiele

Members:

Prof. Dr. habil. Dr. h.c. U. Arnold

Prof. Dr. N.M.M.D. Fouto

Prof.dr.ir. J.I.M. Halman

Prof.dr.ir. J. Henseler

Prof.dr. M.R. Kabir

All rights reserved. No part of this publication may be reproduced, stored in a database or retrieval system, or published in any form or in any way, electronically, mechanically, by print, photo print, microfilm, or any other means without prior written permission by the author and Volkswagen AG. Publications concerning the content of this work require the written consent of Volkswagen AG. The results, opinions and conclusions expressed in this thesis are not necessarily those of Volkswagen AG. 



\section{ACKNOWLEDGEMENTS}

"A magic dwells in each beginning"

Hermann Hesse

Writing these lines, it is natural to reflect on where I was at the beginning of this thesis. Throughout my diploma/master studies, I have tried to combine theory with practice. It has always and still fascinates me how elements and people in a complex system collaborate to ultimately generate a meaningful output.

Following my interests, I decided to combine academia and practice as a doctoral student in the area of purchasing and supply management. Coming from a manufacturing major background, at first, things seemed utterly unfamiliar. Yet, I remember myself being confronted with an entirely new vocabulary, roles and responsibilities. However, as German poet Hermann Hesse would say: "A magic dwells in each beginning". I found this magic in being able to enjoy both an excellent academic environment and a highly professional purchasing organization. After several highly inspiring years, I am highly excited to present you this thesis as one tangible outcome of my work.

This dissertation would certainly not have been possible without the support and encounters with many people, the most important ones of whom I would like to mention here.

First, I would like to express my heartfelt gratitude to my supporter and supervisor Prof. Dr. habil. Holger Schiele. Dear Holger, I admire your ability to give the right advice at the right time. You have believed in me and motivated me from the beginning and never ceased to support me. From you, I did not only learn about how to produce excellent academic output, but also how to be a humane and humble character. Thank you for showing me the big picture when I lost myself in details. 
Many thanks go to the participants of the IPSERA, EurOMA and AutoUni conferences, doctoral seminars and the IFPSM summer school for their fruitful early feedback on various earlier versions of the studies presented in this thesis.

Furthermore, I would like to express my gratitude to Prof. Dr. habil. Dr. h.c. Ulli Arnold, Prof. Dr. Nuno Manoel Martins Dias Fouto, Prof.dr.ir. Johannes Halman, Prof.dr.ir. Jörg Henseler, Prof.dr. Rezaul Kabir and Prof.dr. Theo Toonen for your interest in the topic and for being part of the promotion committee.

Particular thanks go to my sponsors Ralf Brandstätter and Dr. Jochen Brüning, my supervisor Marco Philippi, the team from the purchasing board office, and my colleagues. Thank you for your support and your willingness to listen to the challenges and obstacles I encountered during my journey. Marco, thank you for the trust you put into my work and for setting the excellent conditions for me to pursue my ideas.

Special thanks also go to Dr. Frank Czymmek. Frank, thank you for making things happen. You did not only offer numerous valuable opportunities for feedback and exchange, but also taught me how rewarding it can be to give before you receive.

I would not have been able to experience so many facets of the life as a doctoral student without my peers in the $\mathrm{PhD}$ network. You gave me an invaluable sense of companionship during the inevitable ups and downs of my journey. I will always remember the social events and gatherings that helped me find new friends and feel that I am not the only one out there coping with the challenges of a dissertation in the industry.

Last but not least, I would like to thank my family. Your unconditional love and support helps me in countless ways every day of my life. Thank you for believing in me and for instilling in me the right values and capabilities to realise my dreams. Thank you for showing and reminding me of the magic in each day.

Frank Henrik Hesping 


\section{Table of Contents}

Acknowledgements. I

Chapter 1: Thesis Background and Research Structure .....................................1

1.1. Introduction: the need for developing different tactics for specific sourced product categories. 1

1.2. Sourcing categories and tactical sourcing levers: not all materials and buyer-supplier relationships are to be managed in the same way 2

1.3. Research questions: the relationship among sourcing levers, sourcing category characteristics and performance.

1.4. Research design: research themes, objectives and adopted methodologies .5

1.5. Research setting: an academic-practitioner collaborative research approach

1.6. Research contribution: advancing theory and practice at the category level of purchasing.

Chapter 2: Purchasing strategy development - a multi-level review.................17

2.1. Introduction: a fragmented research field of strategy in purchasing ..........17

2.2. Material collection: a structured keyword search

2.3. Descriptive analysis: assessing formal aspects of selected publications ....21

2.4. Qualitative analysis: toward a hierarchical framework of strategy development in purchasing 24

2.5. Conclusions and implications: a hierarchy of strategies and tactics.......

\section{Chapter 3: Sourcing levers - developing a formative method of} measurement

3.1. Introduction: sourcing levers require a method for measurement .............43

3.2. Conceptual framework: sourcing tactics to reach performance targets......45

3.3. Methodology: index development with formative indicators

3.4. Conclusions and implications: study results enable future empirical investigations and serve as a checklist cost saving potentials

Chapter 4: Matching sourcing levers with the Kraljič matrix - Empirical evidence on purchasing portfolios

4.1. Introduction: a portfolio perspective on tactical sourcing levers.

4.2. Literature review: contemporary research on purchasing portfolio models and sourcing levers 
4.3. Methodology: a survey instrument aiming to capture strategic importance, supply risk and sourcing lever profiles

4.4. Analysis and findings: comparative tests reveal significant differences in sourcing lever profiles across portfolio quadrants

4.5. Conclusions: tactical sourcing levers are applied additively, rather than as alternatives

Chapter 5: The cost and innovation effect of sourcing levers - empirical evidence at the category level.

5.1. Introduction: the influence of tactical sourcing levers on cost and innovation performance

5.2. Conceptual framework: tactical sourcing levers and performance.

5.3. Methodology: a survey instrument measuring sourcing lever application and performance.

5.4. Results and discussion: all tactical sourcing levers in one model showed only weak to moderate explanatory power 108

5.5. Conclusions: the study goes beyond previous works by providing empirical and simultaneous analysis of all seven core sourcing levers....114

Chapter 6: The moderating role of the sourcing category - a contingency theory perspective.

6.1. Introduction: a tailored set of tactics for each sourcing category...

6.2. Literature review and conceptual framework: linking contingency theory and tactical sourcing levers

6.3. Methodology: a multi-step survey development process

6.4. Moderation analysis: comparing low vs. high sourcing lever application under different contingency factors

6.5. Discussion: more is not always better

6.6. Conclusions: purchasing agents are advised to adapt their choice of tactical sourcing levers to the requirements of the sourcing category ......135

\section{Chapter 7: Summary and Conclusions}

7.1. Introduction: a tailored mix of tactical sourcing levers

7.2. Main findings: contributions to theory and practice and research propositions

7.3. Limitations: areas for improvement in future studies 
Appendix

References 187

Samenvatting (Summary in Dutch) .219 


\section{List of Figures}

Figure 1: Defining tactical sourcing levers - bundles of similar activities ...........3

Figure 2: Moderated effects of tactical sourcing levers - research model ...........5

Figure 3: Research design and structure ........................................................ 6

Figure 4: Structuring extant literature - five levels of analysis ......................... 19

Figure 5: Methodological approaches in extant literature ................................22

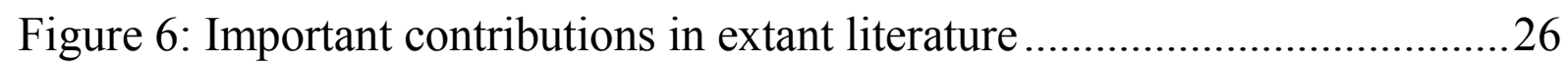

Figure 7: Index development with formative indicators ..................................48

Figure 8: Indicator specification with world café methodology .........................55

Figure 9: Sourcing levers profiles per portfolio quadrant ..................................83

Figure 10: Changes in sourcing lever scores along the portfolio quadrants .......87

Figure 11: Performance effects of tactical sourcing levers - structural model 111

Figure 12: Moderation analysis (exemplary simple slope diagram) .................129

Figure 13: Low vs. high sourcing lever application (cost performance) ..........131

Figure 14: Low vs. high sourcing lever application (innovation performance)134 


\section{List of Tables}

Table 1: Structuring extant literature - keyword search ...................................21

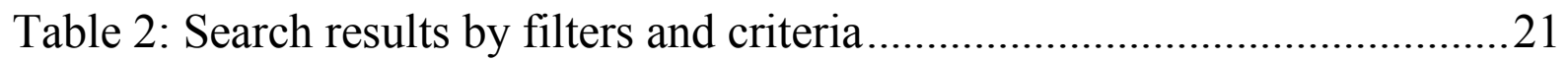

Table 3: Conceptual content - defining tactical sourcing levers .......................49

Table 4: Test results - formative measurement models (sourcing levers) ..........59

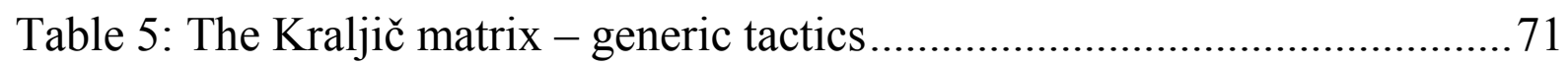

Table 6: Cross loadings, means and standard deviations ..................................79

Table 7: Inter-construct loadings and reliabilities............................................. 80

Table 8: Characteristics of reflective measurement models (performance) ..... 104

Table 9: Discriminant validity - analysis of cross-loadings ..............................105

Table 10: Discriminant validity - Fornell-Larcker Criterion...............................105

Table 11: Characteristics of formative models (sourcing levers) ....................... 107

Table 12: Regression results - Models I-VII ................................................... 109

Table 13: Regression results - Models VIII-X ….........................................110

Table 14: Structural model - collinearity statistics and predictive accuracy....112

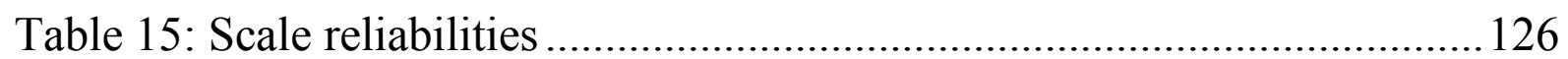

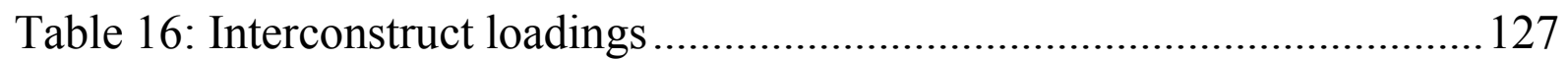

Table 17: Publications by addressed hierarchical level ...................................159

Table 18: Tactical sourcing levers and corresponding activities ...................... 163

Table 19: Formative indicators - descriptive statistics (sourcing levers)..........166

Table 20: Reflective indicators - descriptive statistics (Kraljič matrix)...........168

Table 21: Reflective indicators - descriptive statistics (performance) ..............169

Table 22: Reflective indicators - descriptive statistics (contingency factors).. 170

Table 23: Usage of tactical sourcing lever across portfolio quadrants ............. 172

Table 24: Portfolio quadrants analysed for differences and similarities............174

Table 25: Reflective indicators - cross loadings (contingency factors) ............176

Table 26: Moderated effects of sourcing levers - cost performance .................178

Table 27: Moderated effects of sourcing levers - innovation performance ..... 182 



\section{CHAPTER 1: \\ THESIS BACKGROUND AND RESEARCH STRUCTURE}

\subsection{INTRODUCTION: THE NEED FOR DEVELOPING DIFFERENT TACTICS FOR SPECIFIC SOURCED PRODUCT CATEGORIES}

Since the 1970s, the purchasing function has started to gain much greater recognition as a strategic function that significantly contributes to organizational success (Cammish and Keough, 1991; Ellram and Carr, 1994; Narasimhan and Carter, 1998). During that time, in many firms, purchasing evolved "from an obscure buying function" (Chen et al., 2004, p. 505), mainly associated with clerical duties, into a professional, strategic business function focused on value creation (Axelsson et al., 2005; Chen et al., 2004; Gelderman and Van Weele, 2005; González-Benito, 2007).

This development is primarily due to the top decision makers increasingly starting to recognize the capability of purchasing to build and leverage interorganizational relationships in a way that creates sustainable competitive advantage (Cousins, 2005). Firms are increasingly outsourcing various aspects of their activities to suppliers (Kakabadse and Kakabadse, 2002). Consequently, the purchasing function is not only becoming responsible for an increasing proportion of the organization's expenditure, but also manages an ever growing range of capabilities and resources that suppliers contribute to the value creation process (Gottfredson and Phillips, 2005; Kähkönen and Lintukangas, 2012). Savings on the expenditure side have significant effect on the firm's operational profit (Pandit and Marmanis, 2008). Therefore, most purchasing functions have to fulfil substantial annual cost savings targets (Nollet et al., 2008). At the same time, firms are becoming increasingly dependent on external competencies and sources of technology. Presently, a significant number of products, innovations 
and capabilities are developed through the exchange with suppliers in business networks (Pulles et al., 2014). Consequently, the purchasing function has a dual role, as it not only enhances the innovativeness of the firm, but also helps in managing the overall costs (Luzzini and Ronchi, 2011; Nollet et al., 2008; Schiele, 2010).

Owing to the growing interest in understanding the impact of purchasing on performance (Johnson et al., 2011; Van Weele, 2010), several researchers have discussed various antecedents of high-performance purchasing, such as supply management capabilities (Chen et al., 2004), purchasing skills (Knight et al., 2014), alignment of business and purchasing strategies (Baier et al., 2008; Cousins, 2005; González-Benito, 2007), purchasing organization (Luzzini and Ronchi, 2011; Rozemeijer, 2000; Stanley, 1993), supplier selection criteria (Choi and Hartley, 1996; De Boer et al., 2001; Kannan and Tan, 2002), global sourcing (Horn et al., 2013; Quintens et al., 2006b; Trautmann et al., 2009a) and buyer-supplier relationship management (Baxter, 2012; Carey et al., 2011; Inemek and Matthyssens, 2013). Clearly, this extensive body of literature contributes to a better understanding of the role of purchasing and in the overall firm. However, most of the available literature focuses on the overall functional level of purchasing; encompassing the entire expenditures and buyer-supplier relationships management by the purchasing department (Ateş, 2014).

General guidelines and strategies at the department level remain important cornerstones for coherence and integrity (Nollet et al., 2005). However, for the 'front-line' purchasing agents, the overall, generic goals of purchasing strategy are often so vague that they remain without any factual meaning for decisionmaking. Therefore, several authors have highlighted the need for developing different tactics for specific sourced product categories (Ateş et al., 2015; Hesping and Schiele, 2015; Luzzini et al., 2012; Van Weele, 2010).

\subsection{SOURCING CATEGORIES AND TACTICAL SOURCING LEVERS: NOT ALL MATERIALS AND BUYER-SUPPLIER RELATIONSHIPS ARE TO BE MANAGED IN THE SAME WAY}

In practice, it is obvious that "not all materials and buyer-supplier relationships are to be managed the same way" (Karjalainen and Salmi, 2013, p. 114). Rather, "companies frequently buy differently by [product] category" (Caniato et al., 2014, p. 6) as "strategic sourcing decisions [...] are always decided specifically 
for each category and their supply market conditions" (Essig, 2011, p. 143). Consequently, in a modern category management approach, firms differentiate hundreds of so-called 'sourcing categories' (Monczka and Markham, 2007; O'Brien, 2012; Rüdrich et al., 2000). Each sourcing category, e.g., 'metal sheets', 'leather', 'displays', 'cables' etc., comprises of materials or services with similar characteristics, which are purchased from an overlapping number of suppliers forming a coherent supply market (Cousins et al., 2008b; Horn et al., 2013; Monczka et al., 2008; Trautmann et al., 2009b).

Depending on its specific characteristics, each sourcing category requires a tailored set of tactics, which have been named 'sourcing levers' (Hesping and Schiele, 2015; Horn et al., 2013; Luzzini et al., 2012; Schiele et al., 2011a; Schuh et al., 2011; Schumacher et al., 2008). In contrast to the overall purchasing strategy, tactical sourcing levers have an immediate practical relevance to the 'front-line' purchasing agents, as they directly address the actions to be taken in order to achieve performance targets (Cuervo-Cazurra et al., 2013; Hess, 2010; Schiele, 2007; Schiele et al., 2011a). Sourcing tactics form clusters of activities, on which concrete time specifications and traceable milestones are often imposed, in order to operationalize overall, general strategy (Hillman and Hitt, 1999; Mintzberg, 1994).

Figure 1: Defining tactical sourcing levers - bundles of similar activities

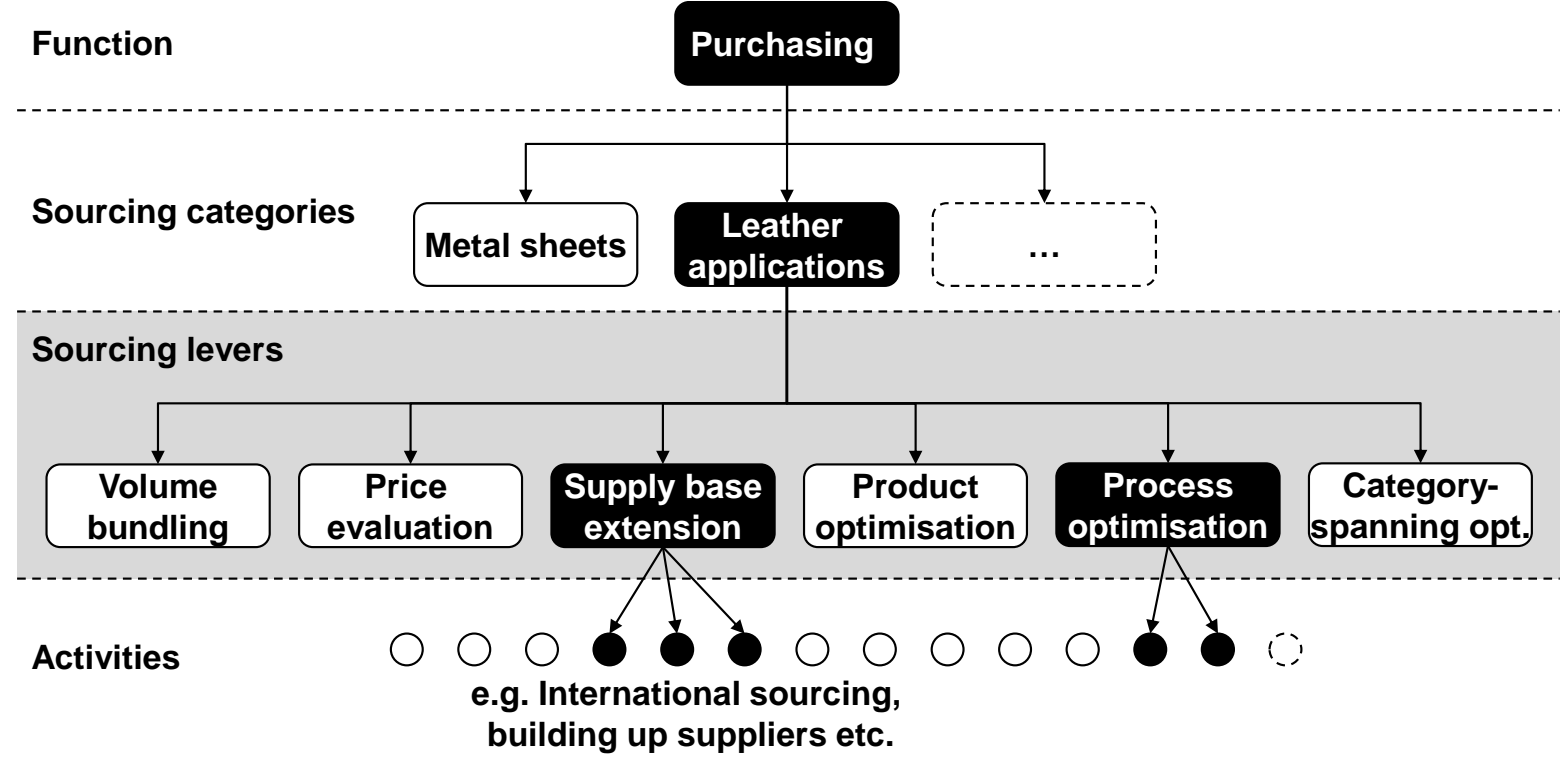


For instance, if scrap rates in the sourcing category 'metal sheets' induce high material costs, the purchasing agent might choose to implement the 'process optimisation' sourcing lever. Consequently, the sourcing team might decide to engage in a collaborative process reengineering project with multiple suppliers. Thereby, they might conduct on-site visits or opt to organize workshops to evaluate corrective actions with multiple partners along the supply chain (see Figure 1, p. 3).

\subsection{RESEARCH QUESTIONS: THE RELATIONSHIP AMONG SOURCING LEVERS, SOURCING CATEGORY CHARACTERISTICS AND PERFORMANCE}

In practice, 'front-line' purchasing agents are frequently required to decide which tactical sourcing levers to implement to reach annual cost saving targets or to enhance innovativeness for the sourcing category they manage. Surprisingly, extant literature provides very little information that would assist in better understanding the relationships among tactical sourcing levers, sourcing category characteristics and performance. One notable exception is the work of Luzzini et al. (2012), who recently clustered sourcing categories into four types and contrasted them with respect to differences in the category strategy. However, the authors "only considered the first steps of portfolio management, i.e. category classification and strategic priorities" (p. 1036) and suggest that "other studies might consider which levers and tools are used according to the different types of categories" (p. 1036).

In an effort to close this gap between the extant knowledge and practice, this study investigated the relationship among tactical sourcing levers, sourcing category characteristics and performance. Hence, the central purpose of this work is to answer the primary research question:

RQ1: What are the effects of tactical sourcing levers on cost and innovation performance and in what way can sourcing category characteristics enhance or hinder sourcing performance?

In addressing this question, the overall research model in this study, includes the seven core tactical sourcing levers, and their impact on cost and innovation performance moderated by complexity, dynamism and competition, as important contingency factors of the sourcing category context (see Figure 2, p. 5). 
Figure 2: Moderated effects of tactical sourcing levers - research model

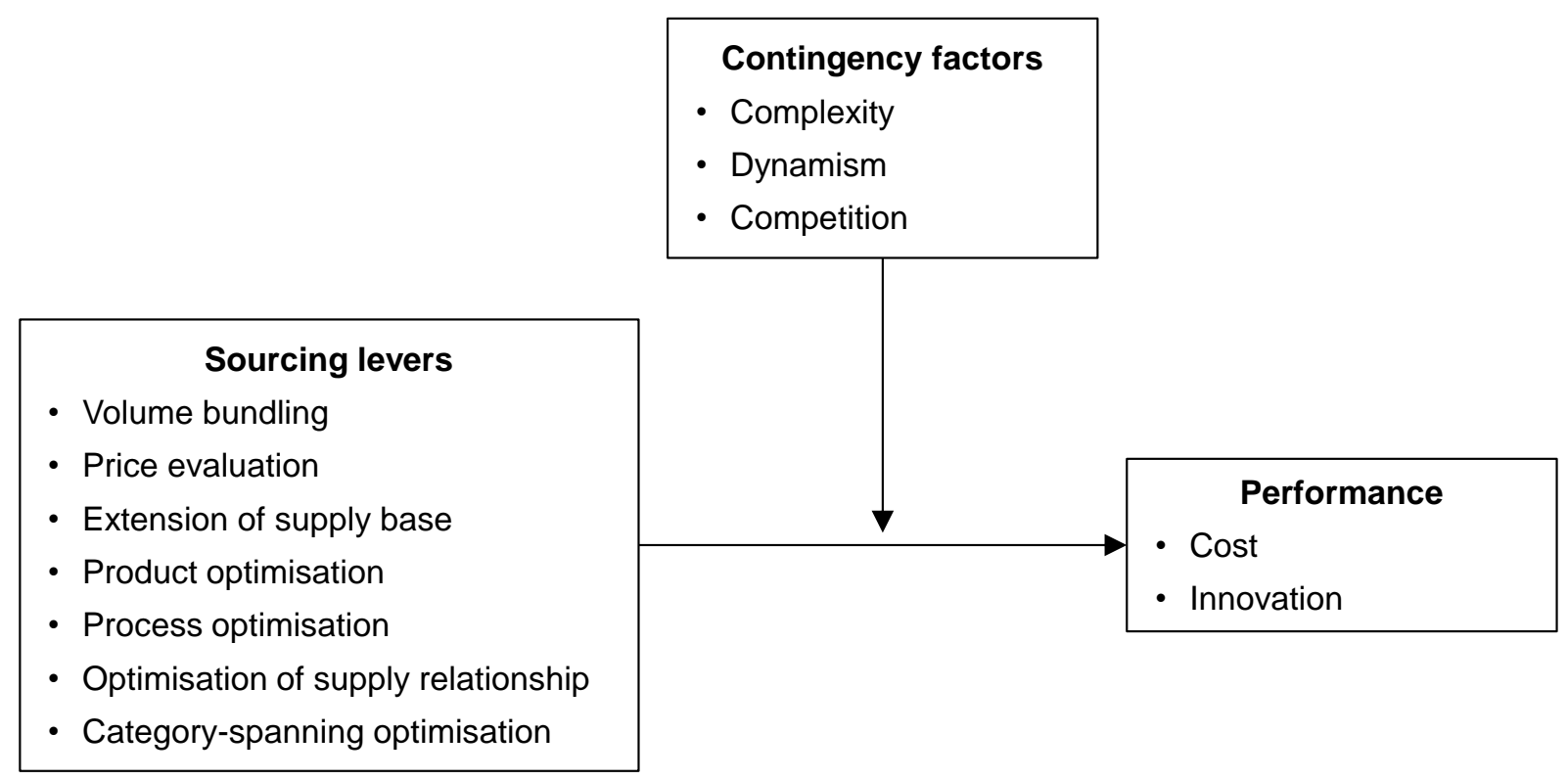

The research goal was to provide practical recommendations regarding what tactical sourcing levers should be selected with respect to the sourcing context. To achieve this objective, the thesis is structured into five scientific papers (Chapter 2, 3, 4, 5 and 6) interconnected by means of a coherent scientific 'storyline'. In the following sections, the research design and structure are presented along these five chapters.

\subsection{RESEARCH DESIGN: RESEARCH THEMES, OBJECTIVES AND ADOPTED METHODOLOGIES}

The primary research question has been answered in multiple steps (see Figure 3, p. 6):

(1) Initially, in Chapter 2, a structured literature review, screening 2,321 publications, w used to place the research focus of this thesis into the existing research landscape.

(2) Chapter 3 reports on an academic-practitioner research collaboration that has been formed with one large, European automotive original equipment manufacturer (OEM). World café discussions, a form of focus group research, with 24 purchasing agents were held at the OEM's European headquarters. That way, sourcing lever indices were developed to enable empirical research in the following steps. These indices were tested based 
on data gathered in a large-scale survey. Unit of analysis was the multitude of sourcing projects managed at the OEM's European headquarters. Key informants were the OEM's category managers, the 'front-line' purchasing agents, responsibly managing most purchasing activities in a sourcing category. That way, data on sourcing lever application, performance outcome and the sourcing category context was collected from 107 sourcing projects.

Figure 3: Research design and structure

Thesis background and research structure

\section{Chapter 2:}

2 Purchasing strategy development - a multi-level review
Aim:

To develop the research framework
Chapter 3:

3

Sourcing levers - developing a formative method of measurement
Chapter 4:

4

Matching sourcing tactics with the Kraljič matrix - empirical evidence on purchasing portfolios
To form sourcing lever profiles for each portfolio quadrant
To develop a measurement instrument for sourcing levers

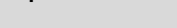

Chapter5:
5

The cost and innovation effect of sourcing levers - empirical evidence at the category level

To test for the performance effects of sourcing levers

To test for the Chapter 6:

6 The moderating role of the sourcing category - a contingency theory perspective moderating effect of the sourcing category
Chapter 7:

Summary and conclusions
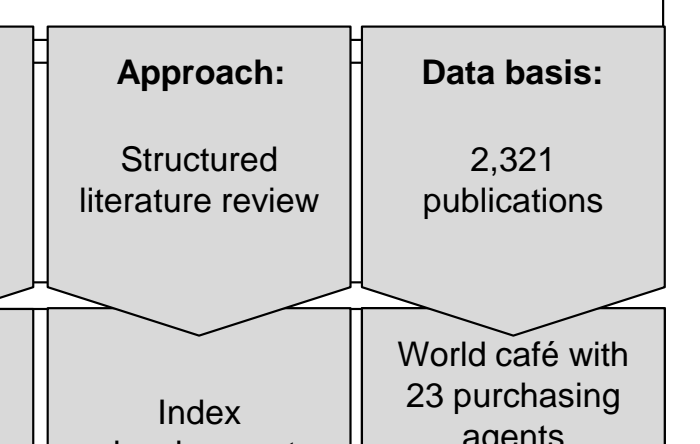

World café with

development

23 purchasing agents

Survey on 107 sourcing projects

Non-parametric tests for differences

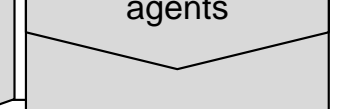


sourcing lever application for each quadrant of the Kraljič matrix, a portfolio matrix with four sourcing categories, have been developed and formally tested for similarities and differences with non-parametric tests.

(4) In Chapter 5, the performance impact of each sourcing lever was addressed. Partial least squares structural equation modelling (PLS-SEM) was used to test for the direct effect of tactical sourcing levers on cost and innovation performance.

(5) Ultimately, in Chapter 6, to complement the thesis, a moderation analysis was carried out. Thereby, the differences in cost and innovation performance between low and high sourcing lever application were investigated under various configurations of complexity, dynamism and competition. The following sections present the research themes, objectives and adopted methodologies for each chapter in more detail.

\subsubsection{Chapter 2: Purchasing strategy development - a multi-level review}

This thesis set out to broaden the knowledge on the tactical sourcing levers that 'front-line' purchasing agents use to improve performance at the category level of purchasing. To build a theoretical basis, Chapter 2 concentrates on placing the focus of this thesis into the context of the existing research landscape. So far, a fragmented research field and a diverse set of understandings (including misunderstandings) of the scope of strategy development at various levels of analysis made a thorough discussion among researchers and practitioners difficult. "What is the meaning of strategy, particularly when applied to supply management?" (Nollet and Beaulieu, 2005, p. 129). In purchasing, the terms 'strategy', 'strategies', 'strategic' and 'tactical' at different levels of analysis are still misused and misunderstood (Nollet et al., 2005; Ramsay and Croom, 2008; Rozemeijer, 2008).

Therefore, the following sub-question has been addressed in this study:

RQ1.1.: Which hierarchical levels of analysis for strategy development in purchasing exist in the purchasing literature, what are their particularities, and how do the different levels relate to one another?

To answer this question, 2,321 publications in German and English literature have been screened. The state of the art in the purchasing strategy literature has been structured as a hierarchical framework fostering a multi-stage understanding of strategy development in purchasing. Research suggests that in 
purchasing, it is difficult to develop a single, all-encompassing strategy. To the contrary, a hierarchy of stages emerges when general strategy is disaggregated into executable and controllable activities: (1) firm strategy, (2) purchasing strategy as a particular functional strategy, (3) category strategies for the multitude of supply markets, (4) effectuation by a set of tactical sourcing levers and (5) strategies for each supplier within a sourcing category. In an effort to conceptualize the research field, Chapter 2 extended existing stages of strategy development in purchasing and, for the first time, completely integrated sourcing categories and tactical sourcing levers as levels of analysis.

Findings of the literature review indicate that, in the past, relevant empirical research has been prevented inasmuch as the sourcing lever concept lacks explicit conceptualization and a method of measurement. To enable later empirical research, measurement instruments for sourcing levers have been developed in Chapter 3.

\subsubsection{Chapter 3: Sourcing levers - developing a formative method of measurement}

The previous chapter identified a lack of theoretical understanding and knowledge about the tactics and actions that 'front-line' purchasing agents use to improve performance for a category of purchases. "The sourcing lever concept $[\ldots]$ has not received significant discussion in the academic literature. Further empirical investigation of what tactics and underlying activities category managers employ would be interesting" (Hesping and Schiele, 2015, p. 148). However, to enable these investigations, sourcing levers require more explicit conceptualisation as well as a method of measurement (Cox, 2014; Hesping and Schiele, 2015; Luzzini and Ronchi, 2011).

To enable the empirical investigations in the later chapters, Chapter 3 addressed the following sub-question:

RQ1.2.: What defines the conceptual content taken by the sourcing lever concept and which measures are capable to capture this?

To answer this question, a formative method of measurement for tactical sourcing levers has been developed. In the index development process, a literature review built the basis for highly interactive world café discussions with business professionals. Resulting measures have been tested in 107 sourcing projects within one large European automotive OEM. The 
measurement models build the basis for future empirical investigations about conditions, contingencies and antecedents for successful sourcing lever application. In practice, the formative indicators can serve as a checklist for cost saving potentials and pave the way for systematic cost saving approaches with strategic sourcing.

Previous findings show that purchasing portfolios have been widely adapted in theory and practice to categorize purchases and to derive appropriate tactical sourcing levers. To better understand the influence of sourcing category characteristics on the use of tactical sourcing levers, Chapter 4 links purchasing portfolio theory to the sourcing lever concept.

\subsubsection{Chapter 4: Matching sourcing levers with the Kraljič matrix - empirical evidence on purchasing portfolios}

The origins of the sourcing category concept can be traced to the Kraljic portfolio matrix (Kraljič, 1977). The Kraljič matrix and its variants presented in various textbooks propose generic tactical sourcing levers for each portfolio quadrant. However, "the logic of the recommendations made in the quadrants [of the Kraljič matrix] are not coherent, are sometimes misguided and often lead to the 'cherry-picking' of tactical sourcing levers from other quadrants [...]" (Cox, 2014, p. 20). Research is needed to empirically verify whether the rather conceptual and normative recommendations on tactical sourcing levers for each portfolio quadrant hold true in practice (Cox, 2014; Gelderman and Van Weele, 2005).

Consequently, the present study addresses the following sub-question:

RQ1.3.: Does the application of tactical sourcing levers vary according to 'strategic importance' and 'supply risk', as suggested by Kraljič and, if so, how?

To answer this question, data sourced from a large-scale survey was used to classify 107 sourcing projects into the 'noncritical', 'leverage', 'bottleneck' and 'strategic' quadrants of the Kraljič matrix, respectively, and to contrast their profiles with respect to the tactical sourcing levers applied in each. The findings of this analysis indicate that, when discussing the Kraljič matrix, extant theoretical approaches may need to be revised. Most such initiatives assume that certain tactics are limited to a single portfolio cell only, without contributing to any of the remaining three. For example, efficient processing is solely applied to 
noncritical purchases, whereas close collaboration pertains to strategic purchases only. Yet, analyses presented in this chapter show that, in practice, purchasers use a mix of all tactical sourcing levers in all portfolio quadrants. Thus, instead of being viewed as mutually exclusive alternatives, as suggested in most available textbooks, tactical sourcing levers are used in an additive way.

The previous chapters provided the theoretical foundation for this thesis, as well as linked existing research with the sourcing lever concept and sourcing category characteristics. In Chapter 5 and 6, empirical investigations that have been conducted on the performance impact of tactical sourcing levers and the moderating effect of sourcing category characteristics are discussed.

\subsubsection{Chapter 5: The cost and innovation effect of sourcing levers - empirical evidence at the category level}

In Chapter 5, the previously developed sourcing lever indices were utilized to address the performance impact of tactical sourcing levers. A purchaser's daily challenge is to generate savings. Surprisingly, research has contributed little to a better understanding of how to reduce the costs of purchased goods and generate savings. Previous studies have evaluated the influence of single tactical sourcing levers on sourcing performance. However, "future research would profit from avoiding inquiries into any single lever, alone and without taking the other levers into consideration" (Schiele et al., 2011a, p. 332). To fill this gap, in this study, all seven core sourcing levers have been analysed simultaneously.

Thereby, the following sub-question has been addressed:

RQ1.4.: Does the application of particular tactical sourcing levers explain differences in a sourcing category's purchasing performance?

To answer this question, PLS-SEM, a multivariate, statistical method designed to test relationships between variables based on correlation (Hair Jr. et al., 2013), was used to assess the influence of tactical sourcing levers on the performance outcome of 107 sourcing projects. The findings yielded by this approach explain why some sourcing projects make a more pronounced contribution to cost or innovation performance relative to others. In addition, the analyses also identify the tactics and activities that decision-makers may select to reach performance targets for a category of purchases.

Chapter 5 addressed the effects of tactical sourcing levers on cost and innovation performance. To fully address the primary research question, in 
Chapter 6, contingency factors of the sourcing category are linked to sourcing lever application and performance outcomes.

\subsubsection{Chapter 6: The moderating role of the sourcing category - a contingency theory perspective}

In Chapter 6, the influence of sourcing category characteristics on sourcing lever success is analysed. The context of the sourcing category influences sourcing success (Luzzini et al., 2012). Therefore, authors from prior studies highlight that purchasing agents frequently adopt their choice of tactical sourcing levers to the contingencies of the sourcing category (Trautmann et al., 2009b; Van Weele, 2010). However, previous studies "only considered the first steps of portfolio management, i.e. category classification and strategic priorities. Other studies might consider which levers and tools are used according to the different types of categories" (Luzzini et al., 2012, p. 1036).

To address this research need, the following sub-question has been answered:

RQ1.5.: Do characteristics of the sourcing category explain the differences in a sourcing lever's contribution to cost or innovation performance?

Simple slope analysis, a form of moderation analysis, was adopted to investigate the performance effect of tactical sourcing levers moderated by contingency factors in the aforementioned 107 sourcing projects. The work presented in this chapter links contingency theory and the sourcing lever concept and provides practical guidelines regarding the sourcing levers that were predicted to lead to more or less cost or innovation performance under different sourcing category conditions.

\subsection{RESEARCH SETTING: AN ACADEMIC-PRACTITIONER COLLABORATIVE RESEARCH APPROACH}

Tactical sourcing levers have an immediate practical relevance as they directly address actions that purchasing agents can take to fulfil performance targets (Cuervo-Cazurra et al., 2013). The strong practical orientation, combined with paucity of academic research on sourcing levers, suggests that an academicpractitioner collaborative research approach is best suited for the present study (Tranfield et al., 2004; Trim and Lee, 2004). In order to answer the presented 
research questions, a research collaboration has been formed with one large, global automotive OEM, bringing together rigor and relevance in management research (Pettigrew, 1997, 2001). As one of its major strengths, this study draws on the knowledge of 'front-line' purchasing agents. Most extant studies focus on views and attitudes of high-level management personnel. However, at this level, management is generally less involved in, and insufficiently informed about, sourcing tactics chosen for each sourcing project. In contrast, 'front-line' purchasing agents responsibly manage most operational purchasing activities and are highly knowledgeable about the extent to which tactical sourcing levers have been applied in specific cases.

In order to bridge the gaps between practice and the research community, the present research was supported by multiple methodological workshops and scientific discussions, namely:

- 2012: IPSERA Colloquium, University of Twente, Enschede, The Netherlands

- 2012: Doctoral Symposium, Cologne Business School, Cologne, Germany

- 2012: Methodological workshop on 'Successful Conceptualization of a Research Project', AutoUni, in cooperation with University of Kaiserslautern, Wolfsburg, Germany

- 2012: Practitioner workshop on 'Sourcing Category Business Planning', Ideenherd, Wolfsburg, Germany

- 2013: Scientific Symposium, Bundesverband Materialwirtschaft, Einkauf und Logistik e.V., in cooperation with University of Würzburg, Würzburg, Germany

- 2013: Conference on 'Cost and Innovation-oriented Sourcing Strategies', AutoUni, Wolfsburg, Germany

- 2013: IFPSM Summer School on Advanced Purchasing, Salzburg, Austria

- 2013: IPSERA Doctoral Workshop, Nantes, France

- 2013: $22^{\text {nd }}$ IPSERA Conference, Nantes, France

- 2013: Doctoral Symposium, AutoUni, Wolfsburg, Germany

- 2013: Methodological workshop on 'Latent Variables and Partial Least Squares', in cooperation with University of Magdeburg, Wolfsburg, Germany 
- 2014: Scientific Symposium 'Purchasing', $16^{\text {th }}$ Industrieforum, Wolfsburg, Germany

- 2014: Methodological workshop on 'Quantitative Research Methods and SPSS', AutoUni, in cooperation with University of Stuttgart, Wolfsburg, Germany

- 2014: EurOMA Doctoral Workshop, Palermo, Italy

- 2014: $21^{\text {st }}$ EurOMA Conference, Palermo, Italy

- 2014: Doctoral Symposium, AutoUni, Wolfsburg, Germany

- 2014: UTIPS Research Retreat, University of Twente, Renesse, The

Netherlands

- 2015: $24^{\text {th }}$ IPSERA Conference, Amsterdam, The Netherlands

- 2015: $22^{\text {nd }}$ EurOMA Conference, Neuchâtel, Switzerland

- 2015: Doctoral Symposium, AutoUni, Wolfsburg, Germany

Based on this research setting, the present study makes multiple contributions to theory and practice, which are described in the following section.

\subsection{RESEARCH CONTRIBUTION: ADVANCING THEORY AND PRACTICE AT THE CATEGORY LEVEL OF PURCHASING}

Chapter 2 extends González-Benito's (2007) framework on purchasing competence to fully integrate category strategy and sourcing tactics as levels of analysis. Thereby, the research field of purchasing strategy development was conceptualized as a further step towards theory building (Meredith, 1993). The refined framework enables sound argumentation on the level of analysis in future research and serves as a practical tool for planning and executing strategy in purchasing.

Chapter 3, for the first time, reports on a comprehensive literature review on sourcing tactics and conceptually delineates the sourcing lever concept in a systematic index development process. Aggregation and abstraction have resulted in sourcing lever indices with 23 distinct indicators that may be utilized by practitioners as a checklist for cost saving approaches and serve as measurement models in future empirical research.

Chapter 4 links tactical sourcing levers to the purchasing portfolio theory. The findings provide a novel way of linking sourcing tactics to the sourcing context. The sourcing lever profiles for 'noncritical', 'leverage', 'bottleneck' 
and 'strategic' purchases can be employed by practitioners as a tool for planning tactics to achieve cost reductions. The findings reported here extend the information offered by existing textbooks, which presented a rather deterministic perspective on portfolio models with several tactics limited exclusively to a single portfolio quadrant. In contrast, the findings yielded by this study show that all tactical sourcing levers are applied to all portfolio quadrants, indicating that their application in the Kraljič matrix is additive, rather than exclusive.

Chapter 5 presents the analysis of the direct impact of tactical sourcing levers on cost and innovation performance. The findings presented within highlight the importance of price evaluations in purchasing. In the past, information gained from price evaluations may have been mainly used to attain informational advantage in the negotiations with suppliers. However, the findings yielded by the present study show that price evaluations present an important contribution to innovation, as they foster a fruitful discussion about the impact of product design on costs and the value proposition of the product.

Chapter 6 extends the contingency theory to the sourcing category level. Thereby, it shows that generic recommendations on sourcing tactics offered by authors of previous studies do not hold true under all sourcing category conditions. In contrast to the suggestions made in previous publications, the present investigation reveals that the 'extension of the supply base' lever and 'volume bundling' lever are not a 'condition sine qua non' for sourcing success. Rather, under some conditions, greater efforts dedicated to a tactical sourcing lever may even reduce performance. These findings highlight the importance of considering potential trade-offs among tactical sourcing levers. More specifically, one tactical sourcing lever might improve cost performance, while simultaneously reducing innovation performance. The results presented here thus provide practical guidelines regarding which tactical sourcing levers to choose to improve cost or innovation performance under given sourcing category conditions.

In conclusion, this study advances purchasing and supply management literature by contributing to the knowledge about the relationships among tactical sourcing levers, sourcing category characteristics and performance at the category level. Tactical sourcing levers have a high practical relevance, as they directly address the actions that 'front-line' purchasing agents may take to improve performance for a category of purchases. However, presently, theory 
and empirical evidence about tactical sourcing levers and sourcing categories is lacking. In order to address this shortcoming, the present study drew on intense collaboration between academia and practice. This comprehensive approach addresses the need to conduct additional academic-practitioner collaborative research, bringing together rigor and relevance (Amabile et al., 2001; McAlister, 2006; Schiele and Krummaker, 2011). In the course of this research, references to related research areas, such as operations management, marketing, strategic management and innovation management were often made. In so doing, the present study responds to the calls for conducting cross-disciplinary research fostering scientific development, while also clearly representing the multi-facet and cross-disciplinary decision-making challenges of modern organizations (Chen and Paulraj, 2004; Wilding et al., 2012). The findings reported in this thesis do not only address existing research gaps, but also provide suggestions for future research in this field, while also generating valuable guidelines for purchasing professionals. 



\section{CHAPTER 2: \\ PURCHASING STRATEGY DEVELOPMENT - A MULTI-LEVEL REVIEW}

\subsection{INTRODUCTION: A FRAGMENTED RESEARCH FIELD OF STRATEGY IN PURCHASING}

The scientific community has devoted substantial effort to study decisions and activities of groups or individuals to improve purchasing performance. These decisions and activities have often been loosely discussed as part of 'purchasing strategy' (Nollet et al., 2005; Quayle, 2006; Virolainen, 1998). Unfortunately, scholars largely fail to clearly differentiate the scope of strategy development at different hierarchical levels of analysis. Often, several content areas and stages of the strategy development process are confounded with no acknowledgment of the implications. However, neglecting differences between hierarchical levels of analysis may hinder academic reasoning and mislead managerial actions.

The discussion of global sourcing strategy provides a good example of an area in which substantial effort has been devoted to decoupling different levels of analysis. Global sourcing can be regarded an organization-wide strategy of global standardization and coordination spanning across several functions, such as purchasing, manufacturing and logistics (Hultman et al., 2011; Lintukangas et al., 2009; Quintens et al., 2006a; Trent and Monczka, 2003). Other scholars limit global sourcing strategy to the purchasing function (Kotabe and Murray, 2004; Smith, 1999). More narrowly, Schiele et al. (2011a) define global sourcing as a tactical approach to sourcing a group of materials internationally, while Arnold (1997) uses global sourcing to describe the approach toward a single material or supplier. 
It is clear that formulating a single overall strategy for the purchasing function is a difficult task; rather, a diverse set of strategies and tactics for a diverse set of purchases and suppliers may apply. As recent literature suggests, strategy development in purchasing might only be comprehensively understandable by applying a hierarchical model differentiating while, simultaneously, integrating different levels of analysis (e.g., Essig, 2011; Nollet et al., 2005; Schiele et al., 2011a). Therefore, a central argument presented in this chapter is that it is difficult to formulate a single overall strategy for the purchasing function; rather, strategy development in purchasing "is composed of a series of plans" (Nollet et al., 2005, p.137). Thus, this chapter is guided by the following research question (RQ1.1.): Which hierarchical levels of analysis for strategy development in purchasing exist in the purchasing literature, what are their particularities, and how do the different levels relate to one another?

Against this background, the aim of this study is to present the current status of research by categorizing the strategy development process along hierarchical levels of analysis. In this light, the strategy development process includes strategic and tactical steps that differentiate general strategy into executable and controllable activities (González-Benito, 2007; Nollet et al., 2005). In contrast to the operational activities actually taken by the actors involved, strategy and tactics refer to the approaches that actors plan to take (Burgelman and Grove, 1996; Prahalad and Hamel, 1994).

Following the steps of a structured literature review proposed by Mayring (2003), this study is structured as follows. First, materials were collected using a structured keyword search of electronic databases. Second, descriptive analysis was applied to analyse the number and chronology of identified publications. Third, qualitative analysis was employed to further insights into the content of the extant literature on strategy development in purchasing. The chapter concludes by offering suggestions for future research. To structure the literature review, this study builds on González-Benito's (2007) framework of purchasing competence, adopted from a manufacturing research context. However, this study argues that: (1) firm strategy and (2) purchasing strategy, as one of a firm's functional strategies, can be extended by (3) category strategies for the multitude of supply markets, (4) tactical sourcing levers, i.e., tactics applied to specify category strategies, and (5) supplier strategies toward each supplier within a sourcing category (see Figure 4, p. 19). The extended framework will: (1) contribute to a more complete, hierarchical analysis of strategy development 
in purchasing and offer a shared set of vocabulary for sourcing strategists and further research, (2) enable sound argumentation when discussing sourcing categories and tactical sourcing levers in further research, and (3) serve as a tool for crafting and executing strategy in purchasing.

Figure 4: Structuring extant literature - five levels of analysis

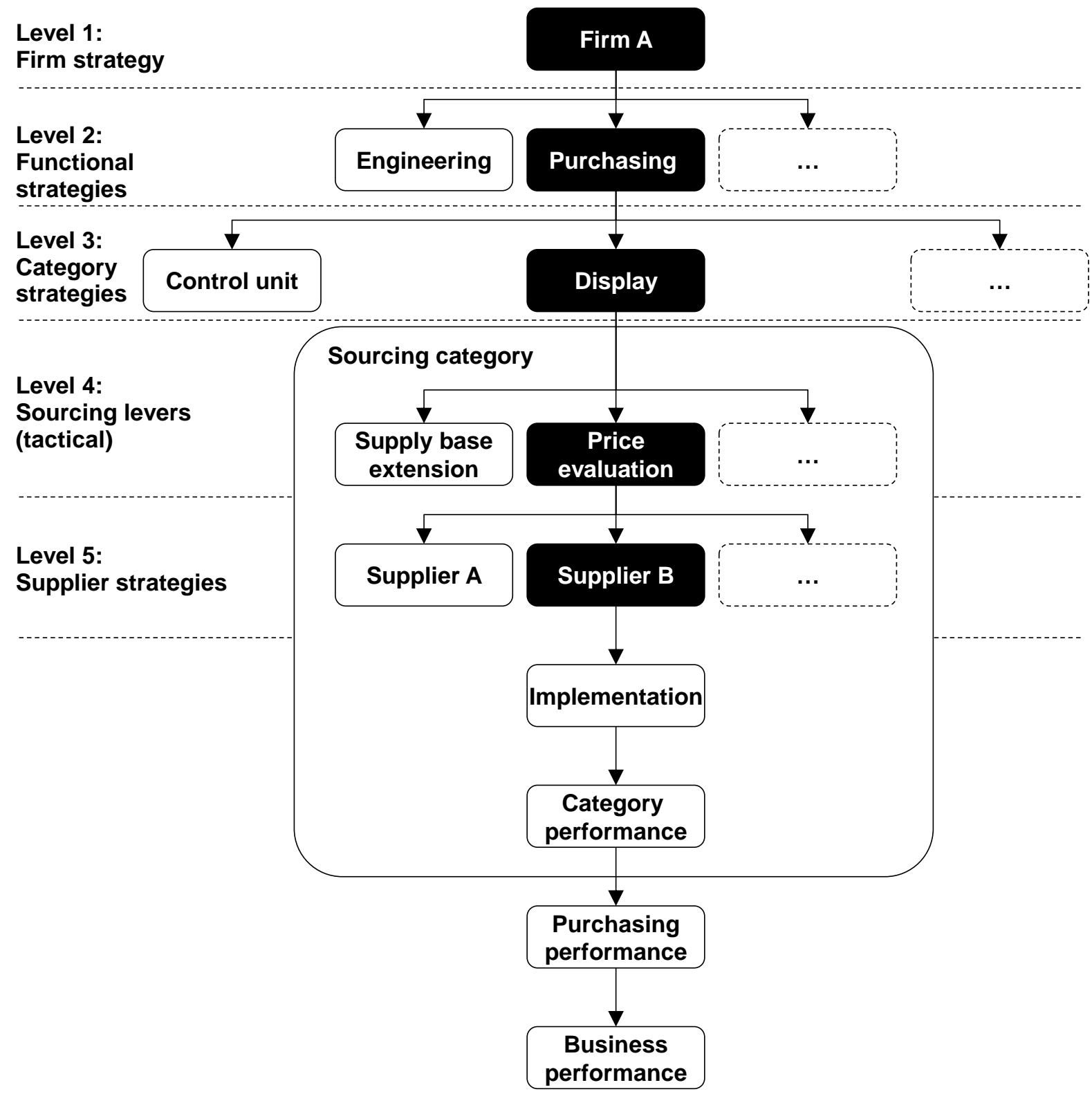

\subsection{MATERIAL COLLECTION: A STRUCTURED KEYWORD SEARCH}

Prior to the structured literature review, English publications were read that address the level of sourcing categories and tactical sourcing levers, which are currently 'blind spots' in González-Benito's (2007) framework of purchasing 
competence. Many of these publications (e.g., Arnold et al., 2005; Baier, 2008; Boutellier and Wagner, 2003; Essig, 2000; Kaufmann, 2002; Schiele, 2007; Schiele et al., 2011a) refer to German publications. To gain a deeper understanding of sourcing categories and tactical sourcing levers, the materials collected for the structured literature review thus included publications in both German and English.

To capture input from various research fields and recent trends, the search was not pre-limited to a certain group of journals. Material collection covered peer-reviewed scientific journals, as well as papers and books written for an audience of practitioners or students. The recognition of the strategic relevance of purchasing dates back to the early 1970s (Ellram and Carr, 1994). Thus, material collection was limited to publications from between 1970 and 2012. A structured keyword search was conducted in the electronic 'Business Source Elite' and 'Springerlink' databases. Keyword-based search might present certain disadvantages, as the results may vary according to the keywords selected. Nevertheless, scanning all sources in those databases would not be appropriate, as the aim of this study is to capture a broad range of concepts reviewed over 42 years of contributions. To address the limitations of keyword-based search, three groups of keywords in both German and English were constructed (Glock and Hochrein, 2011) (see Table 1, p. 21). Group A included terms used to describe the overall research field of purchasing and supply management. Group B included terms that describe the specific research field of hierarchical levels of strategy development in purchasing. Group $\mathrm{C}$ included terms to describe sourcing categories and tactical sourcing levers not included in GonzálezBenito's (2007) framework.

Paper selection was initiated using the online search applications provided by the selected databases (see Table 2, p. 21). Thereby, the relevance of articles in 'Business Source Elite' was assessed by determining whether the title or abstract contained one or several keywords from both groups A and B or from groups A and C. Through this procedure, 2,321 publications could be identified as satisfying the search criteria. For these publications, the abstract and table of contents were further analysed manually. Publications that appeared to be relevant to this literature review were read completely. In this step, 69 publications were identified as relevant. In a second step, while reading the papers, 69 further publications were identified through a 'snowball approach' by 
consulting the references of the previously selected works. In total, 138 publications ( 98 papers and 40 books) were identified as relevant.

Table 1: Structuring extant literature - keyword search

\begin{tabular}{|c|c|}
\hline & Terms \\
\hline Group A English & 'sourcing', 'purchasing', 'procurement', 'supply', 'buying' \\
\hline Group A German & 'Einkauf', 'Beschaffung', 'Beschaffungsmanagement', 'Beschaffungsmarketing' \\
\hline Group B English & 'strategy', 'strategic', 'tactic', 'hierarchy', 'level' \\
\hline Group B German & 'Strategie', 'strategisch', 'strategische', 'Taktik’, 'Hierarchie', 'Ebene' \\
\hline Group C English & $\begin{array}{l}\text { 'commodity', 'category', 'material group', 'product family', 'product group', } \\
\text { 'lever', 'practice', 'concept', 'portfolio' }\end{array}$ \\
\hline Group C German & $\begin{array}{l}\text { 'Materialgruppe', 'Werkstoffgruppe', 'Produktfamilie', 'Produktgruppe', } \\
\text { 'Kategorie', 'Hebel', 'Einkaufshebel', 'Konzept', 'Portfolio' }\end{array}$ \\
\hline
\end{tabular}

Table 2: Search results by filters and criteria

\begin{tabular}{|c|c|c|c|}
\hline Filter type & & $\begin{array}{l}\text { Business } \\
\text { Source Elite } \\
\text { (papers) }\end{array}$ & $\begin{array}{l}\text { Springerlink } \\
\text { (books) }\end{array}$ \\
\hline Peer-reviewed journals and books & \multicolumn{3}{|c|}{$\begin{array}{l}\text { Search for articles and books that appeared in the selected } \\
\text { databases or were cited in one of the analysed publications. }\end{array}$} \\
\hline \multirow{5}{*}{$\begin{array}{l}\text { Keyword search 'title \& abstract': All } \\
\text { articles that contain at least one } \\
\text { keyword in their title and abstract (For } \\
\text { books title and table of content have } \\
\text { been analysed) }\end{array}$} & Group A & $15,228^{a}\left(0^{b}\right)$ & $916(613)$ \\
\hline & Groups $A+B$ & $605(0)$ & $34(10)$ \\
\hline & Groups $A+C$ & $141(0)$ & $0(2)$ \\
\hline & Total (incl. duplicates) & $746(0)$ & $950(625)$ \\
\hline & & \multicolumn{2}{|c|}{2,321} \\
\hline \multirow{4}{*}{$\begin{array}{l}\text { Content analysis \& consolidation: All } \\
\text { publications that focus on strategy } \\
\text { development in purchasing }\end{array}$} & Abstracts & $156(0)$ & $12(41)$ \\
\hline & Entire text & $46(0)$ & $4(19)$ \\
\hline & Snowball approach & \multicolumn{2}{|c|}{$66(3)$} \\
\hline & Final sample size & \multicolumn{2}{|c|}{$116(22)$} \\
\hline
\end{tabular}

${ }^{a}$ Without brackets: Number of English-language publications

${ }^{\mathrm{b}}$ In brackets: Number of German-language publications

\subsection{DESCRIPTIVE ANALYSIS: ASSESSING FORMAL ASPECTS OF SELECTED PUBLICATIONS}

Having identified relevant publications, descriptive analysis was performed to determine: (1) the overall number of publications that addressed the topic to date, (2) the distribution of publications across different journals and (3) the research methodologies applied. 


\subsubsection{Distribution across journals: purchasing-related journals dominate}

The distribution of the identified papers across journals provides insights into different journals' purchasing strategy affinity. The leading positions in the research field are held by journals related to purchasing and supply management: The '(European) Journal of Purchasing and Supply Management' (22 papers) and the 'Journal of Supply Chain Management' (16 papers), which account for $39 \%$ of all identified papers. The marketing-related 'Industrial Marketing Management' journal holds third place ( 7 papers), followed by the more traditional operations management journals, 'International Journal of Operations \& Production Management' (5 papers), 'International Journal of Physical Distribution \& Logistics Management' (5 papers) and 'Journal of Operations Management' (5 papers).

\subsubsection{Number of publications by year: maturity was achieved in 2009}

Regarding the number of publications (books and papers) by year, one can identify three phases of research on strategy development in purchasing (see Figure 5, p. 22):

Figure 5: Methodological approaches in extant literature

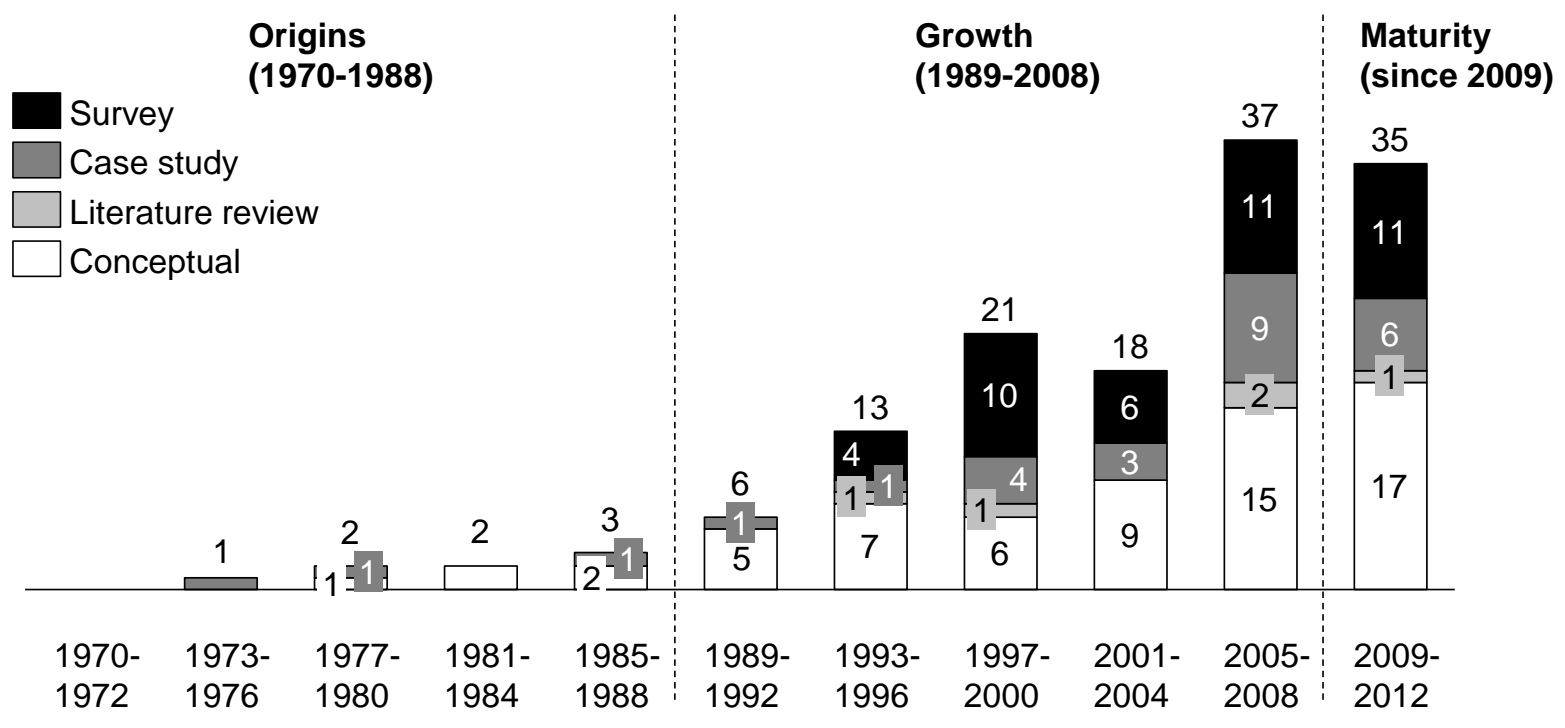


(1) The origins of the field appear to be between the early-1970s and the late-1980s (eight publications).

(2) The growth phase begins in the early-1990s and reaches its peak between 2005 and 2008 (95 publications).

(3) The maturity phase appears to have been reached in 2009, with approximately the same number of publications between 2009 and 2012 as in the previous four-year period (35 publications), thus remaining at a substantially high level.

\subsubsection{Research methodologies applied: authors currently explore new research fields}

Regarding the research methodologies applied, four approaches were distinguished: (1) conceptual or theoretical publications focusing on describing of theory and fundamental relationships, (2) case studies referring to a limited set of observations using real-life examples to develop theory, (3) literature reviews evaluating the existing body of recorded publications and (4) surveys using large-scale empirical data (see Figure 5, p. 22). These approaches represent only a selection of the most frequent research methodologies used. Previous studies show that, in the field of purchasing and supply management, all other methods (i.e. experiment and simulation) are negligible in comparison (Glock and Hochrein, 2011; Seuring and Müller, 2008; Spina et al., 2013).

The largest portion of the identified literature (64 publications) does not present empirical research and is of a relatively conceptual or theoretical nature. Surveys account for 42 of the identified publications, while 27 publications present results from case studies, and five publications conducted a literature review. Over time, the number of empirical works grew significantly. This increase is substantially greater than the growth in the overall number of publications. While the number of conceptual contributions published per year remained nearly constant between 1989 and 2000, the number of surveys increased from zero between 1989 and 1992 to 15 published between 1993 and 2000. Since 2001, the proportions of empirical and conceptual contributions have remained nearly equal. This partially confirms that the research field has reached maturity. Nevertheless, it appears that new ideas enter the research field that lead to new research opportunities. The increase in the number of case studies (15 publications) and the high number of conceptual contributions (32 publications) between 2005 and 2012 suggest that authors are currently 
exploring new research fields. This implies that the research field of strategy development in purchasing has yet to receive sufficient study.

\subsection{QUALITATIVE ANALYSIS: TOWARD A HIERARCHICAL FRAMEWORK OF STRATEGY DEVELOPMENT IN PURCHASING}

The aim of the second step of the literature analysis was to gain deeper insight into the specific content of the identified publications. To do so, a categorization scheme was applied to comprehensively structure the findings, employing an extended framework based on González-Benito's (2007) purchasing competence framework (see Figure 4, p. 19).

\subsubsection{Grouping the literature: extending the theory of purchasing competence}

By adapting the theory of production competence to the purchasing function, González-Benito (2007) distinguished a firm level and a functional level of strategy development. In the purchasing function, as an aspect of a firm's other functions (e.g., manufacturing and marketing), managers may choose among certain purchasing practices to establish how purchasing activities will be performed. Thus, the performance of the purchasing function depends on the degree to which these practices conform to and support purchasing's functional strategy. However, this study argues that frameworks adapted from a manufacturing context may be not sufficient to account for the purchasing challenges of managing a multitude of supply markets that are not encountered in other functions. Therefore, González-Benito's (2007) work was extended to include five levels of strategy development in purchasing (see Figure 4, p. 19).

To address the multitude of supply markets, scholars have recently demonstrated their interest in the sourcing category level (e.g., Akin et al., 2010; Heikkilä and Kaipa, 2009; Luzzini et al., 2012; Monczka and Markham, 2007). At the category level, the overall purchase is segmented into several "categories of purchased items, including materials or services of a similar type provided by the same group of suppliers" (Schiele et al., 2011a, p. 322), which constitute "a single supply market" (Schiele, 2007, p. 279). Within a sourcing category, decision makers may choose among several tactical 'sourcing levers' to plan the activities to be pursued within the specific sourcing category (Schiele et al., 2011a). Ultimately, the supply network must be capable of meeting the defined requirements (Watts et al., 1992). Thus, in the next step, a supplier strategy 
toward each of the sourcing category's suppliers can be defined to reflect and develop the supplier's network capabilities.

These five levels of strategy development were used to group the extant literature for qualitative content analysis (see Appendix - Table 17, p. 159). In the following section, the chronological development of the academic discussion is presented.

\subsubsection{Chronological development: increased attention to specific activities within distinct sourcing categories}

Regarding the chronological development of the academic discussion, one can observe increased attention to decomposing general strategy at the functional level toward specific activities within distinct sourcing categories (see Figure 6, p. 26). Except for Kraljič (1977), early publications primarily focus on the link between firm-level strategy and purchasing's functional strategy (e.g., Watts et al., 1992). Although several of those publications already address certain sourcing 'strategies' to further specify general purchasing strategy (e.g., Nollet et al., 2005), they largely ignore the category level of strategy development. At the beginning of the $21^{\text {st }}$ century, research began to exhibit increasing interest in grouping overall expenditures into distinct categories of similar materials and services, forming a distinct supply market (e.g., Boutellier and Zagler, 2000). Building upon the concept of portfolio models, generic norm strategies were defined for all sourcing categories within a quadrant of the portfolio matrix (e.g., Monczka and Markham, 2007). After 2005, authors addressed certain classes of tactics to shape strategies specific to each sourcing category. Schuh and Bremicker (2005) name these classes sourcing 'levers'. With the emerging recognition of category-specific sourcing strategies, another group of authors sought to shed light on the task of forming a supplier landscape that conforms to the characteristics of the sourcing category. Thereby, authors (e.g., Van Weele, 2010) emphasized the need to define supplier strategies within each sourcing category that reflect the specific context.

Having presented the academic discussion's chronological development, important findings from the extant literature are presented next in addition to the hierarchical levels of strategy development. 
Figure 6: Important contributions in extant literature

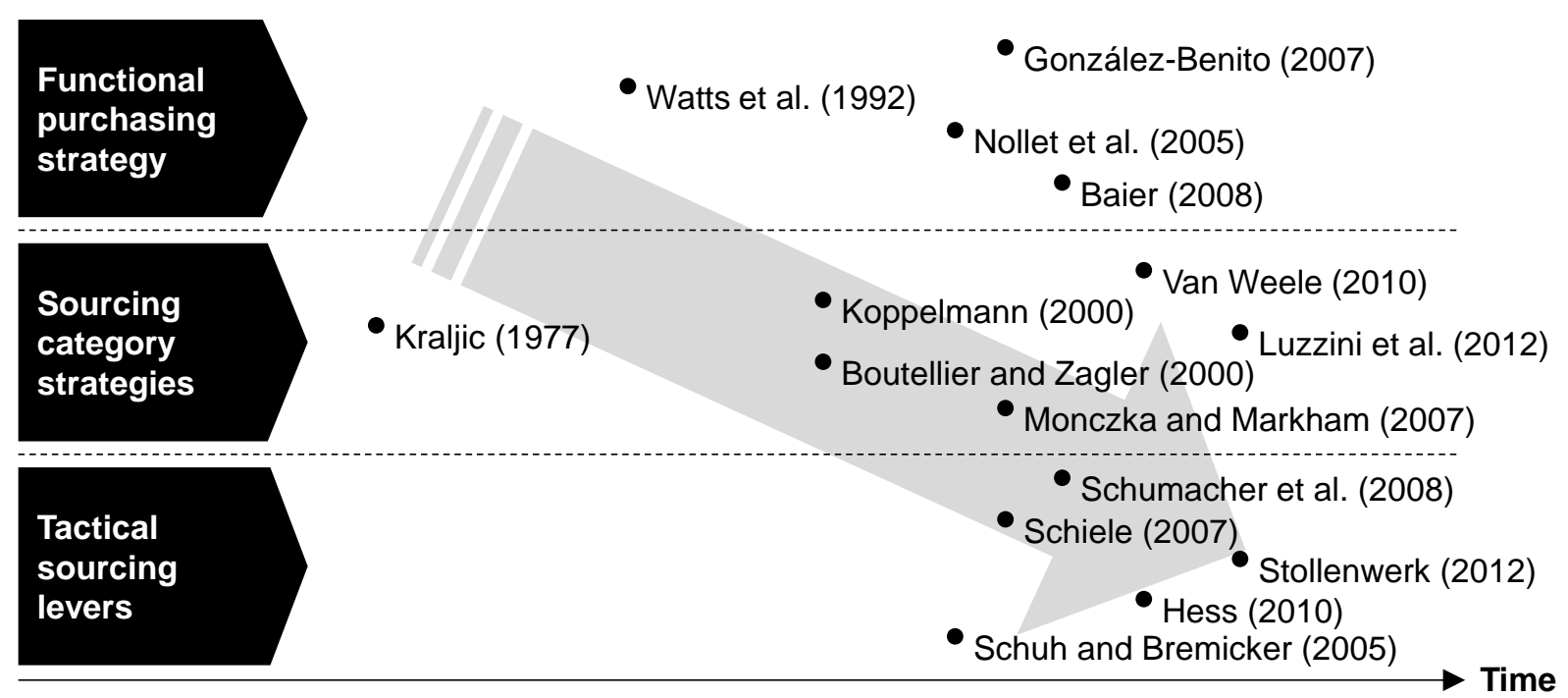

\subsubsection{Purchasing's functional strategy: functional guidelines for firms' purchasing activities}

Within each firm, firm strategy coordinates and integrates activities of the functional units, such as engineering, marketing, purchasing, manufacturing, etc. toward its business goals (Lorange, 1980; Mintzberg, 1994). For example, a firm strategy might define rapid reactions to changes in customer preferences as an important differentiating factor in competition. Consequently, by establishing certain overall targets, the manufacturing function might be urged to increase flexibility in production lines, while the purchasing function might support business strategy by improving lead-time in integrating new suppliers into the firm.

Based on the overall goals established by firm strategy, functional strategies determine the optimal strategic scope of a firm's functions, such as engineering, purchasing and manufacturing. In so doing, strategists add detail to firm-level strategy and strive toward realizing function-specific competitive advantage (Lorange, 1980).

In addition to a firm's other functions, purchasing employees may formulate a functional strategy. In literature, the terms 'purchasing strategy' and 'supply strategy' are most commonly used to describe the functional strategy for purchasing (e.g., Nollet et al., 2005). Purchasing's functional strategy is used to 
determine overall purchasing policies and capabilities to guide and enable the entire firm in its purchasing activities.

As in the case of other strategies, purchasing's functional strategy may be operationalized along general guidelines or programs. For example, security of supply might be identified as an important contribution to firm strategy. Consequently, a function-wide 'risk management program' might be initiated to form a risk management unit that intensively supports certain purchasing categories in implementing risk mitigation strategies (Zsidisin et al., 2000). As the example indicates, purchasing's functional strategy may be translated into further initiatives and forms the basis for other strategies but will not be replaced by them. Purchasing's functional strategy remains "a master plan for coherence and integrity" (Nollet et al., 2005, p. 137), further ensuring the contribution of subordinate 'strategies' to corporate and business strategic objectives.

However, the definition of what purchasing strategy should be or contain is often so vague that formulating a strategy is suspected of being based more on ritual than on any factual meaning. In this line, Kraljič complained that "many firms still understand as 'purchasing strategy' the achievement of the minimum price, the concentration on two or three preferred suppliers and an optimal operational execution." (Kraljič, 1977, p. 73 [our translation]). To change this 'strategy state of emergency', as he terms it, Kraljič proposes the development of different strategies for different categories of sourced products.

Having briefly discussed purchasing's functional strategy, the next section presents a category level of strategy, which has thus far been largely ignored by existing frameworks for strategy development in purchasing.

\subsubsection{Category strategies: differentiating distinct categories of expenditures}

In the early 1970s, Kraljič (1977) adopts a portfolio concept to place purchasing goods into quadrants of what is currently known as 'the Kraljič matrix'. Kraljič (1983) seeks to group materials into coherent supply markets and develop a strategy for each of these 'sourcing categories'. The illustrative example Kraljič uses is bunker oil for shipping, jet fuel for aircraft and gasoline for trucks. All of these materials are offered by the same competing fuel companies and - as one supply market - should be treated as a single sourcing category and not as three different products. The latter aspect is of particular importance: materials and 
services are not coded and grouped based on technical characteristics, legal and tax categories, countries, final products or anything similar; rather, their categorization is based on following a supply market logic, i.e., sourcing categories form a single supply market (Boutellier and Zagler, 2000). Instead of simply purchasing products or services, purchasing may be concerned with managing markets (White and Hanmer-Lloyd, 1999). The distinction into sourcing categories is a key particularity of the purchasing field, which is not observed in most other functional strategies.

Essig (2011) states that "it makes sense not to talk about 'the' purchasing strategy; instead strategic sourcing decisions [...] are always decided specifically for each category and their supply market conditions" (p. 143). In other words, purchasing may develop specific strategies for homogenous supply markets or families of purchased products and services (Cousins et al., 2008b; Karjalainen and Salmi, 2013), called 'categories' (O'Brien, 2012), 'commodity groups' (Schiele, 2007), 'material groups' (Horn et al., 2013), 'product groups' (Luzzini and Ronchi, 2011) and 'product families' (Monczka et al., 2008). These commodity or category groups are defined as "general categories of purchased items, including materials or services of a similar type provided by the same group of suppliers" (Schiele et al., 2011a), which constitute "a single supply market" (Schiele, 2007, p. 279). Commodities in this context are not to be confused with simple products or homogenous raw materials but rather represent families of purchasing goods sourced from an overlapping number of suppliers. To avoid misinterpretation of the word 'commodity', in the following, the term 'sourcing category' is adopted. Consequently, the term 'category strategy' has been used to describe the category level of strategy development. Unlike 'one supplier - one part' sourcing relationships, sourcing categories refer to 'several suppliers - several similar parts' sourcing relationships (Horn et al., 2013). Trautmann and Van Weele refine this understanding by stating that "a category encompasses a group of similar items that are required for specific business activities of the firm" (Trautmann et al., 2009b, p. 58) and can be regarded as "a group of products which can be substituted for one another" (Van Weele, 2010, p. 403). O'Brien (2012) suggests segmenting third-party expenditures into "discrete market-facing areas" (p. 15).

Sourcing categories in purchasing can be understood as the pendent of business segments in marketing (Appelfeller and Buchholz, 2010). Drawing on the notion of 'reverse marketing', purchasers may be invited to take the 
initiative and proactively manage supply markets as bundles of tangible and intangible product and supplier characteristics (Leenders and Blenkhorn, 1988; Spekman and Johnston, 1986). This market understanding of sourcing categories demands moving away from forming sourcing categories along solely technical differentiators, such as the production process, toward market-, competence- or problem-oriented thinking. The logic underlying the formation of sourcing categories determines the purchasing performance potential in terms of cost savings, innovation, flexibility and so on. As the 'traditional' sourcing category 'cables' might include all types of wires and cables, the 'new' sourcing category 'data transfer' might look beyond products and services to "unrecognised and untapped competencies and knowledge already in the supply base" (Monczka and Markham, 2007). For example, a car manufacturer might use the competence of a wireless data transfer provider to substitute for cable solutions.

Most purchasing portfolio models are similar in that they emphasize the definition of norm strategies that are then applied to all sourcing categories assigned to the respective portfolio area (e.g., Nellore and Söderquist, 2000; Olsen and Ellram, 1997; Trautmann et al., 2009a). Kraljič (1983), for example, distinguishes an aggressive ('exploit'), a defensive ('diversify'), and an intermediate ('balance') strategy. These uniform norm strategies have been repeatedly criticized for being excessively simplified (Bräkling and Oidtmann, 2012; Gelderman and Van Weele, 2005; Luzzini et al., 2012). The sourcing categories 'fleet' and 'display', for example, may both be assigned to the 'strategic items' portfolio area. The sourcing category 'display' may play an important role in a technology follower strategy and require multiple suppliers stimulating competition for technological innovations. However, the sourcing category 'fleet', including corporate vehicles for management, would not necessarily have any direct influence on a technology follower strategy. A firm could follow another category strategy by relying on a single source approach. This example illustrates that "purchasers make a clear distinction between several strategies within each quadrant [of Kraljič's portfolio matrix]" (Canièls and Gelderman, 2005, p. 141). Category managers might follow an individual strategy for each sourcing category even when placed in the same portfolio area. Following this argumentation, Akin et al. (2010), Karjalainen and Salmi (2013) and Luzzini et al. (2012) have recently presented approaches to form a taxonomy of category strategies by clustering sourcing categories along 
different competitive priorities, such as cost, quality, delivery, innovation, efficiency and sustainability.

Coordination between activities in each sourcing category may be addressed in a single overall purchasing strategy at the functional level (Baier, 2008; Hess, 2010; Johnson et al., 2010; Nollet et al., 2005). For example, if purchasing agents from multiple sourcing categories focus on generating innovations from their supply base by intensifying cooperation, a functional purchasing strategy might include a program to provide the appropriate tools and processes to do so.

In conclusion, a multitude of authors support a category approach in purchasing. One of the main arguments for a sourcing category approach is the possibility of forming differentiated strategies with respect to specific contextual factors of diverse supply markets. Simultaneously, accounting for functional purchasing strategy, category strategies may also help to achieve overarching functional purchasing goals.

Pursuing category strategy in a subsequent step, so-called tactical sourcing levers may be used on a tactical level to plan a combination of activities for each sourcing category.

\subsubsection{Sourcing levers: tactical building blocks of category strategy}

In analysing publications in the context of purchasing portfolio models, Luzzini et al. (2012) find that most publications "only considered the first steps of portfolio management, i.e., category classification and strategic priorities. Other studies might consider which levers and tools are used according to the different types of categories and different category priorities" (Luzzini et al., 2012, p. 1036). Building on this notion, another stream of the literature addresses the issue of planning the actions to realise category strategies by presenting sets of tactics called sourcing levers (Bräkling and Oidtmann, 2012; Hess, 2010; O'Brien, 2012; Schiele et al., 2011a). In the strategy development process, tactical sourcing levers may present a missing step between formulating general category strategy and implementing ultimate activities toward the respective supply market.

Would the tactics, i.e., sourcing levers, be the same for all sourcing categories? Likely not. If the sourcing category 'fleet' relies on a single source approach, the 'extension of supply base' lever may not be appropriate, but cost 
savings could be achieved, for instance, by applying the 'process improvement' lever, thus reducing the maintenance costs of the fleet.

Recently, several primarily Western European authors discuss the concept of tactical sourcing levers as tactical 'building blocks' of category strategy (Schiele et al., 2011a). A tactical sourcing lever consists of a set of similar activities that are used to improve the firm's sourcing performance in a sourcing category (Schiele, 2007). Several levers can be selected to specify a categorylevel strategy. Portfolio models often suggest only broad norm strategies for all sourcing categories in the same portfolio area. In contrast, tactical sourcing levers permit discussing the usefulness of several tactical approaches and the derivation of specific activities toward each sourcing category and the respective supply market.

In contrast to category strategy, tactical sourcing levers do not provide a general orientation for purchasing activities in a particular sourcing category (Schiele et al., 2011a). They describe a typology of activities through which the goals will be realised (Hess, 2010). The most empirically elaborated lever taxonomy is presented by Schiele (2007) and Schiele et al. (2011a), which has been applied in 134 cross-functional, cost-saving workshops. Their taxonomy includes 'pooling of demand', 'price evaluation', 'extension of supplier base', 'product optimisation', 'process improvement', 'intensification of supply relationship' and 'commodity-spanned' levers. The first three levers are rather adversarial or transaction-oriented and can be realised largely by purchasing personnel alone. The other levers emphasize innovation that requires close collaboration with suppliers and personnel from other functions, such as engineering and logistics (Schiele et al., 2011a). Schuh et al. (2008) state that, in contrast to the ultimate activities adopted by the purchaser, levers are especially useful in interdisciplinary discussions of purchasing with personnel from other functions. Thus, tactical sourcing levers are used to describe certain classes of basic elements, principles, or motives underlying concrete, specific actions taken to make the best purchase from the various suppliers under consideration (Schuh and Bremicker, 2005).

Tactical sourcing levers appear to have attracted the most discussion in the German-speaking world. Using different denominations, Schuh and Bremicker (2005) speak of the 'sourcing lever diamond', Schumacher et al. (2008) use 'seven levers', Schuh et al. (2008) group levers in a 'purchasing chessboard', Hess (2010) again uses the lever term in combination with different 'fields of 
actions', while Büsch (2011) focuses on 'three key levers'. Recently, tactical sourcing levers have also begun to appear in English-language publications, such as O'Brien's (2012) 'five value levers' and Schiele's (2007) 'seven sourcing levers'.

Typically, elements from more than one lever will be used to support the category strategy. Thus, leverage stresses the importance of combining activities in such a way that the overall result is significantly improved relative to the individual results (Büsch, 2011). Schiele et al. (2011a) observed trade-offs particularly between 'international sourcing', 'joint product optimisation' on the one side, and 'intensification of supply relationship' levers on the other side, implying that "firms may have to choose a set of internally consistent sourcing levers which, when aggregated, form a coherent sourcing strategy" (p. 317). To address this concern, category strategy may play an important role as guidance for selecting among several competing levers. In the same vein, Hess (2010) stresses the analytical effect when discussing tactical sourcing levers and recommends formulating category strategy afterwards, integrating several possibly inconsistent courses of action. For example, if strategy in the sourcing category 'display' is intended to create competition in a firm's supply base, category managers may prefer to implement corresponding adversarial levers while further integration with a single source supplier may be considered less appropriate. In this decision process, tactical sourcing levers provide a structure and common basis for creative and open, but integrated, cross-functional planning of actions in which to implement strategy within a sourcing category.

Although most identified publications do not explicitly discuss sourcing 'levers' using that term, certain authors explain that organizations use certain concepts to plan the activities in which strategic sourcing decisions are particularized at a tactical level. For instance, Narasimhan and Das present the concept of purchasing 'practices' as a construct subordinate to purchasing's functional strategy: "Purchasing practices are activities that relate to the purchasing-supply interface" (Narasimhan and Das, 2001, p. 594). Strategic decisions may establish a profile of purchasing practices defining how the purchasing activity will be accomplished (González-Benito, 2007). Narasimhan and Das (2001) discuss four classes of practices: 'supply base leveraging', 'buyer-supplier relationship development', and 'supplier performance evaluation'. Such purchasing practices appear similar to tactical sourcing levers. However, Narasimhan and Das (2001) discuss purchasing practices in the 
context of specifying functional purchasing strategy, while tactical sourcing levers are used to decompose general strategy at the subordinate sourcing category level.

In his 'sourcing toolbox', (Arnold, 1997) lists several attributes of what he calls sourcing 'concepts'. Common combinations of strategic purchasing elements form sourcing concepts (e.g., singular vs. multiple, unit vs. system, local vs. global sourcing). Authors have suggested combining the 'sourcing toolbox' or similar approaches with portfolio models. For each portfolio area, a target profile of sourcing concepts may be compared with the current profile, resulting in the need for action (Appelfeller and Buchholz, 2010; Hess, 2010; Stollenwerk, 2012). All dimensions of the 'sourcing toolbox' have to be addressed when designing a sourcing profile for each individual item (Arnold, 1997; Essig and Wagner, 2003). Thus, sourcing concepts appear to be similar to tactical sourcing levers. However, in their early definition by Arnold (1997), sourcing concepts are directed toward an individual item, while tactical sourcing levers are used to discuss tactics toward a group of similar items (i.e., a sourcing category) and not an individual item.

In summary, tactical sourcing levers can be used for proactive discussion when transitioning from a general category strategy to specific actions at a tactical level. Thus, tactical sourcing levers can be understood as translating category strategy into improvement activities prior to but also continually after supplier selection, allowing a monetary estimation of savings potential related to a certain supply market. Nevertheless, strategic recommendations, derived from portfolio analysis and overall category strategy, might serve as guidance and a plausibility check during the selection of levers and subsequent activities.

Whereas category strategies and tactical sourcing levers refer to groups of materials or services purchased, ultimately, decision makers must select the supplier from which to buy. Consequently, in the existing literature, tactical sourcing levers are further translated into strategies for the category's suppliers.

\subsubsection{Supplier strategies: how to work with each supplier in the future}

A supplier strategy describes the way to approach an individual supplier in a sourcing category. In each sourcing category, several suppliers offer their products. Therefore, supplier strategy and category strategy are not identical. The type of the purchase determines the required supplier capabilities and 
relationships (Stolle, 2008). Thus, supplier relationships and supplier selection criteria vary across sourcing categories (Kaufmann et al., 2012; Masi et al., 2013). Within one sourcing category, different supplier strategies can be applied that reflect diverse supplier roles and capabilities. For instance, one supplier can be defined as the core partner and another as a challenger.

Supplier strategies define how category managers will work with each supplier in the future to implement the category strategy (de Quervain and Wagner, 2003; Essig and Wagner, 2003; Van Weele, 2010; Wagner and Johnson, 2004). The challenge for the firm is to design relationship styles that are appropriate to internal and external conditions, as "different types of relationship will apply in different instances" (Thomas, 1994, p. 167).

To optimally manage the selected supply market, supplier strategies for a sourcing category may be primarily coordinated at the category level. However, certain suppliers may supply goods and services across more than one category or business unit, the so-called 'broadliner' supplier. Thus, at the functional strategy level, supplier strategies can be harmonized across multiple sourcing categories or even be embedded in a corporation-wide pooling concept, for example (Boutellier and Zagler, 2000; Schiele et al., 2011a).

Some of Schiele's (2007) tactical sourcing levers such as 'extension of supply base' and 'intensification of supply relationship' appear to be similar to supplier strategy. Yet, they are not. Before determining supplier strategies, each category manager might ask "Which supplier do we want and why?" (Monczka and Markham, 2007, p. 27). The chosen tactical sourcing levers might determine the answers. The sourcing lever 'extension of supply base' might have different implications for different supplier strategies. One implication would be to implement a challenger strategy for the current single-source supplier. Then, like other strategies, supplier strategy may be operationalized along further initiatives. First, the volume commitment with the single-source supplier may have to be reduced. The 'freed-up' volume might then be allocated to a 'new' supplier within a low-cost country. If the 'new' supplier inherits quality risks, another implication would be to implement a volume security strategy with a third supplier. Consequently, a third share of the volume might be allocated to a known supplier close to the factory. Thus, one tactical sourcing lever might influence several supplier strategies, which in turn are effectuated by multiple initiatives. Therefore, supplier strategies and tactical sourcing levers are not identical. 
Before determining a strategy for each supplier, the sourcing category's portfolio of suppliers might be segmented "into different categories for the purposes of selecting and applying specific inter-organisational governance structures" (Day et al., 2010, p. 626). The list of supplier segmentation models is extensive (Day et al., 2010). Pareto/ABC-analysis, for example, differentiates among suppliers according to annual purchasing volume. Other approaches are to differentiate along supplier capabilities (e.g., innovation capabilities) (Schiele, 2006) or according to a buyer's status from the perspective of the supplier. Thereby, the buyer can be a supplier's regular customer or preferred customer (Schiele et al., 2011b).

In summary, within each sourcing category, category managers may formulate a supplier strategy for each current or potential supplier to define the development of each buyer-supplier relationship. Supplier strategies may be intended to achieve a supplier portfolio, which optimally supports strategic aims for the entire sourcing category, i.e., the category strategy. Thereby, supplier strategies in one sourcing category may be harmonized with other sourcing categories or be included in cooperation-wide approaches at the functional strategy level. The categorization into five levels is quite practically applicable: the overall purchasing strategy is designed to support and shape overall corporate strategy. Then, each sourcing category (team) forms its own strategy, which is operationalized through the application of different sets of tactical sourcing levers, which often translate into cost-saving projects. Finally, a decision must be made regarding which supplier receives how much purchasing volume under what conditions. This is the ultimate consequence of formulating strategies of action toward each supplier.

\subsection{CONCLUSIONS AND IMPLICATIONS: A HIERARCHY OF STRATEGIES AND TACTICS}

Since the rise of strategic purchasing, strategy development has played an important role in purchasing (e.g., Ferguson et al., 1996). However, confusing different hierarchical levels of analysis in the strategy development process without acknowledging the implications of doing so may mislead managerial actions and make a systematic discussion difficult. Practitioners and academics are not precise regarding the level they address when discussing strategy development in purchasing: What is really meant by adopting a 'global sourcing 
strategy'? Does this mean that the entire firm outsources large shares of the value added to foreign firms in all expenditure categories? Does this mean that only the purchasing function formulates guidelines to consider a wider range of suppliers for nomination, or does it mean that only one sourcing category manager nominates a foreign supplier as part of one lever to achieve price reduction? To allow a common understanding when discussing the strategy development process, this study's findings suggest that future research clearly define what level is concerned. Toward filling this gap, this study provides an overview of the current status quo in the literature addressing strategy development in purchasing.

The study sought to present hierarchical levels of strategy development in the purchasing literature. Based on screening 2,321 publications in German and English over the past 42 years, 138 publications have been identified as addressing strategy development in purchasing. While the origins of the research field can be traced back to 1970, contemporary research appears to have reached maturity, with a consistently high level of publications and equal shares of empirical and conceptual research. To obtain a deeper understanding of the current state of research, the content of identified publications was subject to a qualitative analysis. This analysis suggests that five levels of strategy development in purchasing can be distinguished (see Figure 4, p. 19): (1) firm strategy guiding a firm's approach toward product markets, (2) purchasing strategy as an aspect of functional strategies guiding all of a firm's purchasing activities, (3) category strategies guiding activities within groups of materials and services, forming discrete supply markets, (4) tactical sourcing levers, i.e., tactics used to plan activities to execute category strategies, and (5) supplier strategies describing how to approach each of a sourcing category's suppliers.

\subsubsection{Contributions: a coherent, step-wise approach for strategy development}

This study presents four main contributions:

(1) Extending González-Benito's (2007) framework for purchasing competence, this study, for the first time, completely integrated category strategy, tactical sourcing levers and supplier strategy toward a hierarchical framework for strategy development in purchasing. Thus, the research field was conceptualized as an initial foundation for theory building (Meredith, 1993). The refined framework can form the basis for 
future empirical analysis and facilitate comprehensive managerial decision making (Weick, 1995).

(2) The hierarchical structure of the proposed framework informs scholars of the different levels of analysis in purchasing and supply management research. Existing studies do not always explicitly state or stringently remain at their stated level of analysis. Others confuse and move from one level of analysis to another without acknowledging the implications of doing so. Chen et al. (2004), for instance, relate strategic purchasing (the 'function' level) to supplier relationship management practices (the 'supplier' level) to business performance (the 'organization' level). It may be difficult to identify which influence variables at one level of analysis have on variables at a higher level of analysis. Consequently, researchers may need to devote careful attention to selecting the level of analysis when attempting to explain relationships between variables.

(3) The study makes the German-language literature and the respective strategic purchasing concepts accessible to an English-speaking audience. In particular, this study introduces tactical sourcing levers as a level of analysis in the initial attempt to systematically review knowledge on levers.

(4) The proposed framework supports purchasing in bridging the gap between product markets and supply markets. The hierarchical structure offers a coherent, step-wise approach for strategy development. In this way, the framework helps practitioners to decompose general strategy into executable and controllable activities. The research results suggest that purchasing managers are well advised to differentiate and coordinate a hierarchy of multiple levels of analysis. This hierarchy can help to translate product market characteristics into requirements for each supply market and enable effective actions and efficient resource allocation.

In addition to the presented contributions, the study offers multiple suggestions for future works.

\subsubsection{Shortcomings of existing research: academia could build on existing concepts}

The existing purchasing literature presents several strategy development concepts, such as the 'sourcing lever diamond' (Schuh and Bremicker, 2005), 
the 'purchasing chess board' (Schuh et al., 2008), the '15M architecture' (Hess, 2010), the 'power in procurement system' (Bräkling and Oidtmann, 2012), as well as the concepts of 'category management' (O'Brien, 2012) and 'sourcing levers' (Schumacher et al., 2008). However, most of these concepts were developed in or for practical application and did not refer to theory or previous academic work, or if they did, only incidentally. Thus far, academia has contributed rather little. Future research could build on the above concepts, contributing to an improved academic and theoretical foundation, as well as empirical testing.

The hierarchical framework informs scholars of the different steps of strategy development and levels of analysis. A systematic review of the levels of analysis addressed in other purchasing research streams might help to identify and carve out new research domains. Taking research questions from existing research fields and transferring them to yet unexplored or neglected levels of analysis, such as the sourcing category and sourcing lever levels, might reveal new research opportunities. In the same matter, it may be interesting to search for differences between levels or influences of one level on another.

Several research propositions arise from the study results:

(1) Horizontal and vertical integration mechanisms: Sourcing categories may lead to further decentralized purchasing organizations. Horizontal and vertical integration mechanisms become increasingly important for uniting these decentralized efforts to accomplish the organization's overall goals (Lawrence and Lorsch, 1967; Trautmann et al., 2009b). Thus, it may be fruitful to explore the following issue: What aspects determine the degree of integration necessary within and across sourcing categories? The concepts of 'category management' as presented in German publications (e.g., Boutellier and Zagler, 2000) and information processing theory might be promising frameworks for further investigations (e.g., Trautmann et al., 2009b).

(2) Formation of sourcing categories: The literature is lacking theoretically sound and empirically based classifications of sourcing categories. Portfolio models have often been criticized for the difficulty in operationalizing their dimensions, presenting only rough or minimally tested criteria to allocate products or services. Thus far, no commonly acknowledged and theoretically sound approach could be identified that 
answers the question of what products or services to combine in a sourcing category. Only recently did Luzzini et al. (2012) present four category clusters ('steady', 'volatile', 'special', and 'risky') based on item characteristics derived from transaction cost theoretical considerations. Future research might build on the work by Ateş (2014) and further investigate how to structure expenditures and the supply base to support certain competitive priorities. It might be interesting to determine whether certain material or supplier constellations best support cost or innovation strategies, for example.

(3) Understanding and conceptualizing tactical sourcing levers: The sourcing lever concept was developed in consulting practice and has not received significant discussion in the academic literature. Further empirical investigation of what tactics and underlying activities category managers employ would be interesting. An inappropriate combination of tactical sourcing levers might lead to suboptimal or even negative results (Schiele et al., 2011a). Therefore, it might be beneficial to further examine what tactical sourcing levers align well to allow for synergies and avoid tradeoffs (Büsch, 2011; Schiele et al., 2011a).

(4) Influence of contextual factors: Differentiating sourcing categories and suppliers was motivated by the aim of allowing for improved consideration of contextual factors when selecting sourcing strategies. Nevertheless, the literature still lacks conceptual and empirical works addressing what contextual factors, or their configurations, influence the success of each tactical sourcing lever. Future research might seek to provide recommendations regarding what tactical sourcing levers should be selected with respect to the sourcing context.

(5) Performance measurement: The presented hierarchy of strategy development also indicates a hierarchy of performance, i.e., firm performance, purchasing's functional performance, category performance and relationship performance. Nevertheless, knowledge of the particularities of each performance level is largely fragmented. Future research might, for example, investigate differences in performance measurement between levels: Which performance indices are applicable to category managers in contrast to top-management purchasing personnel? 


\subsubsection{Limitations: future studies might consider alternative selection methods}

The focus of this research was intentionally kept narrow to concentrate on the literature that discusses hierarchical levels in strategy development in purchasing. However, the process perspective and the differentiator 'hierarchy' in the literature selection may have limited the scope of literature reviewed. Analyses focusing on one of the five presented levels alone may identify further contributions.

Due to the recentness of several of the presented strategic purchasing concepts, the literature review drew to a considerable extent on publications written for an audience of business professionals. A lack of a theory base has been observed in the majority of the current purchasing literature (Chicksand et al., 2012). Future work might improve this framework by examining each identified research stream in greater detail, i.e., from different theoretical perspectives. This might allow for the fostering of a theoretical foundation and an improved understanding of the concepts related to each level, e.g., 'category management', 'sourcing levers', or 'supplier portfolio management'.

The database search yielded several references to German-language publications that address the sourcing lever level. To date, they have only been incidentally discussed in English-language publications. To shed further light on the concept of tactical sourcing levers, German-language publications were included in the literature search. Consequently, with respect to tactical sourcing levers, this study's findings might only be transferable to other academic or business contexts to a limited extent, despite that no fundamental impediments appear to apply. Future research might improve on and complete this study by examining the applicability of the presented sourcing lever concept in other languages and cultural contexts.

Although the course of research in this chapter followed replicable and methodical steps, the research process and methodology have limitations. First, the databases used (i.e., 'Business Source Premier' and 'Springerlink') may not contain all publications relevant for the review. Furthermore, other selection criteria in terms of keywords used and the research procedure may have defined another sample (Newbert, 2007). To extend the scope of this study, future research might consider alternative search strategies, keywords or databases.

In this chapter, the sourcing category and sourcing lever level of analysis were defined and placed into the exiting research context. Based on these 
definitions, in the next chapter, sourcing lever indices are developed to prepare empirical evaluations in the further course of this study. 



\section{CHAPTER 3: \\ SOURCING LEVERS - DEVELOPING A \\ FORMATIVE METHOD OF MEASUREMENT}

\subsection{INTRODUCTION: SOURCING LEVERS REQUIRE A METHOD FOR MEASUREMENT}

In the past, tactics for purchasing strategy implementation were typically considered for the whole purchasing function encompassing the entire range of materials and buyer-supplier relationships (Hesping and Schiele, 2015) (Karjalainen and Salmi, 2013). Recently however, it became generally accepted that "not all materials and buyer-supplier relationships are to be managed the same way" (Karjalainen and Salmi, 2013, p. 114). Rather, "companies frequently buy differently by [product] category" (Caniato et al., 2014, p. 6) as "strategic sourcing decisions [...] are always decided specifically for each category and their supply market conditions" (Essig, 2011, p. 143). Today, scholars argue that firms may differentiate hundreds of so called 'sourcing categories'. Each sourcing category, e.g., 'metal sheets', 'leather', 'cables' etc., groups similar materials or services purchased from an overlapping group of suppliers (Cousins et al., 2008b; Horn et al., 2013; Monczka et al., 2008). To achieve cost savings, innovation and other performance goals, each sourcing category requires a tailored set of tactics which have been named 'sourcing levers' (Hesping and Schiele, 2015; Horn et al., 2013; Luzzini et al., 2012; Schiele et al., 2011a; Schuh et al., 2011; Schumacher et al., 2008). Tactical sourcing levers have an immediate practical relevance as they directly address actions that decision makers can take to achieve performance targets (CuervoCazurra et al., 2013). If the sourcing category, 'leather' for example relies on a single source, the 'extension of supply base' lever might be used to increase competitive intensity to cut prices. 
However, most publications "only considered the first steps of portfolio management, i.e., category classification and strategic priorities. Other studies might consider which levers and tools are used according to the different types of categories and different category priorities" (Luzzini et al., 2012, p. 1036). In the past, research on purchasing strategies and tactics focused on the overall company or individual products. Rather little has been done to better understand sourcing tactics at the category level of purchasing (Ateş, 2014; Hesping and Schiele, 2015; Karjalainen and Salmi, 2013). Relevant research has been prevented inasmuch as the concept of sourcing levers appears to be only loosely defined in contemporary literature. "The sourcing lever concept $[\ldots]$ has not received significant discussion in the academic literature. Further empirical investigation of what tactics and underlying activities category managers employ would be interesting" (Hesping and Schiele, 2015, p. 148). To enable future empirical investigations, tactical sourcing levers require more explicit conceptualisation as well as a method of measurement (Hesping and Schiele, 2015; Luzzini et al., 2012). The present chapter seeks to fill this gap by answering the following research question (RQ1.2.): What defines the conceptual content taken by the sourcing lever concept and which measures are capable to capture this? The objective of this chapter is to define and provide a method of measurement for the sourcing lever concept as a step towards theory building, enabling future research (Wacker, 1998). World café methodology and survey research were used to empirically validate the developed measures in 107 sourcing projects within one large European automotive OEM. The study makes three important contributions: (1) first, it delineates the conceptual content of the sourcing lever constructs, fostering its theoretical foundation. (2) Second, it makes sourcing lever constructs measurable and thus applicable to a wide range of research questions. (3) Third, it has immediate relevance for practice as it reveals the actions that purchasers may take to improve purchasing performance.

This chapter is a fundamental step towards understanding tactical sourcing levers; the antecedents of purchasing performance at the category level of purchasing. The study provides scholars and practitioners with measures for effective planning of tactical sourcing levers. The chapter is organised as follows: (1) initially, contemporary literature about tactical sourcing levers has been reviewed. (2) Next, measurement models for tactical sourcing levers have 
been developed and tested. (3) The chapter concludes by highlighting implications, discussing limitations and presenting future research opportunities.

\subsection{CONCEPTUAL FRAMEWORK: SOURCING TACTICS TO REACH PERFORMANCE TARGETS}

Most purchasers are confronted with the question about how to achieve yearly cost saving targets. To address this, tactical sourcing levers provide a checklist of possible cost saving approaches.

As a distinguishing feature, tactical sourcing levers focus on a group of purchases. These so called 'sourcing categories' "include materials or services of a similar type provided by the same group of suppliers" (Schiele et al., 2011a, p. 322) forming a distinct supply market (Boutellier and Zagler, 2000; Drake et al., 2013). Examples of sourcing categories may be 'metal sheets', 'leather', 'cables', 'lighting', 'battery systems' and so on. A sourcing category does likely neither include only one single material or supplier nor the entire expenditures managed by the purchasing function. In most cases, a sourcing category includes multiple parts and multiple suppliers (Horn et al., 2013; Li et al., 2014). In a category management approach, firms use dedicated purchasing agents; so called 'category managers' that responsibly manage most sourcing activities within one sourcing category (Ateş, 2014; Driedonks, 2010; Sundtoft and Sigurbjornsson, 2013). The category management concept developed in a retail context, where similar consumer goods were grouped for joint marketing, product offerings and to optimise the overall product portfolio, cross-sales and shelf management (Leeflang and Parreño-Selva, 2012; Lindblom et al., 2009). In purchasing, category management mainly builds on portfolio theory, used to place purchasing goods into a limited number of four or nine portfolio cells (Gelderman and Semeijn, 2006; Nellore and Söderquist, 2000). However, to account better for the peculiarities of each material or service group, organisations moved towards a finer differentiation of sourcing categories. In a modern category management approach, a firm may distinguish several hundreds of sourcing categories based on differentiators such as production technology, supplier competences or market-facing areas (Ateş, 2014; Monczka and Markham, 2007; Van Weele, 2010).

A recent research stream addresses the issue of planning the actions to realise performance goals for a sourcing category. Several authors present sets 
of sourcing tactics that became known as 'sourcing levers' (Hesping and Schiele, 2015; O'Brien, 2012; Schiele et al., 2011a; Schuh et al., 2011; Schumacher et al., 2008; Stollenwerk, 2012). The concept of sourcing levers is not new to literature in the way that it describes tactics used to operationalise general strategy. From strategic management literature one learns that general strategy can be operationalised through a diverse set of tactics (Hillman and Hitt, 1999). Different from general strategy, tactics form clusters of activities with a concrete time specification and traceable milestones (Mintzberg, 1994). When transitioning from general strategic goals for a sourcing category to specific actions, category managers may discuss various tactical sourcing levers. Each tactical sourcing lever consists of "a set of similar measures that are used to improve the firm's sourcing performance in a commodity group [or sourcing category]" (Schiele, 2007, p. 279). In contrast to strategic goals, tactical sourcing levers do not provide a general orientation for purchasing activities, such as achieving annual cost saving targets (Schiele et al., 2011a). Tactical sourcing levers describe a typology of activities through which the goals shall be realised (Hess, 2010) (see Figure 1, p. 3).

Scholars have developed multiple sourcing lever frameworks. Schuh and Bremicker (2005) speak of the 'sourcing lever diamond', Schumacher et al. (2008) use 'seven levers', Schuh et al. (2008) group levers in a 'purchasing chessboard', Hess (2010) again uses the lever term in combination with different 'fields of actions', while Büsch (2011) focuses on 'three key levers', and O'Brien (2012) again presents 'five value levers', while Cox (2014) discusses 'seven groups of tactical sourcing levers'. In the subsequent sections of this study, the so far most empirically elaborated framework by Schiele et al. (2011a) served as a conceptual structure in the measurement development process. Schiele et al. (2011a) report a successful application of seven core tactical sourcing levers in 134 cross-functional cost-saving workshops: (1) 'volume bundling', to leverage larger purchasing volumes; (2) 'price evaluation' as a new form of negotiating prices based on cost information; (3) 'extension of supplier base' to introduce new supply sources; (4) 'product optimisation' to modify the material or service; (5) 'process optimisation' to simplify the buyerseller interface; (6) 'optimisation of supply relationship' to partner with suppliers; (7) 'category-spanning optimisation' to consider possible synergies across sourcing categories (see Figure 1, p. 3). 
Literature emphasises the immediate practical relevance of the sourcing lever concept as a tool "used to achieve the strategic goal of cost reduction" (Schiele et al., 2011a, p. 322). Still, the conceptualisation of tactical sourcing levers in contemporary literature is relatively limited (Hesping and Schiele, 2015). It remains largely unclear, which conceptual content is captured by each tactical sourcing lever. Hence, it was not surprising that the literature review did not identify existing sourcing lever scales that would serve as measures in future empirical studies.

\subsection{METHODOLOGY: INDEX DEVELOPMENT WITH FORMATIVE INDICATORS}

To address the paucity of conceptualisation in literature, this study set out to develop indicators and measurement models that can serve practitioners and academics as a tool to address the sourcing lever concept in future research.

'Indicators', also known as measures or items, "are observable, quantifiable scores obtained through self-report, interview, observation, or other empirical means. They are used to examine 'constructs', which are abstractions that describe a phenomenon of theoretical interest or other empirical means (Petter et al., 2007, p. 625). Indicators can be used in a reflective or a formative 'measurement model' to capture the conceptual content of an unobservable construct (Jarvis et al., 2003). From a theoretical point of view, the main difference between reflective and formative models is the direction of causality (Cenfetelli and Bassellier, 2009). In a reflective model, the construct exists independently of the indicators used. All reflective indicators of a construct share a common theme and are assumed to be equally valid (Cenfetelli and Bassellier, 2009; MacKenzie et al., 2011). But, a formative construct is a combination or index of its indicators. Formative indicators do not need to share a common theme (Coltman et al., 2008; Diamantopoulos et al., 2008).

For this study, formative measurement models have been chosen due to theoretical and practical considerations. On a theoretical level, tactical sourcing levers consist per definition of a set of distinct, directly addressable activities (O'Brien, 2012; Schiele, 2007; Schiele et al., 2011a; Schuh and Bremicker, 2005) and the formative model "provides an option for researchers to use measures that tend to be specific, actionable attributes of a phenomenon" (Cenfetelli and Bassellier, 2009, p. 690). On a practical level, formative 
measurement of tactical sourcing levers makes a strong diagnostic tool, since decision makers are able to track and consider addressing the contribution of each indicator (i.e., a specific sourcing activity such as sourcing from a supplier in a low cost country) to the corresponding index for the sourcing lever construct (Cenfetelli and Bassellier, 2009). In the essence, the indicators in formative sourcing lever models represent a checklist of specific, actionable cost saving activities which can be interpreted in isolation and directly implemented by 'front-line' purchasing agents. To develop the formative measurement models, the study follows the index development procedure proposed by (Diamantopoulos and Winklhofer, 2001): (1) 'content specification' to delineate each sourcing lever's conceptual content; (2) 'indicator specification' to refine relevant indicators for each sourcing lever; (3) 'empirical evaluation' to test the measurement models in a large-scale survey (see Figure 7, p. 48).

Figure 7: Index development with formative indicators

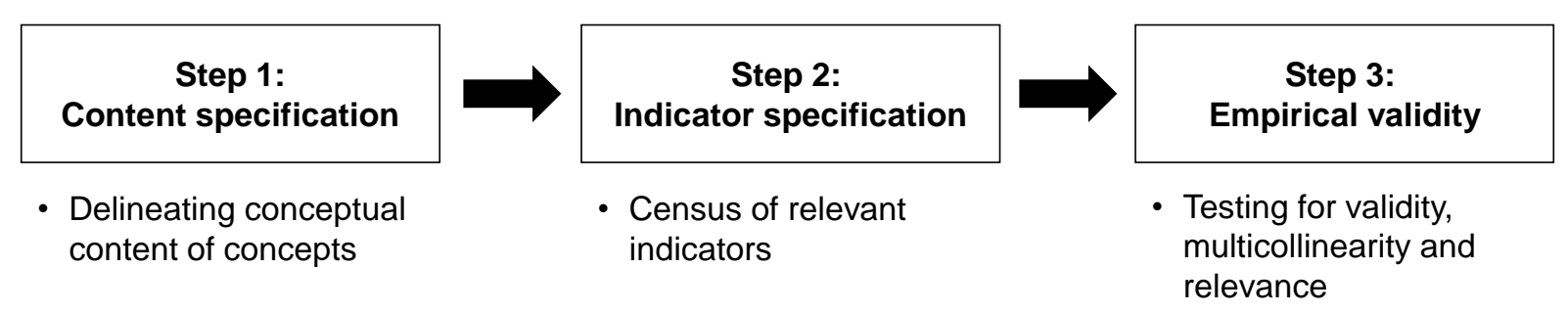

\subsubsection{Content specification: delineating the conceptual content of the concepts}

In the first step of index development, a literature review has been used to define the conceptual content (i.e., the phenomenon of theoretical interest) for each of the seven core tactical sourcing levers (Churchill, 1979; Diamantopoulos and Winklhofer, 2001) (see Table 3, p. 49). Based on these definitions, cost saving approaches have been grouped that might serve as indicators in the formative measurement models (see Appendix - Table 18, p. 163). Literature search focused on journals in the disciplines of operations and supply (chain). 


\section{Volume bundling: consolidating demand and increasing purchasing volume per request for quotation}

Bundling is "the aggregation of two or more items (product and/or services) by the buyer into a bundle that is put up for a bid to potential suppliers as a single RFQ [request for quotation]" (Schoenherr and Mabert, 2008, p. 81). A main argument for bundling are volume effects and associated price discounts due to scale effects (Kaicker et al., 1995; Prince et al., 2013). Beyond volume, items can be bundled to tie unattractive items (e.g., with small volume) to attractive items to create offer dependence for example (Schoenherr and Mabert, 2008). To tap bundling potential, volumes can be concentrated on a few sources (Smart and Dudas, 2007), demand can be consolidated across product groups and business units (Karjalainen and van Raaij, 2011; Nollet and Beaulieu, 2005) and new volume can be tied to existing volume (Schoenherr and Mabert, 2008; Stremersch and Tellis, 2002).

The conceptual content of the 'volume bundling' lever is limited to the category managers' engagement in consolidating demand and increasing purchasing volume per request for quotation.

Table 3: Conceptual content - defining tactical sourcing levers

Tactical

sourcing lever

\begin{tabular}{|c|c|c|}
\hline & & The category managers' engagement in... \\
\hline VB. & Volume bundling & $\begin{array}{l}\text {... consolidating demand and increasing purchasing volume per } \\
\text { request for quotation. }\end{array}$ \\
\hline PE. & Price evaluation & $\begin{array}{l}\text {... forming price targets and analysing suppliers' bids and cost } \\
\text { structures. }\end{array}$ \\
\hline ESB. & Extension of supply base & $\begin{array}{l}\ldots \text { increasing the number of sources and bidders per request for } \\
\text { quotation. }\end{array}$ \\
\hline PRD. & Product optimisation & $\begin{array}{l}\text {... making modifications to the design, functions and materials of the } \\
\text { purchased items. }\end{array}$ \\
\hline PRC. & Process optimisation & ... optimising processes related to the buyer-supplier interfaces. \\
\hline OSR. & $\begin{array}{l}\text { Optimisation of supply } \\
\text { relationship }\end{array}$ & $\begin{array}{l}\text {... establishing and maintaining effective relationships between } \\
\text { buyer and suppliers in the market. }\end{array}$ \\
\hline CS. & $\begin{array}{l}\text { Category-spanning } \\
\text { optimisation }\end{array}$ & $\begin{array}{l}\text {.. optimising the interfaces to and balancing trade-offs with other } \\
\text { sourcing categories to enforce and coordinate mutual approaches. }\end{array}$ \\
\hline
\end{tabular}




\section{Price evaluations: forming price targets and analysing suppliers' bids and cost} structures

Due to its intensive supplier contact, purchasing is particularly related to supplier cost management and price analysis (Kulmala, 2004; Romano and Formentini, 2012). Transparency about suppliers' costs and prices does not only help to evaluate the products' total cost impact beyond purchase price but also builds the basis for identifying technical cost drivers and discussing possible price reduction opportunities with the suppliers. Price evaluation techniques include price analysis and cost structure analysis (Ellram, 1996). Price analysis techniques focus on comparison of quoted prices with past offers or similar purchases (Daly and Nath, 2005; Ellram, 1996). Cost structure analysis can be used to compare own calculations with offered prices (Ellram, 1996) and includes cost breakdowns (Romano and Formentini, 2012), cost regression (Newman and Krehbiel, 2007) and value analysis (Hartley, 2000; Yoshikawa et al., 1994).

The conceptual content of the 'price evaluation' lever is limited to the category managers' engagement in forming price targets and analysing suppliers' bids and cost structures.

\section{Extension of supply base: increasing the number of sources and bidders per request for quotation}

The supply base design, and thus the number of suppliers, determines competition in the supply market $(\mathrm{Li}, 2013)$. Introducing new suppliers into the supply base, even if not awarded with a contract, may lead to better offers by the established bidders (Gnyawali and Madhavan, 2001). Extension of the supply base may be done through international sourcing and developing local or foreign sources. International purchasing offices may be used in a global scouting to identify overseas suppliers (Jia et al., 2014a; Sartor et al., 2014), competences of potential suppliers may be developed directly (Sillanpää et al., 2015; Sucky and Durst, 2013) or indirectly by gradually awarding business to build their capability and experience for future successful bids (Handfield et al., 2000; Krause et al., 1998).

The conceptual content of the 'extension of supply base' lever is limited to the category managers' engagement in increasing the number of sources and bidders per request for quotation. 


\section{Product optimisation: making modifications to the design, functions and materials of the purchased items}

The product design determines development and production costs as well as bargaining power and dependence in supply markets. High technological complexity often hinders participation of a number of suppliers, e.g., from a low-cost country, in competitive bidding (Khan et al., 2008; Luo et al., 2011; Smith, 1999). Furthermore, common, reused parts enable to increase volumes per part and thus bargaining power (Luo et al., 2011). Moreover, product design and degree of customisation have effects on logistics (Pradhan and Routroy, 2014; Ratha, 2014), as well as the ability to switch suppliers (Patala et al., 2014) or to respond to changing volume requirements and bottlenecks (Khan et al., 2008). Product optimisation includes internal engagement of purchasing into cross-functional product development teams (Danese and Filippini, 2010; Hong and Hartley, 2011; Lakemond et al., 2001; Melander and Lakemond, 2014) and bringing suppliers' external expertise into the product development process (Handfield et al., 1999; McGinnis and Vallopra, 1999; Wagner, 2012). Furthermore, purchasing may stimulate supplier competition to break technological lock-in situations and ultimately pressure suppliers to engage in product improvements (Song and Di Benedetto, 2008; Wynstra et al., 2003).

The conceptual content of the 'product optimisation' lever is limited to the category managers' engagement in making modifications to the design, functions and materials of the purchased items.

\section{Process optimisation: optimizing processes related to the buyer-supplier interfaces}

Process optimisation addresses the efficiency and effectiveness of the buyersupplier interface to reduce transaction costs between companies. These improvements mainly focus on information exchange, transparency (Yang et al., 2009) and fast process cycle (Emiliani, 2000). Process improvements include electronic data exchange, collaboration and joint business process engineering (Labro, 2006). Electronic data exchange can be used to enhance information processing through the internet (Emiliani, 2000; Mukhopadhyay and Kekre, 2002; Tai et al., 2010). Collaboration encourages supply chain partners to jointly engage in planning, forecasting, replenishment, resource sharing as well as collaborative process operation and improvement (Nakano, 2009; Ramanathan 
and Gunasekaran, 2014). This includes several practices such as vendor managed inventory, continuous replenishment, quality and capacity management (Cao and Zhang, 2011; Gunasekaran et al., 2001).

The conceptual content of the 'process optimisation' lever is limited to the category managers' engagement in optimising processes related to the buyersupplier interfaces.

\section{Optimisation of supply relationship: establishing and maintaining effective relationships between buyer and suppliers in the market}

Optimisation of supply relationship focuses on a long-term perspective and joint efforts with suppliers (Hüttinger et al., 2012; Loppacher et al., 2011; Lui and Ngo, 2012; Nyaga et al., 2010). Relationship efforts may include supplier qualification, supplier incentives and relationship marketing. Supplier qualification includes investments into training suppliers, quality advice and site visits (Blonska et al., 2013; Krause and Scannell, 2002; Li et al., 2012a). Supplier incentives require less direct involvement and can be used to encourage suppliers' improvements through goal setting, supplier evaluation, rewards and certification (Blonska et al., 2013; Krause et al., 2007). To gain preferential treatment, a buyer may strive to become a preferred customer of the supplier. Relationship marketing tools may include extensive field contact, timely payments and fairly behaviour (Hüttinger et al., 2012; Schiele et al., 2012a).

The conceptual content of the 'optimisation of supply relationship' lever is limited to the category managers' engagement in establishing and maintaining effective relationships between buyer and suppliers in the market.

\section{Category-spanning optimisation: optimizing the interfaces to and balancing trade-offs between sourcing categories}

Sourcing categories may be interrelated. Cheaper paper might increase ink usage and thus the overall costs per page (Schumacher et al., 2008). Changes to the car frame may cause changes to cable design and corresponding attachment clips. Some categories share the same or similar components or one product platform and thus buy from the same group of suppliers (Agrawal et al., 2013; Liu et al., 2010; Thomas et al., 2014). Therefore, as Kamakura and Kang (2007) state, category managers should think globally (across categories) and act locally (for their category). Coordinating a supplier's volume across categories 
for example can be used to determine a desired overall dependence on supply chain partners and a joint supplier strategy (Castaldo et al., 2009). To realise synergy potentials and enforce mutual approaches, decentralised category teams may coordinate their activities in a category-spanning, category management approach (Driedonks, 2010; Englyst et al., 2008; Schotanus and Telgen, 2007).

The conceptual content of the 'category-spanning optimisation' lever is limited to the category managers' engagement in optimising the interfaces to and balancing trade-offs with other sourcing categories to enforce and coordinate mutual approaches.

\subsubsection{Indicator specification: a census of relevant indicators}

The second step of index development, builds on the sourcing lever definitions from the previous sections. Potential indicators for each tactical sourcing lever were recorded during the literature review. This initial list of indicators was further developed through intense collaboration with practitioners, with the aim to use the refined indicators as items in the ultimate survey stage.

The initial list of potential indicators included a collection of cost saving approaches identified in literature. However, the indicators in this list showed large conceptual overlaps (see Appendix - Table 18, p. 163). For example, literature addressing the 'extension of supply base' lever uses terms such as 'global sourcing' (Kotabe and Murray, 2004), 'international outsourcing' and 'offshore sourcing' (Nassimbeni, 2006) to describe very similar aspects of purchasing from a supplier in a foreign country.

However, formative measurement models require high conceptual disparity between the indicators (Cenfetelli and Bassellier, 2009; Diamantopoulos et al., 2008). Furthermore, different from reflective indicators, formative indicators cannot be a selection of indicators relating to the construct. In formative measurement models, all relevant indicators must be included to capture all major facets of the construct (Diamantopoulos and Winklhofer, 2001; Hair Jr. et al., 2013).

Therefore, a research partnership between academia and one large European automotive OEM has been formed, with the aim to eliminate conceptual overlaps in the initial list of indicators and to discuss potentially missing indicators. In the indicator specification phase, literature offers multiple methods of an academic-practitioner research collaboration: (1) delphi method, 
(2) focus groups and (3) world café methodology (Kidd and Parshall, 2000; Merton, 1990; Morgan, 1997).

The delphi method uses a structured series of questionnaires with items and rankings followed by controlled feedback (Rowe and Wright, 2001). However, the iterative, several week long survey process was found to be disadvantageous as it may lead to a low response rate.

Different from the delphi method, "focus groups are a form of group interview that capitalises on communication between research participants in order to generate data" (Kitzinger, 1995, p. 299). However, it was found to be disadvantageous that the ideal focus group size is limited to 8 to 12 participants (Morrison, 1998) and that reoccurring sessions for the same group may have to be scheduled to collect rich and stable data (Kidd and Parshall, 2000).

Instead, the world café uses "intimate conversations at small café-style tables, or in small conversation clusters, [which] link, and build on each other as people move between groups, cross-pollinate ideas and make new connections around questions that really matter to their life, work, or community" (Tan and Brown, 2005, p. 85). Although the world café shares some characteristics with focus groups, it has some distinguishing features that made it more suitable for the setting of this study. First, the number of 'café' tables could be adjusted to allow involvement of 24 purchasing category managers representing a wide range of sourcing categories. Second, the world café can be held in one session avoiding problems from reoccurring sessions, such as the unavailability of participants (Brown and Isaacs, 2005). Consequently, the study adopted the world café structure as suggested by Brown and Isaacs (2005), Prewitt (2011) and Hoffmann et al. (2013) (see Figure 8, p. 55):

(1) In the early preparation, academics and practitioners engaged over several months to come to a shared foundation of the sourcing lever concept. Simultaneously, moderators, location and possible participants have been identified. Three tables with six to seven seats were set up to include multiple participants from diverse backgrounds, but still keeping an 'intimate' atmosphere that facilitates interaction (Brown and Isaacs, 2005; Prewitt, 2011).

(2) Three to four tactical sourcing levers were discussed at each table. Three discussion rounds were held, each round lasting 30 to 40 minutes. After each round, participants at each table split up to form new group 
constellations at different tables. Each participant had to sit at each table, but not in a pre-defined order, and had the chance to engage into discussion of all presented tactical sourcing levers and their indicators. To stimulate table discussions, the initial list of indicators was printed on DIN A0 posters. During the discussion rounds, participants were allowed to change, add or integrate indicators by making notes on the posters.

Figure 8: Indicator specification with world café methodology

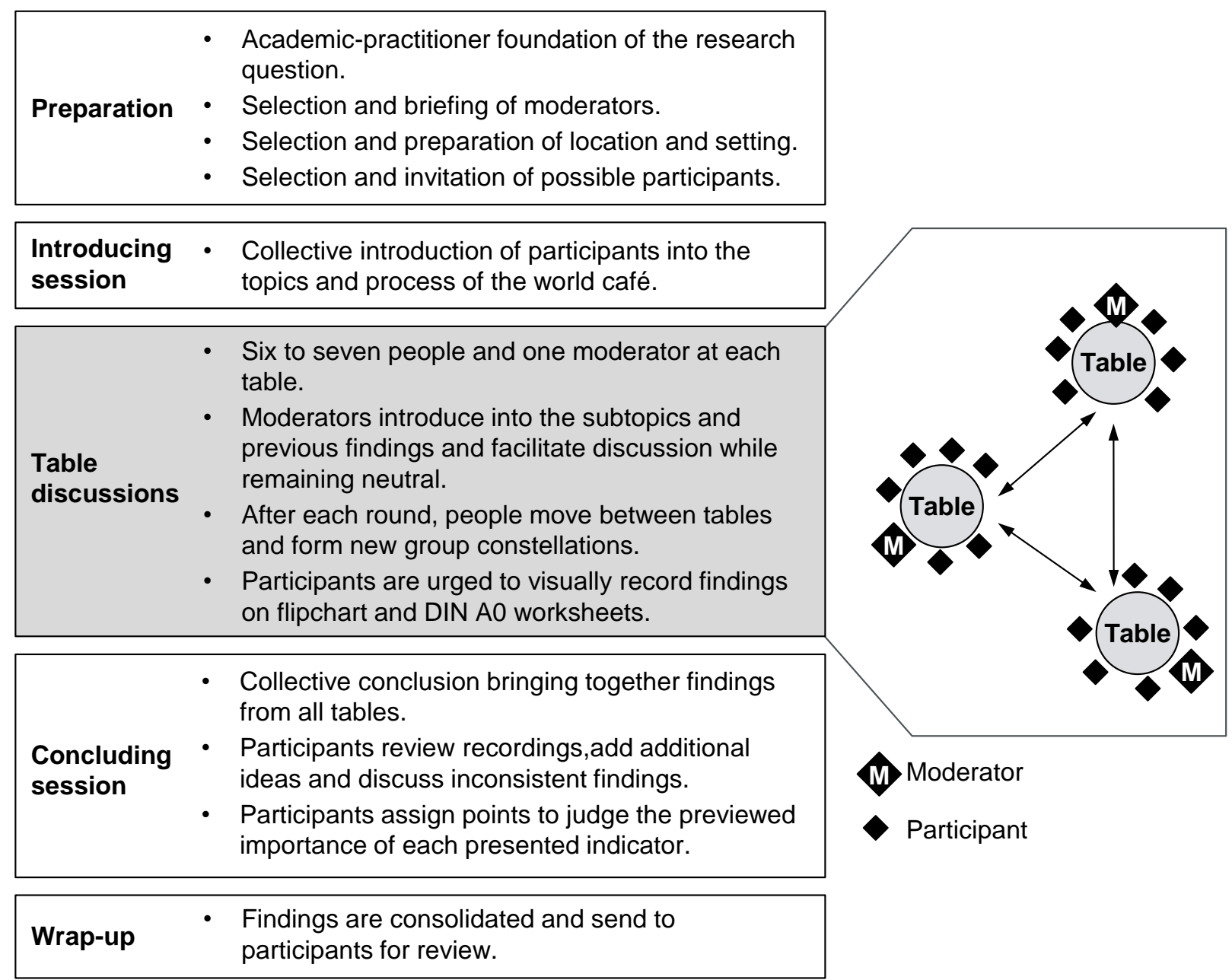

(3) At the end of the discussion rounds, academic facilitators and participants came together for a collective concluding session. Having just discussed all of the presented indicators, participants now had the chance to contrast all of them, eliminating further conceptual overlaps and inconsistent findings. Then, each participant had the chance to 
evaluate the results by placing stickers on the indicators they considered to be most important. In conclusion, the initial list of indicators, identified during the literature review, could be aggregated into 23 refined indicators assigned to the seven tactical sourcing levers (see Appendix - Table 19, p. 166). Throughout the discussion rounds, conceptual overlaps between the indicators have been minimised. This resulted into a comprehensive list of activities used to realise cost savings in a sourcing project.

In the next section, the refined indicators have been used as survey items for empirical evaluation of the measurement models.

\subsubsection{Data collection: a survey of 107 sourcing projects}

In the third step of index development, the indicators for the sourcing lever constructs were embedded in a survey to test for validity and reliability of the measurement models. Each indicator and the corresponding survey items were evaluated in a further pre-test by an expert panel of 27 'front-line' purchasing agents which did not previously take part in the world café process. They were asked to identify possibly vague wordings or unfamiliar terms and to check that there were no right or wrong questions.

Unit of analysis was the multitude of sourcing projects managed at the European headquarters of the same automotive OEM that took part in the world café. The study intentionally focused on a single OEM in order to get access to a reasonable number of comparable sourcing projects and 'front-line' purchasing agents.

Most of the analysed tactical sourcing levers may be relevant to both direct and indirect purchases. However, the analyses focused on direct purchases only. Indirect purchases have been excluded as the focal firm follows distinct purchasing policies for indirect purchases that might have biased the choice of sourcing levers (Cox et al., 2005; Karjalainen and Salmi, 2013).

Key informants were focal firm's category managers. In a sourcing project, these 'front-line' purchasing agents are responsible for most of the purchasing activities in a sourcing category and are highly knowledgeable about the extent to which tactical sourcing levers have been applied. Each sourcing project begins with obtaining price quotes from multiple suppliers and ends awarding contracts to one or several nominated suppliers. The focal firm has an 
established category management process, forcing category managers to regularly review their sourcing projects in the context of related sourcing categories and the entire purchasing department. This breath of experience allowed the respondents to relate to a wider range of sourcing projects when discussing the 'category-spanning optimisation' lever.

For the category managers, the overarching strategy for the entire purchasing department only functions as rough guidelines. At the core of their decision making is not the purchasing department strategy, but the specific contextual factors of the sourcing category and the respective supply market the category manager is responsible for (Hesping and Schiele, 2015). Nevertheless, as a possible limitation, the OEM's overall purchasing goals and policies might have limited the choice of tactical sourcing levers by the questioned category managers (Baier, 2008). To minimize this limitation, at the beginning of this study, academics and practitioners engaged for a period of more than two years. Thereby, it was found that the OEM's purchasing organization has reached a high degree of maturity (Paulraj et al., 2006; Schiele, 2007; Van Weele, 2010). Next to cost saving targets, purchasing policies include targets for innovation, security of supply, quality and sustainability which are broken down to each sourcing category. Therefore, it is expected that an extensive range of tactical sourcing levers is applied to the OEM's sourcing projects.

All survey items were pre-tested with an expert panel of category managers from the focal firm, who did not previously take part in the research process. They were asked to check that there were no wrong or right questions and to identify possibly vague concepts or unfamiliar terms.

To minimize bias arising from information recall, the supplier nomination stage was chosen as the point of reference for the purchaser. For supplier nomination, the responsible category manager has to present the strategic rationale of the respective sourcing project to the management at the corporate sourcing committee. Each time a supply contract was awarded and registered in the IT system, the responsible category manager was visited by the researcher and the questionnaire was completed jointly. In this way, maximum validity was ensured, generating high quality data (Srinivasan and Ratchford, 1991).

Respondents indicated the extent to which they applied each of the formative indicators (grouped into seven sourcing lever constructs), using a seven-point Likert scale anchored to $1=$ 'not used' to $7=$ 'extensively used': 
'For this sourcing project, which activities of the following tactical sourcing levers are used (also in team with other functions)?' (see Appendix - Table 19, p. 166). A total of 107 responses has been collected.

\subsubsection{Empirical evaluation: testing for validity, multicollinearity and relevance}

The formative measurement models have then been tested for (1) convergent validity, using redundancy analysis with an additional global item per measurement model, (2) multicollinearity, based on variance inflation factors and (3) indicator relevance, provided by outer weights and loadings (Cenfetelli and Bassellier, 2009; Diamantopoulos and Winklhofer, 2001; Hair et al., 2010).

For formative measurement models, convergent validity is used to test whether all relevant facets of the construct have been sufficiently covered by the selected formative indicators (Diamantopoulos et al., 2008; Hair Jr. et al., 2013). "Convergent validity is the extent to which a measure correlates positively with other measures (indicators) of the same construct" (Hair Jr. et al., 2013, p. 121). Therefore, literature suggests a redundancy analysis, using the formatively measured construct as an exogenous variable to predict and endogenous singleitem construct (Hair Jr. et al., 2013; Sarstedt et al., 2013). Global items (singleitems) were added, which respondents indicated the essence of each sourcing lever construct on a seven-point Likert scale anchored to $1=$ 'not used' to $7=$ 'extensively used': 'To summarise, to which extent have measures for [tactical sourcing lever] been used in this sourcing project?'. For redundancy analysis, the path coefficients have been calculated between each formative construct (exogenous) and the corresponding global-item construct (endogenous), using the SmartPLS 2.0 software with the path weighting scheme (Ringle et al., 2005). Results show that all path coefficients are well above the threshold of 0.8 , indicating that the used formative indicators sufficiently cover the content of the construct they purport to measure (Chin, 1998; Hair Jr. et al., 2013) (see Table 4, p. 59).

As the formative measurement model is based on multiple regression, multicollinearity among the indicators can lead to instable indicator weights in a way that each indicator's influence on the construct cannot be determined distinctly (Cenfetelli and Bassellier, 2009; Diamantopoulos and Winklhofer, 2001). Therefore, literature suggests collinearity checks, based on the variance 
inflation factor (VIF). VIF values have been calculated for each formative construct and the corresponding indicators, using SPSS 22.0 software (IBM, 2013).

Table 4: Test results - formative measurement models (sourcing levers)

\begin{tabular}{|c|c|c|c|c|c|}
\hline $\begin{array}{l}\text { Construct } \\
\text { Indicator }\end{array}$ & Path coef. ${ }^{a}$ & $\mathrm{VIF}^{\mathrm{b}}$ & Outer weight & $\mathrm{t}$ value & Outer loading \\
\hline \multicolumn{6}{|c|}{ VB. Volume bundling } \\
\hline volumeB_1 & \multirow{4}{*}{0.865} & 1.123 & $0.300^{* * *}$ & 4.879 & 0.563 \\
\hline volumeB_2 & & 1.257 & $0.283^{\star \star *}$ & 4.317 & 0.634 \\
\hline volumeB_3 & & 1.237 & $0.285^{\star * *}$ & 4.726 & 0.626 \\
\hline volumeB_4 & & 1.421 & $0.554^{* * *}$ & 8.595 & 0.854 \\
\hline \multicolumn{6}{|c|}{ PE. Price evaluation } \\
\hline priceE_1 & \multirow{3}{*}{0.855} & 1.210 & $0.409^{* * *}$ & 5.194 & 0.721 \\
\hline priceE_2 & & 1.157 & $0.265^{\star * *}$ & 4.047 & 0.583 \\
\hline priceE_3 & & 1.209 & $0.637^{* * *}$ & 8.337 & 0.865 \\
\hline \multicolumn{6}{|c|}{ ESB. Extension of supply base } \\
\hline eSupplyBase_1 & \multirow{3}{*}{0.904} & 1.255 & $0.571^{* * *}$ & 9.308 & 0.839 \\
\hline eSupplyBase_2 & & 1.303 & $0.362^{\star * \star}$ & 5.567 & 0.734 \\
\hline eSupplyBase_3 & & 1.207 & $0.371^{* * *}$ & 5.135 & 0.689 \\
\hline \multicolumn{6}{|c|}{ PRD. Product optimisation } \\
\hline productOpt_1 & \multirow{4}{*}{0.967} & 1.524 & $0.234^{* * *}$ & 4.179 & 0.681 \\
\hline productOpt_2 & & 1.987 & $0.292^{\star * *}$ & 5.662 & 0.830 \\
\hline productOpt_3 & & 2.178 & $0.317^{* * *}$ & 6.529 & 0.856 \\
\hline productOpt_4 & & 2.178 & $0.380^{* * *}$ & 7.647 & 0.858 \\
\hline \multicolumn{6}{|c|}{ PRC. Process optimisation } \\
\hline processOpt_1 & & 1.262 & $0.379^{* * *}$ & 5.837 & 0.687 \\
\hline processOpt_2 & 0.857 & 1.531 & $0.282^{\star * \star}$ & 4.255 & 0.745 \\
\hline processOpt_3 & & 1.414 & $0.608^{* * *}$ & 9.209 & 0.870 \\
\hline \multicolumn{6}{|c|}{ OSR. Optimisation of supply relationship } \\
\hline osRelation_1 & & 1.716 & $0.330^{\star \star \star}$ & 7.909 & 0.803 \\
\hline osRelation_2 & 0.954 & 1.624 & $0.478^{* * *}$ & 9.598 & 0.831 \\
\hline osRelation_3 & & 1.202 & $0.454^{* * *}$ & 8.711 & 0.742 \\
\hline \multicolumn{6}{|c|}{ CS. Category-spanning optimisation } \\
\hline categoryS_1 & & 2.159 & $0.360^{* * *}$ & 5.737 & 0.877 \\
\hline categorys_2 & 0.980 & 2.302 & $0.366^{\star * \star}$ & 5.641 & 0.888 \\
\hline categoryS_3 & & 2.518 & $0.396^{\star * *}$ & 6.590 & 0.909 \\
\hline \multicolumn{6}{|c|}{$\begin{array}{l}7 \text {-point Likert scale anchored at } 1=\text { 'not used' and } 7=\text { 'extensively used' } \\
\text { a Path coefficient between exogenous formative and endogenous global item construct (measure for construc } \\
\text { validity) } \\
{ }^{\circ} \text { Variance Inflation Factor (VIF) used for collinearity assessment in the formative measurement models } \\
{ }^{*} \mathrm{p}<0.10,{ }^{* *} \mathrm{p}<0.05,{ }^{* \star *} \mathrm{p}<0.01 \text { (two-tailed test) } \\
\mathrm{N}=107\end{array}$} \\
\hline
\end{tabular}


Results show that all VIFs are well below the threshold of 3.3, showing that indicators are well distinct and do not carry critical levels of redundant information (Diamantopoulos and Siguaw, 2006; Hair et al., 2013; Petter et al., 2007) (see Table 4, p. 59).

To evaluate indicator relevance, it has been tested whether each indicator's outer weights are significantly different from zero by means of bootstrapping (Hair et al., 2013). The bootstrapping procedure in SmartPLS 2.0 has been used to draw 5,000 random subsamples (Ringle et al., 2005). The outer weights in all formative measurement models have a p-value smaller than 0.01 , indicating a high relative contribution of the formative indicators (Hair et al., 2013). Moreover, all outer loadings in the same models are well above the threshold of 0.5 , indicating also a high absolute contribution of the indicators (see Table 4, p. $59)$.

To summarise, survey results confirm that the developed indicators and measurement models well cover the conceptual content of the sourcing lever concept. As required, the formative indicators do not carry any critical level of redundant information and highly contribute to the construct they intend to measure. Overall, results show strong empirical support for retaining all indicators in the used survey instrument (Cenfetelli and Bassellier, 2009; Diamantopoulos et al., 2008; Hair et al., 2013; Petter et al., 2007).

\subsection{CONCLUSIONS AND IMPLICATIONS: STUDY RESULTS ENABLE FUTURE EMPIRICAL INVESTIGATIONS AND SERVE AS A CHECKLIST COST SAVING POTENTIALS}

The study presents that, with the raise of strategic purchasing, it became commonly acknowledged that not all materials and buyer-supplier relationships are to be managed the same way (Karjalainen and Salmi, 2013). Rather, firms group similar purchases into sourcing categories (Cousins et al., 2008; Horn et al., 2013; Monczka et al., 2008). To achieve cost savings, each sourcing category requires a tailored set of tactics (Schiele et al., 2011). These tactical sourcing levers have an immediate practical relevance and are at the core of decision making of 'front-line' purchasing agents. To enable future research, it was found that tactical sourcing levers require a more explicit conceptualisation and a method of measurement (Hesping and Schiele, 2015; Luzzini et al., 2012; Wacker, 1998). But, in contemporary literature it remained unclear to which 
extent tactical sourcing levers can be defined as theoretical concepts and which conceptual content they capture. To fill this gap, this study built on a framework of seven tactical sourcing levers and developed developed corresponding formative measurement models.

Contemporary literature was reviewed to define the conceptual content for each of the seven core tactical sourcing levers and to generate an initial list of indicators. Building on this list, world café discussions with 24 category managers was held to identify further indicators and to minimise conceptual overlaps among them. The research concluded by assessing the formative measurement models in a survey of 107 sourcing project at one large European automotive OEM. Tests for convergent validity, multicollinearity and indicator relevance show strong empirical support that the developed sourcing lever constructs well tap the phenomenon of interest. The refined list of 23 indicators may serve practitioners as a checklist of potential cost saving opportunities.

Findings from the literature review identified a wide range of overlapping terms used to describe purchasing strategies and tactics. In the past, literature has not been very precise about the level of analysis to which these strategies and tactics relate. The literature about 'volume bundling' tactics, produces a good example about where different levels of analysis exist in literature. Halman et al. (2003) for example relate to the firm level of analysis and describe 'volume bundling' as an organisation-wide product platform strategy to reduce product variants and thus to increase volume for the remaining product types. Karjalainen and van Raaij (2011) again address the functional level and limit 'volume bundling' to the purchasing function and the consolidation of demand through centralisation of purchasing activities. Yet, Schiele et al. (2011) focus on the sourcing category level and state that 'volume bundling' might be limited to only one category of purchases while other categories require different tactics. These observations correspond to recent findings calling for a hierarchical approach in purchasing strategy development. "In purchasing, it is difficult to develop a single, all-encompassing strategy. To the contrary, a hierarchy of stages emerges when general strategy is disaggregated into executable and controllable activities" (Hesping and Schiele, 2015, p. 138). The sourcing lever constructs in this study directly address this difficulty and support academics and practitioners to take a differentiated and focused approach to implementing strategy at the so far less explored category level of purchasing. 
Furthermore, the study illustrates the applicability of the world cafe methodology in the index development process (Brown and Isaacs, 2005; Hoffmann, 2012; Lagrosen and Lagrosen, 2013; Prewitt, 2011). Different from the majority of other quantitative and qualitative research approaches, in a world café, practitioners are seen as co-researchers rather than objects of inquiry (Susman and Evered, 1978). Relevance was demonstrated as participants highly valued to be actively engaged into discussion and evaluation of findings (Schiele and Krummaker, 2011; Vermeulen, 2007). As participants move from table to table to exchange ideas, they can further build capabilities, gaining immediate return on the time invested into the process. Construct validity could be increased as participants moved between tables, challenging and refining emerging constructs from different perspectives (Maxwell, 1992). Formative measurement models require a minimal conceptual overlap between the different indicators, avoiding multicollinearity (Diamantopoulos and Winklhofer, 2001). The world café proved to be a promising methodology to refine sometimes vague and not clearly delineated indicators from literature into distinct constructs with minimal conceptual overlaps.

Overall, the study's sourcing lever indices serve future research as a starting point to address relevant research questions about the antecedents, conditions and consequences of sourcing lever application, which have hardly been studied so far. Each indicator of the sourcing lever constructs represents a specific activity that purchasers can implement to achieve cost savings for a category of purchases. In a formative measurement model, each indicator's contribution to the construct can be interpreted by its weight. For example, in the 107 analysed sourcing projects, 'packaging of several requests' (volumeB_4) has been used most to achieve volume bundling. Yet, 'gathering a large number of technically different offers' (priceE_2) has been used least for price evaluations (see Table 4, p. 59).

This raises new academic and practical questions: Why, did purchasers rely more on a certain activity than on another? Do the firm's processes or policies overemphasise certain activities, while others are neglected? Future research might use the indicator weights to evaluate, for example, which share each activity contributed to different dimensions of sourcing performance across multiple sourcing projects. In practice, this may allow concentrating on the most promising levers depending on the performance goals to be realised. 


\subsubsection{Implications: sourcing tactics have become measureable}

The previous conclusions lead to a multiple theoretical and managerial implications:

(1) Sourcing levers are tactics that purchasing teams use to fulfil cost savings targets. Therefore, it is surprising that this chapter is one of few studies that systematically addresses cost saving approaches for a sourcing category. For the first time, the study reports results from a comprehensive literature review on sourcing tactics to implement strategy at the category level of purchasing. It lists, delineates and groups a wide range of cost saving approaches as an important step towards theory building (Meredith, 1993). The presented framework of seven tactical sourcing levers can serve to structure existing knowledge and future academic discussion. Future research may use the results to contrast sourcing lever application and performance outcomes across sourcing categories. Does the 'product optimisation' lever for example lead to different performance outcomes in a sourcing category with low and high technological complexity?

(2) None of the tactical sourcing levers have systematically been conceptually delineated and empirically evaluated before. Therefore, it is not surprising, that the literature review revealed large conceptual overlaps between the identified cost saving approaches. Multiple wordings have been used to describe aspects that appear conceptually very similar. This complicated or even hindered academic reasoning and cross-study comparison (Speed, 1993). To overcome this barrier for academic progress, this study highly engaged academics and practitioners during the research process. Using world café methodology, conceptual overlaps between the cost saving approaches, found in literature have been minimised. Aggregation and abstraction led to 23 distinct indicators. Instead of using a confusing amount of conceptually overlapping concepts, future research may focus on this aggregated list of cost saving approaches covering all of the main aspects of the sourcing lever concept.

(3) The study results have an immediate practical relevance as they reveal a wide range of cost saving approaches. The developed list of indicators represents specific, actionable activities that may serve practitioners as a 'toolbox' or 'checklist' to plan upcoming sourcing activities and to 
discuss improvement potentials that have not been addressed so far. The identified cost saving approaches may be used in cross-functional lever analysis workshops that have been described as a promising, new costcutting methodology (Schiele, 2007; Schiele et al., 2011; Schuh et al., 2011). Practitioners might, for example, evaluate whether they have considered all potential tactical sourcing levers to achieve their goals or if their choice of tactics fits to the approaches taken in another sourcing category.

(4) So far, research had little valid measures to capture the conceptual content of the sourcing lever concept. With this study, indices with formative indicators have become available and can be applied to a wide range of practical and academic questions. In contemporary literature, the relationships of tactical sourcing levers to other constructs remain unclear. The antecedents, conditions and consequences of sourcing lever application have hardly been studied so far. Multiple research questions arise: Under which internal organisational and external supply market conditions are tactical sourcing levers most successful? How do tactical sourcing levers influence cost, innovation and other performance aspects? Which configurations of tactical sourcing levers are most successful? Do potential trade-offs exist among tactical sourcing levers, in a way that certain tactical sourcing lever combinations reduce overall expected performance? Which tactical sourcing levers can be combined to realise synergies and to maximise overall cost savings? In which order shall tactical sourcing levers be applied to reach most cost savings? Are certain tactical sourcing levers more successful at the beginning while others should be applied preferably at the end of a sourcing project? Do certain tactical sourcing levers lose their effect when being applied several times in the same sourcing category? Can tactical sourcing levers be added to regain cost saving potentials from tactical sourcing levers that lost their potential over time? How do cross-functional sourcing teams influence the choice and success of tactical sourcing levers? What are the required competencies of category managers to apply tactical sourcing levers most successfully? The list of possible research questions is extensive. This chapter offers the instruments to address several of them. 


\subsubsection{Limitations: sourcing lever indices - a work-in-progress}

The development of sourcing lever indices can still be considered as a work-inprogress. A number of limitations suggest further research:

(1) The research took part in one large, global automotive OEM and focused on direct purchases only. Findings from the automotive industry are generally expected to be more generalisable than from other industries. Still, further data collection for additional testing of the developed sourcing lever indices in other industries, including indirect, servicebased purchases is desirable. Broader cross-industrial investigations in further regions and cultural settings might help to strengthen the usability of the developed constructs across a wider range of research problems.

(2) The developed measurement models have been grounded in recent literature and further investigated in the context of contemporary perceptions of 'front-line' category managers. Both, literature and practitioners' opinions can vary over time and affect how tactical sourcing levers and corresponding activities are framed and used. Especially in the automotive industry, new technologies are constantly integrated into the product portfolio; e.g., digitalisation of the car. Future research might want to monitor these changes in this young research field and seek to deepen the knowledge about which tactics and activities 'front-line' purchasing agents may use to address upcoming challenges.

(3) Purchasing agents increasingly work in cross-functional teams which can also affect their choice of tactical sourcing levers. Future research might therefore aim to broaden the evaluation of tactical sourcing levers and also integrate practitioners from further supply market-related functions such as engineering or quality into the research process.

In this chapter, sourcing lever indices have been developed to enable empirical research in the following chapters. In the next chapters, these indices have been used to prepare profiles of sourcing lever application for each quadrant of the Kraljič matrix, a purchasing portfolio matrix. 



\section{CHAPTER 4: \\ MATCHING SOURCING LEVERS WITH THE \\ KRALJIČ MATRIX - EMPIRICAL EVIDENCE ON PURCHASING PORTFOLIOS}

\subsection{INTRODUCTION: A PORTFOLIO PERSPECTIVE ON TACTICAL SOURCING LEVERS}

Compelling evidence indicates that strategic management of supply markets can provide competitive advantage (Chen et al., 2004; Mol, 2003). However, in an effort to improve performance, not all purchased materials and buyer-supplier relationships should be managed the same way (Gelderman and Van Weele, 2003). This suggests that professional purchasing requires differentiation and some sort of classification of these resources. Consequently, many portfolio models have been developed, some of which are widely adopted in practice to manage different types of materials or buyer-supplier relationships (Bensaou, 1999; Kraljič, 1983; Olsen and Ellram, 1997). One of the most commonly used approaches is the $2 \times 2$ 'Kraljič matrix' (Kraljič, 1983), which distinguishes a noncritical, leverage, bottleneck and strategic portfolio quadrant along two dimensions: (1) 'strategic importance' and (2) 'supply risk'. For each portfolio quadrant, extant literature offers the buying firms corresponding generic strategic and tactical recommendations (Canièls and Gelderman, 2005; Cousins et al., 2008b; Gelderman and Semeijn, 2006; Gelderman and Van Weele, 2005; Lysons and Farrington, 2012; Monczka et al., 2011; Van Weele, 2010). Tactics are used to particularize overall strategic approaches when transitioning from general strategy to ultimate activities (Cox, 2014; Hesping and Schiele, 2015; O'Brien, 2012; Schuh et al., 2011). Unfortunately, literature often confusingly uses the term 'purchasing strategies' to describe strategical as well as tactical approaches (Hesping and Schiele, 2015). To avoid confusion, this study uses the 
terms 'purchasing strategy' to describe strategic approaches related to the overall purchasing department and 'tactical sourcing levers' to describe sets of tactics used to operationalize strategy as combination of activities in a sourcing category. Thereby, a 'sourcing category' includes materials or services of a similar type, which constitute a single supply market (Hesping and Schiele, 2015; Schiele et al., 2011a). In contrast to purchasing strategy, tactical sourcing levers do not provide a general orientation for purchasing activities such as achieving annual cost saving targets or fostering innovation. Tactical sourcing levers describe a typology of activities through which the goals shall be realised; often with a concrete time specification and traceable milestones (Hesping and Schiele, 2015; Hess, 2010; Mintzberg, 1994; Schiele, 2007; Schiele et al., 2011a).

The traditional, prescriptive view of the Kraljič matrix is intuitively appealing. It suggests that, in order to maximize performance, purchasers implement the quadrant-specific strategic recommendations and tactics for all purchases in the same portfolio quadrant. "Failure to achieve the right outcomes indicates either a failure of the tool or a failure of the user" (Jarzabkowski and Kaplan, 2008, p. 6). However, in practice, strategy implementation is often not that simplistic. Recommendations made by management tools, such as the Kraljič matrix, may not be seen as prescriptions but as starting points for structured discussion between different actors (Jarzabkowski and Kaplan, 2008; Spee and Jarzabkowski, 2009). Therefore, over a decade ago, authors of several studies called for moving away from teaching a strict adherence to the generic recommendations of the Kraljič matrix, noting that not all items in the same portfolio cell are to be managed the same way (Gelderman and Van Weele, 2003). Rather, experience shows that practitioners also pick tactical sourcing levers from adjacent quadrants that will allow them to move from a current difficult to a future much easier quadrant or power scenario (Canièls and Gelderman, 2005; Cox, 2004, 2014; Gelderman and Van Weele, 2003; Monczka et al., 2011). It has been hypothesized that sourcing practice demands that many, if not all, tactical sourcing levers may be used in each of the four quadrants (Cox, 2014; Hesping and Schiele, 2015; Luzzini et al., 2012; Schiele et al., 2011a; Schumacher et al., 2008).

Surprisingly, research on purchasing portfolio models contributes little to verify how tactical sourcing levers are actually applied in practice. Prior works contrasted portfolio quadrants by differences in product characteristics (Kraljič, 
1983; Van Weele, 2010), purchasing skills (Knight et al., 2014), buyer-supplier relationships (Bensaou, 1999; Dubois and Pedersen, 2002; Gadde and Snehota, 2000), power structures (Canièls and Gelderman, 2005; Pazirandeh and Norrman, 2014) and organizational structures (Gelderman and Semeijn, 2006). Yet, there is evident paucity of empirical investigations on tactical sourcing levers that can be employed in each portfolio quadrant. The move from theoretical consideration to empirical reality is still missing.

Consequently, the aim of this study is to investigate if tactical sourcing levers are applied according to the generic suggestions made by purchasing portfolio models. To do so, the chapter is guided by the following research question (RQ1.3.): Does the application of tactical sourcing levers vary according to 'strategic importance' and 'supply risk', as suggested by Kraljič and, if so, how? To answer this question, (1) a detailed review of extant literature about purchasing portfolio models and sourcing levers was first conducted. (2) Subsequently, a measurement instrument for supply risk, strategic importance and tactical sourcing levers was developed and applied to 107 sourcing projects. (3) Each sourcing project was later classified into the noncritical, leverage, bottleneck or strategic quadrant of the Kraljič matrix. (4) Finally, sourcing lever profiles for each portfolio quadrant were contrasted with the help of nonparametric tests.

A major strength of this study lies in the research design, which directly integrates 'front-line' purchasing agents and their experience in the application of tactical sourcing levers to various sourcing projects. Thus, the study findings have important implications for purchasing portfolio theory and practice.

In a traditional view, according to several textbooks, each quadrant of the Kraljič matrix requires specific, generic tactics. Thereby, most recommendations are limited exclusively to a single portfolio quadrant (Cavinato, 2006; Handfield et al., 2009; Johnson et al., 2011; Lysons and Farrington, 2012; Monczka et al., 2011). From such publications, it might be assumed, for example, that only noncritical purchases require efficient processing while exploitation of purchasing power is limited to leverage items. However, the findings yielded by this study support a more differentiated approach to that suggested in previous works (Canièls and Gelderman, 2005; Cox, 2014; Gelderman and Van Weele, 2003). More specifically, in the analysed sample, the entire range of tactical sourcing levers has been found to be used in each portfolio quadrant. In addition, as the strategic importance 
increases and supply risk reduces, tactical sourcing levers are more extensively used. Tactical sourcing levers are applied additively, rather than exclusively, as was suggested in most textbooks. This suggests rethinking the task of teaching and applying the usage of the Kraljič matrix and management tools in general. The Kraljič matrix may not be seen as providing mutually exclusive prescriptions to choosing the right strategic and tactical approaches. The Kraljič matrix may be more usefully conceptualized and taught as a space for debate and dialogue to bring together actors with different viewpoints in a way that strategic choices can be made (Chesley and Wenger, 1999; Jarzabkowski and Kaplan, 2008; Spee and Jarzabkowski, 2009).

The discussion and analysis of the aforementioned issues commences with Section 4.2, providing an overview of relevant literature about purchasing portfolios and tactical sourcing levers. In Section 4.3, the survey design and measurement models are presented. The resulting sourcing lever profiles a for each portfolio quadrant are contrasted and discussed in Section 4.4, and conclusions, implications and suggestions for further research are presented in Section 4.5.

\subsection{LITERATURE REVIEW: CONTEMPORARY RESEARCH ON PURCHASING PORTFOLIO MODELS AND SOURCING LEVERS}

\subsubsection{Purchasing portfolio models: generic tactics for different types of purchases}

Kraljič (1977) adopted the portfolio concept to the purchasing context, offering "pragmatic advice on how top management can recognize the extent of its own supply weakness and treat it with a comprehensive strategy to manage supply" (Kraljič, 1983, p. 109). In the Kraljič matrix, purchased items are classified along the dimensions of 'strategic importance' and 'supply risk' (low vs. high). The outcome is a $2 \times 2$ matrix, known as the 'Kraljič matrix', which provides a classification into four portfolio quadrants, namely noncritical, leverage, bottleneck and strategic purchases (Kraljič, 1983). In his original publications, Kraljič $(1977,1988)$ recommends specific tactics for each single portfolio quadrant (see Table 5, p. 71): 
Table 5: The Kraljič matrix - generic tactics

Portfolio quadrant

Tactic

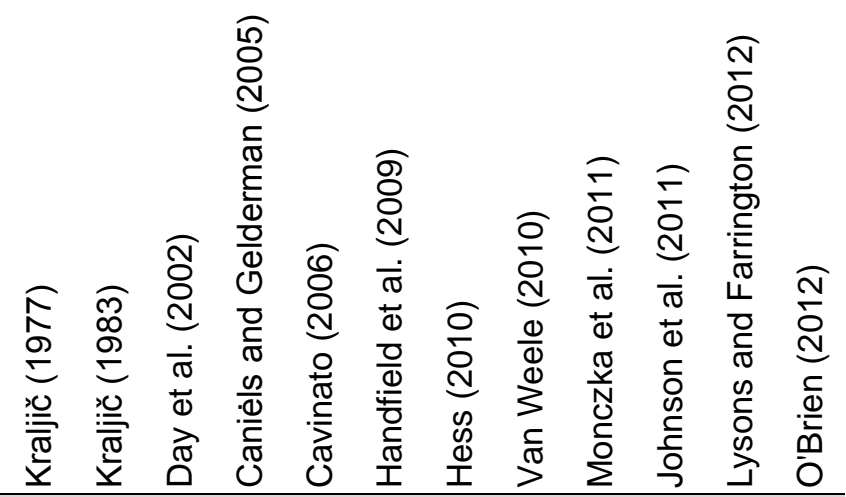
Efficient processing/ acquisition
Product standardization
Consolidate/ leverage volume
Inventory optimisation

Noncritical (low strategic importance; low supply risk)

Rationalize supply base

Decentralize procurement
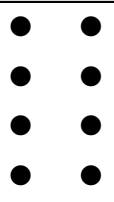

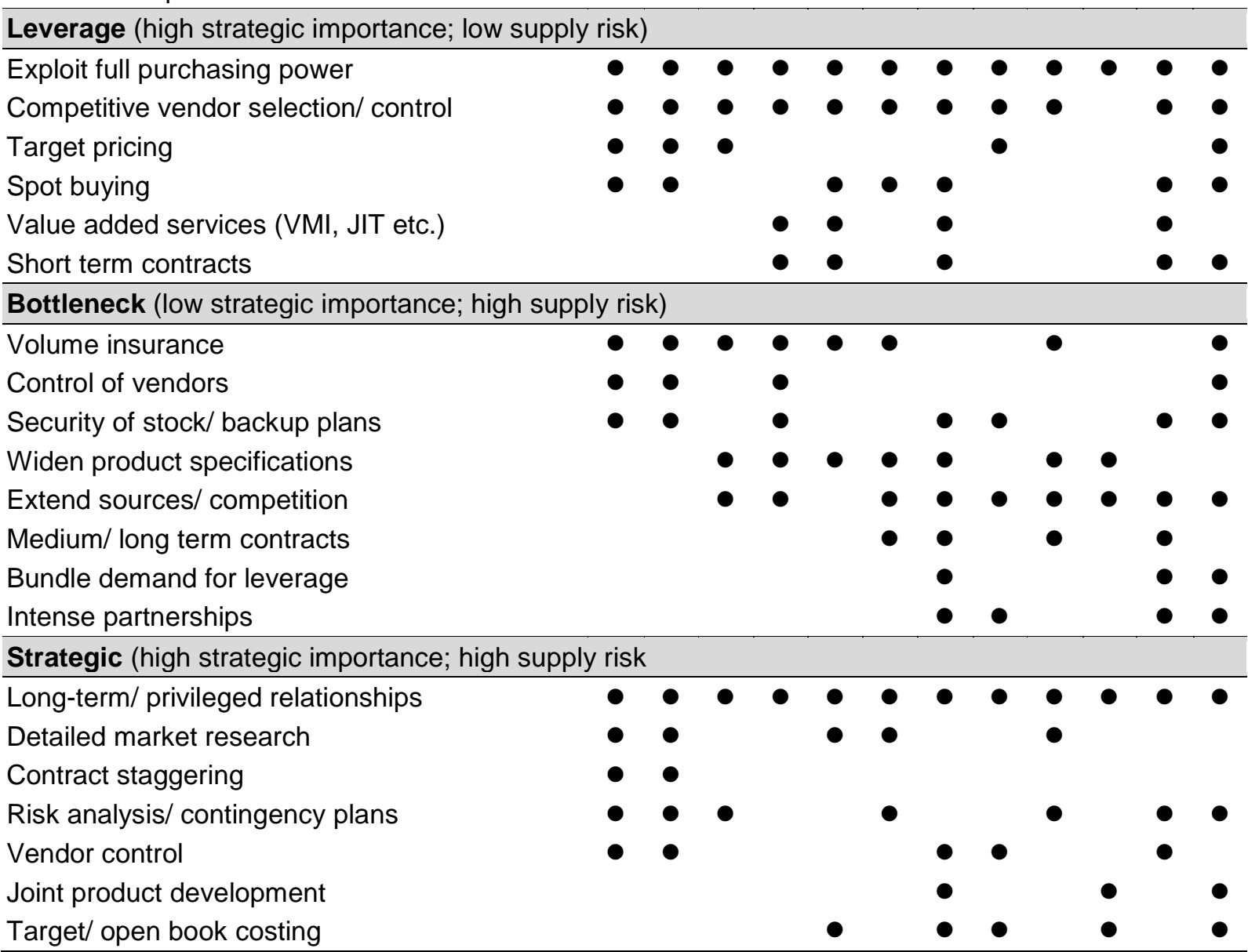


(1) Noncritical purchases are of low strategic importance and ordered frequently from many alternative sources. Thus, pertinent tactics focus on reducing transaction costs through efficient processing, reducing variants, consolidating orders and decentralizing procurement activities.

(2) Leverage purchases include strategically important expenditures in a large marketplace with many alternative suppliers. This diversity allows exploitation of full purchasing power, vendor selection, product substitution, targeted pricing negotiations, a mix between contract and spot purchasing and order volume optimisation.

(3) Bottleneck purchases have a low strategic importance and are only available from a small number of sources. The tactics that are relevant in this case focus on volume insurance, control of vendors, security of inventories and backup plans.

(4) Strategic purchases are critical to profitability and operations and can be obtained from a limited number of qualified sources. They require accurate demand forecasting, detailed market research, development of long-term supply relationships, make-or-buy decisions, contract staggering, risk analysis, contingency planning as well as logistics, inventory and vendor control.

Over time, several authors have refined the analytical variables on the axes of the Kraljič matrix and added or changed recommendations for the portfolio quadrants (see Table 5, p. 71) (Elliott-Shircore and Steele, 1985; Hadeler and Evans, 1994; Handfield et al., 2000; Kamann, 2000; Olsen and Ellram, 1997; Pagell et al., 2010; Svensson, 2004; Van Weele, 2010).

Still, the practical application of the Kraljič matrix exceeds and sometimes contradicts its theoretical use. When making such recommendations, authors of contemporary textbooks give the impression that specific sourcing tactics are exclusively applied to a single portfolio quadrant. Monczka et al. (2011) and Handfield et al. (2009), for example, listed distinct essential elements of strategy, tactics and actions in each quadrant of the portfolio matrix. According to these authors, each element should be attributed to a single quadrant exclusively. Similarly, Lysons and Farrington (2012) listed 32 'aims and main tasks'; however, only three of these items were included in more than one quadrant. On the other hand, Johnson et al. (2011) recognized that firms may aim to move products into another quadrant, yet still listed exclusive tactics for each quadrant. 
However, other authors report that most tactical sourcing levers may be used in multiple if not all quadrants of the Kraljič matrix. For example, Cox et al. (2003) argue that the original Kraljič matrix fails to recognize tactics aiming to change a purchase's position in the portfolio matrix (dynamic leverage). Motivated by moving certain purchased items from one quadrant to another, purchasing agents were found to adopt tactical sourcing levers which, in the original design, were associated with adjacent portfolio quadrants (Canièls and Gelderman, 2005; Cox et al., 2003; Gelderman and Van Weele, 2003). Furthermore, Faes and Matthyssens (2009) found that several tactical sourcing levers (e.g. a concentration on few sources) can be implemented in multiple portfolio quadrants. Similarly, Krause et al. (2009) and Pagell et al. (2010) report that sustainability objectives motivated companies to adopt tactical sourcing levers others than the ones suggested by the Kraljič matrix (e.g. intense collaboration and long-term contracts). In a recent work, Ateş (2014) "illustrated that many purchase category strategies can be implemented equally effectively in the same Kraljič quadrant" (p. 59). Cox (2014) even proposes that most tactical sourcing levers may be used for all purchases, no matter in which quadrant of the Kraljič matrix they were classified. Consequently, Hesping and Schiele (2015) state that, although certain category purchases may be assigned to the same portfolio quadrant, each category requires an individual set of tactical sourcing levers.

This brief summary clearly indicates that further research is needed to empirically verify if and how the distinct suggestions for each quadrant are applied in practice. To address this need, this study developed sourcing lever profiles for each quadrant of the Kraljič matrix from data collected in practice.

\subsubsection{Sourcing levers: tactics that can be adopted to achieve cost savings}

There are several models of leverage in purchasing literature. While some studies focus on a rather strategic leverage such as long-term outsourcing decisions, this study focuses on the tactical sourcing levers used to implement strategy (Hesping and Schiele, 2015).

Distinct from general strategy, tactics form clusters of activities with a concrete time specification and tractable milestones (Mintzberg, 1994). In contrast to purchasing strategy, tactical sourcing levers do not provide a general orientation for purchasing activities, such as achieving annual cost reduction 
targets or fostering innovation (Schiele et al., 2011a). Tactical sourcing levers describe a sets of similar activities used to operationalize strategy as combination of activities in a sourcing category (Hess, 2010; Schiele, 2007). Thereby, they cover multiple competitive priorities such as cost reduction, quality, innovation or security of supply (Ateş, 2014; Ateş et al., 2015; Hesping and Schiele, 2015; Luzzini et al., 2012).

Literature describes several lever models with various activities merged into coherent groups or sets Some models range from fifteen 'value levers' merged into five 'lever groups' (O'Brien, 2012), 64 'methods' grouped into sixteen 'levers' in a 'purchasing chessboard' (Schuh et al., 2011) to 114 'tactical levers' merged into seven 'categories' of tactical levers (Cox, 2014). Yet, despite this diversity, seven core sourcing levers are commonly discussed (Schiele, 2007; Schiele et al., 2011a; Schuh and Bremicker, 2005; Schumacher et al., 2008):

(1) 'Volume bundling', which refers to the consolidation of demand and increasing the purchase volume for quotation (Karjalainen, 2011; Prince et al., 2013; Schoenherr and Mabert, 2008);

(2) 'Price evaluation', which refers to forming price targets and analysing suppliers' bids and cost structures (Ellram, 1996; Newman and Krehbiel, 2007; Romano and Formentini, 2012);

(3) 'Extension of supply base', pertaining to increasing the number of sources and bidders per request for quotation to raise bargaining power (Caniëls and Gelderman, 2007; Lonsdale, 2001; McMillan, 1990);

(4) 'Product optimisation', referring to modifications to the design, functions and materials of the purchased items (Handfield et al., 1999; Khan et al., 2008; Luo et al., 2011; McGinnis and Vallopra, 1999; Smith, 1999; Wagner, 2012);

(5) 'Process optimisation', which refers to efficient and effective processes related to the buyer-seller interfaces (Foster Jr et al., 2011; Labro, 2006; Manrodt and Vitasek, 2004; Quintens et al., 2006a);

(6) 'Optimisation of supply relationship', which pertains to establishing and maintaining a long-term, mutually beneficial, privileged relationship between buyer and supplier (Adobor and McMullen, 2014; Blonska et al., 2013; Handfield et al., 2000; Hüttinger et al., 2012; Krause et al., 2007; Nagati and Rebolledo, 2013; Schiele et al., 2012a); and

(7) 'Category-spanning optimisation', which relates to balancing trade-offs among multiple sourcing categories (e.g., design changes in a common 
platform) and adopting mutual approaches, applied by otherwise distinct sourcing teams (Driedonks, 2010; Schiele, 2007; Schumacher et al., 2008; Thomas et al., 2014). It is worth mentioning that these seven levers appear similar to the seven 'categories of tactical levers' by Cox (2014). However, to avoid confusion with the term 'sourcing category, we adopted the wording 'tactical sourcing lever' to describe a set of similar tactical sourcing activities.

Some tactical sourcing levers may appear identical to a strategy; yet, as discussed in Chapter 2, they are not. Purchasing strategy may be defined in terms of strategic priorities such as cost, flexibility and innovation (Ateş, 2014; Ateş et al., 2015; Baier et al., 2008; González-Benito, 2007). To reach these strategic priorities, managers can choose a mix of sourcing tactics, i.e. tactical sourcing levers, made up of a set of activates to implement overall strategy. For example, to reach the strategic goal of innovation, managers might opt for the tactical sourcing lever 'product optimisation' followed by various activities to make modifications to the design, functions and materials of the purchased items. As another option, they might choose to implement the tactical sourcing lever 'optimisation of supplier relationships' in order to become more attractive towards a selected number of suppliers and their innovative products. Hence, 'optimisation of supplier relationships' can be understood as one out of several tactical sourcing levers to reach the strategic goal of innovation but not as a strategy by itsself. Nevertheless, to be able to implement the tactical sourcing lever 'optimisation of supplier relationships', appropriate supplier strategies at a subordinate level may be needed (Hesping and Schiele, 2015).

Recent studies present conceptual frameworks linking purchasing portfolios and tactical sourcing levers. Among those, Handfield et al. (2009), Schuh et al. (2011), Hess (2010), Lysons and Farrington (2012) and O'Brien (2012) are noted for grouping tactical sourcing levers into the cell of a purchasing portfolio matrix. However, in these literature sources, these concepts were developed solely for practical application, or only incidentally referred to previous academic work. In sum, thus far, academics contributed relatively little to the identification of tactical sourcing levers that are most suitable for specific portfolio quadrants within the Kraljič matrix. 


\subsection{METHODOLOGY: A SURVEY INSTRUMENT AIMING TO CAPTURE STRATEGIC IMPORTANCE, SUPPLY RISK AND SOURCING LEVER PROFILES}

The present study aimed to assess whether and how the application of tactical sourcing levers varies among noncritical, leverage, bottleneck and strategic purchases. To achieve this objective, sourcing projects had to be classified and sourcing lever profiles developed for each portfolio quadrant. To do so, a multiitem scales were developed to collect data about 'strategic importance', 'supply risk' and sourcing lever profiles for 107 sourcing projects within one large, global automotive OEM. Depending on a 'low' or 'high' score for 'strategic importance' and 'supply risk', each observation could be classified into one of the four quadrants of the Kraljič matrix. Ultimately, the sourcing lever profiles of the quadrants were formally tested for differences and similarities using nonparametric tests.

A multi-step process was used to develop and validate the survey instrument (Churchill, 1979; Diamantopoulos and Winklhofer, 2001; Rossiter, 2002). Initially, a review of purchasing, marketing, operations and supply chain management literature was conducted to identify construct definitions and existing items for strategic importance and supply risk. The sourcing lever indices have been adopted from the world café findings in Chapter 3.

\subsubsection{Strategic importance and supply risk: existing multiple-item scales sourced from extant literature}

The original analytic variables of Kraljič $(1977,1983)$ do not provide robust reflective, multi-item scales. For example, both, Kraljič (1977) and Kraljič (1983), state that their mentioned analytic variables are not complete. The list of analytic variables in Kraljič (1983) ends with “... and so on” (p. 111); indirectly asking the reader to complement them. Over time, researchers have built on Kraljič's seminal work, developed and refined reflective, multi-item scales for 'strategic importance' and 'supply risk'. Therefore, to enable empirical evaluations in the subsequent course of this research, this chapter moves beyond Kraljič's (1983) original analytic variables and integrates refined multi-item scales from contemporary literature: 
- 'Strategic importance' relates to the financial and strategic significance of the purchase (Cannon and Perreault Jr, 1999), reflecting not only the direct monetary value of the purchase but also the impact of the purchase outcome on the buying firm's goals, profitability and customer relationships (Cannon and Perreault Jr, 1999; Ellis et al., 2010; Krause, 1999; Lau et al., 1999). This also includes the degree to which the purchase is critical to the manufacture of a firm's own products (Ellis et al., 2010). To measure this construct, a 5-item scale was developed, incorporating two items related to monetary value and effect on profitability from Lau et al. (1999), one item about management priority, and two items about relative importance from Ellis et al. (2010).

- 'Supply risk' relates to the threat of a temporary or permanent perturbation or disruption of supply associated with a firm's supply network (Wagner and Bode, 2006). This includes supplier business risks, such as capacity constraints, quality problems or effects of technological changes on the supply market (Zsidisin et al., 2000). In particular, this dimension pertains to the threat of financial instability of suppliers and the consequences of supplier default (Wagner and Johnson, 2004). Empirical evidence suggests that supply risk may stem from poor operational performance or opportunistic behaviour of suppliers (Hallikas et al., 2004; Spekman and Davis, 2004). In this respect, lock-in situations are an important threat, as they make a purchasing organization highly dependent on a supplier, due to the very limited number of alternative sources (Hoffmann et al., 2013; Hunter et al., 2006; Schoenherr and Mabert, 2011). For measuring this construct, a 7-item scale was developed that incorporates three items about capacity shortages, supply problems and supplier demise. Three further items about the availability of alternative sources were sourced from Hunter et al. (2006), whereas one additional item about supplier capacities was adopted from Schoenherr and Mabert (2011).

In completing the questionnaire, the respondents were required to state the extent to which they agreed with the corresponding statements on a 7-point Likert scale anchored at $1=$ 'strongly disagree' and $7=$ 'strongly agree' (see Appendix - Table 20, p. 168). 


\subsubsection{Tactical sourcing levers: relevant activites were developed in a world café}

Over time, literature discussed multiple sets of tactics related to purchasing portfolio models (see Table 5, p. 71). As discussed previously, recent studies have systematized this knowledge and developed a taxonomy of seven core tactical sourcing levers, whereby each lever consists of a set of similar activities that are used to improve sourcing performance for a sourcing category (Hesping and Schiele, 2015; Schiele, 2007). However, contemporary literature provides very limited guidance regarding activites related to each lever, which may serve as indicators in emperical investigations. Consequently, the present study capitalized on extensive collaboration with one large, global automotive OEM to develop a list of indicators that were consistent with the operational defintions of the seven core sourcing levers. In a world café approach, in Chapter 3, 23 activities were assigned to the seven core tactical sourcing levers. In the subsequent survey, the respondents indicated the extent to which they applied each tactical sourcing activity (grouped into seven core sourcing levers) using a 7-point Likert scale anchored at $1=$ 'not used' and $7=$ 'extensively used' (see Appendix - Table 19, p. 166).

\subsubsection{Sample frame and data collection: 'front-line' purchasing agents were questioned at the point of supplier nomination}

Unit of analysis was the multitude of sourcing projects managed at the European headquarters of the same automotive OEM that took part in the world café. Therefore, the study drew on the same survey data set that has been collected earlier in this study (for details see Section 3.3.3, p. 56).

All survey items were pre-tested with an expert panel of category managers from the focal firm, who did not previously take part in the research process. They were asked to check that there were no wrong or right questions and to identify possibly vague concepts or unfamiliar terms.

To minimize bias arising from information recall, the supplier nomination stage was chosen as the point of reference for the purchaser. Each time a supply contract was awarded and registered in the IT system, the responsible category manager was visited by the researcher and the questionnaire was completed jointly. In this way, maximum validity was ensured, generating high quality data (Srinivasan and Ratchford, 1991). 


\subsection{ANALYSIS AND FINDINGS: COMPARATIVE TESTS REVEAL SIGNIFICANT DIFFERENCES IN SOURCING LEVER PROFILES ACROSS PORTFOLIO QUADRANTS}

Initially, confirmatory factor analysis (CFA) was employed to assess reliability and validity of the multi-item reflective scales for 'strategic importance' and 'supply risk' (Hair Jr. et al., 2013). The survey items, item-to-construct loadings, means and standard deviations are listed in Table 6 (p. 79). All itemto-construct loadings were significant $(p<0.001)$ and were well above the cutoff value of 0.7 , indicating a substantive contribution.

Table 6: Cross loadings, means and standard deviations

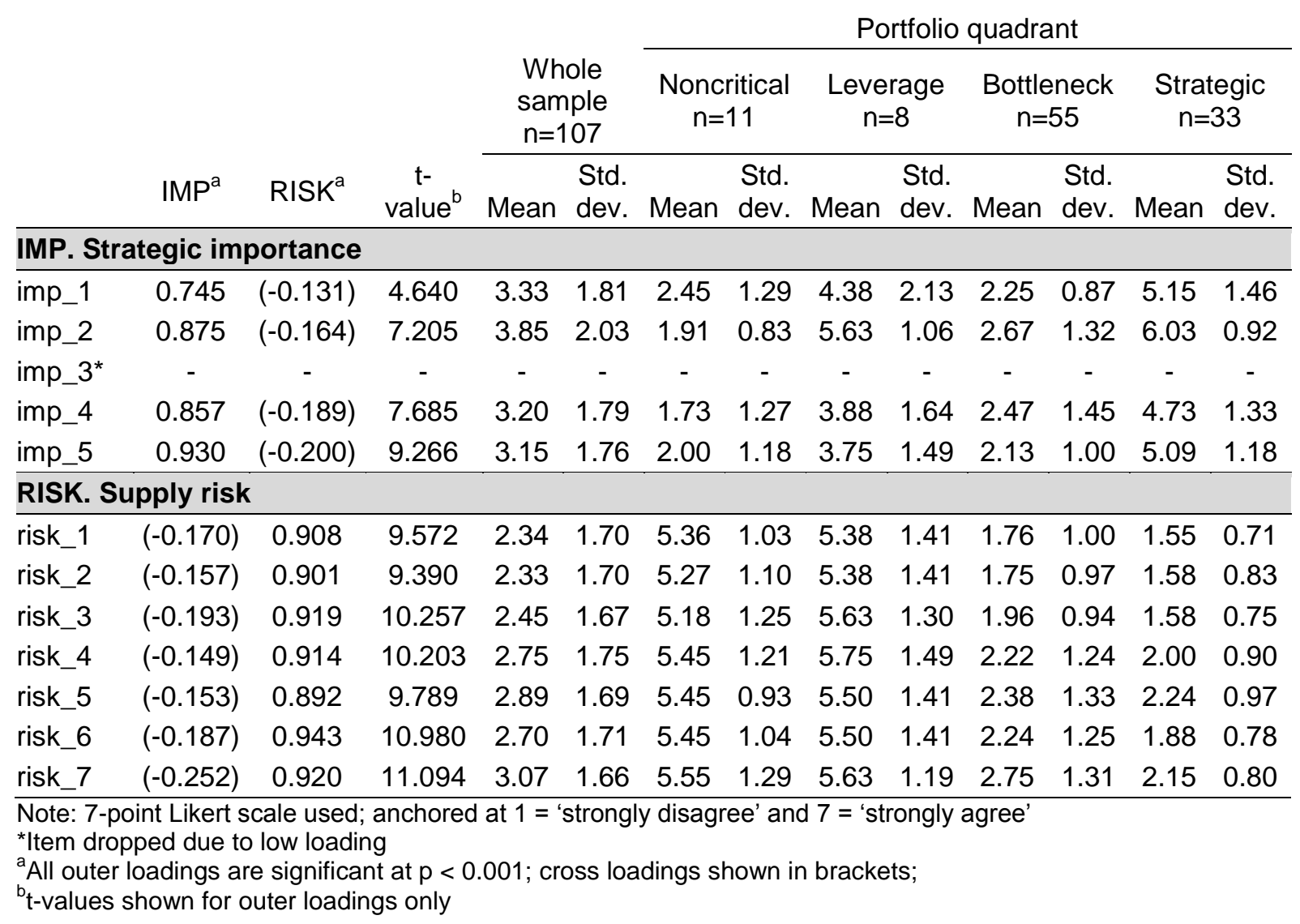

Table 7, (p. 80) reports on inter-construct loadings and scale reliabilities. Reliability of the scales was tested using Cronbach's alpha (Cronb. $\alpha$ ), average variance extracted (AVE), and composite reliability (CR) scores. Cronbach's alpha and CR statistics both substantially exceed the threshold value of 0.7 , indicating internal consistency. In addition, both scales surpassed the minimum 
value of 0.5 for AVE, indicating convergent validity. Discriminant validity of the scales was also assessed by checking the item-to-construct loadings and using the Fornell-Larcker criterion. The item loadings onto the corresponding construct showed no critical levels of cross-loadings, while all square roots of the AVE were higher than the corresponding inter-construct correlations, indicating unidimensionality (Hair Jr. et al., 2013).

Table 7: Inter-construct loadings and reliabilities

\begin{tabular}{lccccc} 
& Cronb. a & CR & AVE & IMP & RISK \\
\hline IMP. Strategic importance & 0.876 & 0.915 & 0.730 & $\mathbf{0 . 8 5 4}$ & - \\
RISK. Supply risk & 0.967 & 0.973 & 0.835 & -0.204 & $\mathbf{0 . 9 1 4}$ \\
\hline
\end{tabular}

Square roots of AVE on the diagonal; marked in bold (Fornell-Larcker criterion)

Thereafter, the analysed sourcing projects were classified into the quadrants of the Kraljič matrix; namely noncritical ('low strategic importance' and 'low supply risk'), leverage ('high strategic importance' and 'low supply risk'), bottleneck ('low strategic importance' and 'high supply risk') and strategic purchases ('high strategic importance' and 'high supply risk'). Using dichotomization by mean split, the continuous measurements for 'strategic importance' and 'supply risk' have been used to create 'low' and 'high' groups based on whether the scores were greater or less than the mean of the 7-point Likert scale (Cohen, 1983; DeCoster et al., 2009; MacCallum et al., 2002). An observation was classified as 'low' if the variable score was below ' 4 ' and as 'high' if the score was equal or above ' 4 '. Using these categorical variables, each sourcing project was classified as 'noncritical', 'leverage', 'bottleneck' or 'strategic'.

\subsubsection{Sourcing lever profiles by portfolio quadrant: not all tactics align with the suggestions of the Kraljič matrix}

Finally, as a part of this investigation, sourcing lever profiles were developed for each of the four portfolio quadrants. Sourcing lever scores were calculated from the mean of the corresponding sourcing activities. These profiles were subsequently compared with the average profile across all 107 sourcing projects (for details, see Appendix - Table 23, p. 172). Then, the sourcing lever profiles were tested for significant differences and similarities using nonparametric test 
(Kruskal-Wallis H and Mann-Whitney U test) (Hollander et al., 2013) (for details, see Appendix - Table 24, p. 174). Subsequently, sourcing lever profile and significant differences across portfolio quadrants were discussed in relation to the generic tactics from the literature review listed in Table 5 (p. 71).

Noncritical purchases $(n=11)$ account for 10.3 percent of all cases. This portfolio quadrant is characterized by a below average strategic importance (2.02) and a below average supply risk (2.61) (see Table 6, p. 79). The below average score for 'optimisation of supply relationship' (2.27) (see Figure 9.6., p. 83) and 'product optimisation' (3.11) (see Figure 9.4., p. 83) fit well to the generic tactical suggestions listed in Table 5 (p. 71). This is intuitive, as noncritical purchases are less complex and important to the business. Therefore, available literature suggests forging a greater variety of transactional supplier relationships, while product standardization becomes important for reducing the effort of managing a large number of technical variants (Handfield et al., 2009; Kraljič, 1983; Lysons and Farrington, 2012; O'Brien, 2012). However, in contrast to this advice, in this study 'volume bundling' (4.14) was the least utilized approach across all four portfolio quadrants (see Figure 9.1., p. 83) (Hess, 2010; Kraljič, 1983; Lysons and Farrington, 2012). In comparison to strategic purchases, noncritical purchases show similar scores for 'extension of supply base' (-0.04; $p=0.957)$ (see Figure 9.3., p. 83) and 'price evaluation' $(+0.01 ; p=0.978)$ (see Figure 9.2., p. 83). This finding is surprising, as noncritical products were supposed to require a rationalization of the supply base, without the need to conduct price evaluation, such as target or open book costing (Cavinato, 2006; Handfield et al., 2009; Johnson et al., 2011; Monczka et al., 2011; O'Brien, 2012).

Leverage purchases $(n=8)$ account for 7.5 percent of all cases. This portfolio quadrant is characterized by an above average strategic importance (4.41) and a below average supply risk (2.46) (see Table 6, p. 79). Leverage purchases scored below average for 'product optimisation' (2.25) only (see Figure 9.4., p. 83). Such purchases are of a high monetary value and allow choosing among several alternative suppliers. Therefore, as the pertinent literature suggests (see Table 5, p. 71), purchasing teams strongly exploit the company's buying power through 'price evaluation' (5.50), 'volume bundling' (4.78) and 'extension of supply base' (3.71) (see Figure 9.1. to Figure 9.3., p. 83 ). On the other hand, they do not actively collaborate with suppliers in terms of 'product optimisation' (2.25) (Canièls and Gelderman, 2005; Cavinato, 2006; 
Day et al., 2002; Handfield et al., 2009; Hess, 2010; Kraljič, 1983; Lysons and Farrington, 2012; Monczka et al., 2011; O'Brien, 2012; Van Weele, 2010). In comparison to the other portfolio quadrants, in the present study, purchasing teams relied the most on 'price evaluation' and significantly more than when making bottleneck purchases $(+1.53 ; p=0.006)$ (see Figure 9.2., p. 83). At the same time, they relied the least on 'product optimisation' and significantly less than when considering strategic purchases $(-1.29 ; p=0.038)$ (see Figure 9.4., $\mathrm{p}$. $83)$.

Bottleneck purchases $(n=55)$ account for 51.4 percent of all cases. This portfolio quadrant is characterized by a below average strategic importance (2.38) and an above average supply risk (5.85) (see Table 6, p.79). Bottleneck purchases scored below average for six out of seven tactical sourcing levers. Only 'optimisation of supply relationship' approached the average value. As listed in Table 5 (p. 71), available literature suggests focusing on volume insurance (Canièls and Gelderman, 2005; Cavinato, 2006; Day et al., 2002; Handfield et al., 2009; Kraljič, 1983; Monczka et al., 2011; O'Brien, 2012). However, it is surprising that purchasing teams analysed in the present study relied more on 'optimisation of supply relationships' (3.12) (see Figure 9.6., p. 83) than on 'extension of supply base' (2.93) to establish alternative sources (see Figure 9.3., p. 83). In comparison to strategic purchases, significantly less effort was invested into 'extension of supply bases' $(-0.73 ; p=0.037)$ (see Figure 9.3., p. 83) while, in comparison to noncritical purchases, when making bottleneck purchases, participants were much more reliant on 'optimisation of supply relationship' $(+0.85 ; p=0.093)$ (see Figure 9.6., p. 83). In addition, 'product optimisation' (2.35) (see Figure 9.4., p. 83) seems to have a very limited potential only. In the case of strategic purchases, purchasers invest significantly more effort into 'product optimisation' $(+1.19 ; p=0.0001)$ (see Figure 9.4., p. 83).

Strategic purchases $(n=33)$ account for 30.8 percent of all cases. This portfolio quadrant is characterized by an above average strategic importance (5.25) and an above average supply risk (6.15) (see Table 6, p. 79). Strategic purchases scored above average for six out of seven tactical sourcing levers. Only 'category-spanning optimisation' barely reached the average value (-0.01), while the highest scores were noted for 'product optimisation' $(+0.75)$ followed by 'volume bundling' $(+0.47)$ (see Figure 9, p. 83). Literature on this subject suggests sophisticated and privileged cooperative sourcing approaches for 
strategic purchases (see Table 5, p. 71) (Canièls and Gelderman, 2005; Day et al., 2002; Gelderman and Van Weele, 2005; Handfield et al., 2009; Hess, 2010; Johnson et al., 2011; Kraljič, 1983; Lysons and Farrington, 2012; Monczka et al., 2011; O'Brien, 2012; Van Weele, 2010). In line with this recommendation, this study's findings show that a wide range of tactical sourcing levers and much effort is invested into strategic purchases. Thereby, at the same time, purchasing teams placed great importance on 'product optimisation' (3.45) (see Figure 9.4., p. 83) and 'optimisation of supply relationships' (3.33) (see Figure 9.6., p. 83). In comparison to leverage purchases $(-1.29 ; p=0.038)$ and bottleneck purchases $(+1.19 ; p=0.0001)$, purchasing teams relied significantly less on 'product optimisation' (see Figure 9.4., p. 83). Across all four portfolio quadrants, strategic purchases scored the highest on 'optimisation of supply relationship' and significantly higher than noncritical purchases $(+0.85 ; p=0.093)$ (see Figure 9.6., p. 83). However, in variance to the recommendations in literature, attaining bargaining power seems to be even more important for the current study participants, as 'volume bundling' (4.94) (see Figure 9.1., p. 83) and 'extension of supply base' (3.66) (see Figure 9.3., p. 83) were identified as the most frequently used tactical sourcing levers for strategic purchases.

Figure 9: Sourcing levers profiles per portfolio quadrant

Figure 9.1.: Volume bundling

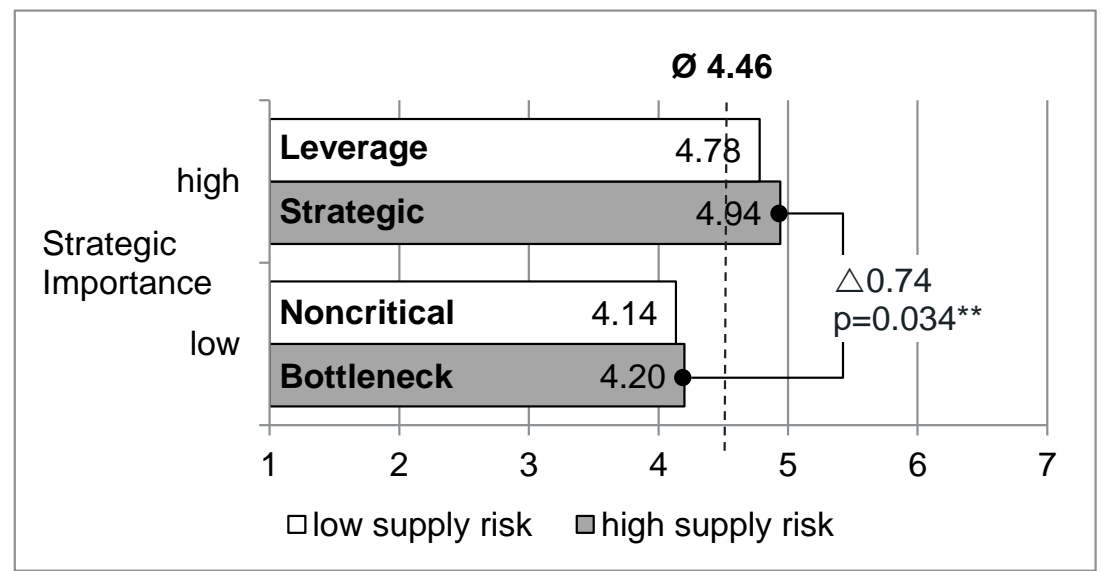


Figure 9.2.: Price evaluation

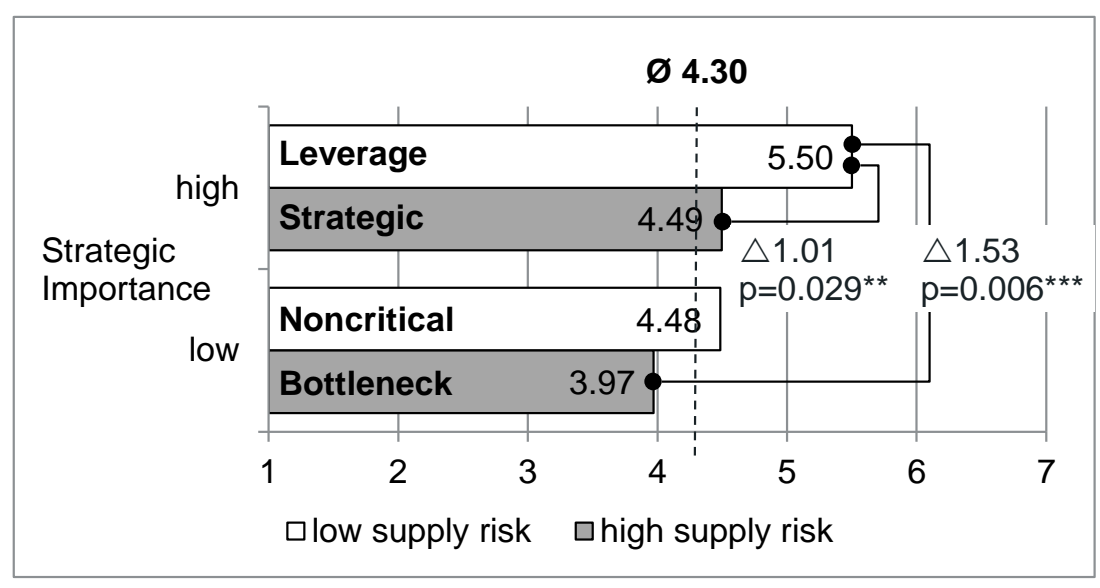

Figure 9.3.: Extension of supply base

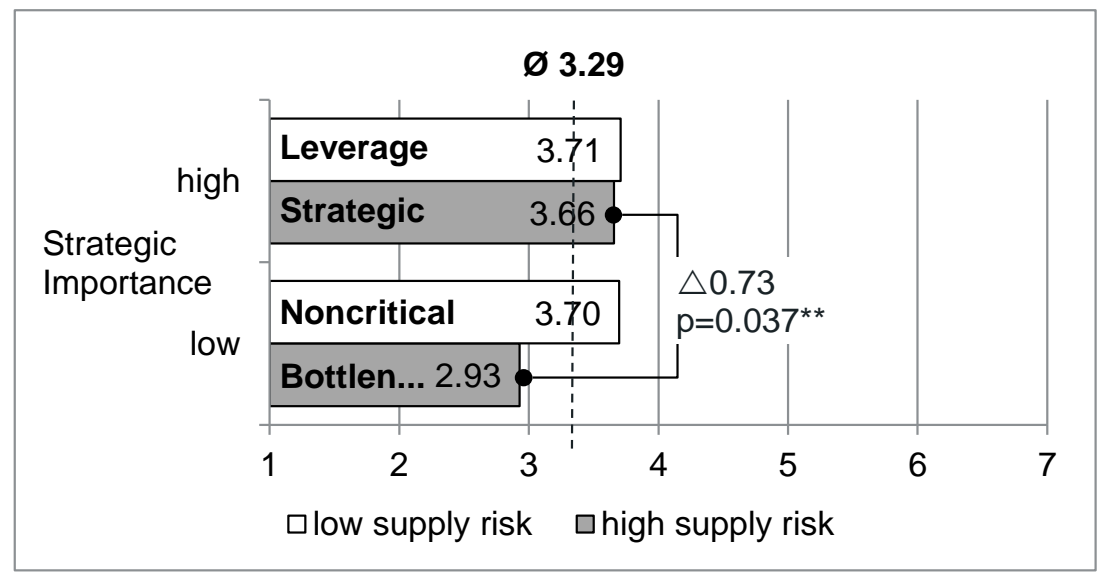

Figure 9.4.: Product optimisation

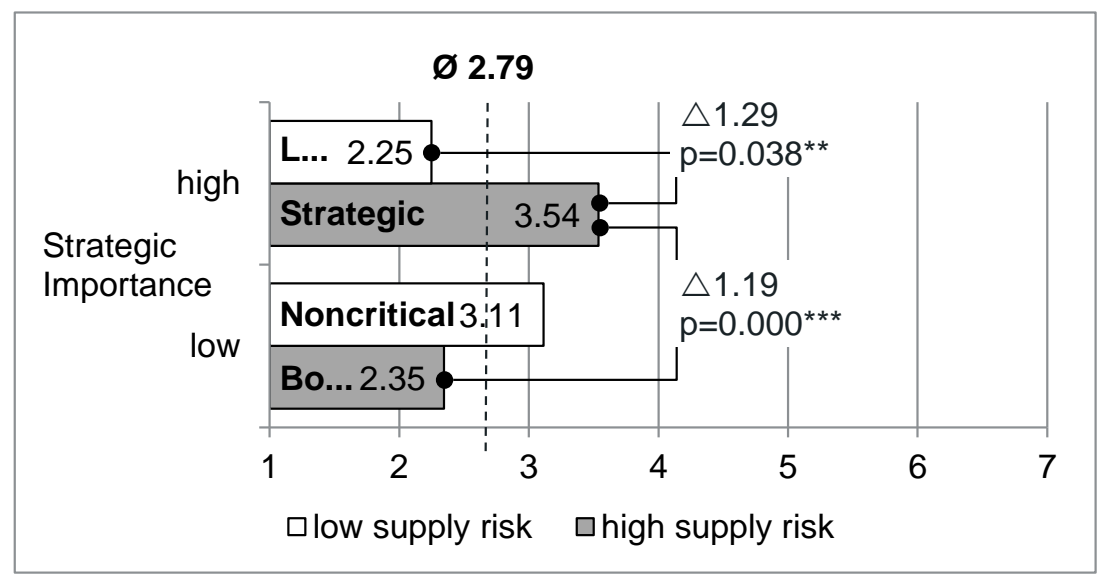


Figure 9.5.: Process optimisation

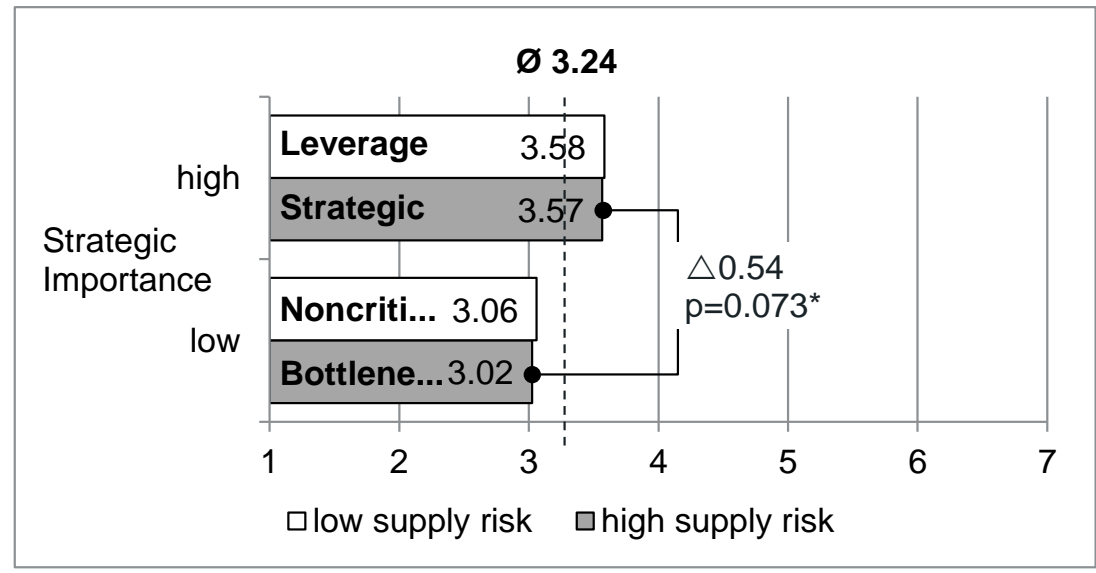

Figure 9.6.: Optimisation of supply relationship

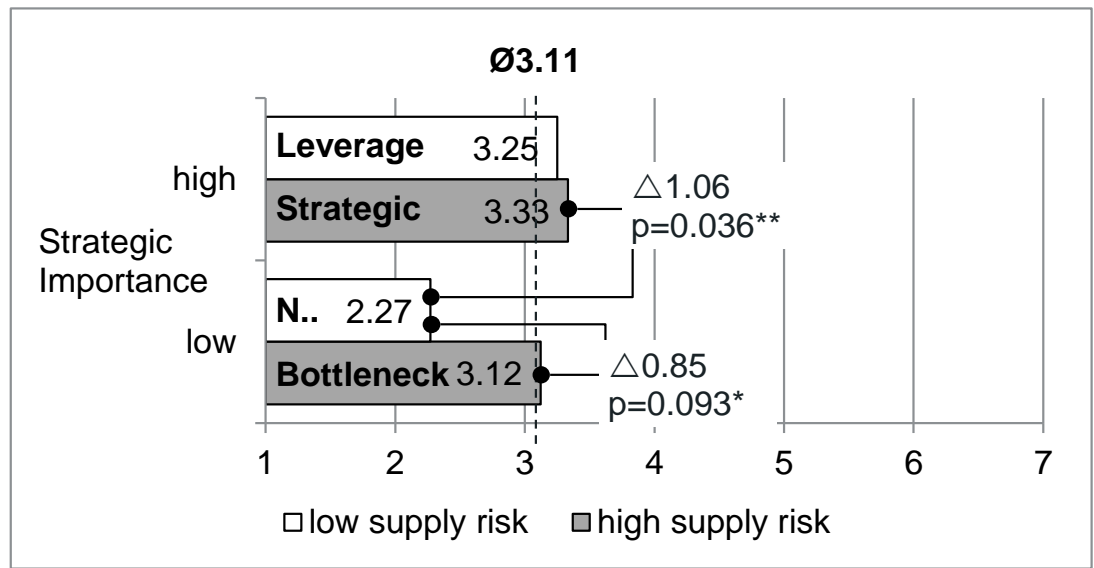

Figure 9.7.: Category-spanning optimisation

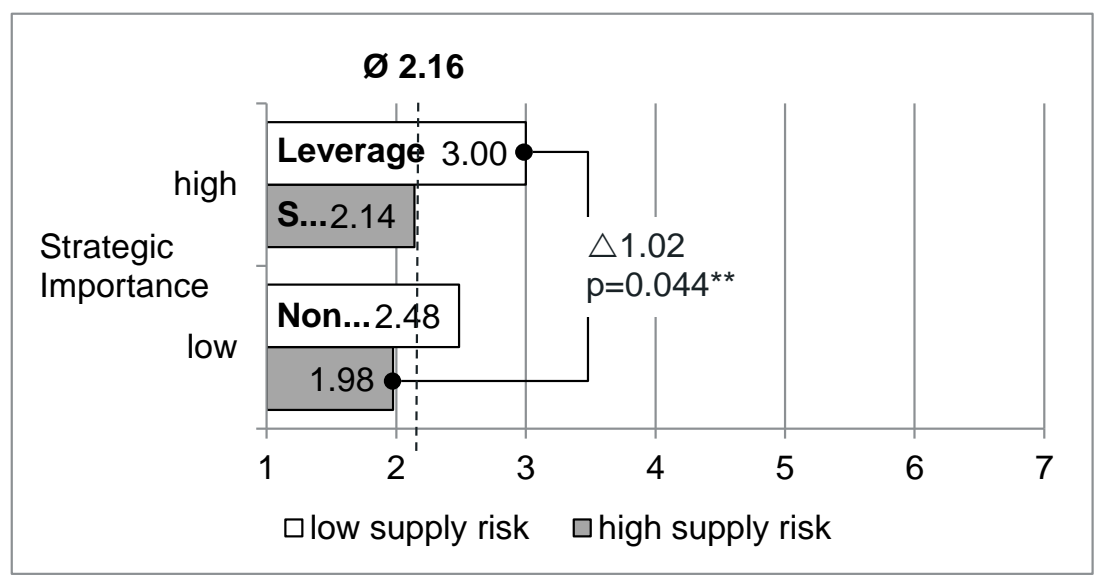

Note: The Mann-Whitney $U$ test has been used to evaluate the significance of difference between each pair of portfolio quadrant

${ }^{* * *}$ very highly significant $(p \leq 0.01)$; ${ }^{* *}$ highly significant $(0.01<p \leq 0.05)$; ${ }^{*}$ significant $(0.05<p \leq 0.1)$

$\varnothing$ shows the average score across all portfolio quadrants together (107 sourcing projects) 
Findings yielded by the present study identify two groups of tactical sourcing levers, the first of which consists of 'volume bundling', 'price evaluation' and 'extension of supply base'. In nearly all portfolio quadrants, these are the most frequently employed levers. These represent what authors call the transactionoriented, more traditional sourcing levers focused on 'capturing most of the value' on the supply market in a rather adversarial approach (O'Brien, 2012; Schiele et al., 2011a; Schumacher et al., 2008). The second group consists of 'product optimisation', 'process optimisation', 'optimisation of supply relationship' and 'category-spanning optimisation'. In this study, these are the least used levers for nearly all portfolio quadrants. According to the extant literature, these levers are intended to focus on 'creating value' in the supply market via a relationship-oriented, more advanced approach (O'Brien, 2012; Schiele et al., 2011a; Schumacher et al., 2008). In the analysed sourcing projects, purchasing teams generally tend to apply transaction-oriented levers to all portfolio quadrants and then selectively add more efforts to relationshiporiented levers, when strategic importance increases and supply risk reduces.

While several of the present study findings are well aligned with the tactics recommended in pertinent literature, in many cases, empirical realism diverges from the conceptual, normative recommendations (see Table 5, p. 71). For example, for noncritical purchases, 'volume bundling' is the least used approach, although several sources strongly recommend consolidating demand to allow for leverage and efficient processing (Canièls and Gelderman, 2005; Kraljič, 1983; Monczka et al., 2011). On the other hand, 'optimisation of supply relationships' is frequently used for bottleneck purchases, instead of the recommended 'extension of supply base' as a means of expanding the network of alternative sources (Johnson et al., 2011; Lysons and Farrington, 2012; Van Weele, 2010). For strategic purchases, 'volume bundling' and 'price evaluation' are even more important than the highly recommended 'optimisation of supply relationships'.

Moreover, several recent textbooks limit most tactical sourcing levers exclusively to a single portfolio quadrant. For example, efficient processing is deemed applicable solely to noncritical purchases, while long-term supply relationships pertain to strategic purchases only (Handfield et al., 2009; Johnson et al., 2011; Lysons and Farrington, 2012; Monczka et al., 2011). However, findings yielded by this study confirm that, although generic recommendations are made for a certain portfolio cell, "this does not mean the rest of the 
requirements does not apply in that quadrant; they do, but it helps to understand [the] prime focus for each quadrant" (O'Brien, 2012, p. 142). The present study is the first to provide empirical evidence derived from a large-scale survey supporting the conclusion that tactical sourcing levers are not exclusive to a certain portfolio quadrant. Rather, the entire range of tactical sourcing levers is applied in practice to each portfolio quadrant. In addition, purchasers tend to dedicate more effort to the process when moving from bottleneck to noncritical, to strategic and finally to leverage purchases. Overall, the least effort was invested into bottleneck purchases. For noncritical purchases, more effort was added, especially to 'extension of supply base' $(+0.77)$, 'product optimisation' $(+0.77)$ and 'price evaluation' $(+0.52)$. Efforts increased further for strategic purchases, in particular for 'optimisation of supply relationship' $(+1.06)$ and 'volume bundling' $(+0.80)$. Ultimately, for leverage purchases, even more effort was invested into 'price evaluation' $(+1.01)$ and 'category-spanning optimisation' $(+0.86)$, for instance (see Figure 10, p. 87). In sum, in variance to the prevailing impression created by pertinent literature and textbooks, in practice, sourcing tactics are applied in an additive, rather than exclusive manner.

Figure 10: Changes in sourcing lever scores along the portfolio quadrants

\begin{tabular}{|c|c|c|c|c|c|c|c|}
\hline Volume bundling & \multicolumn{3}{|c|}{4.20} & \multicolumn{2}{|c|}{+0.80} & & \\
\hline Price evaluation & \multicolumn{3}{|c|}{3.97} & +0.52 & +1.01 & & \\
\hline Extension of supply base & 2.93 & +1 & .77 & & & & \\
\hline Product optimisation & 2.35 & $+0.77+($ & .42 & & & & \\
\hline Process optimisation & 3.02 & +( & .51 & & & & \\
\hline Optimisation of supply relationship & 3.12 & & +1.06 & & & & \\
\hline \multirow[t]{2}{*}{ Category-spanned optimisation } & $1.98+0.51$ & +0.86 & & & & & \\
\hline & 2 & 3 & & 4 & 5 & 6 & 7 \\
\hline Bottleneck & $\square$ Noncritical & $\square$ Strat & egic & $\square$ Leve & & & \\
\hline
\end{tabular}




\subsection{CONCLUSIONS: TACTICAL SOURCING LEVERS ARE APPLIED} ADDITIVELY, RATHER THAN AS ALTERNATIVES

To date, purchasing portfolio models have been widely adopted to cluster and strategically manage different types of purchases. Although it still attracts criticism, the Kraljič matrix remains the dominant approach in purchasing portfolio management (Gelderman and Van Weele, 2005; Nellore and Söderquist, 2000). The traditional idea of the Kraljič matrix is intuitively appealing, as purchases are grouped into four portfolio quadrants, namely 'noncritical', 'leverage', 'bottleneck' and 'strategic' purchases. This classification is based on the strategic importance of each acquisition, and the supply risk. Purchasers follow tactical recommendations for each portfolio quadrant to maximize purchasing performance.

However, in practice, strategy implementation is not that straightforward, as it typically requires discussing and balancing a set of tactics (Canièls and Gelderman, 2005; Gelderman and Van Weele, 2003; Hesping and Schiele, 2015; Monczka et al., 2011). Tactical sourcing levers have an immediate practical relevance, as they describe the activities that purchasers use to achieve their goals (Bräkling and Oidtmann, 2012; Hess, 2010; Luzzini et al., 2012; Schiele, 2007; Schiele et al., 2011a; Schuh et al., 2011; Schumacher et al., 2008). Extant research on portfolio models contributed little to the effort to empirically verify if, in practice, tactical sourcing levers are applied according to the specific, generic recommendations for each portfolio quadrant, as claimed by several textbooks (Handfield et al., 2009; Johnson et al., 2011; Lysons and Farrington, 2012; Monczka et al., 2011).

This study set out to rectify this omission. Following a mixed methods approach, a survey instrument was developed based on a literature review and highly interactive world café discussions.

Thereafter, 107 sourcing projects were analysed for their 'strategic importance', 'supply risk' and sourcing lever profile. The sourcing projects were thus classified into noncritical, leverage, bottleneck and strategic purchases. Finally, these groups of sourcing projects were analysed with respect to differences and similarities in the extent to which purchasing teams applied the seven core sourcing levers. The findings of this study confirm the need for a more differentiated view on the generic recommendations of portfolio models, as was already suggested a decade ago (Canièls and Gelderman, 2005; Cox et 
al., 2003a; Cox et al., 2001; Gelderman and Van Weele, 2003). The study confirms that tactical sourcing levers are not applied as alternatives; rather, a mix of the entire range of tactical sourcing levers is utilized with respect to each portfolio quadrant (Cox, 2014) and more effort is added when moving from bottleneck to leverage purchases.

Previous studies on portfolio models have tended to focus on overall strategic recommendations for each portfolio quadrant. Thereby, they have contrasted portfolio quadrants in terms of differences in product characteristics (Kraljič, 1983; Van Weele, 2010), purchasing skills (Knight et al., 2014), buyersupplier relationships (Bensaou, 1999; Dubois and Pedersen, 2002; Gadde and Snehota, 2000), power structures (Canièls and Gelderman, 2005; Cox et al., 2003b; Cox et al., 2001; Pazirandeh and Norrman, 2014) and organizational structures (Gelderman and Semeijn, 2006). This study goes beyond the approach adopted in these works, as it links specific, actionable sourcing tactics to the purchasing portfolio theory.

\subsubsection{Contributions and implications: when discussing the Kraljič matrix, textbooks may need to be revised}

The study presents multiple novel contributions:

(1) As initially intended by Kraljič's (1983) 'policy issues', the present study confirms that purchasing portfolio theory can play an important role in choosing and configuring a set of tactics to improve purchasing performance. Its findings show that purchasers clearly apply a differentiated profile of tactical sourcing levers to each portfolio quadrant. By operationalizing the seven core tactical sourcing levers, this study provides 23 activities as a practical checklist to identify improvement potentials for each sourcing project (see Appendix - Table 19, p. 166).

(2) The study provides evidence that purchasers differentiate between two groups of tactical sourcing levers. More specifically, 'volume bundling', 'price evaluation' and 'extension of supply base' are mainly transactionoriented and focus on 'capturing existing value' (O'Brien, 2012; Schiele et al., 2011a; Schumacher et al., 2008). These levers have been applied most frequently in the sample analysed in this study, irrespective of the portfolio quadrant. On the other hand, 'product optimisation', 'process 
optimisation', 'optimisation of supply relationship' and 'categoryspanning optimisation' are predominantly relationship-oriented and focus on 'creating value' in collaboration with suppliers (O'Brien, 2012; Schiele et al., 2011a; Schumacher et al., 2008). These levers require collaboration across multiple functions. However, they have been used the least across all portfolio quadrants. For several years, many scholars assumed superiority of relationship-orientation over transactionorientation in the context of purchasing (Chen et al., 2004; Sheth and Sharma, 1997). However, this study yielded contrary findings. Hence, it might be fruitful to further examine at the tactical level why purchasers invest greater effort into transaction-oriented than into relationshiporiented approaches, as well as whether trade-offs exist between these approaches, as Schiele et al. (2011a) suggested.

(3) This study adds empirically-based descriptive realism to the rather conceptual and normative textbook recommendations. Thereby, findings derived from practice surpass information offered by existing textbooks. Existing textbooks presented a rather deterministic perspective on portfolio models. In particular, several strategic recommendations and tactics are limited exclusively to a single portfolio quadrant (Cavinato, 2006; Handfield et al., 2009; Johnson et al., 2011; Lysons and Farrington, 2012; Monczka et al., 2011; Van Weele, 2010). From such publications, it might be assumed, for example, that efficient processing should be fostered only for noncritical purchases, whereas exploitation of purchasing power is limited to leverage items and cooperative partnerships formed for strategic items only. In contrast to these publications, the results yielded by this study show that, in the analysed sample, purchasing teams did not limit certain tactical sourcing levers exclusively to a single portfolio quadrant. Rather, each of the seven core sourcing levers was applied to all portfolio quadrants. 'Volume bundling' and 'price evaluation' were most frequently applied irrespective of the portfolio quadrant, while purchasing teams added further efforts to other tactics when strategic importance increased and supply risk declined. This suggests that the application of tactical sourcing levers within the Kraljič matrix is additive, rather than exclusive. In variance to common, generic recommendations, such as forming cooperative partnerships for all strategic purchases, the full range of tactical sourcing levers may be used in each of the four quadrants (Cox, 2014; Hesping and Schiele, 
2015; Luzzini et al., 2012; Schiele et al., 2011a; Schumacher et al., 2008). That these findings have been made in the automotive industry is by itself important because it is from this sector that much of the nonsense about partnering being best practice emanated. To avoid a mutually exclusive, prescriptive interpretation of the recommendations made by the Kraljič matrix, future teaching and textbooks might better position their point of view in general literature. Purchasing portfolio models and other management tools may serve as spaces for debate and social interaction rather than as being the definite answer to strategic or tactical problems (Chesley and Wenger, 1999; Jarzabkowski and Kaplan, 2008; Spee and Jarzabkowski, 2009).

(4) In his original publications on the Kraljič matrix, Kraljič $(1977,1983)$ focused his discussion on strategic purchases only and merely listed a few 'policy issues' for the other portfolio quadrants. Other scholars have filled this gap and have subsequently elaborated on tactics for each portfolio quadrant. Nonetheless, the contemporary literature gives the impression that all portfolio quadrants require the same attention. O'Brien (2012), for instance, stated that "portfolio analysis is not a tool to prioritize the categories you work on" (p. 142). However, this study shows that purchasing teams clearly concentrated their efforts on leverage and strategic purchases and exerted less effort on noncritical and leverage purchases, which might in fact be a meaningful pattern of time and resource allocation. In most cases, more effort was added to implement tactical sourcing levers when moving from bottleneck, to noncritical, to strategic and finally to leverage purchases. This confirms previous findings stating that a purchasing portfolio analysis should play a major role in determining the size, composition, resources and involvement of a sourcing team and relevant stakeholders (Cox, 2014; Cox et al., 2003).

In conclusion, when discussing the Kraljič matrix, textbooks may need to be revised. Findings in this study confirm that "the logic of the recommendations made in the quadrants [of the Kraljič matrix] are not coherent, are sometimes misguided and often lead to the 'cherry-picking' of sourcing levers from other quadrants [...]" (Cox, 2014, p. 20). In the light of the on-going debate about the rigor and robustness of the Kraljič matrix, it may be time for a paradigm-shift in the purchasing profession. Future research and practice may build on a finer 
differentiated approach as discussed by the 'power positioning tools' (Cox, 2014), 'category management in purchasing' (O'Brien, 2012) or the concept of 'modern category management' (Hesping and Schiele, 2015). To account better for the peculiarities of each material or service group, organizations may move away from a limited number of four or nine portfolio cells towards a finer differentiation of sourcing categories. In a modern category management approach, a firm may distinguish several hundreds of sourcing categories, such as metal sheets, battery systems or leather applications, based on differentiators such as production technology, supplier competences or market-facing areas (Ateş, 2014; Monczka and Markham, 2007; Van Weele, 2010). Ultimately, instead of following generic, norm strategies and tactics for all materials or services placed in the same portfolio quadrant, "category managers might follow an individual strategy for each sourcing category, even when placed in the same portfolio area" (Hesping and Schiele, 2015, p. 145). Purchasing portfolio models may still play an important role to cluster a firm's or department's range of sourcing categories and to discuss general purchasing approaches. However, a finer differentiated market understanding, with potentially hundreds of individual sourcing category strategies, most likely requires entirely new predictive 'tools' that help choosing which activities are more or less appropriate in particular circumstances.

\subsubsection{Limitations: research on tactical sourcing levers is still a work-in- progress}

A major strength of this study lies in the research design, which relies on the experience of 'front-line' purchasing agents most knowledgeable about the sourcing context and tactical sourcing levers they have to consider in their daily work. The study intentionally focused on one large, global automotive OEM to allow for intense academic-practitioner collaboration. Moreover, this focus also facilitated access to the knowledge of a comparable and reasonably large group of purchasing agents within a consistent organizational context. The automotive industry generally includes a large variety of purchased items (Droege, 1998; Taylor and Taylor, 2008). Still, the study is unlikely to provide general guidelines for other industries, and especially for the service or the public sector. Further data collection in other industries and the public sector, for additional testing of the proposed patterns in tactical sourcing lever application, is desirable. 
In the data set, leverage and noncritical purchases were underrepresented. This might be due to the industry sample, as customized and costly systems rather than simple, standardized components are typically purchased in the automotive industry. Furthermore, broader cross-industrial investigations across a greater number of regions and cultures might help to strengthen the generalizability of the findings, along a wider range of research problems. For instance, the low incidence of relation-oriented strategies in this sample may be the expression of corporate culture.

Research on tactical sourcing levers can still be considered as work in progress. Extant literature distinguishes seven core levers. During the development of the data collection instrument employed in this study, the focus was on the existing frameworks and the knowledge gained from the collaboration with purchasing-related practitioners. However, purchasers increasingly work in cross-functional teams, which can also affect their choice of tactical sourcing tactics. Future research might thus go beyond the existing frameworks to integrate practitioners from other supply market-related functions, such as engineering or quality management, into the research process.

So far, the study lacks evidence on tangible outcomes, of whether tactical sourcing levers were, or were not, successfully applied in practice. Future research may address this opportunity and analyse how successful category managers are in 'cherry picking' tactical sourcing levers from any of the recommendations made by Kraljič. If they are successful, although they 'infringe' on Kraljič's or other author's recommendations this could fundamentally question the utility of the Kraljič matrix and portfolio models in general.

In this chapter, the earlier developed sourcing lever indices have been used to better understand the application of sourcing levers within each quadrant of the Kraljič matrix. Thus far, the study lacks evidence on the performance impact of each tactical sourcing lever. Hence, the next chapter reports on findings from statistical analyses on the cost and innovation effect of sourcing levers. 



\section{CHAPTER 5: \\ THE COST AND INNOVATION EFFECT OF SOURCING LEVERS - EMPIRICAL EVIDENCE AT THE CATEGORY LEVEL}

\subsection{INTRODUCTION: THE INFLUENCE OF TACTICAL SOURCING LEVERS ON COST AND INNOVATION PERFORMANCE}

Purchasing departments frequently have to achieve substantial cost-saving targets. At the same time, purchasing is expected to manage buyer-supplier relationships in a manner that enhances innovativeness (Ageron et al., 2013; Song and Di Benedetto, 2008; Wagner, 2012). However, generating cost reductions and innovations in a sourcing project is often not straightforward. "Not all materials and buyer-supplier relationships are to be managed the same way" (Karjalainen and Salmi, 2013, p. 114). Rather, "companies frequently buy differently by [product] category" (Caniato et al., 2014, p. 6) because "strategic sourcing decisions [...] are always decided specifically for each category and their supply market conditions" (Essig, 2011, p. 143). Consequently, firms may differentiate between hundreds of so-called 'sourcing categories', e.g., 'metal sheets', 'leather', and 'cables', which group similar materials or services purchased from an overlapping group of suppliers (Cousins et al., 2008b; Drake et al., 2013; Horn et al., 2013; Monczka et al., 2008). Each sourcing category requires a tailored set of sourcing tactics, which are known as 'sourcing levers' (Hesping and Schiele, 2015; Horn et al., 2013; Luzzini et al., 2012; Schiele et al., 2011a; Schuh et al., 2011; Schumacher et al., 2008). For example, if the sourcing category 'leather' relies on a single supplier, the 'extension of supply base' lever might be used to increase competitive intensity to cut prices by introducing an additional supplier. 
A purchaser's daily challenge is to generate savings. Surprisingly, research has contributed little to a better understanding of how to reduce the costs of purchased goods and generate savings. Prior works have evaluated the influence of various factors on sourcing performance, e.g., supplier characteristics (Kannan and Tan, 2002), product characteristics (Luzzini et al., 2012), supply chain design (Baud-Lavigne et al., 2012), buyer-supplier relationship characteristics (Carey et al., 2011; Cousins et al., 2008a; Sanchez-Rodriguez et al., 2005), the purchasing department's structure (Rozemeijer, 2000), sourcing team effectiveness (Driedonks, 2010), and alignment between purchasing and organizational strategy (Shao et al., 2011). However, investigations on tactical sourcing levers have been neglected, thus far, even though they describe the typical activity of purchasers. Several publications have discussed strategies and tactics for the overall purchasing department, but limited research has been conducted to better understand performance at the sourcing category level of analysis.

Consequently, the aim of this chapter is to investigate the relationships between tactical sourcing levers and performance at the sourcing category level of analysis (RQ1.4.): Does the application of particular tactical sourcing levers explain differences in a sourcing category's purchasing performance? Because previous research has indicated that there might be a trade-off between cost and innovation targets (Schiele et al., 2011a), the current research examines both effects. To achieve this aim, (1) literature on tactical sourcing levers was reviewed to form a conceptual framework. (2) Subsequently, a measurement instrument was developed to capture the extent of cost and innovation performance and tactical sourcing lever application within 107 sourcing projects managed at the European headquarters of a large, global automotive OEM. Every time one of the purchasers in the case company signed a contract, a researcher visited the purchaser to complete a questionnaire that enabled the systematic identification of the levers that led to the contractually ensured savings. (3) The PLS-SEM method was used to examine the influence of tactical sourcing levers on sourcing category performance, based on correlation.

The study is organized as follows: (1) In Section 5.2, relevant findings about tactical sourcing levers are discussed and grouped into a framework. (2) In Section 5.3, a measurement model and survey concept are developed. (3) Section 5.4 presents the statistical analysis and discussion of the findings. (4) In 
Section 5.5, conclusions, implications and suggestions for future research are drawn.

\subsection{CONCEPTUAL FRAMEWORK: TACTICAL SOURCING LEVERS AND PERFORMANCE}

\subsubsection{Tactical sourcing levers: tactics at the sourcing category level of analysis}

In the past, sourcing tactics were considered mainly for the whole purchasing department, encompassing the entire range of materials and buyer-supplier relationships. However, firms frequently buy differently by sourcing category to account for the characteristics and contingencies of various supply markets (Drake et al., 2013; Trautmann et al., 2009b; Van Weele, 2010). Therefore, purchasing agents are frequently confronted with the question of how to improve performance for a category of similar products or services. To address this issue, the concept of tactical sourcing levers was developed to provide a checklist of possible tactics to improve performance in a sourcing category (Hesping and Schiele, 2015).

A distinguishing feature of tactical sourcing levers is that they focus on 'sourcing categories', which "include materials or services of a similar type provided by the same group of suppliers" (Schiele et al., 2011a, p. 322). Examples of sourcing categories include 'metal sheets', 'leather', 'cables', 'lighting', and 'battery systems'. A sourcing category likely does not include only one single material or supplier or include the entire expenditures managed by the firm. In most cases, a sourcing category includes multiple parts and multiple suppliers (Horn et al., 2013; Li et al., 2014).

In a category management approach, firms may use dedicated purchasing agents, so-called 'category managers', who responsibly manage most sourcing activities within one sourcing category (Ateş, 2014; Driedonks, 2010; Sundtoft and Sigurbjornsson, 2013). The category management concept developed in a retail context, where similar consumer goods were grouped for joint marketing, product offerings and the optimisation of the overall product portfolio, crosssales and shelf management (Leeflang and Parreño-Selva, 2012; Lindblom et al., 2009; Nagashima et al., 2015; O'Keeffe and Fearne, 2002). In a purchasing context, category management mainly builds on portfolio models that place 
purchased goods into a limited number of four or nine portfolio cells (Gelderman and Semeijn, 2006; Nellore and Söderquist, 2000). However, to better account for the peculiarities of each material or service group, organizations moved towards a finer differentiation of sourcing categories (Ateş et al., 2015; Hesping and Schiele, 2015). In modern category management, a firm may distinguish several hundreds of sourcing categories based on differentiators such as production technology, supplier competences and marketfacing areas (Ateş, 2014; Monczka and Markham, 2007; Van Weele, 2010).

The concept of tactical sourcing levers is not new to the literature in that it describes tactics used to operationalize general strategy (Hillman and Hitt, 1999). In contrast to general strategy, tactics form clusters of activities with a concrete time specification and tractable milestones (Mintzberg, 1994). Each tactical sourcing lever consists of "a set of similar measures that are used to improve the firm's sourcing performance in a commodity group [or sourcing category]" (Schiele, 2007, p. 279). In contrast to strategic goals, tactical sourcing levers do not provide a general orientation for purchasing practices such as achieving annual cost-saving targets (Schiele et al., 2011a). Tactical sourcing levers describe a typology of activities through which goals will be realised (Hess, 2010) (see Figure 1, p. 3).

There are several models of tactical sourcing levers, ranging from five 'value levers' (O'Brien, 2012) or seven 'lever groups' (Cox, 2014) to sixteen levers in a 'purchasing chessboard' (Schuh et al., 2011). However, seven core tactical sourcing levers have often been discussed (Schiele, 2007; Schiele et al., 2011a; Schuh and Bremicker, 2005; Schumacher et al., 2008):

- 'Volume bundling' refers to consolidating demand and increasing the purchase volume for quotation (Karjalainen, 2011; Prince et al., 2013; Schoenherr and Mabert, 2008).

- 'Price evaluation' refers to forming price targets and analysing suppliers' bids and cost structures (Ellram, 1996; Newman and Krehbiel, 2007; Romano and Formentini, 2012).

- 'Extension of supply base' refers to increasing the number of sources and bidders per request for quotation to raise bargaining power (Caniëls and Gelderman, 2007; Lonsdale, 2001; McMillan, 1990).

- 'Product optimisation' refers to modifications to the design, functions and materials of the purchased items (Handfield et al., 1999; Khan et al., 
2008; Luo et al., 2011; McGinnis and Vallopra, 1999; Smith, 1999; Van Hoek and Chapman, 2007; Wagner, 2012).

- 'Process optimisation' refers to efficient and effective processes related to buyer-seller interfaces (Foster Jr et al., 2011; Labro, 2006; Manrodt and Vitasek; Quintens et al., 2006a).

- 'Optimisation of supply relationship' refers to establishing and maintaining effective relationships between the buyer and suppliers in the market (Adobor and McMullen, 2014; Blonska et al., 2013; Handfield et al., 2000; Hüttinger et al., 2012; Krause et al., 2007; Nagati and Rebolledo, 2013; Schiele et al., 2012a; Wagner et al., 2002).

- 'Category-spanning optimisation' refers to balancing trade-offs between multiple sourcing categories (e.g., design changes in a common platform) and enforcing mutual approaches among otherwise distinct sourcing teams (Driedonks, 2010; Schiele, 2007; Schumacher et al., 2008; Thomas et al., 2014).

Several studies have linked tactical sourcing levers with performance. Schoenherr and Mabert (2011) found that homogenous product bundles lead to higher performance in B2B online auctions. Hartley (2000) performed joint buyer-supplier price analysis and found positive impacts on product costs and learning effects. Horn et al. (2013) concluded that international supply chains often fall behind cost-saving expectations. Williams and Smith (1990) claimed that buyers must play a pivotal role in product optimisation. McGinnis and Vallopra (1999) found that purchasing plays a major role in process improvement. Schiele et al. (2012a) noted that good supplier relationships may lead to privileged treatment by suppliers in terms of innovation. Englyst et al. (2008) stressed the performance impact of information sharing across sourcing categories.

However, these publications focused on one or few tactical sourcing levers. In one of few studies on this topic, Schiele et al. (2011a) simultaneously examined all seven core levers and their influence on expected savings in 134 cross-functional cost-saving workshops. Still, most of these publications were rather descriptive or conceptual in nature. Thus far, academia has contributed rather little to a better understanding of which tactical sourcing levers most contribute to performance. Therefore, "research would profit from avoiding inquiries into any single lever, alone and without taking the other levers into consideration" (Schiele et al., 2011a, p. 332). Further empirical and 
simultaneous analysis of all seven core levers and their influence on performance is needed.

\subsubsection{Performance: cost versus innovation}

Cost and innovation performance are two important purchasing targets that are generally associated with different governance needs and practices (Ateş et al., 2015; Bengtsson et al., 2009; Johnsen, 2009; Schiele, 2010). As firms outsource an increasing number of shares of their value-added to suppliers, the supply management function becomes responsible for an increasing amount of expenditures and supplier competencies. Savings on the expenditure side have high leverage on the firm's profit (Pandit and Marmanis, 2008). At the same time, supplier competencies make valuable contributions to technology and innovation (Pulles et al., 2014). Therefore, most purchasing departments are expected to take a dual role: fulfilling significant cost-saving targets while managing buyer-supplier relationships in a manner that enhances innovativeness (Luzzini and Ronchi, 2011; Schiele, 2010; Schiele et al., 2011b).

To reflect this dual role, the literature distinguishes between two groups of tactical sourcing levers. The first group consists of 'volume bundling', 'price evaluation' and 'extension of supply base'. These levers have been described as rather cost-oriented, transactional and traditional levers focused on 'capturing most of the value' on the supply market in a rather adversarial approach (O'Brien, 2012; Schiele et al., 2011a; Schumacher et al., 2008). The second group includes 'product optimisation', 'process optimisation', 'optimisation of supply relationship' and 'category-spanning optimisation'. These levers have been presented as innovation-oriented, advanced levers focused on 'creating value' in a rather relational approach (O'Brien, 2012; Schiele et al., 2011a; Schumacher et al., 2008). Consequently, the current study proposes the following hypotheses:

- Hla: Cost-oriented tactical sourcing levers have a positive impact on cost performance.

- H2a: Innovation-oriented tactical sourcing levers have a positive impact on innovation performance.

Furthermore, existing studies have found trade-offs between cost-oriented and innovation- oriented supply management approaches. Dankbaar (2007) and 
Bengtsson et al. (2009) reported that innovation-oriented supply chains lead to inferior cost performance compared with cost-oriented supply chains and vice versa. Similarly, it may be expected that tactical sourcing lever application represents a trade-off between reducing costs and enhancing innovativeness. Sourcing categories that apply cost-oriented activities may lack focus and mechanisms to use the remaining resources for innovation-oriented activities (Bengtsson et al., 2009; Schiele et al., 2011a). Consequently, the current study proposes the following hypotheses:

- H1b: Cost-oriented tactical sourcing levers have a negative impact on innovation performance.

- H2b: Innovation-oriented tactical sourcing levers have a negative impact on cost performance.

The following sections present the results of a large-scale survey used to empirically test the hypothesized relationships between tactical sourcing lever application and performance.

\subsection{METHODOLOGY: A SURVEY INSTRUMENT MEASURING SOURCING LEVER APPLICATION AND PERFORMANCE}

The study's aim was to investigate the influence of sourcing tactics on cost and innovation performance at the sourcing category level of analysis. To achieve this aim, a survey instrument was developed to capture the knowledge of 'frontline' purchasing agents of approximately 107 sourcing projects within one large, global automotive OEM. The sourcing projects were statistically tested for differences in tactical sourcing lever application and performance outcomes using PLS-SEM.

A multi-step process was used to develop and validate the survey instrument (Churchill, 1979; Diamantopoulos and Winklhofer, 2001; Rossiter, 2002). Existing items were adapted to assess cost and innovation performance. As few suitable measures for tactical sourcing levers could be found in the literature, world café methodology was used to develop survey items for each tactical sourcing lever in an academic-practitioner collaborative approach. 


\subsubsection{Cost and innovation performance: the adaptation of existing measures}

'Cost performance' relates to the cost or price associated with retaining and contracting suppliers that the buying firm must pay (Krause et al., 2001) reflecting not only the unit prices of the suppliers' product but also the total costs associated with transportation, inspection, tests and supplier nonconformance (Terpend et al., 2011). The study concentrated on the sourcing category level of performance. Therefore, staff productivity, aggregated savings for the overall supply management function (González-Benito, 2007) and impact on the firm's profit or return on investment were not examined (Chen et al., 2004). A four-item scale was developed based on the cost performance scales created by Krause et al. (2001) and Terpend et al. (2011) (see Appendix see Appendix Table 21, p. 169).

'Innovation performance' relates to innovativeness, which can be defined as the capability to introduce new processes, products, or ideas (Hult et al., 2004). Innovation performance depends not only on the supplier's ability to introduce new ideas and products (Krause et al., 2001) but also on the buyer's willingness and ability to adapt its own product and process design (Azadegan and Dooley, 2010). A five-item scale was developed by incorporating the supplier innovativeness scales of Azadegan et al. (2013), Terpend et al. (2011) and Schiele et al. (2011b) (see Appendix Table 21, p. 169).

The respondents rated the degree to which they agreed with the item statements using a 7 -point Likert scale anchored at $1=$ 'strongly disagree' to $7=$ 'strongly agree'.

\subsubsection{Tactical sourcing levers: a formative method of measurement}

The contemporary literature provides little guidance on the activities related to each tactical sourcing lever. Consequently, the current study built on extensive collaboration with practice to develop a list of activities that are consistent with the operational definitions of the seven core tactical sourcing levers. In Chapter 3,23 activities have been developed in a world café approach that served as formative indicators of the sourcing lever constructs.

In the later survey stage, respondents indicated the extent to which they applied each tactical sourcing activity (grouped into seven core tactical sourcing levers) using a 7-point Likert scale anchored at $1=$ 'not used' to $7=$ 'extensively used' (see Appendix Table 19, p. 166). 


\subsubsection{Sample frame and data collection: 'front-line' purchasing agents were questioned at the point of supplier nomination}

The unit of analysis was the multitude of sourcing projects managed at the European headquarters of one large, global automotive OEM. This chapter draws from the survey data that has been collected earlier in this study (for details see Chapter 3.3.3, p. 56). The key informants were the OEM's category managers. In a sourcing project, these 'front-line' purchasing agents are responsible for most purchasing and supply management activities and are highly knowledgeable about the extent to which tactical sourcing levers have been applied. Each sourcing project begins with quotes from multiple suppliers and ends with supplier nomination, i.e., awarding contracts to one or multiple suppliers. To minimize recall bias, the point of supplier nomination was chosen for questioning. Each time a supply contract was awarded and registered in the IT-system, a researcher visited the responsible category manager, and they jointly completed the questionnaire. In this way, maximum validity was ensured, generating high-quality data (Srinivasan and Ratchford, 1991).

\subsubsection{Data analysis and validity: reflective and formative measurement models show high reliability and validity}

PLS-SEM was employed to test the measurement and structural models using the SmartPLS 3.2.1 software (Ringle et al., 2015). For this study, PLS was best suited for multiple reasons. First, PLS is especially suitable during early stages of theory development (Birkinshaw et al., 1995). Second, in contrast to covariance-based models, PLS allows the integration of both formative and reflective indicators. Finally, PLS has been recommended for studies with a sample size less than 250 (Reinartz et al., 2009).

Confirmatory factor analysis (CFA) was used to assess the reliability and validity of the multi-item, reflective scales for cost performance and innovation performance (Hair Jr. et al., 2013) (see Table 8, p. 104). All item-to-construct loadings were significant $(\mathrm{p}<0.001)$ and well above the cut-off value of 0.7 , indicating a substantial contribution. Cronbach's alpha $(\alpha)$ and composite reliability (CR) statistics both well exceeded the threshold value of 0.7 , indicating internal consistency. In addition, both scales surpassed the minimum AVE value of 0.5 , indicating convergent validity. The item loadings onto the corresponding construct showed no critical levels of cross-loadings (see Table 9, 
p. 105), while all square roots of the AVE were higher than the corresponding inter-construct correlations (Fornell-Larcker Criterion) (see Table 10, p. 105), indicating unidimensionality (Hair Jr. et al., 2013).

Table 8: Characteristics of reflective measurement models (performance)

\begin{tabular}{|c|c|c|c|c|c|}
\hline Indicators & $\begin{array}{l}\text { Outer } \\
\text { loadings }^{\mathrm{a}}\end{array}$ & t-value & $\mathrm{CB} \alpha^{\mathrm{b}}$ & $\mathrm{CR}^{\mathrm{C}}$ & $\mathrm{AVE}^{\mathrm{d}}$ \\
\hline \multicolumn{6}{|c|}{ Cost performance based on Krause et al. (2001) and Terpend et al. (2011) } \\
\hline cost_1 & 0.827 & 17.483 & \multirow{4}{*}{0.896} & \multirow{4}{*}{0.927} & \multirow{4}{*}{0.760} \\
\hline cost_2 & 0.834 & 20.600 & & & \\
\hline cost_6 & 0.902 & 31.049 & & & \\
\hline cost_7 & 0.921 & 42.624 & & & \\
\hline \multicolumn{6}{|c|}{$\begin{array}{l}\text { Innovation performance based on Azadegan and Dooley (2010), Schiele et al. (2011b) a } \\
\text { Terpend et al. (2011) }\end{array}$} \\
\hline inno_1 & 0.881 & 19.702 & & & \\
\hline inno_2 & 0.908 & 39.361 & & & \\
\hline inno_6 & 0.888 & 26.754 & 0.938 & 0.953 & 0.802 \\
\hline inno_7 & 0.880 & 21.694 & & & \\
\hline inno_8 & 0.920 & 45.590 & & & \\
\hline
\end{tabular}

${ }^{a}$ All outer loadings are significant at $p<0.001$; cross loadings shown in brackets

${ }^{b}$ Cronbach's alpha (CB $\alpha$ ) used to test for internal consistency reliability

${ }^{c}$ Composite reliability $(\mathrm{CR})$ used to test for internal consistency reliability

${ }^{d}$ Average variance extracted (AVE) used to test for convergent validity

For the tactical sourcing lever constructs, formative measurement models were chosen due to theoretical considerations. By definition, tactical sourcing levers consist of a set of distinct, directly addressable activities (O'Brien, 2012; Schiele, 2007; Schiele et al., 2011a; Schuh and Bremicker, 2005), and the formative measurement model "provides an option for researchers to use measures that tend to be specific, actionable attributes of a phenomenon" (Cenfetelli and Bassellier, 2009, p. 690). 
Table 9: Discriminant validity - analysis of cross-loadings

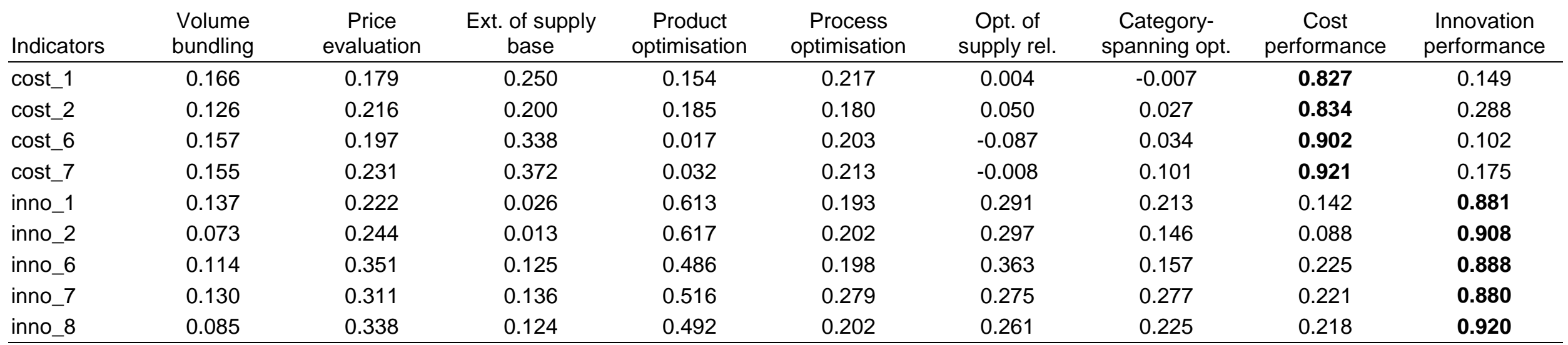

Note: Loadings of indicators on associated constructs printed in bold (reflective indicators only)

Table 10: Discriminant validity - Fornell-Larcker Criterion

\begin{tabular}{|c|c|c|c|c|c|c|c|c|c|c|}
\hline \multicolumn{2}{|c|}{ Constructs } & VB. & PE. & ESB. & PRD. & PRC. & OSR. & CSO. & $\mathrm{CP}$ & IP. \\
\hline VB. & Volume bundling & formative & & & & & & & & \\
\hline ESB. & Ext. of supply base & 0.322 & 0.412 & formative & & & & & & \\
\hline PRC. & Process optimisation & 0.071 & 0.327 & 0.396 & 0.320 & formative & & & & \\
\hline OSR. & Opt. of supply rel. & 0.180 & 0.228 & 0.191 & 0.353 & 0.436 & formative & & & \\
\hline cso. & Category-spanning opt. & 0.220 & 0.288 & 0.186 & 0.400 & 0.374 & 0.240 & formative & & \\
\hline
\end{tabular}

Note: The square root of AVE values are shown on the diagonal and printed in bold (reflective constructs only) 
For the formative measurement models, convergent validity was used to test whether all relevant facets of the construct were sufficiently covered by the selected formative indicators (Diamantopoulos et al., 2008; Hair Jr. et al., 2013). "Convergent validity is the extent to which a measure correlates positively with other measures (indicators) of the same construct" (Hair Jr. et al., 2013, p. 121). Therefore, the literature suggests a redundancy analysis using the formatively measured construct as an exogenous variable to predict an endogenous singleitem construct (Hair Jr. et al., 2013; Sarstedt et al., 2013).

Global items (single items) were added. For these items, respondents indicated the essence of each tactical sourcing lever construct on a seven-point Likert scale (ranging from $1=$ 'not used' to $7=$ 'extensively used'): 'To summarize, to what extent have activities for [tactical sourcing lever] been used in this sourcing project?'.

The results show that all path coefficients between formative constructs (exogenous) and the corresponding global-item constructs (endogenous) were well above the threshold of 0.8 (Chin, 1998; Hair Jr. et al., 2013) (see Table 11, p. 107).

Because the formative measurement model is based on multiple regression, multicollinearity among the indicators can lead to unstable indicator weights such that each indicator's influence on the construct cannot be distinctly determined (Cenfetelli and Bassellier, 2009; Diamantopoulos and Winklhofer, 2001). Therefore, variance inflation factor (VIF) values were calculated for each indicator using SPSS 22.0 software (IBM, 2013). The results show that all VIFs were well below the threshold of 3.3, indicating that formative indicators are distinct and do not carry critical levels of redundant information (Diamantopoulos and Siguaw, 2006; Hair Jr. et al., 2013; Petter et al., 2007).

To evaluate indicator relevance, bootstrapping with 5,000 random subsamples was used (Ringle et al., 2015). Two indicators ('volumeB_1' and 'priceE_1') had to be dropped due to nonsignificant outer weight and low loading. Four other indicators ('volumeB_2' and 'volumeB_4', 'eSupplyBase_3' and 'categoryS_1') showed nonsignificant outer weights but were retained due to high and significant outer loadings (Hair Jr. et al., 2013). All other outer weights in the formative measurement models were significant, indicating the high relative contribution of the formative indicators (Hair Jr. et 
al., 2013). The remaining outer loadings were well above the threshold of 0.5 , indicating the high absolute contribution of the indicators.

Table 11: Characteristics of formative models (sourcing levers)

\begin{tabular}{|c|c|c|c|c|c|c|c|c|c|c|}
\hline $\begin{array}{l}\text { Construct } \\
\text { Indicators }\end{array}$ & $\begin{array}{l}\text { Path } \\
\text { coeff. }^{a}\end{array}$ & $\mathrm{VIF}^{\mathrm{b}}$ & $\begin{array}{c}\text { Outer } \\
\text { weights }\end{array}$ & $\begin{array}{c}\mathrm{t} \\
\text { value }\end{array}$ & $\begin{array}{c}p \\
\text { value }\end{array}$ & Sign. & $\begin{array}{c}\text { Outer } \\
\text { loadings }\end{array}$ & $\begin{array}{c}\mathrm{t} \\
\text { value }\end{array}$ & $\begin{array}{c}\mathrm{p} \\
\text { value }\end{array}$ & Sign. \\
\hline \multicolumn{11}{|c|}{ VB. Volume bundling } \\
\hline volumeB_1 ${ }^{c}$ & \multirow{4}{*}{0.865} & 1.123 & - & - & - & - & - & - & - & - \\
\hline volumeB_2 & & 1.257 & 0.361 & 1.278 & 0.201 & n.s. & 0.625 & 2.296 & 0.022 & $\star \star *$ \\
\hline volumeB_3 & & 1.237 & 0.551 & 1.781 & 0.075 & * & 0.780 & 2.976 & 0.003 & $* * *$ \\
\hline volumeB_4 & & 1.421 & 0.429 & 1.591 & 0.112 & n.s. & 0.803 & 3.633 & 0.000 & *** \\
\hline \multicolumn{11}{|c|}{ PE. Price evaluation } \\
\hline priceE_1 ${ }^{\mathrm{c}}$ & \multirow{3}{*}{0.855} & 1.210 & - & - & - & - & - & - & - & - \\
\hline priceE_2 & & 1.157 & 0.683 & 5.202 & 0.000 & $* * *$ & 0.850 & 9.000 & 0.000 & $* * *$ \\
\hline priceE_3 & & 1.209 & 0.552 & 3.722 & 0.000 & *** & 0.760 & 6.062 & 0.000 & *** \\
\hline \multicolumn{11}{|c|}{ ESB. Extension of supply base } \\
\hline eSupplyBase_1 & \multirow{3}{*}{0.904} & 1.255 & 0.518 & 3.170 & 0.002 & $* * *$ & 0.811 & 5.034 & 0.000 & $* * *$ \\
\hline eSupplyBase_2 & & 1.303 & 0.433 & 2.219 & 0.027 & $* *$ & 0.778 & 4.402 & 0.000 & $* * *$ \\
\hline eSupplyBase_3 & & 1.207 & 0.355 & 1.228 & 0.219 & n.s. & 0.683 & 2.876 & 0.004 & *** \\
\hline \multicolumn{11}{|c|}{ PRD. Product optimisation } \\
\hline productOpt_1 & \multirow{4}{*}{0.967} & 1.524 & 0.208 & 3.815 & 0.000 & *** & 0.666 & 6.540 & 0.000 & *** \\
\hline productOpt_2 & & 1.987 & 0.304 & 7.751 & 0.000 & *** & 0.832 & 16.756 & 0.000 & $* \star \star$ \\
\hline productOpt_3 & & 2.178 & 0.328 & 8.509 & 0.000 & *** & 0.860 & 26.585 & 0.000 & *** \\
\hline productOpt_4 & & 2.178 & 0.378 & 7.580 & 0.000 & *** & 0.861 & 22.013 & 0.000 & *** \\
\hline \multicolumn{11}{|c|}{ PRC. Process optimisation } \\
\hline processOpt_1 & \multirow{3}{*}{0.857} & 1.262 & 0.335 & 1.989 & 0.047 & $* \star$ & 0.679 & 4.262 & 0.000 & $* \star *$ \\
\hline processOpt_2 & & 1.531 & 0.537 & 4.731 & 0.000 & *** & 0.873 & 12.204 & 0.000 & *** \\
\hline processOpt_3 & & 1.414 & 0.394 & 2.831 & 0.005 & *** & 0.770 & 7.039 & 0.000 & $\star \star \star *$ \\
\hline \multicolumn{11}{|c|}{ OSR. Opt. of supply relationship } \\
\hline osRelation_1 & \multirow{3}{*}{0.954} & 1.716 & 0.383 & 4.175 & 0.000 & *** & 0.840 & 10.224 & 0.000 & *** \\
\hline osRelation_2 & & 1.624 & 0.569 & 3.881 & 0.000 & $* * *$ & 0.894 & 10.278 & 0.000 & $* * *$ \\
\hline osRelation_3 & & 1.202 & 0.276 & 1.721 & 0.085 & * & 0.614 & 3.755 & 0.000 & *** \\
\hline \multicolumn{11}{|c|}{ CS. Category-spanning optimisation } \\
\hline categoryS_1 & \multirow{3}{*}{0.980} & 2.159 & 0.280 & 1.604 & 0.109 & n.s. & 0.848 & 7.210 & 0.000 & 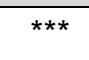 \\
\hline categoryS_2 & & 2.302 & 0.302 & 2.182 & 0.029 & $* *$ & 0.868 & 7.695 & 0.000 & $* \star *$ \\
\hline categoryS_3 & & 2.518 & 0.531 & 2.686 & 0.007 & $* * *$ & 0.943 & 9.202 & 0.000 & $* * *$ \\
\hline \multicolumn{11}{|c|}{ 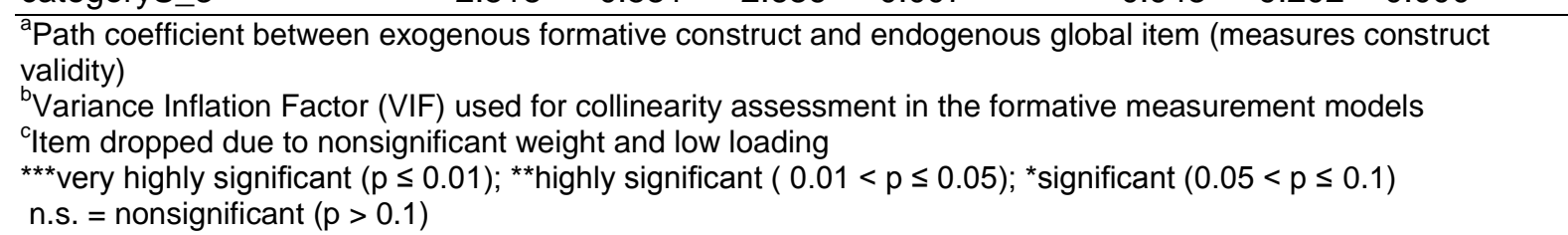 } \\
\hline
\end{tabular}




\subsection{RESULTS AND DISCUSSION: ALL TACTICAL SOURCING LEVERS IN ONE MODEL SHOWED ONLY WEAK TO MODERATE EXPLANATORY POWER}

The significance and relevance of the estimated path coefficients were tested by means of bootstrapping (5,000 samples). The aim of the study was to test the effect of tactical sourcing levers on cost and innovation performance. Therefore, results were obtained from ten different models. Models I to VII tested the effects of each tactical sourcing lever separately. Models VIII and IX included the three cost-oriented and the four innovation-oriented tactical sourcing levers. Finally, Model X tested the effects of all seven tactical sourcing levers together. The coefficients of determination $\left(R^{2}\right)$ were calculated and adjusted by the number of predictor constructs $\left(R^{2}{ }_{a d j}\right)$ to determine each model's predictive accuracy (see Table 12, p. 109 and Table 13 , p. 110).

'Volume bundling', 'price evaluation' and 'extension of supply base' were hypothesized to positively impact cost performance (H1a) and to negatively impact innovation performance (H1b). H1a was only partially supported. In all models, all three levers showed a positive effect on cost performance. However, for 'volume bundling', no effects were significant. The effect of 'price evaluation' on cost performance was only significant in Model II. 'Extension of supply base' was the sole lever that showed a significant effect on cost performance in all models in which it was included. H1b was only partially supported. 'Volume bundling' and 'extension of supply base' had a negative but nonsignificant impact on innovation performance in Model X. In conclusion, no significant trade-off between cost and innovation performance could be found for these three levers. However, in Model X, 'price evaluation' had a strongly significant, positive effect on innovation performance.

Unlike the previous levers, 'product optimisation', 'process optimisation', 'optimisation of supply relationship' and 'category-spanning optimisation' were hypothesized to positively impact innovation performance $(\mathrm{H} 2 \mathrm{a})$ and to negatively impact cost performance (H2b). H2a was only partially supported. In the Models IV-VII, all four levers showed a positive and significant effect on innovation performance. However, in Model X, only 'product optimisation' showed a significant positive effect on innovation performance. 'Categoryspanning optimisation' showed a negative, although nonsignificant, effect on both cost and innovation performance. 
Table 12: Regression results - Models I-VII

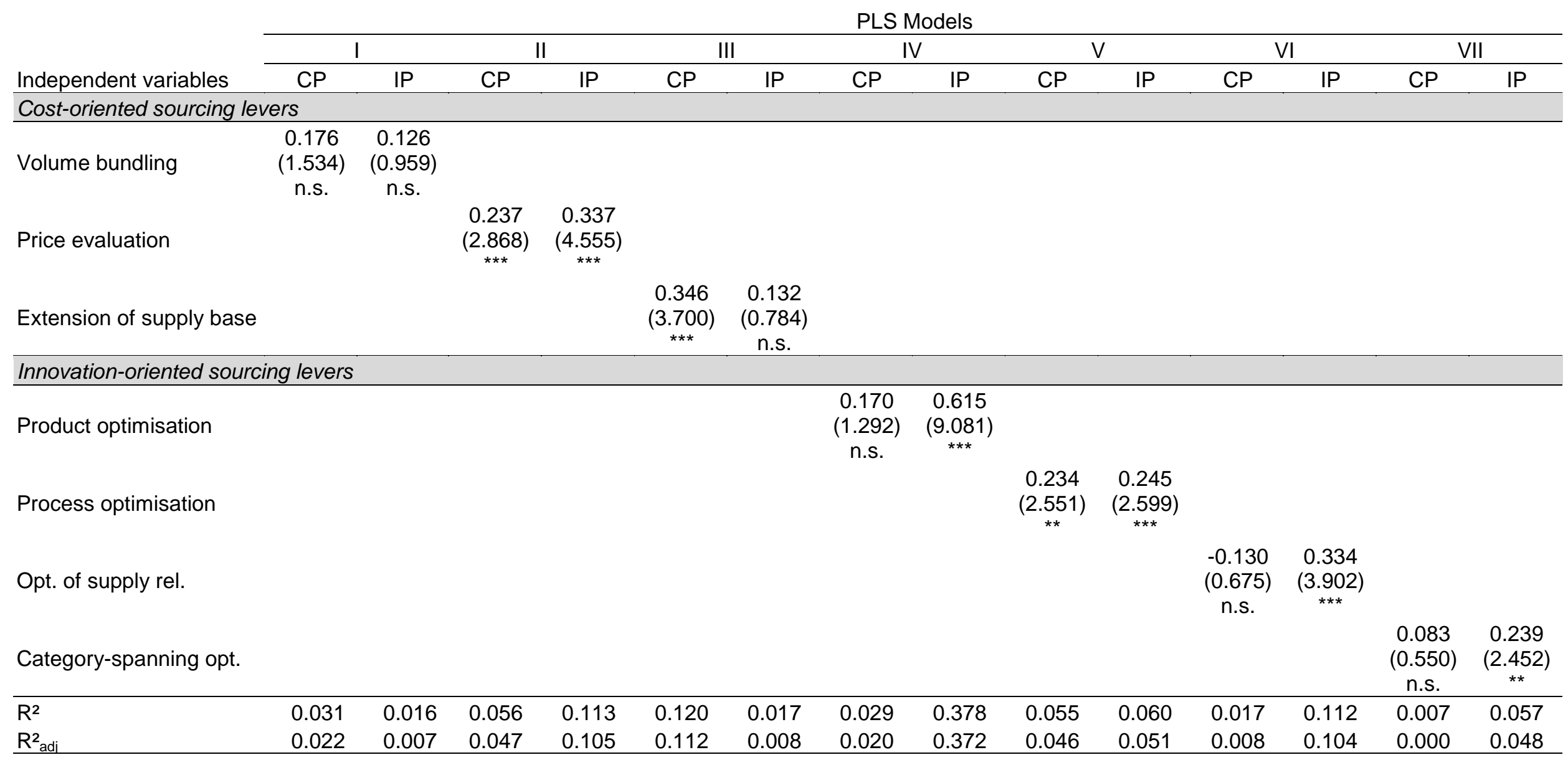

$\mathrm{CP}=$ Cost performance; IP = Innovation performance; Path coeff. (t-values) ${ }^{*} \mathrm{p} \leq 0.1 ;{ }^{* *} \mathrm{p} \leq 0.05 ;{ }^{* * *} \mathrm{p} \leq 0.01 ; \mathrm{n} . \mathrm{s} .=$ nonsignificant $(\mathrm{p}>0.1)$ 
Table 13: Regression results - Models VIII-X

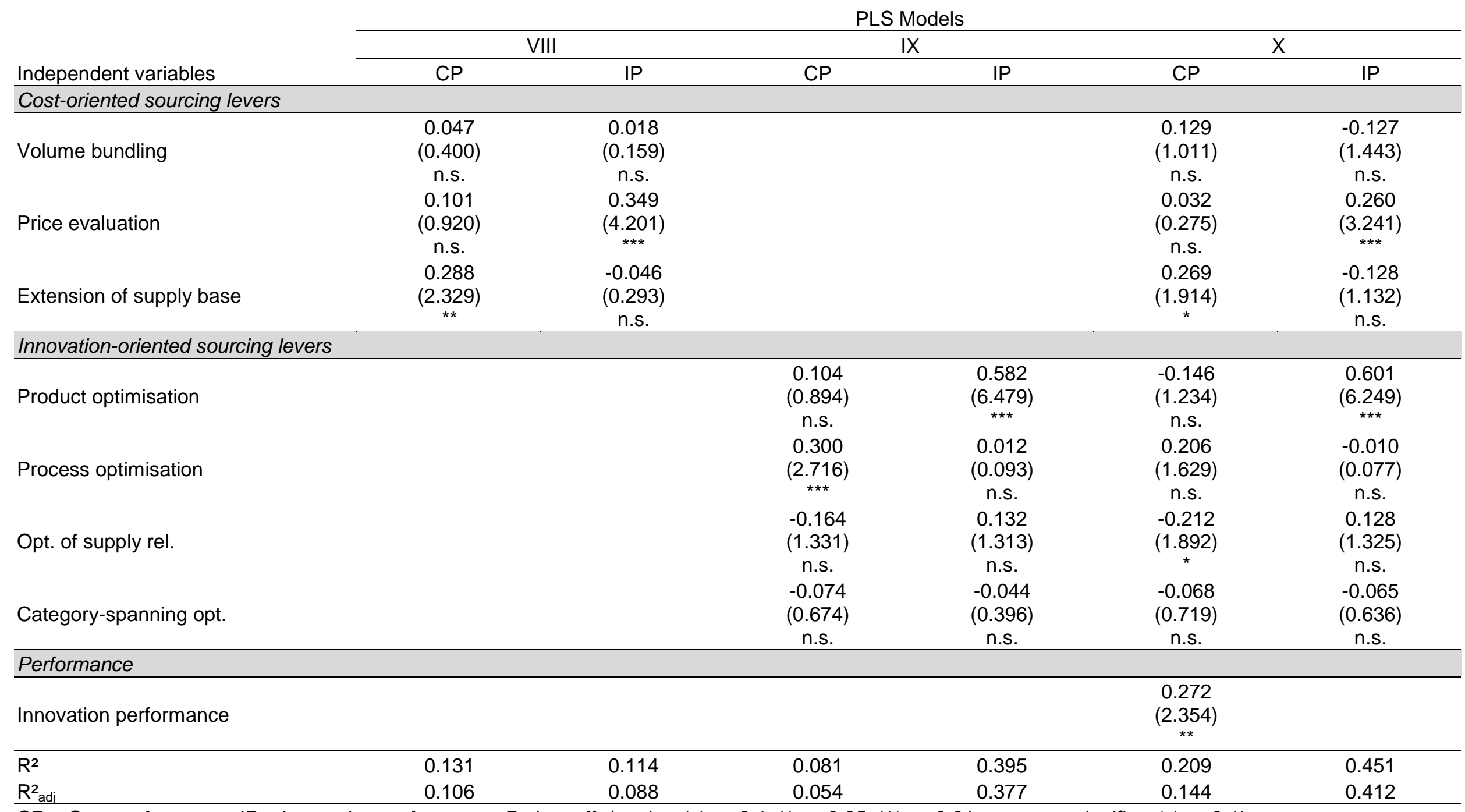

$\mathrm{CP}=$ Cost performance; $\mathrm{IP}=$ Innovation performance; Path coeff. (t-values) ${ }^{*} p \leq 0.1 ;{ }^{* *} p \leq 0.05 ;{ }^{* * *} p \leq 0.01 ;$ n.s. $=$ nonsignificant $(p>0.1)$ 
$\mathrm{H} 2 \mathrm{~b}$ was only partially supported. In Model X, only 'optimisation of supply relation relationships' showed a significant positive effect on innovation performance. In the same model, 'process optimisation' displayed a positive impact on cost performance and a negative impact on innovation performance; however, these results were nonsignificant.

All tactical sourcing levers combined together in the same model (Model X) explained only a small amount of the variance in cost performance $\left(R^{2}=0.209\right.$; $\left.R_{a d j}^{2}=0.144\right)$ and a moderate amount of the variance in innovation performance $\left(R^{2}=0.451 ; R_{a d j}^{2}=0.412\right)$ (see Figure 11, p. 111).

Figure 11: Performance effects of tactical sourcing levers - structural model

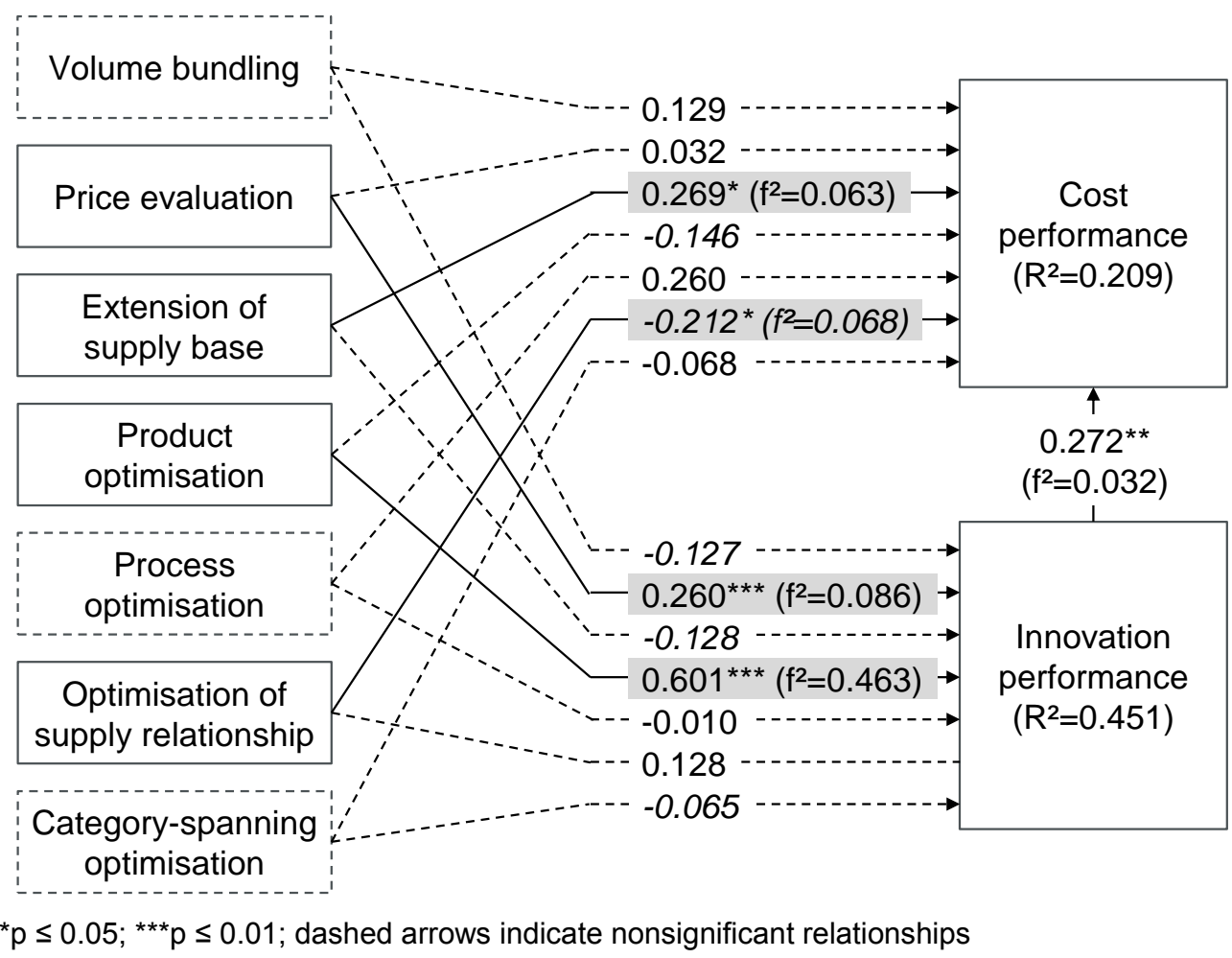

${ }^{*} p \leq 0.1 ;{ }^{* *} p \leq 0.05 ;{ }^{* * *} p \leq 0.01$; dashed arrows indicate nonsignificant relationships

Most levers showed only a small effect on cost and innovation performance. Only 'product optimisation' showed a medium to high effect size $\left(f^{2}=0.463 ; q^{2}\right.$ $=0.305)($ see Table 14, p. 112).

The findings indicate that cost performance has generally been larger in sourcing projects in which sourcing teams extensively engaged in 'extension of supply base' by building up local and foreign sources of supply or extending capacities near the place of demand. This finding strongly confirms previous studies that found that a larger supply base increases buyers' bargaining power 
through competitive bidding and leads to favourable offers by suppliers (Caniëls and Gelderman, 2007; Costantino and Pellegrino, 2010; Ellis et al., 2010). Sourcing projects scored lower on cost performance when sourcing teams strongly invested in 'optimisation of supply relationship'. This result partially confirms previous findings about supplier relationships. Relationship investments are costly and sometimes increase dependence on suppliers, reducing bargaining power (Bensaou, 1999; Caniëls and Gelderman, 2007; Krause et al., 2007; Villena et al., 2011). However, close supplier relationships are expected to lead to larger supplier commitment and better offers (Cannon and Homburg, 2001; Modi and Mabert, 2007; Schiele et al., 2012b; Whipple et al., 2015).

Table 14: Structural model - collinearity statistics and predictive accuracy

\begin{tabular}{|c|c|c|c|c|c|c|}
\hline \multirow[b]{3}{*}{ Independent variables } & & & \multicolumn{4}{|c|}{ Predictive accuracy } \\
\hline & \multicolumn{2}{|c|}{ Collinearity statistics } & \multicolumn{2}{|c|}{$\begin{array}{c}\text { Cost } \\
\text { performance }\end{array}$} & \multicolumn{2}{|c|}{$\begin{array}{l}\text { Innovation } \\
\text { performance }\end{array}$} \\
\hline & $\begin{array}{c}\text { VIF } \\
\text { 1st set }\end{array}$ & $\begin{array}{c}\text { VIF } \\
\text { 2nd set }\end{array}$ & $\begin{array}{l}f^{2} \text { effect } \\
\text { size }\end{array}$ & $\begin{array}{l}q^{2} \text { effect } \\
\text { size }\end{array}$ & $\begin{array}{l}f^{2} \text { effect } \\
\text { size }\end{array}$ & $\begin{array}{c}q^{2} \text { effect } \\
\text { size }\end{array}$ \\
\hline Volume bundling & 1.341 & 1.312 & 0.015 & 0.006 & $0.022^{\mathrm{S}}$ & 0.012 \\
\hline Price evaluation & 1.491 & 1.368 & 0.001 & 0.000 & $0.086^{\mathrm{S}}$ & $0.061^{\mathrm{s}}$ \\
\hline Ext. of supply base & 1.449 & 1.419 & $0.063^{\mathrm{S}}$ & $0.042^{\mathrm{S}}$ & $0.024^{\mathrm{S}}$ & 0.011 \\
\hline Product optimisation & 2.056 & 1.399 & 0.013 & 0.003 & $0.463^{\mathrm{H}}$ & $0.305^{\mathrm{M}}$ \\
\hline Process optimisation & 1.621 & 1.621 & $0.032^{\mathrm{S}}$ & $0.022^{\mathrm{S}}$ & 0.000 & 0.000 \\
\hline Opt. of supply rel. & 1.365 & 1.335 & $0.042^{\mathrm{S}}$ & $0.027^{\mathrm{S}}$ & $0.024^{\mathrm{S}}$ & 0.014 \\
\hline Category-spanning opt. & 1.345 & 1.337 & 0.003 & 0.002 & 0.007 & 0.003 \\
\hline Innovation performance & 1.820 & - & $0.032^{\mathrm{s}}$ & $0.038^{\mathrm{S}}$ & - & - \\
\hline
\end{tabular}

$\overline{{ }^{a}}$ VIF $=$ Variance Inflation Factor; $1^{\text {st }}$ set: cost performance as dependent variable; $2^{\text {nd }}$ set: innovation performance as dependent variable

${ }^{H}$ high $\left(f^{2}, q^{2} \geq 0.35\right) ;{ }^{M}$ medium $\left(f^{2}, q^{2} \geq 0.15\right) ;{ }^{S}$ small $\left(f^{2}, q^{2} \geq 0.02\right)$

In previous studies, 'volume bundling' and 'price evaluation' have been described as rather adversarial, cost-oriented tactical sourcing levers (Schiele et al., 2011a; Schuh et al., 2011; Schumacher et al., 2008). Therefore, it is surprising that 'volume bundling' and 'price evaluation' showed little effect on cost performance. One reason for this finding might be the characteristics of the data set. Appendix - Table 21 (p. 169) shows that purchasing agents indicated high cost performance in most of the 107 analysed sourcing projects (all indicators had a mean above 4.3). At the same time, Appendix - Table 19 (p. 166) shows that 'volume bundling' and 'price evaluation' had similarly high 
indicator scores. Overall, for cost performance, the data set does not seem to have sufficient variance $\left(R^{2}=0.209 ; R_{a d j}^{2}=0.144\right)$ to allow further conclusions.

Another interesting finding is that innovation performance strongly contributed to cost performance. This result indicates that even if tactical sourcing levers have little direct effect on cost performance, they might have a relevant indirect effect mediated by innovation performance. This confirms the assumption that innovation might be a superior performance variable that positively influences other performance variables such as costs (Azadegan and Dooley, 2010). Learning from innovative suppliers might enhance the learning curve of the buyer and, ultimately, lead to more cost-efficient product design and processes (Petersen et al., 2005; Salomon and Martin, 2008).

The model had high explanatory power for innovation performance $\left(R^{2}=\right.$ $\left.0.451 ; R_{a d j}^{2}=0.412\right)$. In general, sourcing teams scored higher on innovation performance when they strongly engaged in 'product optimisation'. 'Product optimisation' had the strongest effect and explanatory power of all variables in the model. This finding confirms previous studies' call for purchasing agents' stronger involvement in product optimisation (Ellis et al., 2012; Johnsen, 2009; Schiele, 2010; Schiele et al., 2011b; Tracey and Neuhaus, 2013).

A surprising finding is that 'price evaluations' had a very highly significant positive impact on innovation performance. In the traditional understanding, information on prices and costs is mostly used to pressure suppliers in terms of prices and leverage an informational edge in negotiations (Ellram and Perrott Siferd, 1993; Miller and Kelle, 1998; Perdue and Summers, 1991; Rajagopal and Bernard, 1993a). This study, however, indicates that 'price evaluations' contain further information that can be used to enhance innovation with suppliers. This confirms recent findings that found that early cost and value analysis may help to build trust in the value proposition and cost impact of unfamiliar, innovative products (Anderson and Wynstra, 2010) and build the basis for a fruitful discussion about product design and functionality with suppliers (Monczka et al., 2011; Vrat, 2014; Wagner, 2008; Zengin and Ada, 2010). 


\subsection{CONCLUSIONS: THE STUDY GOES BEYOND PREVIOUS WORKS BY PROVIDING EMPIRICAL AND SIMULTANEOUS ANALYSIS OF ALL SEVEN CORE SOURCING LEVERS}

Firms frequently buy different by sourcing category (Ateş, 2014; Caniato et al., 2014). At the sourcing category level of analysis, purchasing agents differentiate between a multitude of sourcing tactics to achieve their goals (Hesping and Schiele, 2015; Luzzini et al., 2012). These so-called 'tactical sourcing levers' are of immediate practical relevance to 'front-line' purchasing agents because they directly address the activities undertaken to achieve performance improvements for a category of purchases. Thus far, little effort has been made to better understand which tactical sourcing levers contribute to improved performance at the sourcing category level. To fill this gap, this chapter investigated the influence of tactical sourcing levers on cost and innovation performance.

Previous studies have linked tactical sourcing levers with performance but have concentrated on one of few tactics (Hartley, 2000; Horn et al., 2013; Schoenherr and Mabert, 2011; Williams and Smith, 1990). This study goes beyond previous works by providing results from a large-scale, empirical and simultaneous analysis of all seven core tactical sourcing levers and discussing these levers' influence on cost and innovation performance at the sourcing category level of analysis. Thereby, the study has immediate practical relevance because it describes the tactics and actions that 'front-line' purchasing agents use to improve cost and innovation for a category of purchases.

\subsubsection{Contributions and implications: cost analysis might have been underrated thus far}

The study makes several main contributions:

(1) It highlights the need to distinguish between multiple levels of performance. While previous studies have mainly analysed performance at the functional level and its contribution to the firm's financial or commercial performance, this study, as one of few, recognizes that firms frequently buy differently by sourcing category, i.e., a group of similar materials or services sourced from an overlapping number of suppliers. At the sourcing category level of analysis, the performance of individual 
sourcing projects comes into focus, while aggregated savings generated by the entire purchasing department and contributions to increased firm sales are of secondary relevance. Future research studies should critically assess whether the chosen performance dimensions apply to their level of analysis. It might, for example, be difficult to identify the influence that tactical sourcing levers for a single sourcing project have on the entire firm's commercial performance.

(2) The study provides evidence of the superior performance contribution of innovation. The findings confirm that innovation contributes strongly to cost performance. Certain tactical sourcing levers might have a strong indirect impact on cost performance as mediated by innovation performance. It might be interesting to further evaluate the influence that innovation has on cost performance in supply markets where traditional cost-saving approaches no longer yield the expected potential.

(3) The findings highlight the importance of price evaluations in purchasing. In the past, price analysis teams may have played an underrated role. Information gained from price evaluations may have been mainly used to pressure suppliers in terms of prices and to gain an informational edge for negotiations. However, these findings show that price evaluations may substantially contribute to innovation. Cost and value analysis might build trust into the value proposition and cost impact of unfamiliar, innovative products. Furthermore, it might foster a fruitful discussion about the impact of product design on costs in an early phase of product development.

\subsubsection{Limitations: a broader scope might complement the research results}

A major strength of this study lies in the research design, which relies on the experience of 'front-line' supply chain agents, who have the most knowledge of sourcing tactics and their performance implications at the category level. Thereby, the study intentionally focused on a single, large, global automotive OEM to allow for access to a reasonably large number of comparable sourcing projects. Findings from the automotive industry are generally expected to be more generalizable than those from other industries because globalized automotive supply chains are highly competitive and include a large variety of sourcing categories (Droege, 1998; Taylor and Taylor, 2008). However, this limited scope might have influenced the study results. In the sample, sourcing 
projects with extensive application of 'volume bundling' and 'price evaluation' are overrepresented. Future studies might contrast findings in a broader industry and organizational context where these tactical sourcing levers are applied more restrictively.

To avoid recall bias, the responsible purchasing agents were questioned at the point of supplier nomination. However, sourcing projects with low cost performance are underrepresented in the data set. One reason for this underrepresentation might be that respondents overestimated the contracted performance. Ultimately, the realised performance might be very different due to later technical changes or hidden risks over the life cycle or in the product development phase. Future studies might take this issue into account and evaluate the long-term performance of sourcing projects using a longitudinal approach.

To address the issue of possible trade-offs between tactical sourcing levers, the study intentionally addressed only the cost and innovation dimensions of performance. Future studies might take into account the implications of tactical sourcing levers for other performance dimensions such as flexibility, quality and sustainability.

Overall, this study is one of the first to present findings for a range of sourcing categories. The sourcing category level of analysis, which groups similar materials and services for synergy effects, offers multiple future research opportunities in the field of purchasing and supply management.

In this chapter, the effect of sourcing levers on performance has been tested. The moderating role of the sourcing category context yet has to be addressed. Therefore, to fully cover the primary research question of this study, the next chapter reports on a moderation analysis taking into account complexity, dynamism and competition as important contingency factors. 


\section{CHAPTER 6: \\ THE MODERATING ROLE OF THE SOURCING \\ CATEGORY - A CONTINGENCY THEORY PERSPECTIVE}

\subsection{INTRODUCTION: A TAILORED SET OF TACTICS FOR EACH SOURCING CATEGORY}

Cost reduction and innovation are two important targets of the purchasing function (Bengtsson et al., 2009; Johnsen, 2009; Schiele, 2010). Savings on the expenditure side have a high leverage on the firm's profit (Pandit and Marmanis, 2008). Therefore, most purchasing functions have to meet significant annual cost saving targets (Nollet et al., 2008). At the same time, firms increasingly rely on external competencies and sources of technology. As firms continue to outsource an increasing proportion of their value-added activities to suppliers, more innovations are generated through the exchange in business networks (Pulles et al., 2014). Consequently, purchasing is expected to manage buyer-supplier relationships in a way that enhances innovativeness of the firm (Luzzini and Ronchi, 2011; Schiele, 2010; Schiele et al., 2011b).

However, for the 'front-line' purchasing agent, achieving cost savings and innovation is often not a straightforward task. It is obvious that "not all materials and buyer-supplier relationships are to be managed the same way" (Karjalainen and Salmi, 2013, p. 114). Rather, "companies frequently buy differently by [product] category" (Caniato et al., 2014, p. 6) as "strategic sourcing decisions [...] are always decided specifically for each category and their supply market conditions" (Essig, 2011, p. 143). Consequently, firms differentiate hundreds of so-called 'sourcing categories'. Each sourcing category, such as 'metal sheets', 
'leather', 'displays', 'cables' etc., groups similar materials or services purchased from an overlapping group of suppliers (Cousins et al., 2008b; Horn et al., 2013; Monczka et al., 2008). Moreover, each sourcing category may have unique technological, supply market or relational characteristics.

Depending on its specific characteristics, each sourcing category requires a tailored set of tactics, which have been named 'sourcing levers' (Hesping and Schiele, 2015; Horn et al., 2013; Luzzini et al., 2012; Schiele et al., 2011a; Schuh et al., 2011; Schumacher et al., 2008). Tactical sourcing levers have an immediate practical relevance as they directly address actions that decision makers can take to achieve performance targets (Cuervo-Cazurra et al., 2013). 'Displays', for instance, might be characterised by high technological complexity, and can be provided by only a few suppliers. Therefore, the buyer may rely on a long-term partnership with the largest supplier. On the other hand, 'cables' might be less complex, allowing the buyers to choose among a large number of potential suppliers with whom they have rather adversarial relationships.

Surprisingly, pertinent literature offers very little information that would assist in better understanding the relationships among sourcing category characteristics, tactical sourcing levers and performance outcomes. Prior works have evaluated the influence of various aspects on purchasing performance, such as supplier capabilities (Kannan and Tan, 2002), product characteristics (Luzzini et al., 2012) and the buyer-supplier relationship (Carey et al., 2011; Cousins et al., 2008a; Sanchez-Rodriguez et al., 2005). Yet, investigations on sourcing tactics at the category level have been neglected. As an exception, recently, Luzzini et al. (2012) clustered sourcing categories into four types and contrasted them for differences in the category strategy. However, they "only considered the first steps of portfolio management, i.e. category classification and strategic priorities" (p. 1036) and suggested that "other studies might consider which levers and tools are used according to the different types of categories" (p. 1036).

In order to address the limitations revealed in the extant body of knowledge, the aim of this study was to investigate the relationship among sourcing category characteristics, tactical sourcing levers and performance at the category level (RQ1.5.): Do characteristics of the sourcing category explain the differences in a sourcing lever's contribution to cost or innovation performance? The ultimate objective was to provide practical guidelines on which tactical 
sourcing levers to choose to improve cost or innovation performance under different sourcing category conditions. To achieve this objective, (1) literature on tactical sourcing levers and contingency theory was reviewed to form a conceptual framework. (2) Subsequently, a survey was designed to capture the extent of contingency factors, sourcing lever application and performance within 107 sourcing projects managed at the European headquarters of a large, global automotive OEM. (3) Finally, a moderation analysis was conducted to determine predicted values of performance for configurations of low (high) sourcing lever application and low (high) contingency factor.

As its major strength, this study draws on the knowledge of 'front-line' purchasing agents that are directly involved in determining a set of tactical sourcing levers for their sourcing category. For the first time, the present study extends contingency theory to the category level of purchasing. In addition, the work presented here moves away from generic recommendations about sourcing tactics. It is based on the premise that, under some conditions, dedicating more intensive efforts to a particular tactical sourcing lever may even reduce performance. Thereby, this study provides practical guidelines on the tactical sourcing levers to choose under specific sourcing category conditions.

\subsection{LITERATURE REVIEW AND CONCEPTUAL FRAMEWORK: LINKING CONTINGENCY THEORY AND TACTICAL SOURCING LEVERS}

Following a contingency theory approach, the most successful business decisions are made when contextual factors are taken into consideration (Burns and Stalker, 1961; Kieser and Kubicek, 1977; Lawrence and Lorsch, 1969; Miller and Friesen, 1983; Thompson, 1967). In the purchasing context, investigations on contingency theory are mainly focused on the overall functional level of purchasing (Fernández and Kekäle, 2005; González-Benito et al., 2010; Juha and Pentti, 2008; Stanley, 1993). On the other hand, work at the category level of purchasing has been minimal. To fill this gap, this study commenced by reviewing pertinent literature on tactical sourcing levers and contingency theory, allowing the findings to be linked in a conceptual model. 


\subsubsection{Contingency theory: complexity, dynamism and competition}

Contingency theory implies that the choice of tactical sourcing levers would have to be adapted to the sourcing category characteristics (Miller and Friesen, 1983).

The main attributes of the task environment include (Castrogiovanni, 2002; Pagell and Krause, 2004; Shou et al., 2013): (1) complexity stemming from the number, interconnectedness and distinctiveness of the elements (Bozarth et al., 2009), (2) dynamism reflecting the rate, degree and unpredictability of change of elements and their relations (Dess and Beard, 1984) and (3) competition driven by the availability of resources to support sustained growth (Dess and Beard, 1984; Starbuck, 1976).

In the extant literature, complexity is often described as a continuum between simplicity and complexity of the elements and their relationships in a system (Downey et al., 1975; Jurkovich, 1974). When addressing complexity in this study, the focus was on the static aspect of complexity, while the dynamic aspect was analysed separately in the concept of dynamism. Complexity is a function of the number of elements, their interconnectedness and distinctiveness (Bourgeois, 1980; Bozarth et al., 2009; Child, 1972; Sharfman and Dean, 1991). In this context, the number of elements refers to their numerousness, while interconnectedness refers to their concentration and interaction. Similarly, distinctiveness refers to the variety and range, or a degree of dissimilarity between the elements and their relationships. Simple sourcing environments are characterized by a few, typically homogeneous, suppliers and products with limited interactions among them. In contrast, complex sourcing environments are characterized by many heterogeneous suppliers and products, with high dispersion and high emergence in numerous interactions among each other (Choi and Krause, 2006). Thus, the latter require multiple, distinctive modes of handling and a much wider range of resources and information inputs for purchasing agents (Aldrich, 1979; Choi and Krause, 2006; Dess and Beard, 1984; Khandwalla, 1972; Thompson, 1967).

Dynamism, also referred to as volatility or turbulence, has been described as a continuum between stability and instability (Priem et al., 1995). Dynamism is a function of the rate, degree and predictability of change in elements and relationships over time (Aldrich, 1979; Bourgeois, 1980; Calantone et al., 2003; Dess and Beard, 1984; Jap, 1999; Jurkovich, 1974; Miles et al., 1974; Sharfman 
and Dean, 1991). Thereby, the rate pertains to the frequency and the speed of change. On the other hand, degree describes the magnitude of difference and unpredictability to the irregularity or randomness in the pattern of change. Stable sourcing environments (i.e., those characterized by low dynamism) occur if suppliers, technology and relationships in the supply market change slowly and with low frequency, while the magnitude of difference between the former and the new state is low. It can thus be accurately predicted and is easy to plan for. In turn, instable sourcing environments (i.e., those characterized by high dynamism) are characterized by quick, frequent change with a high magnitude of difference between the former and the new state (Calantone et al., 2003; Jurkovich, 1974). Thus, uncertainty for purchasing agents increases with dynamism, making it hard to anticipate future development (Aldrich, 1979; Kaufmann et al., 2012; Khandwalla, 1972; Lepak et al., 2003; Lumpkin and Dess, 2001).

Competition is influenced by munificence or capacity, describing a continuum between scarcity and abundance of resources and the resulting opportunities for sustained growth (Castrogiovanni, 1991; Dess and Beard, 1984; Randolph and Dess, 1984; Starbuck, 1976). It can thus be defined as a function of the availability of resources relative to the number of actors competing for those (Khandwalla, 1972; Kreiser and Marino, 2002; Lumpkin and Dess, 2001; Mintzberg, 1979; Nandakumar et al., 2010; Sharfman and Dean, 1991; Ward et al., 1995). When sources and resources in the supply market are readily available, the capacity of the sourcing environment is high, buffering firms from dependency, competition and hostility (Boyd et al., 1993; Dess and Beard, 1984; Porter, 1980; Wiersema and Bantel, 1993). Conversely, when supply sources and resources are scarce and difficult to access, the level of competition and hostility increases among the firms in the sourcing environment (Dess and Beard, 1984; Pelham, 1999; Wiersema and Bantel, 1993).

\subsubsection{Sourcing levers: tactics at the category level of purchasing}

Purchasing agents frequently adapt their choice of sourcing tactics to the contingencies of the sourcing category (Trautmann et al., 2009b; Van Weele, 2010). To elucidate this phenomenon, in the extant literature, the concept of tactical 'sourcing levers' was developed, providing a checklist of possible sourcing tactics. As their main distinguishing feature, tactical sourcing levers focus on a group of purchases. These so-called 'sourcing categories' include 
similar materials or services sourced from an overlapping number of suppliers (Horn et al., 2013; Li et al., 2014; Schiele et al., 2011a). In a modern category management approach, a firm may distinguish several hundreds of sourcing categories, such as 'metal sheets', 'leather', 'cables', 'lighting' and 'battery systems', based on the key differentiators, such as production technology, supplier competences or market-facing areas (Ateş, 2014; Monczka and Markham, 2007; Van Weele, 2010).

Tactics form clusters of activities, often with a concrete time specification and traceable milestones, employed to operationalize overall, general strategy (Hillman and Hitt, 1999; Mintzberg, 1994). In contrast to general strategic goals, such as achieving annual cost saving targets, each tactical sourcing lever consists of a set of similar activities through which the goals can be realised (Hesping and Schiele, 2015; Hess, 2010; Schiele, 2007; Schiele et al., 2011a) (see Figure 1, p. 3).

Authors of several extant studies have linked sourcing tactics, performance and context factors. Schoenherr and Mabert (2008), for example, tested for the influence of the supply base and product on volume bundling. Hartley (2000) described contingencies of price and value analysis. On the other hand, Nassimbeni (2006) discussed motives and barriers in the context of extending the supply base internationally. In the same vein, Wagner (2012) argued for a positive impact of supplier integration into product development. Ramanathan and Gunasekaran (2014) concluded that collaborative processes enhance buyersupplier collaboration. In an earlier study, Schiele et al. (2011b) found a positive impact of optimized supply relationship on buyer innovativeness. More recently, Thomas et al. (2014) reported positive influences of category-spanning, product platform approaches.

However, most of these studies focused on either the entire purchasing function or dyadic supplier relationships. The intermediate sourcing category level of analysis, grouping multiple products and multiple suppliers, has received very limited attention thus far. Consequently, academia has provided minimal contribution to enhancing the understanding of sourcing category characteristics that will lead to a greater or lesser sourcing lever success. To address, this chapter analyses how contingency factors moderate the direct relationship between tactical sourcing levers and performance. 


\subsubsection{Conceptual framework: Contingency factors moderate the direct relationship between tactical sourcing levers and performance}

In the previous sections, literature on contingency theory and tactical sourcing levers was reviewed. In the following, the identified concepts are combined and linked in a conceptual framework. Thereby, the study builds on the previous works by González-Benito et al. (2010), assuming that contingency factors moderate the direct relationship between tactical sourcing levers and performance (see Figure 2, p. 5). It is thus based on the premise that "moderation occurs when the effect of an independent variable on a dependent variable varies according to the level of a third variable, termed a moderator variable, which interacts with the independent variable" (Edwards and Lambert, 2007, p. 1).

\subsection{METHODOLOGY: A MULTI-STEP SURVEY DEVELOPMENT PROCESS}

The study's aim was to investigate the relationships among sourcing category characteristics, tactical sourcing levers and performance outcomes. To achieve this aim, a survey instrument was developed to capture the extent of contingency factors, sourcing lever application and performance within 107 sourcing projects.

Complexity, dynamism and competition are multifaceted concepts (Dess and Beard, 1984; Sharfman and Dean, 1991; Starbuck, 1976). To facilitate a meaningful operationalization for data collection, technological, supply market and relational sub-domains of contingency factors were differentiated. In this context, 'technological complexity', 'technological dynamism' and 'technological competition' refer to the uncertainty and availability of the technology related to the purchased products (Lau et al., 1999; Li et al., 2012b; Trkman and McCormack, 2009). On the other hand, 'supply market complexity', 'supply market dynamism' and 'supply market competition' are defined by the structure and capabilities of the suppliers that are potentially able to meet the purchasing need (Cannon and Perreault Jr, 1999; Choi and Krause, 2006; Hunter et al., 2006). Finally, 'relational complexity', 'relational dynamism' and 'relational competition' relate to the multitude, stability and accessibility of relational capital and ties with the contracted supplier (Carey et al., 2011; Lin, 1999; Tsai and Ghoshal, 1998). 
According to the extant literature, 'cost performance' applies to the costs for the buying firm associated with retaining and contracting suppliers (Krause et al., 2001). Hence, it reflects not only the unit prices of the suppliers' product but also the costs associated with transportation, inspection, tests and supplier nonconformance (Terpend et al., 2011). 'Innovation performance' represents capability to introduce new processes, products, or ideas (Hult et al., 2004). It depends on the capabilities of the supplier to introduce new ideas and products (Krause et al., 2001), as well as the willingness and ability of the buyer to adapt proprietary product and process design (Azadegan and Dooley, 2010).

In the present study, contingency factors and sourcing performance were measured by utilizing scales that were adopted from extant literature (see Appendix - Table 21, p. 169 and Appendix - Table 22, p. 170). These required the respondents to state their level of agreement with the item statements by selecting one option form a 7-point Likert scale anchored at $1=$ 'strongly disagree" and $7=$ 'strongly agree'.

Contemporary literature provides little guidance on the activites related to each tactical sourcing lever. Consequently, this chapter draws on the world café findings and the sourcing lever indices developed in previous chapters. In Chapter 3, 23 formative indicators could be assigned to the seven tactical sourcing levers. In the subsequent survey, respondents indicated the extent to which they applied each tactical sourcing activity using a 7-point Likert scale (ranging from $1=$ 'not used' to 7 = 'extensively used') (see Appendix - Table 19, p. 166).

Unit of analysis was the multitude of sourcing projects managed at the European headquarters of one large, global automotive OEM. This chapter uses the same data set that has been collected earlier in this study (for details see Chapter 3.3.3, p. 56). Key informants were the category managers. In a sourcing project, these 'front-line' purchasing agents are responsible for most of the purchasing activities and are highly knowledgeable about the extent to which tactical sourcing levers have been applied. Each sourcing project begins with obtaining price quotes from multiple suppliers and ends with supplier nomination, awarding contracts to one or multiple suppliers. To minimize bias arising from information recall, the supplier nomination stage has been chosen as the point of reference for the purchaser. For supplier nomination, the responsible category manager has to present the strategic rationale of the respective sourcing project to the management at the corporate sourcing 
committee. Each time a supply contract was awarded and registered in the IT system, the responsible category manager was visited by the researcher and the questionnaire was completed jointly. In this way, maximum validity was ensured, generating high quality data (Srinivasan and Ratchford, 1991).

Confirmatory factor analysis (CFA) was used to assess reliability and validity of the multi-item, reflective scales for contingency factors and performance (Hair Jr. et al., 2013). Four indicators ('technC_1', 'supplierC_4', 'relationD_4' and 'relationCT_1') were removed due to low outer loading. All other indicators were statistically significant $(p>0.001)$ and their values were well above the cut-off level of 0.7 , indicating a substantive contribution. The indicator loadings onto the corresponding construct showed no critical levels of cross-loadings (see Appendix - Table 25, p. 176).

Cronbach's alpha $(\alpha)$ and composite reliability (CR) statistics both substantially exceed the threshold value of 0.7 , indicating internal consistency (see Table 15, p. 126). In addition, both scales surpassed the minimum value of 0.5 for average variance extracted (AVE), indicating convergent validity, while all square roots of the AVE are higher than the corresponding inter-construct correlations (Fornell-Lacker Criterion) indicating unidimensionality (Hair Jr. et al., 2013) (see Table 16, p. 127).

For the sourcing lever constructs, formative measurement models were chosen. In line with their definition, tactical sourcing levers consist of a set of distinct, directly addressable activities (O'Brien, 2012; Schiele, 2007; Schiele et al., 2011a; Schuh and Bremicker, 2005) and the formative measurement model "provides an option for researchers to use measures that tend to be specific, actionable attributes of a phenomenon" (Cenfetelli and Bassellier, 2009, p. 690). For the formative sourcing lever indices, convergent validity was used to test whether all relevant facets of the construct have been sufficiently covered by the selected formative indicators (Diamantopoulos et al., 2008; Hair Jr. et al., 2013). The analysis results confirmed that all path coefficients between each formative construct (exogenous) and the corresponding global-item construct (endogenous) are well above the threshold of 0.8 (Chin, 1998; Hair Jr. et al., 2013). Variance inflation factor (VIF) values were also calculated for each indicator using SPSS 22.0 software (IBM, 2013). The findings yielded verified that all VIFs are well below the threshold of 3.3, indicating that formative indicators are sufficiently distinct and do not carry critical levels of redundant information (Petter et al., 2007). All outer weights in the formative measurement 
models have a $p$-value $(5,000$ bootstraps) smaller than 0.01 , indicating a high relative contribution of the formative indicators (Hair Jr. et al., 2013). Moreover, all outer loading in the same models are well above the threshold of 0.5, also indicating a high absolute contribution of the indicators (see Table 11, p. 107).

Table 15: Scale reliabilities

\begin{tabular}{lccc} 
Constructs & Cron. $\alpha^{\mathrm{a}}$ & $\mathrm{CR}^{\mathrm{b}}$ & AVE $^{\mathrm{c}}$ \\
\hline Contingency factors & & & \\
\hline Technological complexity & 0.894 & 0.934 & 0.825 \\
Technological dynamism & 0.924 & 0.946 & 0.814 \\
Technological competition & 0.900 & 0.924 & 0.711 \\
Supply market complexity & 0.850 & 0.899 & 0.692 \\
Supply market dynamism & 0.869 & 0.908 & 0.711 \\
Supply market competition & 0.829 & 0.886 & 0.662 \\
Relational complexity & 0.875 & 0.915 & 0.728 \\
Relational dynamism & 0.900 & 0.935 & 0.828 \\
Relational competition & 0.928 & 0.950 & 0.864 \\
\hline Performance & & & \\
\hline Innovation performance & 0.917 & 0.930 & 0.655 \\
Cost performance & 0.954 & 0.961 & 0.753
\end{tabular}

${ }^{\mathrm{a} C}$ Cronbach's alpha (Cron. $\alpha$ ) used to test for internal consistency reliability

${ }^{\mathrm{b}}$ Composite reliability (CR) used to test for internal consistency reliability

${ }^{\mathrm{c}}$ Average variance extracted (AVE) used to test for convergent validity 
Table 16: Interconstruct loadings

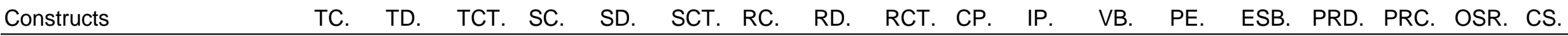

Contingency factors (reflective)

\section{TC. Techn. complexity $\mathbf{0 . 9 0 8}$}

TD. Techn. dynamism $\quad 0.357 \quad \mathbf{0 . 9 0 2}$

TCT. Tech. competition $\quad 0.432 \quad 0.384 \quad \mathbf{0 . 8 4 3}$

SC. Supply m. complexity $0.512 \quad 0.275 \quad 0.269 \quad 0.832$

SD. Supply m. dynamism $\quad-0.051 \quad 0.218 \quad 0.050 \quad 0.197 \quad \mathbf{0 . 8 4 3}$

SCT. Supply m. competition $0.324 \quad-0.040 \quad 0.051 \quad 0.361 \quad-0.104 \quad \mathbf{0 . 8 1 3}$

$\begin{array}{llllllllll}\text { RC. Rel. complexity } & & 0.523 & 0.170 & 0.223 & 0.337 & 0.053 & 0.263 & 0.853\end{array}$

RD. Rel. dynamism $\quad \begin{array}{lllllllll}0.242 & 0.273 & 0.100 & 0.255 & 0.190 & 0.204 & 0.421 & 0.910\end{array}$

$\begin{array}{lllllllllll}\text { RCT. Rel. competition } & 0.081 & 0.045 & 0.091 & -0.039 & -0.050 & 0.134 & 0.021 & 0.220 & 0.930\end{array}$

\section{Performance (reflective)}

IP. Inno. performance

$\begin{array}{llllllllll}0.077 & 0.030 & 0.121 & -0.064 & 0.191 & -0.129 & 0.016 & -0.015 & -0.176 & 0.809\end{array}$

CP. Cost performance

$\begin{array}{lllllllllll}0.236 & 0.184 & 0.206 & 0.398 & 0.278 & 0.148 & 0.219 & 0.272 & -0.160 & 0.210 & 0.868\end{array}$

Sourcing levers (formative)

\begin{tabular}{llllllllllllllll}
\hline VB. & Volume bundling & & 0.263 & 0.202 & 0.145 & 0.103 & 0.114 & -0.063 & 0.096 & 0.095 & -0.059 & 0.156 & 0.082 & form
\end{tabular}

$\begin{array}{llllllllllllllllllllllll}\text { PE. Price evaluation } & & -0.067 & 0.026 & -0.027 & 0.060 & 0.331 & -0.158 & -0.044 & 0.050 & -0.046 & 0.268 & 0.260 & 0.331 & \text { form. }\end{array}$

ESB. Ext. of supply base $\begin{array}{lllllllllllllll}0.233 & 0.176 & 0.219 & 0.202 & 0.270 & 0.138 & 0.162 & 0.084 & -0.139 & 0.292 & 0.139 & 0.334 & 0.426 & \text { form. }\end{array}$

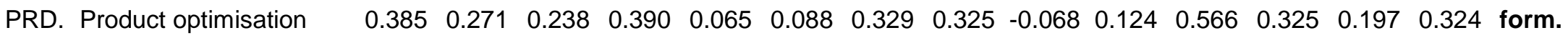

$\begin{array}{llllllllllllllllll}\text { PRC. Process optimisation } & 0.209 & 0.102 & 0.145 & 0.151 & 0.154 & 0.061 & 0.254 & 0.157 & -0.042 & 0.188 & 0.260 & 0.090 & 0.365 & 0.411 & 0.370 & \text { form. }\end{array}$

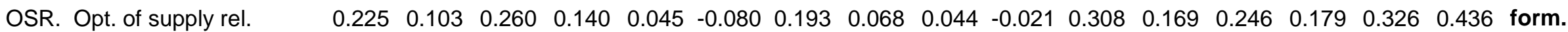

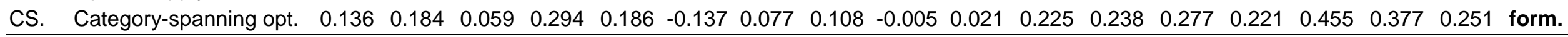

Note: form. = formative 


\subsection{MODERATION ANALYSIS: COMPARING LOW VS. HIGH SOURCING LEVER APPLICATION UNDER DIFFERENT CONTINGENCY FACTORS}

Simple slope analysis, a form of moderation analysis, may be used to predict the value of a dependent variable in relation to either low or high values of an independent and a moderator variable. In a simple slope analysis, the value of the dependent variable $(D V)$ is described by a linear regression equation, comprising of the independent variable $(I V)$, the moderator variable $(M)$ and the interaction term $(I V \times M)$ related to the moderation effect, as shown in Equation I below (Carey et al., 2011; Cohen et al., 2013; Dawson, 2014; Zhou et al., 2014).

$$
\mathrm{DV}=\mathrm{b}_{0}+\mathrm{b}_{1} \times \mathrm{IV}+\mathrm{b}_{2} \times \mathrm{M}+\mathrm{b}_{3} \times \mathrm{IV} \times \mathrm{M}
$$

In this equation, $b_{0}$ is the intercept (the expected value of $D V$, when $I V$ and $M=$ 0 ). The coefficients $b_{1}$ and $b_{2}$ determine whether there is a main effect of $I V$ and $M$ (the expected change in $D V$ corresponding to a change of one unit in $I V$ or $M$ ), while $b_{3}$ determines whether moderation can be observed (Dawson, 2014). For simple slope analysis, predicted values of $D V$ are calculated under different conditions (high and low values of $I V$ and $M$, respectively). Typically, values that are one standard deviation ( $s d$ ) below (for 'low') or above (for 'high') the mean (mean) are used (see Equation II).

$$
\begin{aligned}
& \mathrm{DV}=\mathrm{b}_{0}+\mathrm{b}_{1} \times(\text { meanIV}+/-\mathrm{sdIV})+\mathrm{b}_{2} \times(\text { meanM }+/-\mathrm{sdM})+\mathrm{b}_{3} \times \\
& (\text { meanIV }+/ \text {-sdIV }) \times(\text { meanM }+/-\mathrm{sdM})
\end{aligned}
$$

The following example, demonstrates the simple slope analysis for the dependent variable 'cost performance' $(C P)$, the independent variable 'volume bundling' $(V B)$, and the moderator 'technological complexity' $(T C)$ :

The intercept $\left(b_{0}=4.484\right)$ and the unstandardized regression coefficients $\left(b_{1}\right.$ $\left.=0.160 ; b_{2}=-0.009 ; b_{3}=-0.090\right)$ have been determined via the linear regression function available in the SPSS 22.0 software (IBM, 2013). The same software provides the mean and standard deviation of $V B($ mean $V B=4.44 ; s d V B=1.59)$ and TC $($ meanTC $=4.16 ; s d T C=1.66)$.

For low 'volume bundling' (meanVB $-s d V B$ ) and high 'technological complexity' (meanTC $+s d T C$ ), the predicted value for $C P$ is 3.39 (see Equation III). 
(III) $3.39=4.484+0.160 \times(4.44-1.59)+(-0.009) \times(4.16+1.66)+$ $(-0.090) \times(4.44-1.59) \times(4.16+1.66)$

For high 'volume bundling' (mean $V B+s d V B$ ) and high 'technological complexity' (meanTC $+s d T C$ ), the predicted value for $C P$ is 2.23 (as given in Equation IV)

$$
\begin{aligned}
& \text { (IV) } 2.23=4.484+0.160 \times(4.44+1.59)+(-0.009) \times(4.16+1.66)+ \\
& (-0.090) \times(4.44+1.59) \times(4.16+1.66)
\end{aligned}
$$

The above example reveals that, if 'volume bundling' is extensively applied in conditions of high 'technological complexity', the predicted value for 'cost performance' decreases by 1.16 (see Equation V) in comparison to a case characterized by low 'volume bundling' scores.

$$
\text { (V) } 2.23-3.39=-1.16
$$

This suggests that, if 'cost performance' is increased, 'volume bundling' should not be intensified in conditions of high technological complexity.

For visual interpretation, the results may be plotted on a simple slope diagram (see Figure 12, p.129).

Figure 12: Moderation analysis (exemplary simple slope diagram)

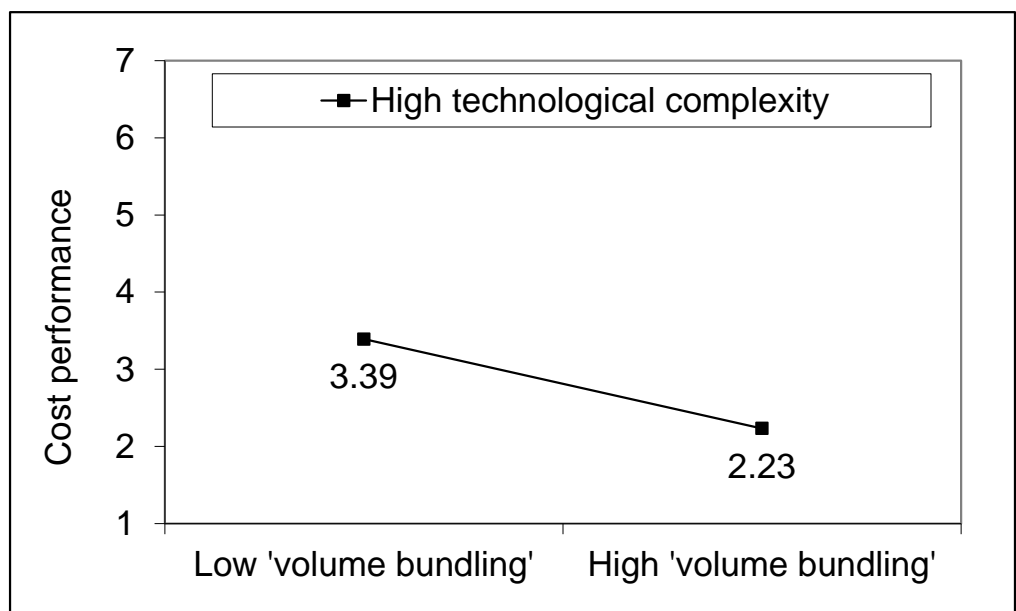

The aim of the present study was to elucidate the influence of nine contingency factors (moderating variables) on seven tactical sourcing levers (independent variables) and two performance variables (dependent variables). A simultaneous 
simple slope analysis of all these variables in one model would not allow for a meaningful interpretation due to overlapping effects of the variables and small sample size.

Therefore, a stepwise simple slope analysis was performed instead. Similarly to the presented example, each possible combination of one tactical sourcing lever, one contingency factor and one performance variable was analysed separately. This approach allowed the predicted values for cost performance and innovation performance to be calculated for each tactical sourcing lever and each contingency factor (see Appendix - Table 26, p. 178 and Table 27, p. 182).

\subsection{DISCUSSION: MORE IS NOT ALWAYS BETTER}

To allow for a visual interpretation, in the following sections, the mean scores of the predicted performance scores for 'technological complexity', 'supply market complexity and 'relational complexity' are calculated, yielding overall performance scores for 'complexity'. The same approach was applied to obtain the 'dynamism' and 'competition' overall scores.

\subsubsection{Cost performance: increased sourcing lever application sometimes reduces cost savings}

In a highly complex sourcing project, the purchaser has to deal with a wide range of dissimilar, interrelated technological, supply market and relational aspects, requiring distinct modes of handling (Choi and Krause, 2006). Consequently, information and resource requirements for the purchasing agent increase, making it difficult to understand the effects of actions taken (Bozarth et al., 2009). Therefore, it was not surprising that, under conditions of high 'complexity' (see Figure 13.1., p. 131), dedicating greater efforts to 'process optimisation' and 'price evaluation' were predicted to most strongly contribute to cost performance $(+2.15 /+1.72)$. In extant literature, these analytical tactics have been posited to reduce complexity and to contribute to information gains for proactive actions. More specifically, 'extension of the supply base' aims to introduce new sources of supply and may ultimately increase complexity and the difficulty associated with managing the purchasing process. Therefore, it was somewhat surprising that, in situations characterized by high complexity, 'extension of supply base' was predicted to increase cost savings $(+1.08)$. In 
previous studies, 'volume bundling' has been posited to increase bargaining power when negotiating prices. Yet, the findings yielded by the present study show that, in complex situations, increased effort into 'volume bundling' might even have a negative effect on cost performance (-0.25). In the same vein, this study contradicts previous findings, which generally implied that forming close partnerships with suppliers would be beneficial. However, in this data set, 'optimisation of supply relationships' in highly complex situations was predicted to significantly reduce cost performance (-1.01).

In a highly dynamic sourcing project, changes in the technological, supply market and relational aspects are frequent, fast and unpredictable. Consequently, the purchasing agents face great difficulty when attempting to plan for future developments (Hough and White, 2003; Kaufmann et al., 2012). The present study findings indicate that highly dynamic situations seem to be less favourable for cost performance relative to highly complex situations. In comparison to highly complex sourcing projects, in highly dynamic projects, exerting more efforts on any of the tactical sourcing levers was predicted to yield fewer cost savings. Moreover, the results suggest that further efforts dedicated to five out of seven tactical sourcing levers would even have a negative impact on cost performance (see Figure 13.2., p. 131).

Figure 13: Low vs. high sourcing lever application (cost performance)

Figure 13.1.: High complexity

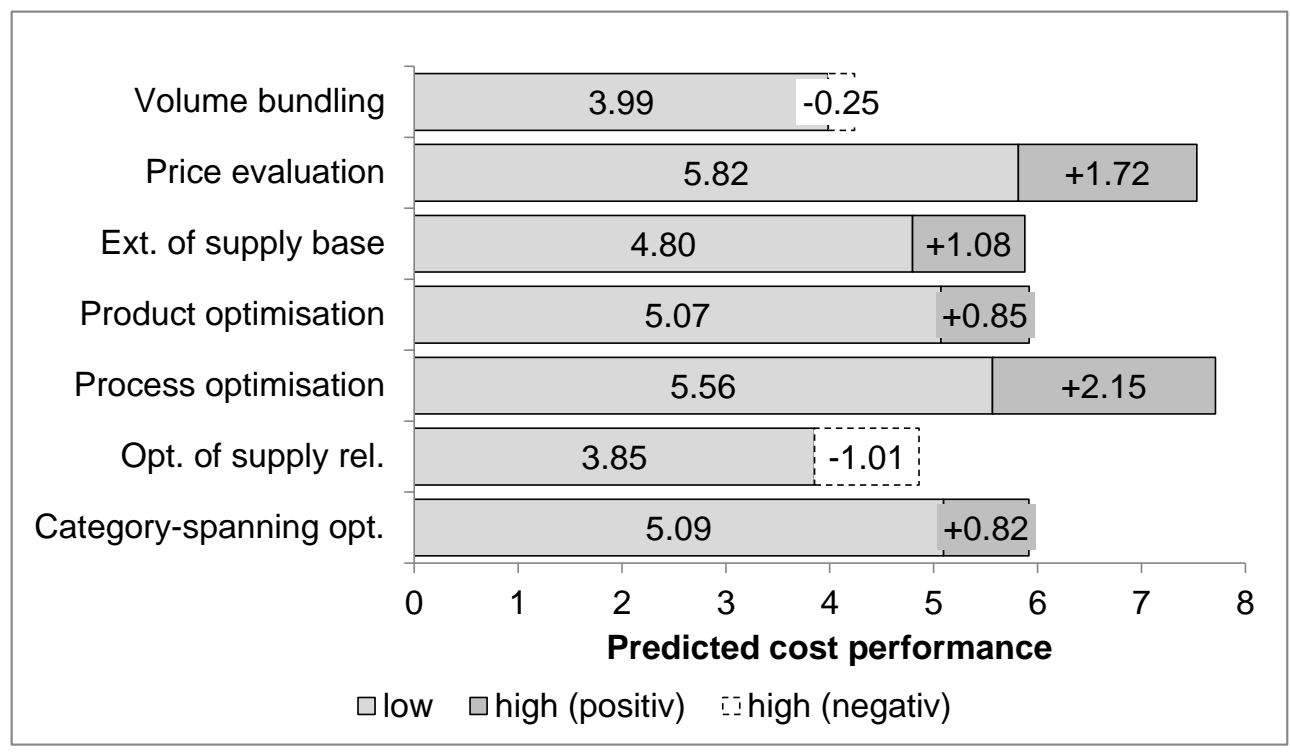


Figure 13.2.: High dynamism

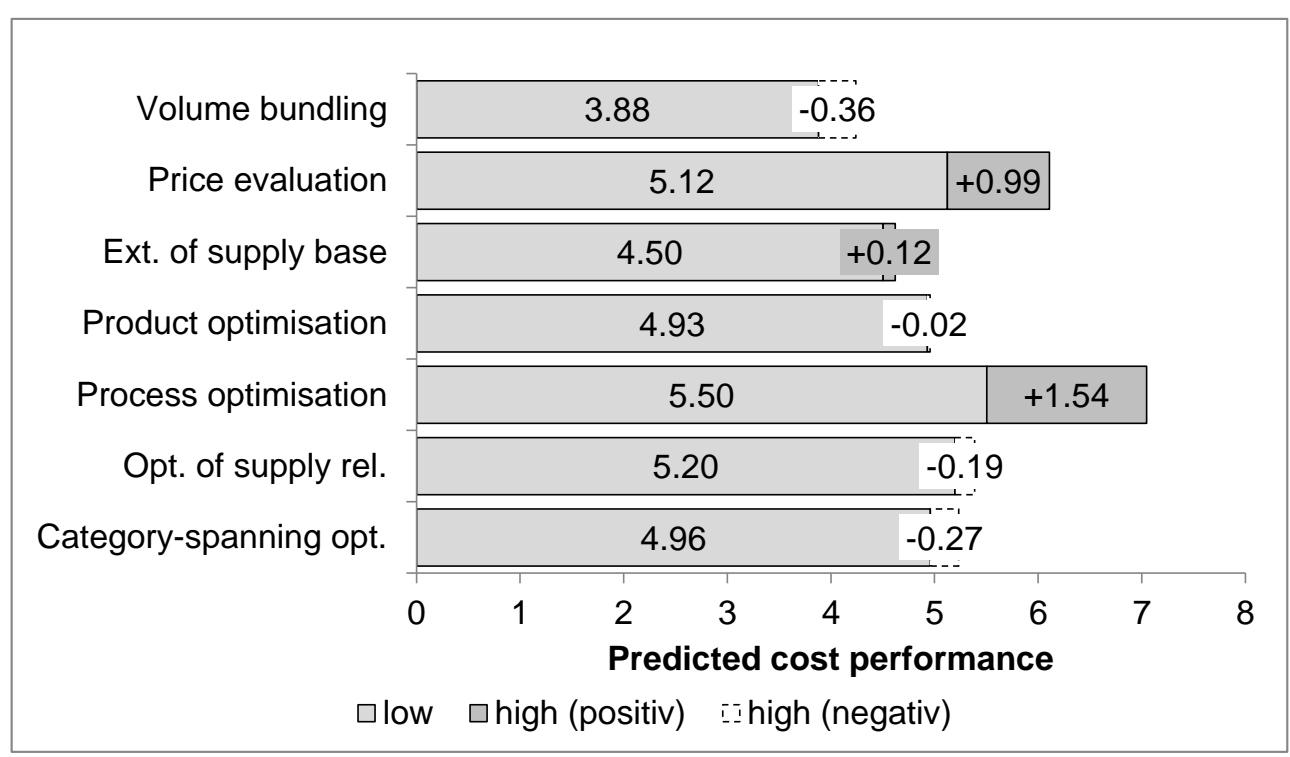

Figure 13.3.: High competition

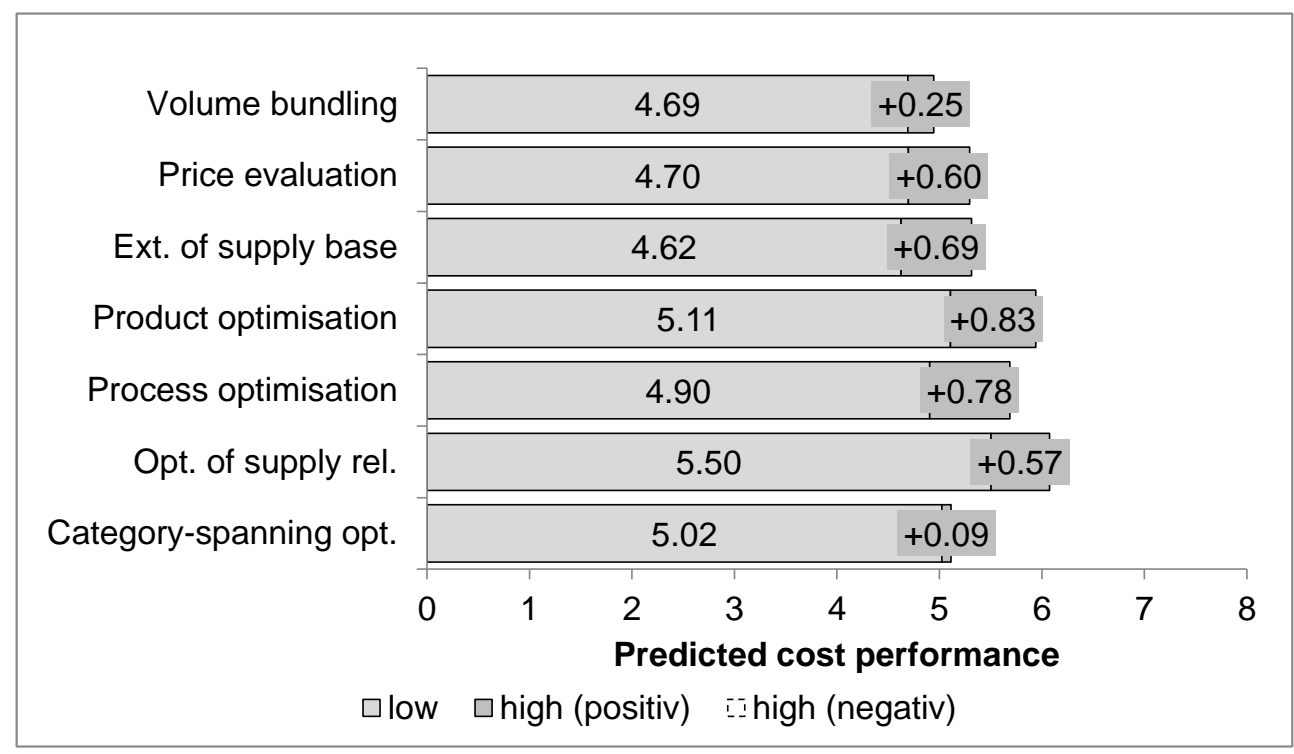

In a sourcing project characterized by high competition, resources and potential sources of supply are scarce. Under these conditions, study findings predict that increasing efforts dedicated to any of the seven tactical sourcing levers would only slightly enhance cost performance (see Figure 13.3, p. 131). According to the extant literature, 'extension of supply base' aims to increase the number suppliers and thus secure additional sources of supply. Similarly, the aim of the 'optimisation of supply relationship' is to secure preferential access to the suppliers' resources (Baxter, 2012; Hüttinger et al., 2012). Therefore, it was 
expected that, under highly competitive conditions, investing additional efforts into 'extension of supply base' and 'optimisation of supply relationship' would strongly contribute to cost performance. However, the cost performance was predicted to increase only slightly when these levers are used more intensively $(+0.69 /+0.57)$.

\subsubsection{Innovation performance: more efforts spent on tactical sourcing levers are not always better for innovation}

Additional effort invested into 'product optimisation' was found to strongly contribute to innovation performance even under conditions of high complexity $(+1.96)$, dynamism $(+1.49)$ and competition (+2.63) (see Figure 14, p. 134). Similarly, intense 'price evaluations' may be recommended in highly complex and dynamic conditions. However, it is noteworthy that high competition was predicted to mitigate the positive effect of 'price evaluations' (see Figure 14.3., p. 134). In other words, when resources are scarce, dedicating greater effort to 'price evaluations' may even reduce innovation performance (-0.16). Likewise, in highly competitive conditions, increasing efforts spent on 'volume bundling' was predicted to reduce the already low innovation gains even further $(-0.43)$ (see Figure 14.3., p. 134). This finding is congruent with the results reported in extant studies, in which 'volume bundling' was described as an adversarial sourcing lever focused on cost savings, thus hindering innovativeness (Schiele et al., 2011a).

Furthermore, intense 'extension of supply base' may not be recommended under conditions of high complexity (-0.28) and dynamism (-0.39) and was predicted to yield only minor additional innovation benefits in highly competitive conditions $(+0.37)$. Hence, under these conditions, the purchasing agents might prefer implementing other tactical sourcing levers that promise higher innovation gains. This finding is aligned with those reported in pertinent literature in which a reduction of the supply base and close collaboration with a few suppliers has been recommended if the goal is to increase innovation performance (Ellis et al., 2012; Johnsen, 2009). 
Figure 14: Low vs. high sourcing lever application (innovation performance)

Figure 14.1.: High complexity

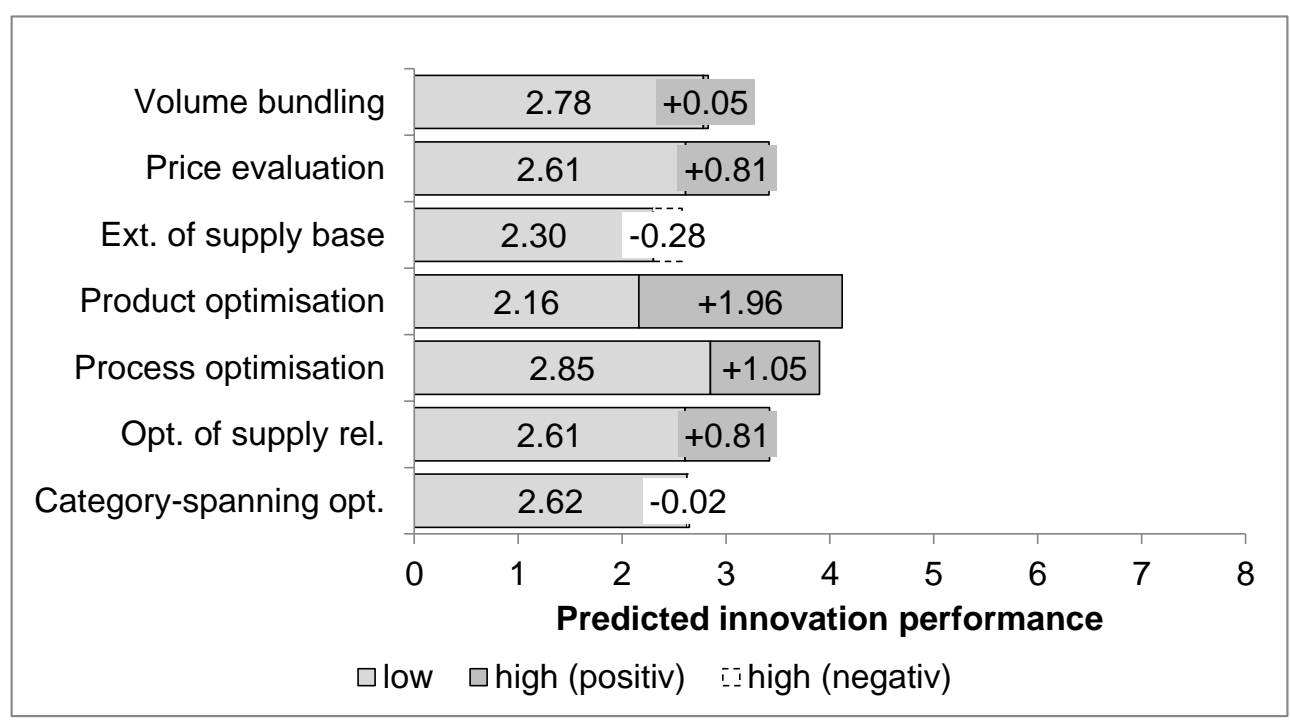

Figure 14.2.: High dynamism

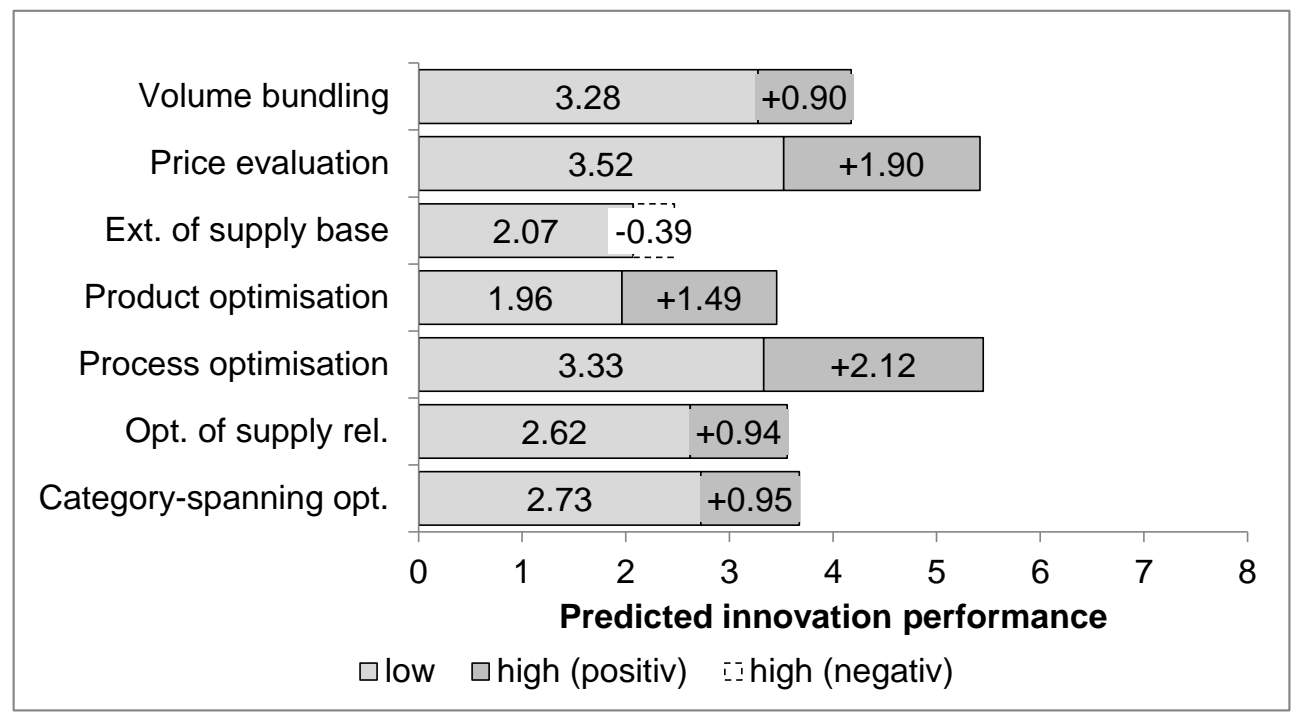


Figure 14.3.: High competition

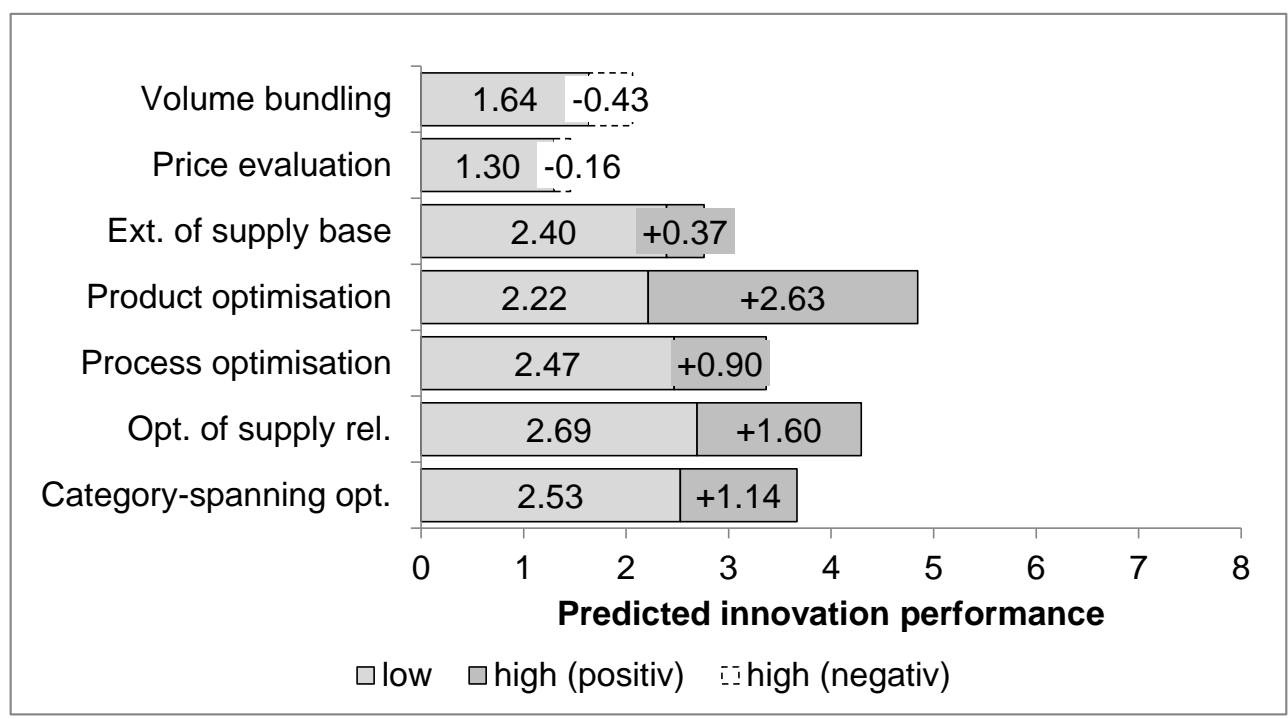

Findings yielded by the present study indicate potential trade-off between cost and innovation performance. More specifically, in sourcing projects characterized by complexity, intense efforts spent on 'extension of supply base' were predicted to yield further cost savings (+1.08) (see Figure 13.1., p. 134). However, under similarly highly complex conditions, 'extension of supply base' was predicted to reduce innovation performance (-0.28) (see Figure 14.1., p. 134). Accordingly, purchasing agents should consider if the performance outcomes of a tactical sourcing lever in the given conditions are aligned with the overall strategic goals (e.g., cost or innovation strategy).

\subsection{CONCLUSIONS: PURCHASING AGENTS ARE ADVISED TO ADAPT THEIR CHOICE OF TACTICAL SOURCING LEVERS TO THE REQUIREMENTS OF THE SOURCING CATEGORY}

To improve sourcing performance, existing literature recommends that purchasing agents adapt their choice of tactical sourcing levers to the conditions of the sourcing category in focus (Hesping and Schiele, 2015; Horn et al., 2013; Schiele et al., 2011a). However, so far, little has been done to empirically establish which sourcing category characteristics will hinder or improve performance. To address this omission, in the present study, a survey instrument was developed to capture the extent of contingency factors, sourcing lever application and performance within 107 sourcing projects managed at the 
European headquarters of a large, global automotive OEM. Moderation analysis was subsequently employed to determine the predicted values of performance for configurations of low (high) sourcing lever application and low (high) contingency factor. This study goes beyond existing works by providing empirical findings yielded by a survey among 'front-line' purchasing agents. Thereby, its findings have immediate relevance, as they can serve as practical guidelines with respect to the tactical sourcing levers that will improve or undermine cost or innovation performance under different sourcing category conditions.

\subsubsection{Contributions: extending contingency theory to the category level}

The study makes several novel contributions:

(1) This study, for the first time, extends contingency theory to category level of purchasing and corresponding sourcing tactics. Its findings show that the success of these levers is strongly influenced by the conditions of the sourcing category. Purchasing agents are thus advised to adapt their choice of tactical sourcing levers to the requirements of the sourcing category.

(2) The study moves away from generic recommendations made in previous publications, such as purchasing portfolio models (Handfield et al., 2009; Kraljič, 1983; Van Weele, 2010). In the past, 'extension of the supply base' through international sourcing, for example, has been seen as "an automatic expectation to respond to competition" (Carter et al., 2008, p. 225). Similarly, Nollet and Beaulieu (2005) noted that there is a general agreement in literature that 'volume bundling' leads to high saving potentials. Beyond anecdotal evidence, to date, few attempts have been made to test if these generic recommendations hold true under various conditions. The findings reported here show that 'extension of supply base' and 'volume bundling' may not be a 'condition sine qua non' for improved performance. Rather, under some conditions, dedicating further efforts to a tactical sourcing lever may even reduce performance.

(3) The study's findings highlight the importance of considering potential trade-offs among tactical sourcing levers. The result shows that, under conditions of high complexity, 'extension of supply base' may be intensified to gain additional cost performance. However, under 
comparably complex conditions, this approach reduces innovation performance. Consequently, purchasing agents are advised to configure a consistent set of tactics that fits the overall strategic goals of the respective sourcing category (e.g., cost or innovation strategy).

(4) Findings reported here suggest a superior role of 'price evaluations'. In the analysed cases, dedicating greater effort to 'price evaluations' has led to both higher cost and improved innovation performance under nearly all conditions. In the past, price evaluations in purchasing may have mainly been concerned with gaining informational advantage as a means of pressuring suppliers in price negotiations. However, the present study findings show that purchasing price evaluations may substantially contribute to both cost savings and innovation.

(5) The study provides practical guidelines that purchasing agents may use when developing and implementing a set of tactics aimed at improving performance for a category of purchases. The presented tactical sourcing levers may serve as a checklist to identify cost saving or innovation potentials. At the same time, empirical findings might be used to verify whether the targeted tactical sourcing levers are actually beneficial for the sourcing conditions faced. This might help to narrow the focus on the most promising tactical sourcing levers.

\subsubsection{Limitations: the research design offers opportunities for future research}

The study intentionally focused on a single, large, global automotive OEM to allow for access to a reasonably large number of comparable sourcing projects. However, this limited scope might have influenced the study results. Distinct industry-specific factors might have favoured the success of certain tactical sourcing levers relative to others. Future studies in a broader industry and organizational context would thus be highly beneficial, as the findings yielded would likely have a greater potential for generalization.

The analyses performed in this study are based on primary, subjective data. Although remedies, such as intense pre-tests and assurance of anonymity to the respondents, have been implemented, the findings might be affected by personal opinions and judgments of the respondents. Thus, it would be fruitful to repeat this study in the future using objective performance data. 
The data utilized in this study was sourced from the survey completed by key informants related to the purchasing department. However, purchasing projects are increasingly managed by cross-functional teams (Driedonks et al., 2013). Therefore, future research might include personnel from other functions, such as engineering and marketing, into the research process. This diversification may reveal further sourcing tactics and thus a more complete picture of the cost savings and innovations realised. 


\section{CHAPTER 7: SUMMARY AND CONCLUSIONS}

\subsection{INTRODUCTION: A TAILORED MIX OF TACTICAL SOURCING LEVERS}

The present study was motivated by the fact that not all materials, services and buyer-supplier relationships should be managed in the same way. In the past, in relation to the growing interest in practice, scholars discussed various antecedents of high-performance purchasing. Thereby, they mainly focused on the functional level of purchasing encompassing the firm's entire expenditure, while largely neglecting the category level of analysis (Ateş et al., 2015). At this level, firms often differentiate up to hundreds of sourcing categories, each encompassing materials and services of a similar type sourced from an overlapping number of suppliers (Cousins et al., 2008a; Monczka et al., 2008; O'Brien, 2012; Rüdrich et al., 2000; Trautmann et al., 2009a; Van Weele, 2010). Depending on its specific characteristics, each sourcing category requires a tailored set of tactical sourcing levers (Cox, 2014; Hesping and Schiele, 2015; Horn et al., 2013; Luzzini et al., 2012; Schiele et al., 2011a; Schuh et al., 2011; Trautmann et al., 2009a). However, existing studies "only considered the first steps of portfolio management, i.e. category classification and strategic priorities. Other studies might consider which levers and tools are used according to the different types of categories" (Luzzini et al., 2012, p. 1036).

Thus far, academic research has failed to elucidate investigations on the relationship among tactical sourcing levers, sourcing category characteristics and performance at the category level of purchasing. 
Hence, the central purpose of this work was to answer one main research question:

RQ1: What are the effects of tactical sourcing levers on cost and innovation performance and in what way can sourcing category characteristics enhance or hinder sourcing success?

This question was answered in several steps. Initially, pertinent literature was structured, for the first time fully integrating sourcing categories and tactical sourcing levers as a level of analysis. This allowed developing formative sourcing lever indices that enable empirical investigations. Thereafter, to better understand if and how purchasers adapt their choice of tactical sourcing levers to the category characteristics, the former were aligned with the Kraljič matrix, a purchasing portfolio matrix. The data required to assess the impact of tactical sourcing levers on performance at the category level pertained to 107 'frontline' sourcing projects. Moderation analysis was subsequently used to investigate performance under various configurations of tactical sourcing levers moderated by contingency factors. The outcome was a set of practical recommendations regarding the specific tactical sourcing levers to select with respect to the sourcing context.

\subsection{MAIN FINDINGS: CONTRIBUTIONS TO THEORY AND PRACTICE AND RESEARCH PROPOSITIONS}

The thesis was structured into five chapters, linked by a coherent 'storyline'. The following sections summarize the main findings, contributions to both theory and practice, and research propositions that can be derived from the work presented in each chapter. The thesis concludes by presenting limitations and suggestions for future research.

\subsubsection{Chapter 2: Purchasing strategy development - a multi-level review}

In Chapter 2, hierarchical levels of strategy development in the purchasing literature were presented. In a structured literature review, 2,321 literature sources published in German and English over the past 42 years were screened. Of these, 138 publications were identified as addressing strategy development in purchasing. The origins of the research fields could be traced back to 1970 . Contemporary research appears to have reached maturity with a consistently high level and equal share of empirical and conceptual contributions. 
Thereby, the following sub-question was addressed:

RQ1.1.: Which hierarchical levels of analysis for strategy development in purchasing exist in the purchasing literature, what are their particularities, and how do the different levels relate to one another?

As a result of the literature analysis, five levels of strategy development could be distinguished: (1) firm strategy guiding a firm's approach toward product markets; (2) purchasing strategy as an aspect of functional strategies guiding all of a firm's purchasing activities; (3) category strategies, guiding activities within groups of materials and services, forming discrete supply markets; (4) sourcing levers, i.e., tactics used to plan activities to execute category strategies; and (5) supplier strategies, describing how to approach each of a sourcing category's suppliers (see Figure 4, p. 19).

These findings have several implications for theory and practice:

At the theoretical level, the chapter extends González-Benito's (2007) framework for purchasing competence and for the first time completely integrates category strategy and tactical sourcing levers into a hierarchical framework of strategy development in purchasing. The research field was conceptualized as the first step towards theory building (Meredith, 1993). Thereby, German-language literature sources and the respective strategic purchasing concepts, in particular the sourcing lever level of analysis, were made accessible to the English-speaking audience. The hierarchical structure of the framework informs scholars about different levels of analysis in purchasing and supply management research. In previous studies, scholars have vacillated between various levels of analysis, or have used them interchangeably, without acknowledging the implications of doing so. Chen et al. (2004), for instance, related strategic purchasing (the 'function' level) to supplier relationship management practices (the 'supplier' level) to business performance (the 'organization' level). In such an approach, it may be difficult to identify the influence of variables at one level of analysis on performance at a higher level of analysis. Consequently, when attempting to explain relationships between variables, researchers may need to be more vigilant in the level of analysis selection.

At the practical level, the hierarchical structure of the proposed framework offers a coherent, step-wise approach for strategy development. Practitioners may address each level to decompose general strategy into executable and 
controllable activities. Findings yielded by the present study indicate that purchasing managers are well advised to differentiate and coordinate a hierarchy of multiple levels of strategy development. Along this hierarchy, overall goals in product markets may be translated into requirements and targets for each sourcing category and the respective supply market, enabling effective actions and efficient resource allocation.

Several research propositions arise from the work presented in this chapter. First, as sourcing categories lead to further decentralized purchasing organizations, horizontal and vertical integration mechanisms may become increasingly important for uniting decentralized effort for common goals. In order to do so, purchasers need to understand the aspects affecting the degree of integration necessary within and across sourcing categories. The concepts of 'category management', as presented in German-language publications (e.g., Boutellier and Zagler, 2000) and information processing theory, might be promising frameworks for further investigations (e.g., Trautmann et al., 2009b). Second, contemporary literature lacks theoretically sound and empirically grounded approaches to classify products or services. This may pose a challenge when determining the criteria to be used when identifying purchases to be combined in a sourcing category. Future research may build on recent works by Luzzini et al. (2012) or Ateş (2014) and investigate whether certain material or supplier constellations best support certain competitive priorities or power and dependence in a supply market, for example. Third, the presented hierarchy of strategy development also indicates a hierarchy of performance, i.e., firm performance, functional performance of purchasing, category performance and relationship performance. As one of the few useful sources in this context, Caniato et al. (2014) clearly distinguished among different levels of purchasing performance measurement. Future studies might aim to identify performance indices that are applicable to a sourcing category and at the functional level of purchasing, respectively.

\subsubsection{Chapter 3: Sourcing levers - developing a formative method of measurement}

In the previous chapter, a loose definition of the sourcing lever concept, as well as absence of a suitable method of measurement was found. Therefore, to allow further empirical investigations in the later chapters, the conceptual content of the sourcing lever concept was delineated and formative methods of 
measurement were developed. Chapter 3 followed the index development procedure proposed by Diamantopoulos and Winklhofer (2001). This study phase commenced with a detailed literature review on sourcing strategies and tactics. Consequently, an initial list of sourcing activities could be generated, which served as guidance for world café discussions with 24 category managers. In the world café rounds, further sourcing activities could be identified and conceptual overlaps among them could be minimized. Following the fruitful, world café discussions, 23 indicators, grouped into seven tactical sourcing levers, were tested using the data from a survey among 107 sourcing projects at the European headquarters of one large, global automotive OEM.

Thereby, the following sub-question was addressed:

RQ1.2.: What defines the conceptual content taken by the sourcing lever concept and which measures are capable to capture this?

As a result, conceptual definitions for each of the seven core tactical sourcing levers proposed by Schiele et al. (2011a) could be formed. Based on these definitions, sourcing lever indices with multiple indicators could be developed. The test results provided strong empirical evidence, confirming that the developed indicators adequately cover the conceptual content of the sourcing lever concept (see Table 4, p. 59).

Consequently, the chapter makes several contributions to theory and practice:

At the theoretical level, the findings presented advance theory as, for the first time, a wide range of sourcing tactics from contemporary literature are listed and categorized (Meredith, 1993). In addition, owing to the present study, definitions for each sourcing lever construct could be formed, delineating their conceptual content from other constructs. Furthermore, the study illustrates the applicability of the world café methodology in the index development process (Brown and Isaacs, 2005; Hoffmann, 2012; Lagrosen and Lagrosen, 2013; Prewitt, 2011). The initial literature review revealed that sourcing activities tend to be defined using incongruent and often confusing language, making them appear conceptually very similar. In the past, this lack of accurate definition hindered academic reasoning and cross-study comparisons (Speed, 1993). In the world café adopted in this study, practitioners and academics were actively engaged in an effort to aggregate various identified activities into 23 indicators with little conceptual overlap. This has provided a sound foundation for future 
research, as instead of using a confusing amount of conceptually overlapping concepts, the studies that follow may focus on this aggregated list of indicators covering all of the main aspects of the sourcing lever concept. Distinct from the majority of other quantitative and qualitative research approaches, in a world café, practitioners are seen as co-researchers rather than objects of inquiry (Susman and Evered, 1978). Relevance of the world café method was demonstrated in this study, as all participants highly valued the active engagement in the evaluation of findings, as this allowed them to develop further capabilities as an immediate return on the time invested. Validity could be improved, as participants moved from table to table challenging previous groups' findings. World café methodology stimulates aggregation and abstraction of concepts and thus seems to be especially suitable for initiatives aiming to form distinct constructs from sometimes vague and not clearly delineated indicators. The developed sourcing lever indices can thus be used in future research as a starting point to address relevant research questions. Some fruitful avenues to explore could be the antecedents, conditions and consequences of sourcing lever application, as these have been largely neglected in extant studies.

At the practical level, the work presented in Chapter 3 reveals a wide range of specific, actionable cost saving approaches that may serve practitioners as a 'toolbox' or 'checklist' to plan upcoming sourcing activities. The identified indictors may, for example, be used in cross-functional lever analysis workshops (Schiele, 2007; Schiele et al., 2011a; Schuh et al., 2011), allowing the participants to discuss improvement potentials that have not been addressed so far. The sourcing lever indices may also be employed as performance indicators to assess the success realised by each sourcing lever construct. Practitioners might, for example, be interested in the extent to which tactical sourcing levers are used and whether certain tactical sourcing levers have been neglected in previous activities.

The chapter closed with the suggestion of several research questions to be approached by future research using the developed sourcing lever indices, namely: Which configurations of tactical sourcing levers are most successful? Do potential trade-offs exist among tactical sourcing levers in a way that certain sourcing lever combinations reduce overall expected performance? Which tactical sourcing levers can be combined to realise synergies and to maximize overall cost savings? In which order should tactical sourcing levers be applied to 
reach most cost savings? Are certain tactical sourcing levers more successful at the beginning, while others should be applied preferably at the end of a sourcing project? Do certain tactical sourcing levers lose their effect when being applied several times in the same sourcing category? Can tactical sourcing levers be added to regain cost saving potentials from tactical sourcing levers that lost their potential over time? How do cross-functional sourcing teams influence the choice and success of tactical sourcing levers? What are the competencies category managers should possess in order to apply tactical sourcing levers most successfully?

\subsubsection{Chapter 4: Matching sourcing levers with the Kraljič matrix - empirical evidence on purchasing portfolios}

In Chapter 4, the sourcing lever concept was linked to the purchasing portfolio theory. Since its inception, the Kraljič matrix has become the dominant approach in purchasing portfolio management. According to many textbooks, purchases should first be grouped into 'noncritical', 'leverage', 'bottleneck' and 'strategic' purchases, depending on how strategically important and risky they are. Next, in order to maximize cost savings, purchasers should follow generic strategic and tactical recommendations for each of these four portfolio quadrants. Extant academic research has criticised this approach (Canièls and Gelderman, 2005; Cox, 2014; Gelderman and Van Weele, 2005). However, very little effort has been made to empirically verify if tactical sourcing levers are applied according to the generic recommendations for each portfolio quadrant of the Kraljič matrix. Therefore, the work presented in Chapter 4 focused on assessing whether and how the application of tactical sourcing levers varies among 'noncritical', 'leverage', 'bottleneck' and 'strategic' purchases. To achieve this aim, 107 sourcing projects were classified by 'strategic importance' and 'supply risk' and allocated to the quadrants of the Kraljič matrix.

Thereby the following sub-question was addressed:

RQ1.3.: Does the application of tactical sourcing levers vary according to 'strategic importance' and 'supply risk', as suggested by Kraljič and, if so, how?

As a result, sourcing lever profiles for each portfolio quadrant could be developed. They show how intense each tactical sourcing lever was used in each quadrant of the Kraljič matrix across the 107 analysed sourcing projects. These 
profiles could be formally tested with respect to differences and similarities. The findings demonstrate that sourcing lever profiles vary between the portfolio quadrants. Still, in variance to previous suggestions, all tactical sourcing levers were applied to each portfolio quadrant.

Based on these results, the chapter has important implications for the ongoing discourse on the Kraljič matrix and purchasing portfolio models in general:

At the theoretical level, this chapter addresses earlier criticism regarding the generic recommendations made for each quadrant of the Kraljič matrix. Previously, it has been hypothesized that, different from the common impression made by earlier studies and textbooks, tactical sourcing levers are not applied as alternatives; rather, a mix of the entire range of tactical sourcing levers is utilized with respect to each portfolio quadrant (Canièls and Gelderman, 2005; Cox, 2014; Hesping and Schiele, 2015). This study adds empirically-based descriptive realism to the rather conceptual and normative textbook recommendations for the use of sourcing tactics. Thereby, the study findings show that existing textbooks may need to be revised. Existing textbooks presented a rather deterministic perspective on portfolio models. In particular, in available publications, several strategic recommendations and tactics are limited exclusively to a single portfolio cell. For example, efficient processing is deemed applicable for noncritical purchases only, whereas exploitation of purchasing power is limited to leverage items, and strategic partnerships are only formed for strategic items (Cavinato, 2006; Handfield et al., 2009; Johnson et al., 2011; Lysons and Farrington, 2012; Monczka et al., 2011; Van Weele, 2010). However, findings presented in this chapter show that each of the seven core tactical sourcing levers was in practice applied to all four portfolio quadrants. More specifically, data analysis revealed that 'volume bundling' and 'price evaluation' were extensively applied to all quadrants, while other tactics where additively pursued when strategic importance increased and supply risk declined. This observation suggests that, in contrast to the pertinent textbooks, in practice, the application of tactical sourcing levers within the Kraljič matrix is additive, rather than exclusive. As another theoretical contribution, the study provides evidence that purchases distinguish between two groups of tactical sourcing levers. More specifically, 'volume bundling', 'price evaluation' and 'extension of supply base' are primarily transaction-oriented and focus on 'capturing existing value' (O'Brien, 2012; Schiele et al., 2011a; Schumacher et 
al., 2008). These levers are most frequently applied in practice, regardless of the portfolio quadrant. On the other hand, 'product optimisation', 'process optimisation', 'optimisation of supply relationship' and 'category-spanning optimisation' are predominantly relationship-oriented and focus on 'creating value' together with suppliers (O'Brien, 2012; Schiele et al., 2011a; Schumacher et al., 2008). These levers are used the least across all portfolio quadrants. A dominant credo in existing research is the superiority of relationship-orientation over transaction-orientation in purchasing (Chen et al., 2004; Sheth and Sharma, 1997). However, this study revealed contrary findings, as transaction-oriented sourcing levers clearly dominated relationship-oriented ones in all portfolio quadrants. Furthermore, previous findings give the impression that purchases in each portfolio quadrant require the same attention and that portfolio models are not a suitable tool for prioritizing sourcing activities (O'Brien, 2012). However, findings presented in this chapter show that purchasers clearly concentrated their efforts on leverage and strategic purchases, while dedicating less effort to noncritical and leverage purchases.

At the practical level, Chapter 4 presents sourcing lever profiles for each quadrant of the Kraljič matrix. Hence, practitioners might use the presented operationalization of the Kraljič matrix to configure a set of sourcing tactics for each portfolio quadrant. The presented sourcing lever profiles might also be employed as a checklist to identify cost savings potentials for each portfolio quadrant. Thereby, the findings delineated in this chapter indicate that all tactical sourcing levers might be relevant to each portfolio quadrant of the Kraljič matrix. Accordingly, practitioners are encouraged to consider transactional sourcing levers for the strategic portfolio quadrant as well, even though textbooks recommend use of relationship-oriented levers.

The findings presented in Chapter 4 can serve as a starting point for further research in this field. For example, it might be fruitful to conduct further tactical-level analyses in order to elucidate why purchasers put more efforts into transaction-oriented than into relationship-oriented approaches, as well as determine if trade-offs exist between the two identified groups of tactical sourcing levers, as Schiele et al. (2011a) suggested. Based on the Kraljič matrix, authors that proposed other portfolio models have developed further dimensions to describe the sourcing context (Bensaou, 1999; Olsen and Ellram, 1997). Future research might adopt the approach used in the work presented in Chapter 4 , while including other category dimensions. This would allow further insights 
to be gained on the patters of sourcing lever application under various conditions.

\subsubsection{Chapter 5: The cost and innovation effect of sourcing levers - empirical evidence at the category level}

In Chapter 5, the direct relationship that tactical sourcing levers have with cost and innovation performance was tested empirically. A purchaser's daily challenge is to generate savings. Surprisingly, academic research on the tactical sourcing levers that exert the greatest influence on cost reduction and innovation at the category level of purchasing has been scarce. Hence, it remained unclear to which extant tactical sourcing levers contribute to a sourcing project's cost and innovation performance (Luzzini et al., 2012; Schiele et al., 2011a). To fill this gap, PLS-SEM was employed in this study, in order to evaluate the influence of tactical sourcing levers on performance. The data gathered from 107 sourcing projects served as model inputs. In a stepwise approach, the performance effects of tactical sourcing levers were tested in 10 different structural models.

Thereby, the following sub-question has been addressed:

RQ1.4.: Does the application of particular sourcing levers explain differences in a sourcing category's purchasing performance?

As a result, it could be found that most tactical sourcing levers have only a weak effect on cost and innovation performance (see Figure 11, p. 111). Only 'product optimization' showed a strong effect on innovation performance. It was surprising that 'volume bundling' and 'price evaluation' showed little effect on cost performance, which previously have been described as a main contributor to cost performance (Nollet et al., 2005). A surprising finding was that 'price evaluations' (Ellram, 1996), which were mainly concerned with a cost reduction approach, had a very highly significant positive impact on innovation performance.

In this chapter, several contributions for theory and practice were presented:

At the theoretical level, the findings address the need that "research would profit from avoiding inquiries into any single lever, alone and without taking the other levers into consideration" (Schiele et al., 2011a, p. 332). The work reported in Chapter 5 goes beyond that conducted in existing publications by providing results from a large-scale, empirical and simultaneous analysis of all 
seven core tactical sourcing levers, discussing their infleuce on cost and innovation performance at the category level. The findings presented in this chapter highlight the need to distinguish multiple levels of purchasing performance. Previous studies and corresponding measures mainly concentrated on the functional level of purchasing and its contribution to a firm's financial or commercial performance. However, when conducting analysis at the category level, the individual sourcing project comes into focus. At this level, the performance related to a group of a few similar products and suppliers becomes relevant, while contribution to overall firm success remains of minor importance. Furthermore, Chapter 5 provides evidence of the superior performance contribution of innovation. Findings yielded by the analyses confirm that innovation strongly contributes to cost performance. Although innovation-oriented levers exhibited limited direct impact on cost performance, several had a strong indirect impact mediated by innovation performance. Additionally, the study findings highlight the importance of price evaluations in purchasing. Surprisingly, in the analysed sample, price evaluations had a highly significant effect on innovation performance. Traditionally, price evaluations have been associated with a transactional character focused on challenging suppliers' prices through informational advantage in negotiations. However, this chapter presents findings confirming that 'price evaluations' contain further information that can be used to enhance innovation with suppliers. This confirms recent findings arguing for a value analysis approach in purchasing to build a fruitful basis for discussion with suppliers about the value propositions, product design and functionality of the offered concepts early on in the process (Monczka et al., 2011; Vrat, 2014; Wagner, 2008; Zengin and Ada, 2010).

The discussions and results presented in Chapter 5 have immediate practical relevance, as they reveal the tactics and actions that 'front-line' purchasing agents might take towards a sourcing project to reach the important goals of cost reduction and innovation. They further indicate that, for certain sourcing categories, innovations might be more relevant than are direct cost savings. Therefore, practitioners might use the results noted in this chapter to focus on the levers that have a significant impact on innovation performance. Furthermore, in the past, price analysis teams might have played an underrated role in the purchasing department. However, based on the insights provided in this chapter, firms may consider developing and implementing price evaluation 
and value analysis capabilities in order to increase both cost and innovation performance.

Future research might build on the work presented in this chapter and investigate differences in performance measurement among firm, functional and category levels of purchasing. These efforts could be guided by the following question: Which performance aspects play a role at the category level, in contrast to the requirements at the functional or firm level? This study intentionally focused on cost and innovation performance which are associated with different governance needs and sourcing tactics (Ateş et al., 2015; Baier et al., 2008; Terpend et al., 2011). Other authors have described further competitive priorities, such as flexibility, quality and sustainability. Hence, it would be advisable that future investigations repeat this study while taking into account additional performance variables.

\subsubsection{Chapter 6: The moderating role of the sourcing category - a contingency theory perspective}

In the previous chapters of this thesis, the focus was either on the link between tactical sourcing levers and category characteristics or tactical sourcing levers and performance. In contrast, in the work presented in Chapter 6, tactical sourcing levers, category characteristics and performance were analysed simultaneously. To improve performance, authors of previous studies suggested the need to tailor the choice of tactical sourcing levers to the requirements of the sourcing category and related contingency factors (González-Benito, 2010; Luzzini et al., 2012; Schiele et al., 2011a). Recently, Ateş (2014) emphasises that "understanding the supply market from which the purchases are made is amongst the most important tasks of purchasing professionals" (p. 149). However, in existing studies, investigations on the impact of sourcing category characteristics and the underlying supply market conditions on sourcing lever success have been neglected. Consequently, it remained unclear if and to which extent characteristics of the sourcing category explain differences in a sourcing lever's contribution to cost or innovation performance. Therefore, in the work presented in Chapter 6, moderation analysis was used to determine predicted values of performance for configurations of low (high) sourcing lever application and low (high) complexity, dynamism and competition, as important contingency factors of the sourcing category. 
Thereby, the following sub-question was addressed:

RQ1.5.: Do characteristics of the sourcing category explain the differences in a sourcing lever's contribution to cost or innovation performance?

As a result, it was found that more efforts do not always lead to better results. More efforts spend into the implementation of tactical sourcing levers often led to better performance in various sourcing category contexts. However, under some conditions of complexity, dynamism and competition, increased emphasis on certain tactical sourcing levers reduced sourcing performance (see Figure 13, p. 131 and Figure 14, p. 134).

Discussing these findings, the chapter has several implications for theory and practice:

At the theoretical level, in this study, contingency theory was extended to the category level of analysis for the first time. Previous studies on contingency theory mainly addressed the firm or functional level (González-Benito et al., 2010). The present study thus extends the existing knowledge by adapting measures for complexity, dynamism and competition to the category level of purchasing. Findings yielded by analyses discussed in Chapter 6 indicate that contingency factors explain large differences in performance gained from each tactical sourcing lever. While contingency theory has been used for several decades in the manufacturing context, it might provide a strong theoretical basis for future research to identify the relevant factors that explain performance differences in purchasing. Furthermore, the study highlights that existing generic recommendations of portfolio theory might not completely apply to the category level of purchasing. Beyond anecdotal evidence, few attempts have been made to ascertain if these generic recommendations yield expected performance under various conditions. Previous studies have described 'extension of supply base' and 'volume bundling' as implicit expectations to reach performance gains in purchasing (Carter et al., 2008; Nollet and Beaulieu, 2005). However, the findings presented in Chapter 6 show that 'extension of supply base' and 'volume bundling' may not be a 'condition sine qua non' for enhanced performance. Rather, under some conditions, dedicating more intensive efforts to these levers may even reduce performance. Another theoretical contribution of the present study stems from the finding that potential trade-offs among sourcing levers might occur. The analysed data shows that, under conditions of high complexity, 'extension of supply base' may be 
intensified to gain additional cost performance. However, under comparable conditions, this approach reduces innovation performance. Theoretical models might thus benefit from taking these effects into consideration.

At the practical level, similar to Chapter 5, in this chapter, the importance of price analysis was highlighted once again. In the analysed cases, dedicating more efforts to 'price evaluations' led to both greater cost and enhanced innovation performance under nearly all conditions. Furthermore, findings reported in this chapter show that the success of sourcing tactics is strongly influenced by the conditions of the sourcing category. In other words, if conditions change over time, previously successful sourcing levers might become less beneficial or even reduce overall performance if applied to a certain sourcing project. The chapter closes by providing practical guidelines for 'frontline' purchasers to verify whether the targeted tactical sourcing levers are actually beneficial for the sourcing conditions faced. This might help practitioners to focus their efforts on the most promising tactical sourcing levers.

Future research might build on the findings presented in this chapter. The concepts of contingency theory have been developed in various research fields over time. Future research might use this valuable knowledge as a strong theoretical basis and test whether the assumptions and findings of contingency theory can be transferred to the purchasing context. That way, future research might address the common critique that context factors, used in purchasing portfolio models to group sourcing categories, are too simplified and lack a theoretical foundation (Gelderman and Van Weele, 2005).

\subsection{LIMITATIONS: AREAS FOR IMPROVEMENT IN FUTURE STUDIES}

This study aimed to minimize methodological limitations by adopting a mixed method approach (i.e., a structured literature review, world café methodology and survey as a data collection instrument) and by taking precautions and remedies to increase validity and reliability. However, as in any study, there are some areas for improvement that may be addressed in future research in this field.

The work performed in this study was based on a hierarchical framework of purchasing strategy, as discussed in Chapter 2. Relevant concepts were placed in a hierarchical context to related concepts. Due to the recentness of the sourcing category and sourcing lever concepts, the literature review drew to a 
considerable extent on publications written for an audience of business professionals. Absence of a sound theoretical base has been observed in the majority of the current purchasing literature (Chicksand et al., 2012). Future research might improve this framework by analysing each hierarchical level of strategy development through various theoretical lenses. This approach might help in fostering the theoretical foundation and allow for a better understanding of related concepts, such as 'category management', 'sourcing levers', or 'supplier portfolio management'. Similarly, other selections of keywords and search strategies in literature databases might yield further insights into each level of analysis.

As its major strength, this study relied on collaboration with 'front-line' purchasing agents and their knowledge about the sourcing context and tactics. Previous studies mainly focused on higher-level management opinions, resulting in the omission of the 'front-line' staff experience at the category level in purchasing. Consequently, the data collection performed in this work intentionally focused on one large, global automotive OEM. This facilitated intense academic-practitioner collaboration and allowed access to the knowledge of a comparable and reasonably large group of 'front-line' purchasing agents within a consistent organizational context. Findings from the automotive industry are generally expected to be more generalizable than those pertaining to other industries, as the globalized automotive supply chains are highly competitive and include a large variety of sourcing categories (Droege, 1998; Taylor and Taylor, 2008). Nonetheless, further data collection and testing of the proposed relationships in other industries, including indirect, servicebased purchases is desirable. In this work, distinct automotive industry-factors might have favoured certain context variables, tactical sourcing levers or performance outcomes over others. Hence, broader cross-industrial investigations across more regions and cultures might help to strengthen the applicability of the findings across a wider range of research problems.

Research on tactical sourcing levers can still be considered as a work in progress. In the index development process, the present study focused on the knowledge of purchasing-related practitioners. However, purchasing agents increasingly work in cross-functional teams, which influences their range and choice of tactical sourcing levers. Future research might thus broaden the evaluation of tactical sourcing levers and include further supply market functions, such as engineering, quality and logistics into the research process. 
The analysis performed in this work was based on primary, subjective data and was grounded in recent literature, which is a common approach in social sciences (Hair et al., 2010). Although remedies, such as intense pre-tests and assurance of anonymity to the respondents, have been taken, the findings might be influenced by personal opinions and judgments of the respondents. Therefore, future research might repeat this study using objective performance data (Ketokivi and Schroeder, 2004).

Furthermore, especially in the automotive industry, new technologies are constantly being integrated into the product portfolio, such as digitalization of the car. Consequently, literature and practitioners' opinions can vary over time and affect how tactical sourcing levers and corresponding activities are framed and used. Future research might thus focus on monitoring these changes in order to investigate how 'front-line' purchasing agents or sourcing teams address upcoming challenges in supply markets and technology.

To avoid bias arising from information recall, the supplier nomination phase was chosen as a point of reference when purchasers responded to the survey. Every time as supply contract was registered in the IT system during the survey time frame, the responsible purchasing agent was visited by the researcher and the survey was completed jointly. That way, maximum validity was ensured, generating high quality data (Srinivasan and Ratchford, 1991). However, sourcing projects characterized by low cost performance are underrepresented in the current data set, likely due to the respondents' inclination to overestimate performance at the point of supplier nomination. In practice, it is likely that the actually realised performance after several months would be very different due to later technical changes or unidentified risks over the life cycle or product development phase. Future studies might take this issue into account and evaluate the long-term performance of sourcing projects using a longitudinal approach. Such methodology might also help uncover dynamic relationships among tactical sourcing levers, context and performance, as suggested by Cox (2014).

Notwithstanding these limitations, this study is indeed a major step forward in the effort to elucidate previously insufficiently explored category level of analysis. Its findings equip academia with the measures to investigate tactical sourcing levers and sourcing category performance in various contexts and conditions. This might inspire future research on tactical sourcing levers and sourcing categories and help in bridging the gap between theory and practice. 


\section{ACADEMIC OUTPUT PER CHAPTER}

\section{Chapter 2}

This chapter is based on:

Hesping, F.H., Schiele, H., 2015. Purchasing strategy development: A multilevel review.

- The paper has been published in the Journal of Purchasing and Supply Management 21, 138-150 (ISI Impact factor 2014: 1.609; SCImago Journal Rank (SJR) 2013: 0.924)

Partially, the following publication also relies on findings from this chapter:

- Hesping, F.H., Schiele, H., 2013. Towards a framework for strategy in purchasing: German and English language literature, Published in Supply Management Research. Gabler Verlag, Wiesbaden pp. 57-86.

An earlier version has been presented at:

- 2012: Doctoral Symposium, Cologne Business School, Cologne Germany

- 2013: $6^{\text {th }}$ Scientific Symposium “Supply Management”, BME, University of Würzburg

- 2013: AutoUni Research Colloquium, Wolfsburg, Germany

- 2013: $22^{\text {nd }}$ IPSERA Conference, Nantes, France

- 2013: IFPSM summer school, Salzburg, Austria

- 2014: Scientific Symposium "Purchasing", $16^{\text {th }}$ Industrieforum, Wolfsburg, Germany 


\section{Chapter 3}

This chapter is based on:

Hesping, F.H., Schiele, H., 2015. Sourcing tactics to achieve cost savings: developing a formative method of measurement

- The paper has been accepted for publication in the "International Journal of Procurement Management" (SCImago Journal Rank (SJR) 2013: $0.254)$

An earlier version has been presented at:

- 2013: AutoUni Research Colloquium, Wolfsburg, Germany

- 2014: $21^{\text {st }}$ EurOMA Conference, Palermo, Italy

- 2014: Scientific Symposium “Purchasing", $16^{\text {th }}$ Industrieforum, Wolfsburg, Germany

- 2014: UTIPS Research retreat, Renesse, The Netherlands

- 2015: $24^{\text {th }}$ IPSERA Conference, Amsterdam, The Netherlands

\section{Chapter 4}

This chapter is based on:

Hesping, F.H., Schiele, H., 2015. Matching sourcing tactics with the Kraljič matrix: empirical evidence on purchasing portfolios

- The paper has been accepted for review by the "International Journal of Production Economics" (SCImago Journal Rank (SJR) 2013: 2.393)

An earlier version has been presented at:

- 2014: Autouni Research Colloquium, Wolfsburg, Germany

- $2015: 24^{\text {th }}$ IPSERA Conference, Amsterdam, The Netherlands

\section{Chapter 5}

This chapter is based on:

Hesping, F.H., Schiele, H., 2015. Sourcing tactics for cost reduction and innovation: empirical evidence at the category level of performance 
- The paper has been submitted for review a reputable, international journal in the area of purchasing and supply management

An earlier version has been presented at:

- 2015: $22^{\text {nd }}$ EurOMA Conference, Neuchâtel, Switzerland

\section{Chapter 6}

This chapter is based on:

Hesping, F.H., Schiele, H., 2015. Sourcing tactics to achieve cost savings and innovation: a contingency theory perspective

- The paper has been submitted for review to a reputable, international journal in the area of operations management

An earlier version has been presented at:

- 2015: $22^{\text {nd }}$ EurOMA Conference, Neuchâtel, Switzerland 



\section{APPENDIX}

Table 17: Publications by addressed hierarchical level

\begin{tabular}{|c|c|c|c|c|c|c|c|}
\hline $\begin{array}{l}\text { Language } \\
\text { Source }\end{array}$ & 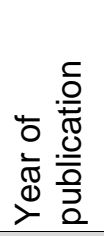 & 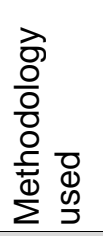 & 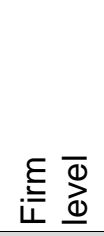 & 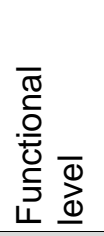 & 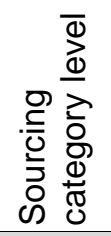 & 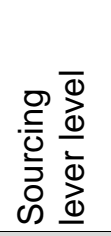 & 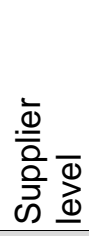 \\
\hline \multicolumn{8}{|l|}{ German-language books } \\
\hline Bräkling and Oidtmann & 2012 & $\mathrm{CO}$ & & & $\bullet$ & $\bullet$ & $\bullet$ \\
\hline Stollenwerk & 2012 & $\mathrm{CO}$ & & $\bullet$ & $\bullet$ & $\bullet$ & $\bullet$ \\
\hline Büsch & 2011 & $\mathrm{CO}$ & & & $\bullet$ & $\bullet$ & $\bullet$ \\
\hline Fuchs and Kaufmann & 2010 & $\mathrm{CO}$ & & & $\bullet$ & & $\bullet$ \\
\hline Göpfert and Grünert & 2010 & $S$ & & & $\bullet$ & $\bullet$ & $\bullet$ \\
\hline Appelfeller and Buchholz & 2010 & $\mathrm{CO}$ & $\bullet$ & $\bullet$ & $\bullet$ & $\bullet$ & $\bullet$ \\
\hline Hess & 2010 & $\mathrm{CO}$ & & $\bullet$ & $\bullet$ & $\bullet$ & $\bullet$ \\
\hline Large & 2009 & $\mathrm{CO}$ & & $\bullet$ & $\bullet$ & & $\bullet$ \\
\hline Schuh et al. & 2008 & $\mathrm{CO}$ & & & $\bullet$ & $\bullet$ & $\bullet$ \\
\hline Schumacher et al. & 2008 & $\mathrm{CO}$ & $\bullet$ & $\bullet$ & $\bullet$ & $\bullet$ & $\bullet$ \\
\hline Arnold & 2006 & $\mathrm{CO}$ & & & $\bullet$ & $\bullet$ & $\bullet$ \\
\hline Jahns & 2005 & $S$ & & $\bullet$ & $\bullet$ & & \\
\hline Schuh and Bremicker & 2005 & $\mathrm{CO}$ & & & & $\bullet$ & \\
\hline Pfohl and Large & 2003 & $\mathrm{CO}$ & & $\bullet$ & & $\bullet$ & \\
\hline de Quervain and Wagner & 2003 & $\mathrm{CO}$ & & $\bullet$ & $\bullet$ & $\bullet$ & $\bullet$ \\
\hline Koppelmann & 2000 & $\mathrm{CO}$ & & $\bullet$ & $\bullet$ & $\bullet$ & $\bullet$ \\
\hline Boutellier and Zagler & 2000 & $\mathrm{CO}$ & & & $\bullet$ & & \\
\hline Arnold & 1997 & $\mathrm{CO}$ & $\bullet$ & $\bullet$ & $\bullet$ & & $\bullet$ \\
\hline Total $(\mathrm{N} 1=18)$ & & & 3 & 10 & 16 & 13 & 14 \\
\hline \multicolumn{8}{|l|}{ German-language papers } \\
\hline Amann & 2011 & $S$ & & & $\bullet$ & & \\
\hline Essig and Wagner & 2003 & $\mathrm{CO}$ & $\bullet$ & $\bullet$ & $\bullet$ & $\bullet$ & \\
\hline Arnold and Essig & 2000 & $\mathrm{CO}$ & & & & $\bullet$ & \\
\hline Kraljič & 1977 & $\mathrm{CO}$ & & $\bullet$ & $\bullet$ & $\bullet$ & \\
\hline Total $(\mathrm{N} 2=4)$ & & & 1 & 2 & 3 & 3 & 0 \\
\hline \multicolumn{8}{|l|}{ English-language books } \\
\hline Lysons and Farrington & 2012 & $\mathrm{CO}$ & $\bullet$ & $\bullet$ & $\bullet$ & & $\bullet$ \\
\hline O'Brien & 2012 & $\mathrm{CO}$ & & $\bullet$ & $\bullet$ & $\bullet$ & $\bullet$ \\
\hline
\end{tabular}


(continued)

\begin{tabular}{|c|c|c|c|c|c|c|c|}
\hline $\begin{array}{l}\text { Language } \\
\text { Source }\end{array}$ & 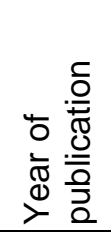 & 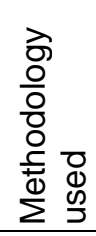 & $\underline{\underline{E}} \underline{\underline{\underline{D}}}$ & 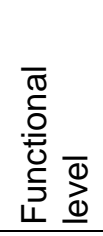 & 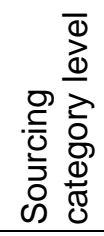 & 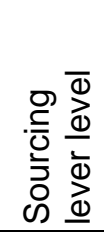 & 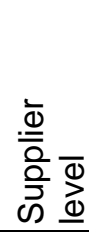 \\
\hline Burt et al. & 2011 & $\mathrm{CO}$ & & $\bullet$ & $\bullet$ & & $\bullet$ \\
\hline Sollish and Semanik & 2011 & $\mathrm{CO}$ & & $\bullet$ & $\bullet$ & & $\bullet$ \\
\hline Gadde et al. & 2010 & $\mathrm{CO}$ & & $\bullet$ & $\bullet$ & & $\bullet$ \\
\hline Johnson et al. & 2010 & $\mathrm{CO}$ & $\bullet$ & $\bullet$ & $\bullet$ & & $\bullet$ \\
\hline Van Weele & 2010 & $\mathrm{CO}$ & & $\bullet$ & $\bullet$ & & $\bullet$ \\
\hline Benton & 2009 & $\mathrm{CO}$ & & $\bullet$ & & $\bullet$ & $\bullet$ \\
\hline Handfield et al. & 2009 & $\mathrm{CO}$ & $\bullet$ & $\bullet$ & $\bullet$ & & $\bullet$ \\
\hline Baier & 2008 & $S$ & $\bullet$ & $\bullet$ & $\bullet$ & $\bullet$ & \\
\hline Baily et al. & 2008 & $\mathrm{CO}$ & & $\bullet$ & $\bullet$ & & $\bullet$ \\
\hline Cousins et al. & 2008 & $\mathrm{CO}$ & $\bullet$ & $\bullet$ & $\bullet$ & & $\bullet$ \\
\hline Monczka et al. & 2008 & $\mathrm{CO}$ & $\bullet$ & $\bullet$ & $\bullet$ & $\bullet$ & $\bullet$ \\
\hline Moser & 2007 & $S$ & & $\bullet$ & $\bullet$ & & $\bullet$ \\
\hline Matthyssens et al. & 2006 & $\mathrm{CO}$ & & $\bullet$ & & & \\
\hline Carter & 2006 & $\mathrm{CO}$ & & & $\bullet$ & & $\bullet$ \\
\hline Quayle & 2006 & $\mathrm{CO}$ & $\bullet$ & $\bullet$ & & & \\
\hline Dubois and Wynstra & 2005 & CS & & & $\bullet$ & & \\
\hline Burt et al. & 2003 & $\mathrm{CO}$ & & $\bullet$ & $\bullet$ & & $\bullet$ \\
\hline Laseter & 1998 & $\mathrm{CO}$ & & & $\bullet$ & & $\bullet$ \\
\hline Dobler et al. & 1990 & $\mathrm{CO}$ & $\bullet$ & $\bullet$ & $\bullet$ & & \\
\hline Leenders and Blenkhorn & 1988 & $\mathrm{CO}$ & $\bullet$ & $\bullet$ & $\bullet$ & & $\bullet$ \\
\hline Total (N3=22) & & & 9 & 19 & 19 & 4 & 17 \\
\hline \multicolumn{8}{|l|}{ English-language papers } \\
\hline Karjalainen and Salmi & 2012 & $S$ & & & $\bullet$ & $\bullet$ & \\
\hline Luzzini et al. & 2012 & $S$ & & & $\bullet$ & & \\
\hline Hartmann et al. & 2012 & $\mathrm{~S}$ & & $\bullet$ & $\bullet$ & & \\
\hline Akin et al. & 2011 & $S$ & & & $\bullet$ & & \\
\hline Pohl & 2011 & CS & & $\bullet$ & $\bullet$ & $\bullet$ & \\
\hline Schiele et al. & 2011 & $S$ & & & $\bullet$ & $\bullet$ & \\
\hline Terpend et al. & 2011 & $S$ & $\bullet$ & $\bullet$ & $\bullet$ & & $\bullet$ \\
\hline Akin et al. & 2010 & $S$ & & & $\bullet$ & $\bullet$ & \\
\hline Day et al. & 2010 & L & & & & $\bullet$ & $\bullet$ \\
\hline González -Benito et al. & 2010 & $S$ & & $\bullet$ & & $\bullet$ & \\
\hline Lee and Drake & 2010 & CS & & & $\bullet$ & & $\bullet$ \\
\hline Heikkilä and Kaipa & 2009 & CS & & & $\bullet$ & & \\
\hline Ahtonen and Virolainen & 2009 & CS & & $\bullet$ & $\bullet$ & & $\bullet$ \\
\hline Lawson et al. & 2009 & $S$ & & $\bullet$ & & $\bullet$ & $\bullet$ \\
\hline Svahn and Westerlund & 2009 & $\mathrm{CO}$ & & $\bullet$ & $\bullet$ & $\bullet$ & $\bullet$ \\
\hline Trautmann et al. & 2009 & CS & & & $\bullet$ & $\bullet$ & \\
\hline Trautmann et al. & 2009 & CS & & & $\bullet$ & $\bullet$ & \\
\hline Dubois and Fredriksson & 2008 & CS & & & & & $\bullet$ \\
\hline Rozemeijer & 2008 & $\mathrm{CO}$ & & • & & • & $\bullet$ \\
\hline
\end{tabular}


(continued)

\begin{tabular}{|c|c|c|c|c|c|c|c|}
\hline $\begin{array}{l}\text { Language } \\
\text { Source }\end{array}$ & 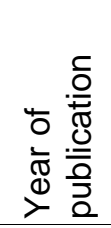 & 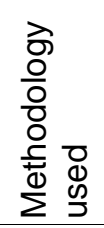 & 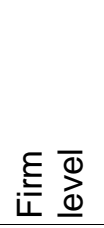 & 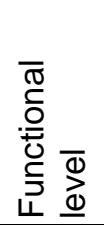 & 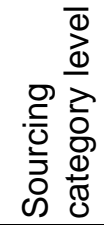 & 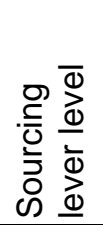 & 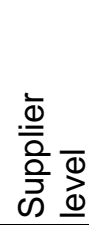 \\
\hline Steinle and Schiele & 2008 & CS & & & $\bullet$ & $\bullet$ & $\bullet$ \\
\hline Baier et al. & 2008 & $S$ & $\bullet$ & $\bullet$ & & $\bullet$ & \\
\hline Sanderson and Cox & 2008 & CS & & & $\bullet$ & & \\
\hline Cousins and Lawson & 2007 & $S$ & & & $\bullet$ & & $\bullet$ \\
\hline Caniëls and Gelderman & 2007 & $\mathrm{~S}$ & & & $\bullet$ & & \\
\hline González -Benito & 2007 & $S$ & & $\bullet$ & & $\bullet$ & \\
\hline Schiele & 2007 & $S$ & & & $\bullet$ & $\bullet$ & \\
\hline Zheng et al. & 2007 & $\mathrm{~L}$ & & $\bullet$ & & & \\
\hline Monczka and Markham & 2007 & $\mathrm{CO}$ & & & $\bullet$ & & $\bullet$ \\
\hline Quintens et al. & 2006 & $S$ & & $\bullet$ & & & \\
\hline Day and Lichtenstein & 2006 & $\mathrm{CO}$ & & & & $\bullet$ & $\bullet$ \\
\hline Gelderman and Semeijn & 2006 & CS & & $\bullet$ & $\bullet$ & & $\bullet$ \\
\hline Quintens et al. & 2006 & $\mathrm{~L}$ & & $\bullet$ & & & \\
\hline Loppacher et al. & 2006 & CS & $\bullet$ & $\bullet$ & & & \\
\hline Cousins & 2005 & $S$ & $\bullet$ & $\bullet$ & & & $\bullet$ \\
\hline Rendon & 2005 & CS & & $\bullet$ & $\bullet$ & $\bullet$ & $\bullet$ \\
\hline Canièls and Gelderman & 2005 & $S$ & & & $\bullet$ & $\bullet$ & \\
\hline Nollet et al. & 2005 & $\mathrm{CO}$ & & • & & $\bullet$ & \\
\hline Gelderman and Van Weele & 2005 & CS & & & $\bullet$ & & \\
\hline Ogden et al. & 2005 & CS & & $\bullet$ & & $\bullet$ & \\
\hline Rossetti and Choi & 2005 & $\mathrm{CO}$ & & $\bullet$ & $\bullet$ & $\bullet$ & \\
\hline Talluri and Narasimhan & 2004 & $S$ & & & & & $\bullet$ \\
\hline Wagner and Johnson & 2004 & CS & & & $\bullet$ & $\bullet$ & $\bullet$ \\
\hline Knudsen & 2003 & $\mathrm{CO}$ & $\bullet$ & $\bullet$ & & & \\
\hline Gelderman and Van Weele & 2003 & CS & & & $\bullet$ & & $\bullet$ \\
\hline Smeltzer et al. & 2003 & CS & & & $\bullet$ & $\bullet$ & $\bullet$ \\
\hline Rink et al. & 2003 & $\mathrm{CO}$ & & $\bullet$ & $\bullet$ & & \\
\hline Dubois and Pedersen & 2002 & $\mathrm{CO}$ & & & $\bullet$ & & $\bullet$ \\
\hline Carr and Pearson & 2002 & $S$ & & & & & \\
\hline Ellram et al. & 2002 & $S$ & & $\bullet$ & & & \\
\hline Gelderman and Van Weele & 2002 & $S$ & & & $\bullet$ & & $\bullet$ \\
\hline Ramsay & 2001 & $\mathrm{CO}$ & & $\bullet$ & & & \\
\hline Krause et al. & 2001 & $S$ & & $\bullet$ & & & \\
\hline Narasimhan and Das & 2001 & $S$ & & $\bullet$ & & & \\
\hline Ramsay & 2001 & $\mathrm{CO}$ & & $\bullet$ & & & \\
\hline Carr and Smeltzer & 2000 & $S$ & $\bullet$ & $\bullet$ & & & \\
\hline Petersen et al. & 2000 & $S$ & $\bullet$ & & & & \\
\hline Nellore and Söderquist & 2000 & CS & & & $\bullet$ & & $\bullet$ \\
\hline Nellore and Taylor & 2000 & CS & & & $\bullet$ & & \\
\hline Smith & 1999 & CS & & & $\bullet$ & & \\
\hline Harland et al. & 1999 & CS & & • & & & \\
\hline
\end{tabular}


(continued)

\begin{tabular}{|c|c|c|c|c|c|c|c|}
\hline $\begin{array}{l}\text { Language } \\
\text { Source }\end{array}$ & 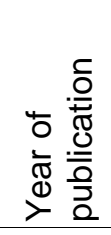 & $\begin{array}{l}\text { वे } \\
\frac{0}{0} \\
0 \\
0 \\
0 \\
\frac{0}{0} \\
\sum \frac{d}{2} \\
\end{array}$ & $\stackrel{\underline{\underline{\Sigma}}}{\bar{\Phi}}$ & 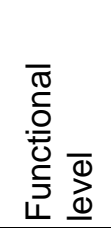 & 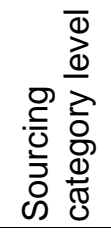 & 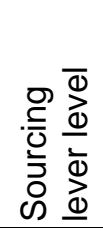 & 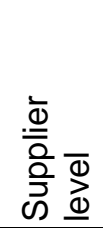 \\
\hline Carr and Pearson & 1999 & $S$ & $\bullet$ & $\bullet$ & $\bullet$ & $\bullet$ & $\bullet$ \\
\hline Goh et al. & 1999 & $S$ & $\bullet$ & $\bullet$ & & & \\
\hline Dyer et al. & 1998 & $S$ & & & $\bullet$ & & $\bullet$ \\
\hline Virolainen & 1998 & $\mathrm{~L}$ & & $\bullet$ & $\bullet$ & & $\bullet$ \\
\hline Narasimhan and Carter & 1998 & S & $\bullet$ & $\bullet$ & & $\bullet$ & \\
\hline Samli et al. & 1998 & $S$ & & $\bullet$ & & & \\
\hline Bozarth et al. & 1998 & $S$ & & $\bullet$ & & $\bullet$ & $\bullet$ \\
\hline Carr and Smeltzer & 1997 & $S$ & $\bullet$ & $\bullet$ & & & \\
\hline Olsen and Ellram & 1997 & $\mathrm{CO}$ & & & $\bullet$ & & $\bullet$ \\
\hline Birou et al. & 1997 & $S$ & & & $\bullet$ & $\bullet$ & \\
\hline Cox & 1996 & $\mathrm{CO}$ & & & $\bullet$ & & \\
\hline Ferguson et al. & 1996 & $S$ & & & & & \\
\hline Carter and Narasimhan & 1996 & $S$ & $\bullet$ & $\bullet$ & & & \\
\hline Chatterjee et al. & 1995 & $S$ & & & $\bullet$ & $\bullet$ & \\
\hline Brandes & 1994 & CS & & & $\bullet$ & $\bullet$ & \\
\hline Gadde and Hakansson & 1994 & $\mathrm{CO}$ & & $\bullet$ & & & \\
\hline Rajagopal and Bernard & 1994 & $\mathrm{CO}$ & $\bullet$ & $\bullet$ & & & \\
\hline Hadeler and Evans & 1994 & $\mathrm{CO}$ & & & $\bullet$ & & $\bullet$ \\
\hline Ellram and Carr & 1994 & $\mathrm{~L}$ & & $\bullet$ & & & \\
\hline Spekman et al. & 1994 & $\mathrm{CO}$ & $\bullet$ & $\bullet$ & & & \\
\hline Cavusgil et al. & 1993 & $\mathrm{CO}$ & & $\bullet$ & & & \\
\hline Monczka et al. & 1993 & $S$ & & & & & $\bullet$ \\
\hline Rajagopal and Bernard & 1993 & $\mathrm{CO}$ & & & $\bullet$ & & \\
\hline Watts et al. & 1992 & $\mathrm{CO}$ & $\bullet$ & $\bullet$ & & $\bullet$ & $\bullet$ \\
\hline Monczka and Trent & 1991 & $\mathrm{CO}$ & & $\bullet$ & & & $\bullet$ \\
\hline Ramsay and Wilson & 1990 & $\mathrm{CO}$ & & $\bullet$ & & & $\bullet$ \\
\hline Pearson and Gritzmacher & 1990 & $\mathrm{CO}$ & $\bullet$ & $\bullet$ & & & $\bullet$ \\
\hline Sutton & 1989 & CS & $\bullet$ & $\bullet$ & & & \\
\hline Caddick and Dale & 1987 & CS & $\bullet$ & $\bullet$ & & & \\
\hline Spekman & 1985 & $\mathrm{CO}$ & & $\bullet$ & & & \\
\hline Kraljič & 1983 & $\mathrm{CO}$ & & $\bullet$ & $\bullet$ & $\bullet$ & \\
\hline Spekman & 1981 & $\mathrm{CO}$ & $\bullet$ & $\bullet$ & & & \\
\hline Choffray and Lilien & 1980 & CS & & & $\bullet$ & & \\
\hline Rink & 1976 & CS & & $\bullet$ & & & \\
\hline Total (N4= 94) & & & 19 & 52 & 46 & 31 & 33 \\
\hline
\end{tabular}

CO: conceptual; L: literature review; CS: case study; S: survey 
Table 18: Tactical sourcing levers and corresponding activities

\section{Sourcing lever}

Activity
VB. Volume bundling

Bundling complementary products

Outsourcing/make-or-buy

Purchasing group/consortia

Reducing suppliers/sources

Single sourcing

Standardizing products/reducing variants

\section{PE. Price evaluation}

Cost or bid breakdown

Value engineering/ value analysis

Reverse (online) auctions

Activity-based costing

Life cycle costing analysis

Open book accounting

Linear performance pricing

Total cost of ownership analysis

Value stream mapping

Competitive price comparison

Target pricing/costing
Sources

Kaicker et al. (1995)

Kroes and Ghosh (2010)

Essig (2000); Nollet and Beaulieu (2005); Tella and Virolainen (2005); Wang and Archer (2007)

Stump (1995); Wagner and Bode (2006)

Wagner and Bode (2006)

Schoenherr and Mabert (2008)

\begin{tabular}{ll} 
& $(2000)$; Zengin and Ada (2010) \\
\hline ESB. Extension of supply base & \\
\hline Building up sources & Handfield et al. (2000); Krause et al. (1998) \\
$\begin{array}{l}\text { Global scouting } \\
\text { Global sourcing }\end{array}$ & $\begin{array}{l}\text { Sartor et al. (2014) } \\
\text { Cavusgil et al. (1993); Holweg et al. (2011); Kotabe and Murray } \\
\text { (2004); Mol et al. (2005) }\end{array}$ \\
Import sourcing & Nassimbeni (2006) \\
International outsourcing & Mol et al. (2005) \\
International purchasing offices & Jia et al. (2014b); Sartor et al. (2014) \\
International sourcing & Min et al. (1994); Mol et al. (2005); Nassimbeni (2006); Schiele et \\
& al. (2011a) \\
Multiple sourcing & Whitney et al. (2014) \\
Offshore sourcing & Nassimbeni (2006) \\
Supplier diversification & Whitney et al. (2014) \\
Supply base configuration & Wagner and Johnson (2004) \\
World-wide sourcing & Nassimbeni (2006) \\
\hline PRD. Product optimisation & \\
\hline Co-development & Fliess and Becker (2006); Wagner (2012) \\
Develop or buy decision & Wynstra et al. (2003) \\
Integrating development activities & Hong and Hartley (2011); Wynstra et al. (2003) \\
of different supplier & \\
\hline
\end{tabular}




\section{(continued)}

\section{Sourcing lever}

Activity

Modular product design

Product development collaboration

Product platforms

Purchasing integration in product development

Supplier integration/involvement in (collaborative) new product development

Value engineering

Sources

Danese and Filippini (2010); Hong and Hartley (2011); Luo et al. (2011); Parente et al. (2011); Salvador and Villena (2013)

Ylimäki (2014)

Salvador and Villena (2013); Thomas et al. (2014)

Hong and Hartley (2011); Lakemond et al. (2001); Williams and Smith (1990); Wynstra et al. (2003)

Atuahene-Gima (1995); Fliess and Becker (2006); Handfield et al. (1999); Jayaram (2008); Labro (2006); Parker et al. (2008); Ragatz et al. (2002); Salvador and Villena (2013); Smals and Smits (2012); Song and Di Benedetto (2008); Thomas (2013); Yeniyurt et al. (2014)

Labro (2006); Maffin and Braiden (2001); McGinnis and Vallopra (1999)

\section{PRC. Process optimisation}

Process standardization

Capacity management Manrodt and Vitasek (2004); Quintens et al. (2006b)

Collaborative processes operation Dekkers (2002)

Cao and Zhang (2011); Nakano (2009); Pramatari (2007); Ramanathan and Gunasekaran (2014)

Electronic data interchange

E-procurement Mukhopadhyay and Kekre (2002); Pramatari (2007)

Information sharing Puschmann and Alt (2005)

Process integration Cao and Zhang (2011) Cao and Zhang (2011)

Supply chain quality management Forker (1997); Foster Jr et al. (2011) Supply chain risk management Tai et al. (2010)

\section{OSR. Optimisation of supply relationship}

\begin{tabular}{ll}
\hline Becoming a preferred customer & Baxter (2012); Nagati and Rebolledo (2013); Nollet et al. (2012); \\
& Schiele et al. (2012a) \\
Dedicated investments & Nyaga et al. (2010); Yeung et al. (2013) \\
Develop strong partnership & Autry and Golicic (2010); Lui and Ngo (2012); Nyaga et al. (2010); \\
& Rese (2006); Rogers et al. (2007); Tuten and Urban (2001) \\
Ensure equitable treatment & Nollet et al. (2012) \\
Information sharing/exchange & Li et al. (2012b); Modi and Mabert (2007); Nollet et al. (2012); \\
& Nyaga et al. (2010); Rogers et al. (2007); Tuten and Urban (2001) \\
Joint action/events & Lui and Ngo (2012); Nollet et al. (2012) \\
Long-term commitment & Li et al. (2012a) \\
Profit/ cost sharing & Rese (2006) \\
Recognition and awards & Krause and Ellram (1997); Krause and Scannell (2002) \\
Reverse marketing & Nollet et al. (2012) \\
Strategic alliances & Lui and Ngo (2012) \\
Supplier development & Blonska et al. (2013); Ghijsen et al. (2010); Handfield et al. \\
& (2000); Krause and Ellram (1997); Krause et al. (1998); Krause \\
& and Scannell (2002); Li et al. (2012a); Modi and Mabert (2007); \\
& Nagati and Rebolledo (2013); Rogers et al. (2007); Wagner \\
& (2011) \\
& Krause and Ellram (1997); Krause and Scannell (2002); Nagati \\
& and Rebolledo (2013); Wagner (2011) \\
\hline
\end{tabular}


(continued)

Sourcing lever

Activity

Sources

\section{CSO. Category-spanning optimisation}

Category leadership

Cooperative purchasing

Cross-category competition

Cross-category demand
O'Keeffe and Fearne (2002)

Driedonks (2010); Englyst et al. (2008); Schotanus et al. (2010)

Bandyopadhyay (2009)

Bezawada et al. (2009); Cachon and Kök (2007); Chintagunta and Haldar (1998); Leeflang and Parreño-Selva (2012)

Cross-category marketing activities Song and Chintagunta (2006)

Optimizing technical aspects across sourcing categories
Agrawal et al. (2013); Thomas et al. (2014) 
Table 19: Formative indicators - descriptive statistics (sourcing levers)

\begin{tabular}{|c|c|c|c|}
\hline $\begin{array}{l}\text { Construct } \\
\text { Indicator }\end{array}$ & & Mean & $\begin{array}{l}\text { Std. } \\
\text { dev. }\end{array}$ \\
\hline VB. Volume bun & dling & & \\
\hline volumeB_1 & Concentrate volumes on one or very few suppliers. & 5.19 & 2.04 \\
\hline volumeB_2 & Bundling with subsidiaries and regions. & 4.21 & 2.39 \\
\hline volumeB_3 & Linking new allocations with current series volumes. & 4.45 & 2.29 \\
\hline volumeB_4 & Bundling of several requests into a package with a large volume. & 4.02 & 2.44 \\
\hline global item & $\begin{array}{l}\text { To summarize, to which extent have activities for 'volume } \\
\text { bundling' been used in this sourcing project? }\end{array}$ & 4.64 & 1.87 \\
\hline PE. Price evalua & ation & & \\
\hline priceE_1 & Determination of own price target for negotiation preparation. & 5.23 & 1.78 \\
\hline priceE_2 & Gather more (also technically different) offers than is customary. & 3.46 & 1.81 \\
\hline priceE_3 & Recalculation of the offered prices. & 4.21 & 2.31 \\
\hline global item & $\begin{array}{l}\text { To summarize, to which extent have activities for 'price } \\
\text { evaluations' been used in this sourcing project? }\end{array}$ & 4.69 & 1.53 \\
\hline ESB. Extension & of supply base & & \\
\hline eSupplyBase_1 & Building up suppliers; e.g. by increasing volumes stepwise. & 3.89 & 2.28 \\
\hline eSupplyBase_2 & Drive forward use of suppliers from cost-competitive countries. & 3.17 & 2.28 \\
\hline eSupplyBase_3 & $\begin{array}{l}\text { Drive forward (deep) localization, thereby expanding capacities } \\
\text { near place of demand. }\end{array}$ & 2.81 & 2.06 \\
\hline global item & $\begin{array}{l}\text { To summarize, to which extent have activities for 'extension of } \\
\text { supply base' been used in this sourcing project? }\end{array}$ & 3.62 & 1.87 \\
\hline PRD. Product of & ptimisation & & \\
\hline productOpt_1 & Drive forward standardization of parts (reduction of variants). & 2.72 & 1.98 \\
\hline productOpt_2 & $\begin{array}{l}\text { Drive forward use of cost-effective technology/functions } \\
\text { (technical simplification). }\end{array}$ & 2.79 & 1.90 \\
\hline productOpt_3 & $\begin{array}{l}\text { Early involvement in development teams to e.g. encourage } \\
\text { product improvements with suppliers. }\end{array}$ & 2.93 & 1.90 \\
\hline productOpt_4 & $\begin{array}{l}\text { Request technical alternatives from suppliers, e.g. } \\
\text { innovation/concept competition. }\end{array}$ & 2.70 & 1.95 \\
\hline global item & $\begin{array}{l}\text { To summarize, to which extent have activities for 'product } \\
\text { optimisation' been used in this sourcing project? }\end{array}$ & 2.86 & 1.62 \\
\hline PRC. Process o & ptimisation & & \\
\hline processOpt_1 & $\begin{array}{l}\text { Optimize (inbound) logistics to e.g. save on packaging or } \\
\text { condense transport. }\end{array}$ & 2.60 & 2.00 \\
\hline processOpt_2 & $\begin{array}{l}\text { Quality dialogues with suppliers to e.g. avoid release costs and } \\
\text { quality defects. }\end{array}$ & 2.99 & 1.86 \\
\hline processOpt_3 & $\begin{array}{l}\text { Initiate early capacity planning with suppliers to e.g. avoid } \\
\text { bottlenecks and excessive capacities. }\end{array}$ & 4.12 & 2.15 \\
\hline global item & $\begin{array}{l}\text { To summarize, to which extent have activities for 'process } \\
\text { optimisation' been used in this sourcing project? }\end{array}$ & 3.47 & 1.57 \\
\hline OSR. Optimisati & ion of supply relationship & & \\
\hline osRelation_1 & $\begin{array}{l}\text { Increase appeal with suppliers (Preferred Customer) to e.g. gain } \\
\text { preferred access to innovations or capacities. }\end{array}$ & 3.31 & 1.86 \\
\hline osRelation_2 & $\begin{array}{l}\text { Building up specific capabilities of suppliers; e.g. with joint } \\
\text { supplier qualification. }\end{array}$ & 3.24 & 1.78 \\
\hline osRelation_3 & $\begin{array}{l}\text { Use individual contract conditions to e.g. arrange specific price } \\
\text { amendments or incentives for suppliers. }\end{array}$ & 2.78 & 2.06 \\
\hline global item & $\begin{array}{l}\text { To summarize, to which extent have activities for 'optimisation of } \\
\text { supply relationship' been used in this sourcing project? }\end{array}$ & 3.22 & 1.62 \\
\hline
\end{tabular}




\section{(continued)}

Construct

Std.

Indicator

Mean

dev.

CSO. Category-spanning optimisation

categoryS_1 Avoid conflicts with adjacent sourcing categories, e.g. in supplier strategy or inbound logistics.

categoryS_2 Bundle volumes with adjacent sourcing categories, e.g. main and

categoryS_3 Optimize technical aspects in collaboration with adjacent sourcing categories, e.g. promote cooperation between suppliers $\quad 2.10 \quad 1.65$ of common components.

global item To summarize, to which extent have activities for 'categoryspanning optimisation' been used in this sourcing project?

7-point Likert scale anchored at $1=$ 'not used' and 7 = 'extensively used'

$\mathrm{N}=107$ 
Table 20: Reflective indicators - descriptive statistics (Kraljič matrix)

\section{Construct}

Indicator

Mean Std. dev.

\begin{tabular}{|c|c|c|c|}
\hline \multicolumn{4}{|c|}{ IMP. Strategic importance - based on Lau et al. (1999) and Ellis et al. (2010) } \\
\hline imp_1 & $\begin{array}{l}\text { This sourcing project makes up a high proportion of the annual } \\
\text { purchasing volume (monetary) of our field. }\end{array}$ & 3.33 & 1.81 \\
\hline imp_2* & This sourcing project is of high priority to our management. ${ }^{*}$ & 3.85 & 2.03 \\
\hline imp_3 & $\begin{array}{l}\text { The end customer easily recognizes the quality of the requested } \\
\text { parts. }\end{array}$ & 3.33 & 2.19 \\
\hline imp_4 & $\begin{array}{l}\text { The requested parts are more important than most other parts in } \\
\text { our field. }\end{array}$ & 3.20 & 1.79 \\
\hline imp_5 & $\begin{array}{l}\text { This sourcing project is more important than most other sourcing } \\
\text { processes in our field. }\end{array}$ & 3.15 & 1.76 \\
\hline
\end{tabular}

RISK. Supply risk - based on Hunter et al. (2006), Schoenherr and Mabert (2011) and Wagner and Bode (2006)

\begin{tabular}{|c|c|c|c|}
\hline risk_1 & $\begin{array}{l}\text { Many alternative suppliers can ensure the supply of parts during } \\
\text { capacity bottlenecks. }\end{array}$ & 2.34 & 1.70 \\
\hline risk_2 & $\begin{array}{l}\text { Many alternative suppliers can ensure the supply of parts in the } \\
\text { event of supply problems. }\end{array}$ & 2.33 & 1.70 \\
\hline risk_3 & $\begin{array}{l}\text { Many alternative suppliers can ensure the supply of parts if a } \\
\text { supplier is eliminated. }\end{array}$ & 2.45 & 1.67 \\
\hline risk_4 & We can choose between a variety of alternative suppliers. & 2.75 & 1.75 \\
\hline risk_5 & Many alternative suppliers are possible for these parts. & 2.89 & 1.69 \\
\hline risk_6 & $\begin{array}{l}\text { There are many alternative suppliers who can supply us with } \\
\text { these parts. }\end{array}$ & 2.70 & 1.71 \\
\hline risk_7 & $\begin{array}{l}\text { Many alternative suppliers have the necessary capacities to } \\
\text { manufacture these parts. }\end{array}$ & 3.07 & 1.66 \\
\hline
\end{tabular}

7-point Likert scale anchored at 1 = 'strongly disagree' and 7 = 'strongly agree' *Item dropped due to low loading $\mathrm{N}=107$ 
Table 21: Reflective indicators - descriptive statistics (performance)

\begin{tabular}{|c|c|c|c|}
\hline \multicolumn{4}{|c|}{$\begin{array}{l}\text { Construct } \\
\text { Indicator }\end{array}$} \\
\hline \multicolumn{4}{|c|}{ CP. Cost performance - based on Krause et al. (2001) and Terpend et al. (2011) } \\
\hline cost_1 & $\begin{array}{l}\text { It has been possible to achieve higher than average reductions in } \\
\text { cost. }\end{array}$ & 4.91 & 1.76 \\
\hline cost_2 & $\begin{array}{l}\text { It has been possible to achieve more cost-effective than average } \\
\text { total costs. }\end{array}$ & 4.64 & 1.72 \\
\hline cost_3 & We are satisfied with the low total costs achieved. & 5.59 & 1.27 \\
\hline cost_4 & We are satisfied with the low part costs achieved. & 5.70 & 1.17 \\
\hline cost_5 & $\begin{array}{l}\text { We are satisfied with the overall cost-effective conditions of the } \\
\text { completed contract. }\end{array}$ & 5.50 & 1.25 \\
\hline cost_6 & $\begin{array}{l}\text { The reductions in cost achieved are considerably higher than } \\
\text { expected. }\end{array}$ & 4.44 & 1.81 \\
\hline cost_7 & $\begin{array}{l}\text { The total costs achieved are considerably better value than } \\
\text { expected. }\end{array}$ & 4.36 & 1.78 \\
\hline \multicolumn{4}{|c|}{$\begin{array}{l}\text { IP. Innovation performance - based on Azadegan and Dooley (2010). Schiele et al. (2011b) and } \\
\text { Terpend et al. (2011) }\end{array}$} \\
\hline inno_1 & $\begin{array}{l}\text { It has been possible to achieve more product and process } \\
\text { improvements than average. }\end{array}$ & 2.74 & 1.62 \\
\hline inno_2 & $\begin{array}{l}\text { It has been possible to identify more useful ideas for the } \\
\text { improvement of the requested parts than average with the } \\
\text { supplier. }\end{array}$ & 2.69 & 1.60 \\
\hline inno_3 & $\begin{array}{l}\text { Product and process improvements have been created and are } \\
\text { likely to be implemented. }\end{array}$ & 3.09 & 1.69 \\
\hline inno_4 & $\begin{array}{l}\text { It has been possible to identify useful ideas for the improvement } \\
\text { of the requested parts with the supplier. }\end{array}$ & 2.76 & 1.57 \\
\hline inno_5 & $\begin{array}{l}\text { The properties of the requested parts have been or are likely to } \\
\text { be improved considerably than before the sourcing process. }\end{array}$ & 2.53 & 1.54 \\
\hline inno_6 & $\begin{array}{l}\text { It has been possible to identify progressive ideas or novel } \\
\text { capacities in the supplier pool. }\end{array}$ & 2.50 & 1.57 \\
\hline inno_7 & $\begin{array}{l}\text { The product and process improvements achieved are } \\
\text { considerably better than expected. }\end{array}$ & 2.48 & 1.46 \\
\hline inno_8 & $\begin{array}{l}\text { It has been possible to identify considerably more useful ideas } \\
\text { for improvements of the requested parts than expected. }\end{array}$ & 2.37 & 1.48 \\
\hline
\end{tabular}

7-point Likert scale anchored at $1=$ 'strongly disagree' and $7=$ 'strongly agree'

$\mathrm{N}=107$ 
Table 22: Reflective indicators - descriptive statistics (contingency factors)

\section{Construct}

Indicator

Std.

TC. Technological complexity - based on Lau et al. (1999)

\begin{tabular}{ll}
\hline technC_1* & There are few comparable technical alternatives (substitute). ${ }^{*}$ \\
technC_2 & These parts are technically complicated and have a number of
\end{tabular} complex mechanisms.

technC_3

It is complex or difficult to compare technical alternatives.

$4.12 \quad 1.92$

technC_4

A high level of specialist knowledge is required to understand product and manufacturing technology.

$3.89 \quad 1.81$

$4.36 \quad 1.88$

\begin{tabular}{|c|c|c|c|}
\hline \multicolumn{4}{|c|}{ TD. Technological dynamism - based on Trkman and McCormack (2009) } \\
\hline technD_1 & Product and manufacturing technology changes very rapidly. & 2.68 & 1.52 \\
\hline technD_2 & $\begin{array}{l}\text { It is difficult to predict how product and manufacturing technology } \\
\text { will be in } 2-3 \text { years. }\end{array}$ & 2.72 & 1.66 \\
\hline technD_3 & $\begin{array}{l}\text { Technical developments result in a large number of } \\
\text { modifications. }\end{array}$ & 2.87 & 1.79 \\
\hline technD_4 & $\begin{array}{l}\text { There are often considerable modifications in product and } \\
\text { manufacturing technology. }\end{array}$ & 2.50 & 1.49 \\
\hline \multicolumn{4}{|c|}{ TCT. Technological competition - based on Li et al. (2012b) } \\
\hline technCT_1 & $\begin{array}{l}\text { The ineffective process for technical innovations restricts the } \\
\text { growth of many suppliers. }\end{array}$ & 2.74 & 1.39 \\
\hline technCT_2 & $\begin{array}{l}\text { Access to technical innovations is difficult and late for many } \\
\text { suppliers. }\end{array}$ & 2.83 & 1.50 \\
\hline technCT_3 & $\begin{array}{l}\text { Technical innovations are mostly offered by one and the same } \\
\text { supplier. }\end{array}$ & 3.27 & 1.65 \\
\hline technCT_4 & Only very few suppliers have access to technical innovations. & 3.12 & 1.55 \\
\hline technCT_5 & Only very few suppliers benefit from technical innovations. & 3.40 & 1.66 \\
\hline \multicolumn{4}{|c|}{ SC. Supply market complexity - based on Lau et al. (1999) } \\
\hline supplierC_1 & It is difficult to compare alternative suppliers. & 2.82 & 1.48 \\
\hline supplierC_2 & The supplier structures are complex and difficult to understand. & 2.47 & 1.18 \\
\hline supplierC_3 & $\begin{array}{l}\text { It is complex and difficult to compare offers from alternative } \\
\text { suppliers. }\end{array}$ & 2.63 & 1.40 \\
\hline supplierC_4* & There are large differences between the suppliers. ${ }^{*}$ & 3.45 & 1.35 \\
\hline supplierC_5 & $\begin{array}{l}\text { It is complex and difficult to compare the supply chains of } \\
\text { alternative suppliers. }\end{array}$ & 3.04 & 1.45 \\
\hline
\end{tabular}

SD. Supply market dynamism - based on Kaufmann et al. (2012) and Trkman and McCormack (2009)

\begin{tabular}{|c|c|c|c|}
\hline supplierD_1 & A number of changes occur in the supply chains over time. & 3.10 & 1.58 \\
\hline supplierD_2 & A number of changes occur in the supplier structure over time. & 3.02 & 1.34 \\
\hline supplierD_3 & $\begin{array}{l}\text { It is very difficult to predict how the supplier structure will be in } 2- \\
3 \text { years. }\end{array}$ & 3.16 & 1.60 \\
\hline supplierD_4 & The supplier structure frequently changes over time. & 2.75 & 1.39 \\
\hline \multicolumn{4}{|c|}{ SCT. Supply market competition (reverse coded) - based on Li et al. (2012b) } \\
\hline supplierCT_1 & $\begin{array}{l}\text { The access to suppliers and capacities is not a bottleneck for our } \\
\text { future growth. }\end{array}$ & 3.42 & 1.51 \\
\hline supplierCT_2 & $\begin{array}{l}\text { The suppliers are always prepared to supply us with sufficient } \\
\text { parts. }\end{array}$ & 2.83 & 1.26 \\
\hline supplierCT_3 & $\begin{array}{l}\text { We have access to enough suppliers and capacities on the } \\
\text { procurement market. }\end{array}$ & 3.62 & 1.50 \\
\hline supplierCT_4 & $\begin{array}{l}\text { We have easy access to enough suppliers and capacities for } \\
\text { future growth. }\end{array}$ & 3.65 & 1.44 \\
\hline
\end{tabular}




\section{(continued)}

Construct

Std.

Indicator

Mean

dev.

RC. Relational complexity - based on Su et al. (2008). and Villena et al. (2011)

relationC_1 Our cooperation with the supplier involves an above-average

$3.82 \quad 1.60$

relationC_2

amount of details.

$4.15 \quad 1.64$

relationC_3

Our exchanges with the supplier are more detailed than average.

$4.40 \quad 1.65$

relationC_4 with the supplier are more detailed than average. detailed than average.

\begin{tabular}{|c|c|c|c|}
\hline \multicolumn{4}{|c|}{ RD. Relational dynamism - based on Trkman and McCormack (2009) } \\
\hline relationD_1 & $\begin{array}{l}\text { Agreements with the supplier (e.g. technology and supply } \\
\text { conditions) change more often and quickly than average. }\end{array}$ & 2.64 & 1.36 \\
\hline relationD_2 & $\begin{array}{l}\text { More changes than average occur in the cooperation with the } \\
\text { supplier over time. }\end{array}$ & 2.77 & 1.30 \\
\hline relationD_3 & $\begin{array}{l}\text { Content and aspects of our cooperation with the supplier change } \\
\text { more often and quickly than average. }\end{array}$ & 2.58 & 1.25 \\
\hline relationD_4* & $\begin{array}{l}\text { It is very difficult to predict how the cooperation with the supplier } \\
\text { will be in 2-3 years. }{ }^{*}\end{array}$ & 3.09 & 1.48 \\
\hline \multicolumn{4}{|c|}{ RCT. Relational competition (reverse coded) - based on Li et al. (2012a) } \\
\hline relationCT_1* & $\begin{array}{l}\text { The supplier provides sufficient resources (specialist knowledge. } \\
\text { capacities etc.) for our future growth. }\end{array}$ & 3.21 & 1.39 \\
\hline relationCT_2 & The supplier always provides sufficient resources. & 3.05 & 1.29 \\
\hline relationCT_3 & $\begin{array}{l}\text { The required resources are very easy for us to acquire from the } \\
\text { supplier. }\end{array}$ & 3.27 & 1.27 \\
\hline relationCT_4 & $\begin{array}{l}\text { The supplier is always prepared to supply us with sufficient } \\
\text { resources. }\end{array}$ & 2.98 & 1.24 \\
\hline
\end{tabular}

7-point Likert scale anchored at $1=$ 'strongly disagree' and 7 = 'strongly agree'

* Item dropped due to low loading

$\mathrm{N}=107$ 
Table 23: Usage of tactical sourcing lever across portfolio quadrants

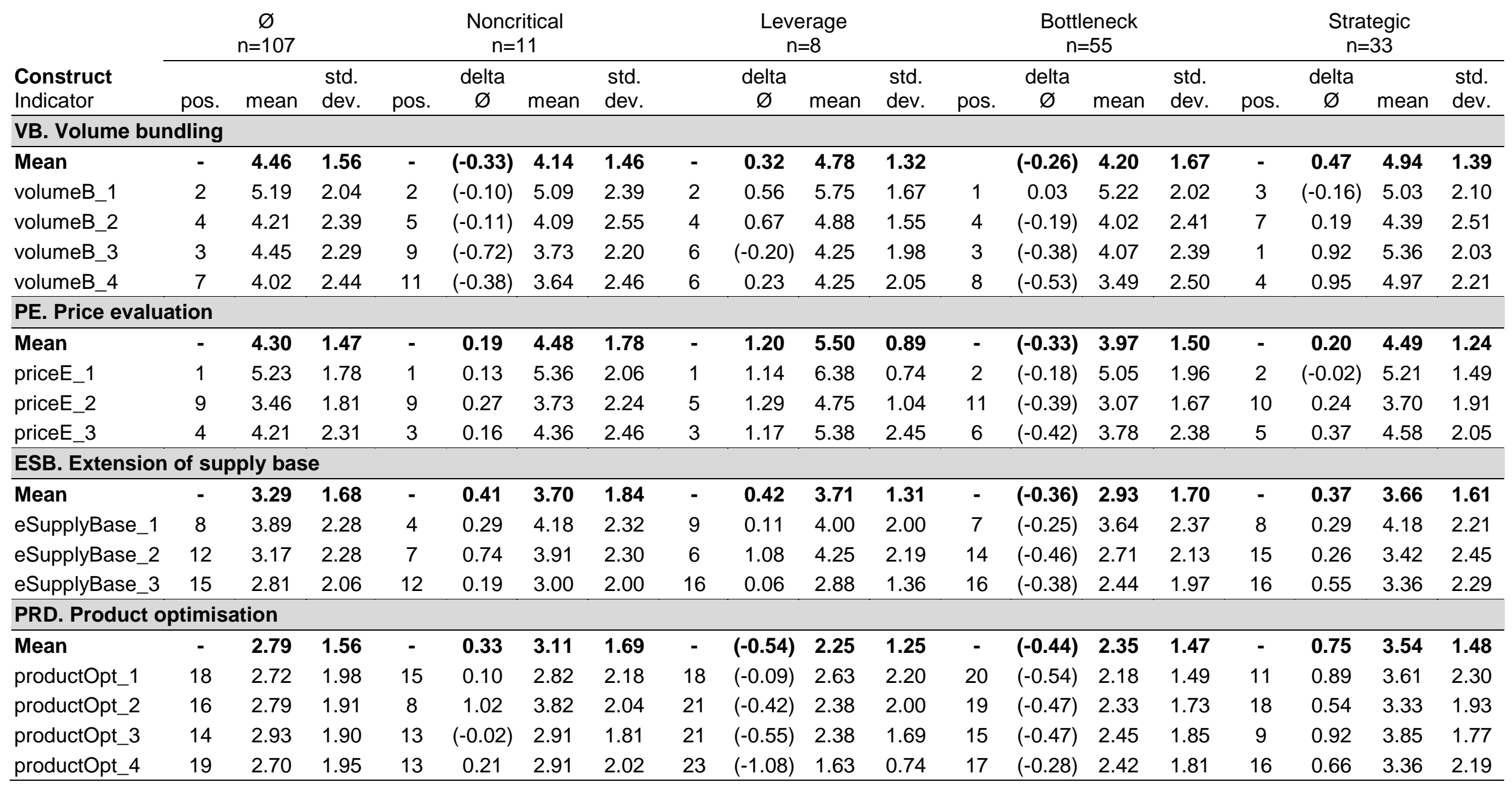


(continued)

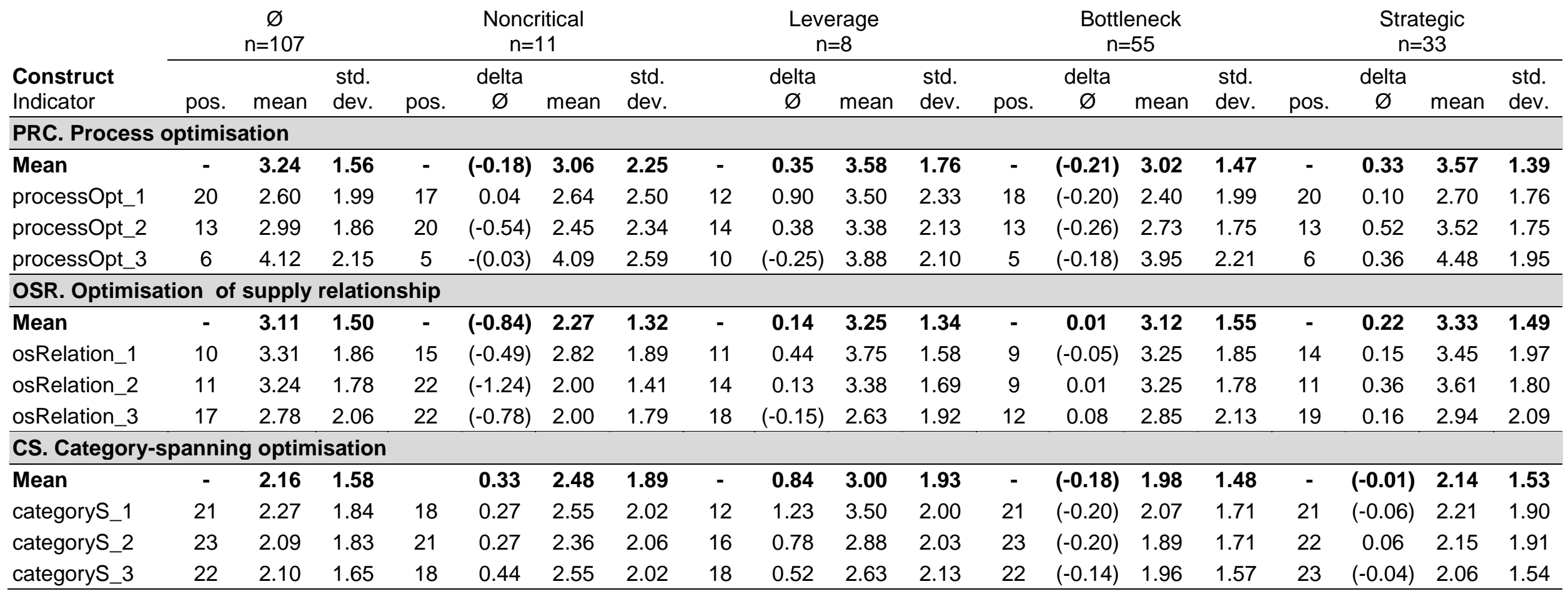


Table 24: Portfolio quadrants analysed for differences and similarities

\begin{tabular}{|c|c|c|c|c|c|c|c|c|c|c|c|c|c|c|}
\hline \multirow[b]{2}{*}{$\begin{array}{l}\text { Construct } \\
\text { Indicator }\end{array}$} & \multicolumn{2}{|c|}{$\begin{array}{l}\text { Noncritical } \\
\text { Leverage } \\
\text { Bottleneck } \\
\text { Strategic }\end{array}$} & \multicolumn{2}{|c|}{$\begin{array}{l}\checkmark \text { Noncritical } \\
\diamond \text { Leverage }\end{array}$} & \multicolumn{2}{|c|}{$\begin{array}{l}\S \text { Noncritical } \\
\diamond \text { Bottleneck }\end{array}$} & \multicolumn{2}{|c|}{$\begin{array}{l}\backsim \text { Noncritical } \\
\diamond \text { Strategic }\end{array}$} & \multicolumn{2}{|c|}{$\begin{array}{l}\text { そLLeverage } \\
\diamond \text { Bottleneck }\end{array}$} & \multicolumn{2}{|c|}{$\begin{array}{l}\text { ßLeverage } \\
\diamond \text { Strategic }\end{array}$} & \multicolumn{2}{|c|}{$\begin{array}{l}\checkmark \text { Bottleneck } \\
\diamond \text { Strategic }\end{array}$} \\
\hline & $\begin{array}{c}\text { delta } \\
\text { mean }\end{array}$ & $\mathrm{p}$-value & $\begin{array}{l}\text { delta } \\
\text { mean }\end{array}$ & $p$-value & $\begin{array}{l}\text { delta } \\
\text { mean }\end{array}$ & $p$-value & $\begin{array}{l}\text { delta } \\
\text { mean }\end{array}$ & $p$-value & $\begin{array}{l}\text { delta } \\
\text { mean }\end{array}$ & $p$-value & $\begin{array}{l}\text { delta } \\
\text { mean }\end{array}$ & $p$-value & $\begin{array}{c}\text { delta } \\
\text { mean }\end{array}$ & $\mathrm{p}$-value \\
\hline \multicolumn{15}{|c|}{ VB. Volume bundling } \\
\hline Mean & & 0.132 & 0.64 & 0.199 & 0.06 & $0.979^{\# \#}$ & 0.80 & 0.118 & $(-0.58)$ & 0.311 & 0.16 & 0.692 & 0.74 & $0.034^{\star \star}$ \\
\hline volumeB_1 & - & 0.859 & 0.66 & 0.828 & 0.13 & 0.803 & $(-0.06)$ & 0.613 & $(-0.53)$ & 0.522 & $(-0.72)$ & 0.421 & $(-0.19)$ & 0.709 \\
\hline volumeB_4 & - & 0.053 & 0.61 & 0.616 & $(-0.15)$ & 0.782 & 1.33 & 0.114 & $(-0.76)$ & 0.371 & 0.72 & 0.267 & 1.48 & $0.009^{* * *}$ \\
\hline \multicolumn{15}{|c|}{ PE. Price evaluation } \\
\hline Mean & - & 0.036 & 1.02 & 0.318 & $(-0.52)$ & 0.403 & 0.01 & $0.978^{\# \#}$ & $(-1.53)$ & $0.006^{\star \star \star}$ & $(-1.01)$ & $0.029^{\star \star}$ & 0.53 & 0.155 \\
\hline priceE_1 & - & 0.192 & 1.01 & 0.378 & $(-0.31)$ & 0.503 & $(-0.15)$ & 0.353 & $(-1.32)$ & $0.065^{*}$ & $(-1.16)$ & $0.023^{* *}$ & 0.16 & 0.856 \\
\hline priceE_2 & - & $0.057^{*}$ & 1.02 & 0.260 & $(-0.65)$ & 0.405 & $(-0.03)$ & $0.978^{\# \#}$ & $(-1.68)$ & $0.007^{\star * *}$ & $(-1.05)$ & 0.125 & 0.62 & 0.146 \\
\hline priceE_3 & - & 0.203 & 1.01 & 0.214 & $(-0.58)$ & 0.569 & 0.21 & $0.945^{\#}$ & $(-1.59)$ & $0.082^{*}$ & $(-0.80)$ & 0.139 & 0.79 & 0.163 \\
\hline eSupplyBase_3 & - & 0.206 & $(-0.13)$ & $1.000^{\# \# \#}$ & $(-0.56)$ & 0.232 & 0.36 & 0.824 & $(-0.44)$ & 0.207 & 0.49 & 0.635 & 0.93 & $0.063^{*}$ \\
\hline \multicolumn{15}{|c|}{ PRD. Product optimisation } \\
\hline Mean & - & $0.001^{\star \star \star}$ & $(-0.86)$ & 0.260 & $(-0.77)$ & 0.103 & 0.42 & 0.392 & 0.10 & $0.925^{\#}$ & 1.29 & $0.038^{\star \star}$ & 1.19 & $0.000^{\star \star \star}$ \\
\hline productOpt_1 & - & $0.071^{*}$ & $(-0.19)$ & 0.829 & $(-0.64)$ & 0.440 & 0.79 & 0.397 & $(-0.44)$ & 0.694 & 0.98 & 0.345 & 1.42 & $0.007^{\star \star *}$ \\
\hline productOpt_2 & - & $0.017^{* *}$ & $(-1.44)$ & 0.119 & $(-1.49)$ & $0.017^{* *}$ & $(-0.48)$ & 0.483 & $(-0.05)$ & 0.870 & 0.96 & 0.174 & 1.01 & $0.010^{* *}$ \\
\hline productOpt_3 & - & $0.002^{* * *}$ & $(-0.53)$ & 0.493 & $(-0.45)$ & 0.332 & 0.94 & 0.117 & 0.08 & $0.965^{\# \#}$ & 1.47 & $0.026^{* *}$ & 1.39 & $0.000^{* * *}$ \\
\hline productOpt_4 & - & 0.121 & $(-1.28)$ & 0.209 & $(-0.49)$ & 0.471 & 0.45 & 0.578 & 0.79 & 0.365 & 1.74 & $0.051^{*}$ & 0.95 & $0.052^{*}$ \\
\hline
\end{tabular}


(continued)

\begin{tabular}{|c|c|c|c|c|c|c|c|c|c|c|c|c|c|c|}
\hline \multirow[b]{2}{*}{$\begin{array}{l}\text { Construct } \\
\text { Indicator }\end{array}$} & \multicolumn{2}{|c|}{$\begin{array}{l}\text { Noncritical } \\
\text { Leverage } \\
\text { Bottleneck } \\
\text { Strategic }\end{array}$} & \multicolumn{2}{|c|}{$\begin{array}{l}\nwarrow \text { Noncritical } \\
\diamond \text { Leverage }\end{array}$} & \multicolumn{2}{|c|}{$\begin{array}{l}₫ \text { Noncritical } \\
\diamond \text { Bottleneck }\end{array}$} & \multicolumn{2}{|c|}{$\S$ Noncritical } & \multicolumn{2}{|c|}{$\begin{array}{l}\text { ఇLeverage } \\
\diamond \text { Bottleneck }\end{array}$} & \multicolumn{2}{|c|}{ ßLeverage } & \multicolumn{2}{|c|}{$\begin{array}{l}\text { \Bottleneck } \\
\diamond \text { Strategic }\end{array}$} \\
\hline & $\begin{array}{l}\text { delta } \\
\text { mean }\end{array}$ & $\mathrm{p}$-value & $\begin{array}{l}\text { delta } \\
\text { mean }\end{array}$ & $\mathrm{p}$-value & $\begin{array}{l}\text { delta } \\
\text { mean }\end{array}$ & $\mathrm{p}$-value & $\begin{array}{l}\text { delta } \\
\text { mean }\end{array}$ & $p$-value & $\begin{array}{l}\text { delta } \\
\text { mean }\end{array}$ & $\mathrm{p}$-value & $\begin{array}{l}\text { delta } \\
\text { mean }\end{array}$ & $\mathrm{p}$-value & $\begin{array}{l}\text { delta } \\
\text { mean }\end{array}$ & $p$-value \\
\hline \multicolumn{15}{|c|}{ PRC. Process optimisation } \\
\hline Mean & - & 0.260 & 0.52 & 0.506 & $(-0.04)$ & 0.562 & 0.51 & 0.187 & $(-0.56)$ & 0.407 & $(-0.02)$ & $0.961^{\# \#}$ & 0.54 & $0.073^{\star}$ \\
\hline processOpt_1 & - & 0.315 & 0.86 & 0.274 & $(-0.24)$ & 0.822 & 0.06 & 0.421 & $(-1.10)$ & 0.134 & $(-0.80)$ & 0.380 & 0.30 & 0.188 \\
\hline \multicolumn{15}{|c|}{ OSR. Optimisation of supply relationship } \\
\hline Mean & - & 0.203 & 0.98 & 0.132 & 0.85 & $0.093^{*}$ & 1.06 & $0.036^{\star \star}$ & $(-0.13)$ & 0.656 & 0.08 & 0.869 & 0.21 & 0.436 \\
\hline osRelation_1 & - & 0.654 & 0.93 & 0.270 & 0.44 & 0.483 & 0.64 & 0.308 & $(-0.50)$ & 0.407 & $(-0.30)$ & 0.653 & 0.20 & 0.634 \\
\hline osRelation_2 & - & $0.068^{*}$ & 1.38 & $0.061^{*}$ & 1.25 & $0.028^{* *}$ & 1.61 & $0.009^{* * *}$ & $(-0.12)$ & 0.817 & 0.23 & 0.750 & 0.35 & 0.365 \\
\hline osRelation_3 & - & 0.661 & 0.63 & 0.402 & 0.85 & 0.274 & 0.94 & 0.206 & 0.23 & $0.940^{\#}$ & 0.31 & 0.798 & 0.08 & 0.815 \\
\hline \multicolumn{15}{|c|}{ CSO. Category-spanning optimisation } \\
\hline
\end{tabular}

Difference: ***very highly significant $(p \leq 0.01) ;{ }^{* *}$ highly significant $(0.01<p \leq 0.05) ;{ }^{*}$ significant $(0.05<p \leq 0.1)$

Similarity: ${ }^{\# \#}$ very highly significant $(p \geq 0.99)$; ${ }^{\prime \prime}$ highly significant $(0.99>p \geq 0.95)$; ${ }^{\prime \prime}$ significant $(0.95>p \geq 0.9)$

Moving between portfolio quadrants: $\checkmark$ from...; $\diamond$ to... 
Table 25: Reflective indicators - cross loadings (contingency factors)

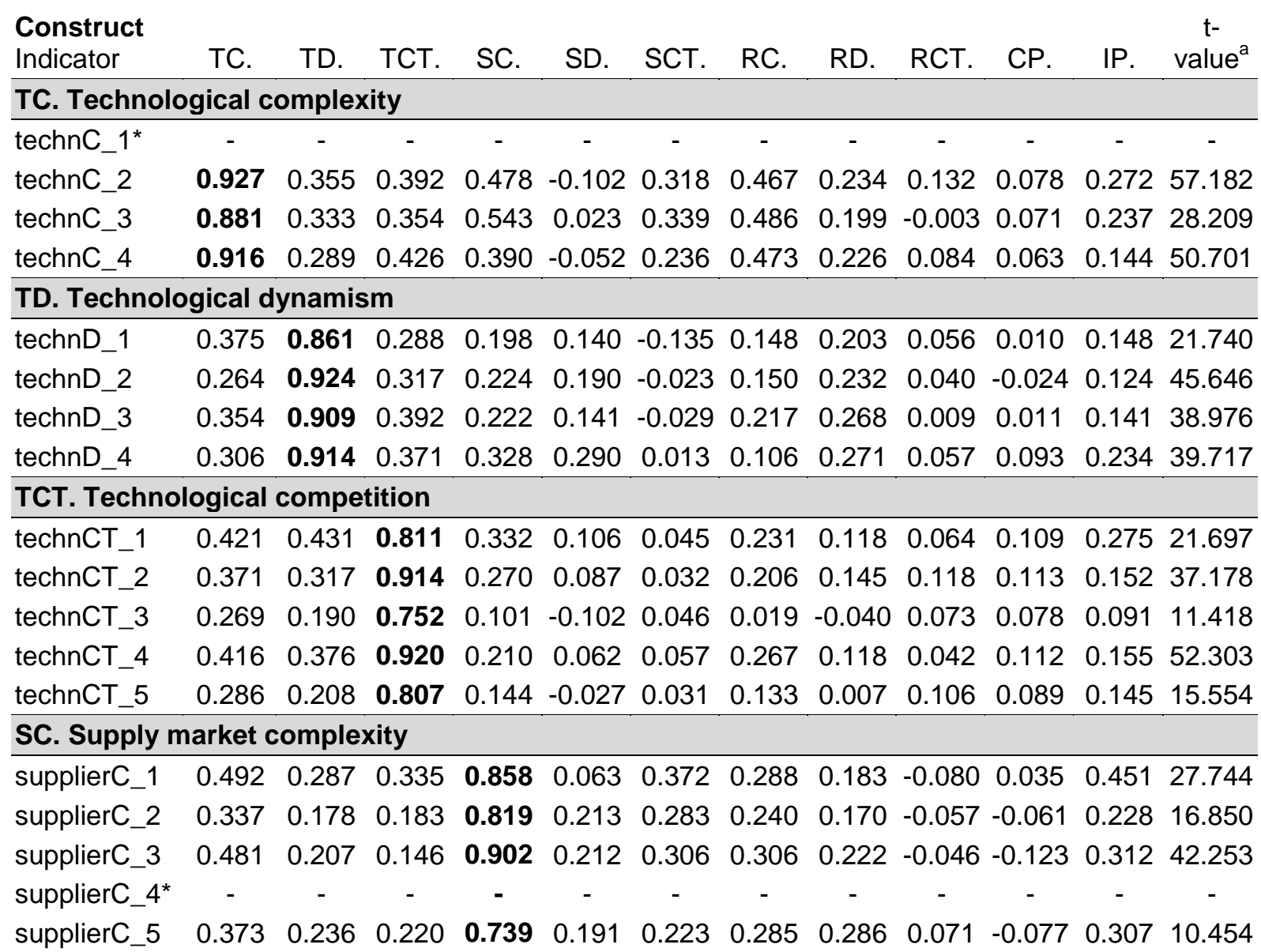

SD. Supply market dynamism

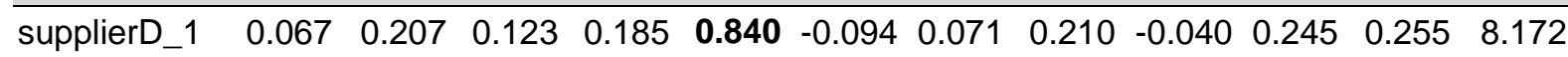

$\begin{array}{llllllllllllll}\text { supplierD_2 } & -0.023 & 0.205 & 0.054 & 0.182 & 0.882 & -0.076 & 0.077 & 0.218 & 0.017 & 0.078 & 0.213 & 9.964\end{array}$

$\begin{array}{lllllllllllll}\text { supplierD_3 } & -0.099 & 0.119 & -0.061 & 0.125 & \mathbf{0 . 7 6 9} & 0.033 & 0.038 & 0.032 & -0.128 & 0.118 & 0.196 & 5.865\end{array}$

$\begin{array}{llllllllllllll}\text { supplierD_4 } & -0.154 & 0.174 & -0.009 & 0.157 & 0.879 & -0.149 & -0.009 & 0.114 & -0.068 & 0.182 & 0.262 & 8.644\end{array}$

SCT. Supply market competition

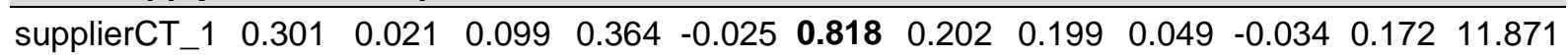
$\begin{array}{lllllllllllll}\text { supplierCT_2 } & 0.129 & 0.008 & 0.006 & 0.278 & -0.022 & 0.728 & 0.083 & 0.168 & 0.136 & -0.057 & 0.139 & 9.507\end{array}$ $\begin{array}{lllllllllllll}\text { supplierCT_3 } & 0.291 & -0.099 & -0.023 & 0.202 & -0.163 & 0.832 & 0.278 & 0.121 & 0.134 & -0.140 & 0.091 & 10.102\end{array}$ \begin{tabular}{lllllllllllll} 
supplierCT_4 & 0.316 & -0.078 & 0.056 & 0.300 & -0.145 & 0.869 & 0.289 & 0.163 & 0.134 & -0.197 & 0.070 & 13.834 \\
\hline RC.Relation
\end{tabular} RC. Relational complexity

\begin{tabular}{lllllllllllll}
\hline relationC_1 & 0.384 & -0.020 & 0.120 & 0.243 & 0.066 & 0.289 & $\mathbf{0 . 8 2 4}$ & 0.393 & 0.001 & -0.013 & 0.183 & 16.484
\end{tabular} $\begin{array}{lllllllllllll}\text { relationC_2 } & 0.425 & 0.089 & 0.178 & 0.294 & 0.031 & 0.193 & 0.909 & 0.311 & -0.066 & 0.080 & 0.165 & 23.174\end{array}$ $\begin{array}{lllllllllllll}\text { relationC_3 } & 0.443 & 0.176 & 0.164 & 0.291 & 0.086 & 0.228 & 0.859 & 0.374 & 0.066 & 0.042 & 0.157 & 17.515\end{array}$ $\begin{array}{lllllllllllll}\text { relationC_4 } & 0.515 & 0.294 & 0.280 & 0.313 & 0.005 & 0.199 & 0.819 & 0.363 & 0.064 & -0.053 & 0.238 & 18.505\end{array}$ RD. Relational dynamism

\begin{tabular}{lllllllllllll}
\hline relationD_1 & 0.235 & 0.305 & 0.060 & 0.238 & 0.154 & 0.170 & 0.393 & 0.912 & 0.245 & -0.002 & 0.297 & 23.663
\end{tabular} $\begin{array}{llllllllllllll}\text { relationD_2 } & 0.214 & 0.228 & 0.148 & 0.217 & 0.190 & 0.185 & 0.407 & 0.921 & 0.187 & 0.010 & 0.237 & 20.523\end{array}$ $\begin{array}{lllllllllllll}\text { relationD_3 } & 0.207 & 0.182 & 0.067 & 0.243 & 0.182 & 0.215 & 0.337 & 0.897 & 0.143 & -0.063 & 0.179 & 16.268\end{array}$ relationD_4* 
(continued)

Construct

Indicator

TC. TD. TCT. SC.

SD. SCT. RC.

$\mathrm{t}-$

\begin{tabular}{|c|c|c|c|c|c|c|c|c|c|c|c|c|}
\hline \multicolumn{13}{|c|}{ RCT. Relational competition } \\
\hline relationCT_1* & - & - & - & - & - & - & - & - & - & - & - & - \\
\hline relationCT_2 & 0.034 & 0.040 & 0.076 & -0.106 & -0.047 & 0.088 & -0.094 & 0.089 & 0.898 & -0.156 & -0.201 & 8.521 \\
\hline relationCT_3 & 0.104 & 0.034 & 0.077 & -0.034 & -0.094 & 0.123 & 0.035 & 0.258 & 0.961 & -0.164 & -0.145 & 10.705 \\
\hline relationCT_4 & 0.056 & 0.053 & 0.102 & -0.013 & 0.016 & 0.146 & 0.048 & 0.186 & 0.929 & -0.173 & -0.138 & 9.237 \\
\hline \multicolumn{13}{|c|}{ CP. Cost performance } \\
\hline cost_1 & 0.138 & 0.068 & 0.172 & -0.114 & 0.137 & -0.220 & 0.047 & -0.064 & -0.124 & 0.822 & 0.158 & 5.268 \\
\hline cost_2 & 0.140 & 0.090 & 0.200 & 0.017 & 0.143 & -0.092 & 0.034 & 0.004 & -0.099 & 0.901 & 0.265 & 5.330 \\
\hline cost_3 & -0.068 & 0.028 & 0.044 & -0.132 & 0.152 & -0.115 & -0.144 & -0.023 & -0.252 & 0.772 & 0.167 & 5.116 \\
\hline cost_4 & -0.033 & 0.019 & -0.006 & -0.158 & 0.095 & -0.139 & -0.078 & -0.032 & -0.237 & 0.778 & 0.041 & 4.371 \\
\hline cost_5 & -0.106 & 0.033 & -0.133 & -0.105 & 0.195 & -0.178 & -0.109 & -0.062 & -0.258 & 0.760 & 0.080 & 4.432 \\
\hline cost_6 & 0.111 & -0.103 & 0.088 & -0.054 & 0.153 & -0.004 & 0.140 & 0.013 & -0.107 & 0.778 & 0.111 & 4.790 \\
\hline cost_7 & 0.078 & -0.044 & 0.075 & 0.027 & 0.212 & -0.039 & 0.102 & 0.034 & -0.085 & 0.845 & 0.163 & 5.497 \\
\hline \multicolumn{13}{|c|}{ IP. Innovation performance } \\
\hline inno_1 & 0.249 & 0.307 & 0.234 & 0.322 & 0.131 & 0.148 & 0.199 & 0.360 & -0.056 & 0.195 & 0.860 & 18.586 \\
\hline inno_2 & 0.260 & 0.159 & 0.221 & 0.348 & 0.132 & 0.164 & 0.178 & 0.240 & -0.090 & 0.107 & 0.892 & 23.929 \\
\hline inno_3 & 0.195 & 0.067 & 0.127 & 0.280 & 0.206 & 0.109 & 0.153 & 0.212 & -0.161 & 0.112 & 0.820 & 14.738 \\
\hline inno_4 & 0.177 & 0.147 & 0.197 & 0.297 & 0.306 & 0.057 & 0.198 & 0.176 & -0.229 & 0.187 & 0.879 & 22.228 \\
\hline inno_5 & 0.208 & 0.118 & 0.123 & 0.398 & 0.333 & 0.080 & 0.215 & 0.181 & -0.188 & 0.155 & 0.840 & 17.601 \\
\hline inno_6 & 0.168 & 0.188 & 0.231 & 0.299 & 0.285 & 0.074 & 0.156 & 0.159 & -0.185 & 0.245 & 0.864 & 19.381 \\
\hline inno_7 & 0.237 & 0.116 & 0.156 & 0.451 & 0.283 & 0.198 & 0.260 & 0.274 & -0.131 & 0.212 & 0.891 & 23.600 \\
\hline inno_8 & 0.126 & 0.101 & 0.114 & 0.348 & 0.302 & 0.157 & 0.142 & 0.205 & -0.129 & 0.206 & 0.895 & 22.958 \\
\hline
\end{tabular}

7-point Likert scale anchored at 1 = 'strongly disagree' and 7 = 'strongly agree'

* Item dropped due to low outer loading

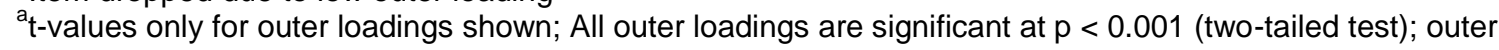
loadings marked in bold

$\mathrm{N}=107$ 
Table 26: Moderated effects of sourcing levers - cost performance

\begin{tabular}{|c|c|c|c|c|c|c|c|c|c|c|c|c|c|c|c|c|}
\hline \multirow{4}{*}{$\begin{array}{l}\text { IV } \\
\text { M }\end{array}$} & \multirow{3}{*}{\multicolumn{3}{|c|}{ Regression coefficients }} & \multirow{3}{*}{\multicolumn{2}{|c|}{ Mean }} & \multirow{3}{*}{\multicolumn{3}{|c|}{ Std.dev. }} & \multicolumn{2}{|c|}{ Configuration } & \multirow{4}{*}{\multicolumn{2}{|c|}{$\triangle \mathrm{DV}$}} & \multicolumn{2}{|c|}{ Configuration } & \multirow{4}{*}{\multicolumn{2}{|c|}{$\triangle \mathrm{DV}$}} \\
\hline & & & & & & & & & \multirow{3}{*}{\multicolumn{2}{|c|}{$\begin{array}{cc}\begin{array}{cc}\text { Low IV } \\
\text { Low M }\end{array} & \begin{array}{c}\text { High IV } \\
\text { Low M }\end{array} \\
\text { DV } & \text { DV }\end{array}$}} & & & \multirow{3}{*}{\multicolumn{2}{|c|}{ 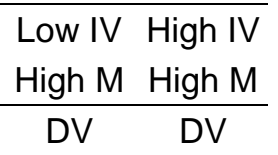 }} & & \\
\hline & & & & & & & & & & & & & & & & \\
\hline & $\mathrm{b}_{0}$ & $b_{1}$ & $b_{2}$ & $b_{3}$ & IV & $M$ & IV & $M$ & & & & & & & & \\
\hline VB. VC & undling & & & & & & & & & & & & & & & \\
\hline TC. & 4.484 & 0.160 & -0.009 & -0.090 & 4.44 & 4.16 & 1.59 & 1.66 & 4.27 & 4.06 & -0.21 & $-5 \%$ & 3.39 & 2.23 & -1.16 & $-34 \%$ \\
\hline TD. & 4.630 & 0.122 & -0.014 & -0.096 & 4.43 & 2.75 & 1.59 & 1.51 & 4.62 & 4.63 & 0.01 & $0 \%$ & 3.76 & 2.84 & -0.91 & $-24 \%$ \\
\hline TCT. & 4.401 & 0.122 & 0.054 & -0.056 & 4.44 & 3.05 & 1.59 & 1.31 & 4.57 & 4.65 & 0.08 & $2 \%$ & 4.30 & 3.92 & -0.38 & $-9 \%$ \\
\hline SC. & 4.810 & 0.141 & -0.107 & -0.108 & 4.45 & 2.72 & 1.58 & 1.14 & 4.56 & 4.46 & -0.09 & $-2 \%$ & 3.60 & 2.73 & -0.88 & $-24 \%$ \\
\hline SD. & 4.027 & 0.133 & 0.157 & -0.025 & 4.45 & 3.00 & 1.58 & 1.24 & 4.56 & 4.84 & 0.28 & $6 \%$ & 4.77 & 4.86 & 0.09 & $2 \%$ \\
\hline SCT. & 5.067 & 0.121 & -0.133 & 0.083 & 4.46 & 3.41 & 1.58 & 1.18 & 5.66 & 6.62 & 0.97 & $17 \%$ & 5.91 & 7.50 & 1.59 & $27 \%$ \\
\hline $\mathrm{RC}$. & 4.423 & 0.125 & 0.025 & 0.050 & 4.44 & 4.14 & 1.59 & 1.46 & 5.23 & 6.05 & 0.82 & $16 \%$ & 5.72 & 7.00 & 1.28 & $22 \%$ \\
\hline RD. & 4.567 & 0.147 & -0.036 & -0.059 & 4.45 & 2.66 & 1.59 & 1.19 & 4.68 & 4.87 & 0.19 & $4 \%$ & 4.20 & 3.94 & -0.26 & $-6 \%$ \\
\hline RCT. & 5.169 & 0.134 & -0.207 & -0.065 & 4.45 & 3.10 & 1.58 & 1.18 & 4.80 & 4.84 & 0.03 & $1 \%$ & 3.87 & 3.42 & -0.45 & $-12 \%$ \\
\hline PE. Pr & uation & & & & & & & & & & & & & & & \\
\hline TC. & 3.971 & 0.226 & 0.043 & -0.025 & 4.24 & 4.12 & 1.43 & 1.70 & 4.54 & 5.01 & 0.47 & $10 \%$ & 4.44 & 4.66 & 0.22 & $5 \%$ \\
\hline TD. & 4.500 & 0.237 & -0.077 & 0.061 & 4.25 & 4.96 & 1.43 & 1.30 & 5.51 & 6.83 & 1.31 & $24 \%$ & 5.76 & 7.53 & 1.77 & $31 \%$ \\
\hline TCT. & 3.885 & 0.237 & 0.077 & -0.061 & 4.25 & 3.04 & 1.43 & 1.30 & 4.39 & 4.76 & 0.38 & $9 \%$ & 4.14 & 4.06 & -0.08 & $-2 \%$ \\
\hline SC. & 4.416 & 0.234 & -0.111 & 0.142 & 4.25 & 2.72 & 1.43 & 1.14 & 5.53 & 6.84 & 1.31 & $24 \%$ & 6.18 & 8.42 & 2.23 & $36 \%$ \\
\hline SD. & 3.968 & 0.198 & 0.093 & 0.049 & 4.24 & 2.99 & 1.43 & 1.24 & 4.93 & 5.74 & 0.81 & $16 \%$ & 5.50 & 6.66 & 1.16 & $21 \%$ \\
\hline SCT. & 4.614 & 0.209 & -0.105 & 0.032 & 4.25 & 3.41 & 1.43 & 1.18 & 5.17 & 5.97 & 0.80 & $15 \%$ & 5.13 & 6.15 & 1.01 & $20 \%$ \\
\hline $\mathrm{RC}$. & 3.900 & 0.242 & 0.050 & 0.124 & 4.25 & 4.15 & 1.43 & 1.47 & 5.65 & 7.30 & 1.65 & $29 \%$ & 6.82 & 9.52 & 2.69 & $39 \%$ \\
\hline RD. & 4.310 & 0.225 & -0.058 & -0.056 & 4.24 & 2.66 & 1.43 & 1.19 & 4.63 & 5.03 & 0.41 & $9 \%$ & 4.11 & 4.14 & 0.03 & $1 \%$ \\
\hline RCT. & 4.838 & 0.216 & -0.202 & 0.020 & 4.25 & 3.10 & 1.43 & 1.18 & 5.17 & 5.89 & 0.73 & $14 \%$ & 4.82 & 5.68 & 0.86 & $18 \%$ \\
\hline
\end{tabular}


(continued)

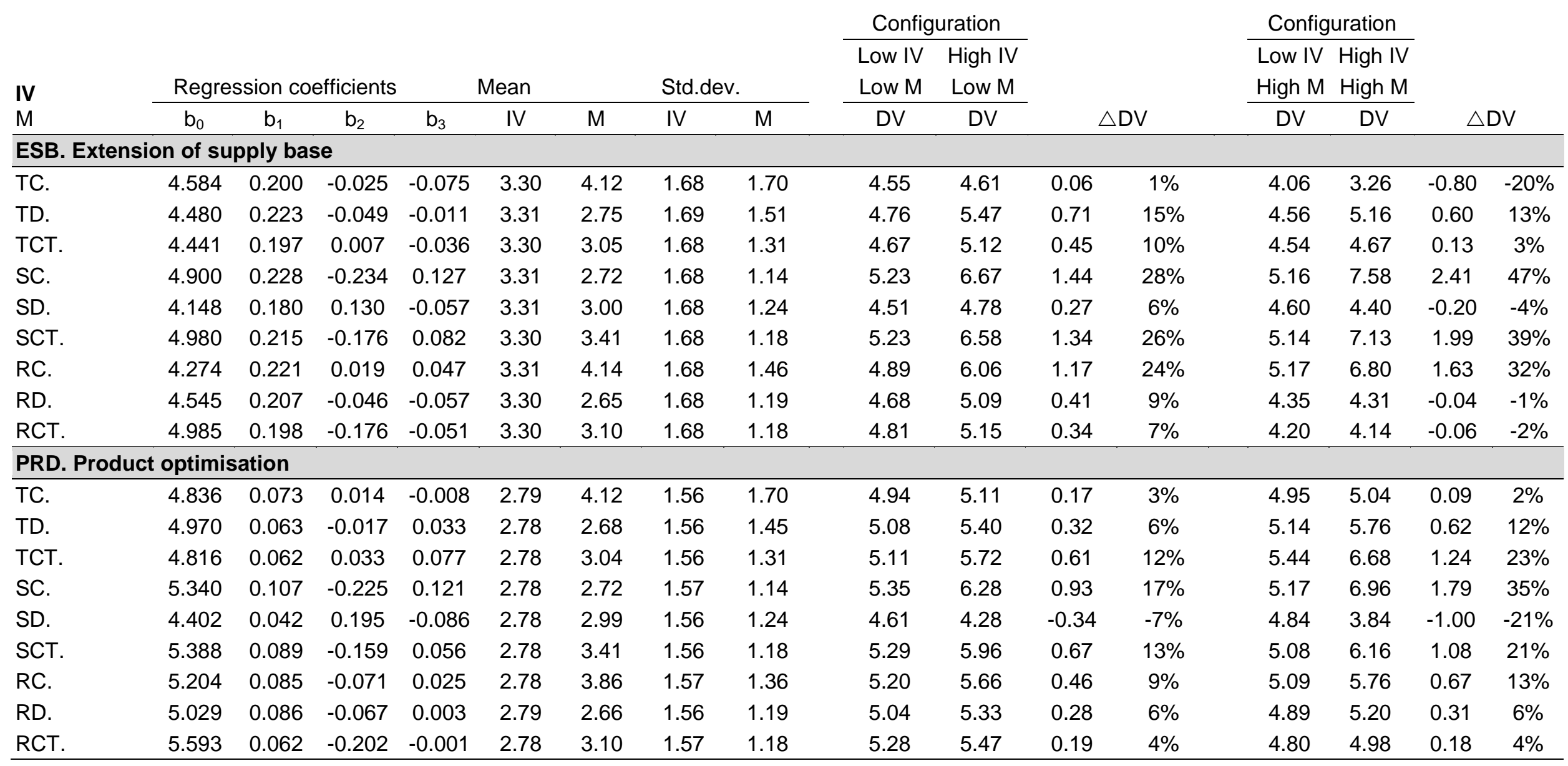


(continued)

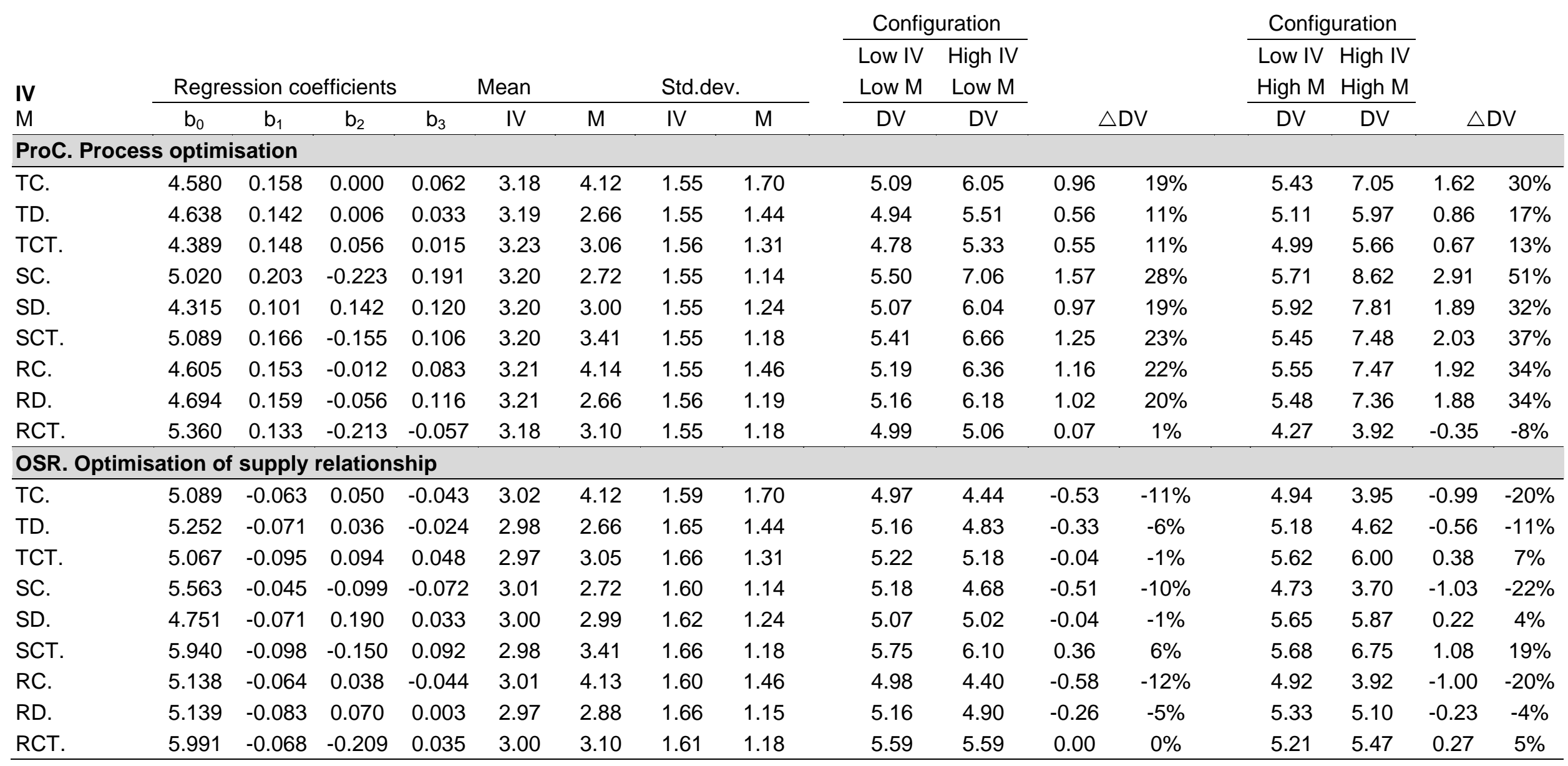


(continued)

\begin{tabular}{|c|c|c|c|c|c|c|c|c|c|c|c|c|c|c|c|c|}
\hline \multirow{3}{*}{$\begin{array}{l}\text { IV } \\
\text { M }\end{array}$} & \multirow{2}{*}{\multicolumn{3}{|c|}{ Regression coefficients }} & \multirow{2}{*}{\multicolumn{2}{|c|}{ Mean }} & \multirow{2}{*}{\multicolumn{3}{|c|}{ Std.dev. }} & \multicolumn{2}{|c|}{ Configuration } & \multirow{3}{*}{\multicolumn{2}{|c|}{$\triangle \mathrm{DV}$}} & \multicolumn{2}{|c|}{ Configuration } & \multirow{3}{*}{\multicolumn{2}{|c|}{$\triangle \mathrm{DV}$}} \\
\hline & & & & & & & & & \multirow{2}{*}{$\begin{array}{l}\text { Low IV } \\
\text { Low M } \\
\text { DV }\end{array}$} & \multirow{2}{*}{$\begin{array}{l}\text { High IV } \\
\text { Low M } \\
\text { DV }\end{array}$} & & & \multirow{2}{*}{\multicolumn{2}{|c|}{$\begin{array}{l}\text { Low IV High IV } \\
\text { High M High M } \\
\text { DV }\end{array}$}} & & \\
\hline & $b_{0}$ & $b_{1}$ & $b_{2}$ & $b_{3}$ & IV & $\mathrm{M}$ & IV & $M$ & & & & & & & & \\
\hline TC. & 4.362 & 0.012 & 0.084 & 0.020 & 2.16 & 4.22 & 1.57 & 1.58 & 4.62 & 4.82 & 0.20 & $4 \%$ & 4.92 & 5.32 & 0.40 & $8 \%$ \\
\hline TD. & 5.140 & 0.006 & 0.022 & -0.044 & 2.17 & 2.68 & 1.59 & 1.45 & 5.14 & 4.99 & -0.15 & $-3 \%$ & 5.13 & 4.57 & -0.56 & $-11 \%$ \\
\hline TCT. & 4.819 & 0.019 & 0.070 & 0.028 & 2.13 & 3.06 & 1.57 & 1.31 & 4.98 & 5.19 & 0.21 & $4 \%$ & 5.20 & 5.65 & 0.44 & $9 \%$ \\
\hline SCT. & 5.627 & 0.015 & -0.147 & 0.051 & 2.11 & 3.42 & 1.58 & 1.18 & 5.37 & 5.77 & 0.40 & $8 \%$ & 5.08 & 5.86 & 0.78 & $15 \%$ \\
\hline $\mathrm{RC}$. & 4.931 & 0.014 & 0.035 & 0.037 & 2.13 & 4.14 & 1.57 & 1.46 & 5.09 & 5.44 & 0.35 & $7 \%$ & 5.25 & 5.95 & 0.70 & $13 \%$ \\
\hline RD. & 5.139 & -0.083 & 0.070 & 0.003 & 0.11 & 0.00 & 1.13 & 0.04 & 5.22 & 5.03 & -0.19 & $-4 \%$ & 5.23 & 5.04 & -0.19 & $-4 \%$ \\
\hline RCT. & 5.956 & -0.026 & -0.239 & -0.059 & 2.23 & 3.10 & 1.71 & 1.18 & 5.43 & 4.95 & -0.48 & $-9 \%$ & 4.79 & 3.83 & -0.96 & $-20 \%$ \\
\hline
\end{tabular}

TC. = Technological complexity; TD. = Technological dynamism; TCT. = Technological competition; SC. = Supply market complexity; SD. = Supply market dynamism; SCT. = Supply market competition; RC. = Relational complexity; RD. = Relational dynamism; RCT. = Relational competition

DV $($ Dependent variable $)=$ Cost performance

$M$ (Moderator) = Contingency factors TC., TD., TCT., SC., SD., SCT., RC., RD., RCT.

IV (Independent variable) = Sourcing levers VB., PE., ESB., PRD., PRC., OSR., CS.

$\triangle \mathrm{DV}=$ Change in the DV, when IV is changed from 'low' to 'high' 
Table 27: Moderated effects of sourcing levers - innovation performance

\begin{tabular}{|c|c|c|c|c|c|c|c|c|c|c|c|c|c|c|c|c|}
\hline \multirow{2}{*}{$\begin{array}{l}\text { IV } \\
\text { M }\end{array}$} & & & & & \multicolumn{2}{|c|}{ Mean } & \multicolumn{2}{|c|}{ Std.dev. } & \multicolumn{2}{|c|}{ Configuration } & & & \multicolumn{2}{|c|}{ Configuration } & & \\
\hline & $\mathrm{b}_{0}$ & $b_{1}$ & $b_{2}$ & $b_{3}$ & IV & $M$ & IV & $M$ & DV & DV & \multicolumn{2}{|c|}{$\triangle \mathrm{DV}$} & DV & $\begin{array}{c}\text { High IV } \\
\text { High M } \\
\text { DV }\end{array}$ & \multicolumn{2}{|c|}{$\triangle \mathrm{DV}$} \\
\hline TC. & 1.698 & 0.057 & 0.171 & -0.034 & 4.25 & 4.19 & 1.73 & 1.60 & 2.07 & 1.96 & -0.11 & $-5 \%$ & 2.34 & 1.86 & -0.48 & $-21 \%$ \\
\hline TD. & 2.033 & 0.049 & 0.144 & 0.015 & 4.23 & 2.68 & 1.76 & 1.45 & 2.38 & 2.62 & 0.24 & $10 \%$ & 2.91 & 3.30 & 0.39 & $14 \%$ \\
\hline TCT. & 1.840 & 0.054 & 0.179 & 0.054 & 4.24 & 3.05 & 1.74 & 1.30 & 2.52 & 3.03 & 0.51 & $20 \%$ & 3.34 & 4.34 & 1.00 & $30 \%$ \\
\hline SCT. & 1.718 & 0.081 & 0.167 & -0.079 & 4.25 & 3.36 & 1.73 & 1.15 & 1.85 & 1.53 & -0.32 & $-18 \%$ & 1.77 & 0.82 & -0.96 & $-54 \%$ \\
\hline RC. & 1.589 & 0.060 & 0.200 & -0.040 & 4.26 & 3.94 & 1.72 & 1.38 & 1.99 & 1.85 & -0.14 & $-7 \%$ & 2.26 & 1.74 & -0.52 & $-23 \%$ \\
\hline RD. & 1.676 & 0.043 & 0.284 & 0.005 & 4.25 & 2.73 & 1.74 & 1.13 & 2.26 & 2.43 & 0.18 & $8 \%$ & 2.93 & 3.14 & 0.21 & $7 \%$ \\
\hline RCT. & 2.952 & 0.077 & -0.211 & -0.108 & 4.26 & 3.10 & 1.73 & 1.18 & 2.22 & 1.77 & -0.45 & $-20 \%$ & 1.08 & -0.25 & -1.33 & $-123 \%$ \\
\hline \multicolumn{17}{|c|}{ PE. Price evaluation } \\
\hline TC. & 0.616 & 0.283 & 0.204 & -0.040 & 4.06 & 4.19 & 1.50 & 1.60 & 1.60 & 2.15 & 0.54 & $34 \%$ & 1.93 & 2.09 & 0.16 & $8 \%$ \\
\hline SCT. & 0.668 & 0.296 & 0.225 & -0.047 & 4.05 & 3.36 & 1.50 & 1.15 & 1.65 & 2.23 & 0.58 & $35 \%$ & 1.90 & 2.15 & 0.25 & $13 \%$ \\
\hline RC. & 0.678 & 0.274 & 0.215 & -0.037 & 4.06 & 3.94 & 1.50 & 1.38 & 1.69 & 2.22 & 0.54 & $32 \%$ & 2.02 & 2.24 & 0.23 & $11 \%$ \\
\hline $\mathrm{RD}$. & 0.704 & 0.252 & 0.329 & 0.121 & 4.05 & 2.73 & 1.51 & 1.13 & 2.37 & 3.71 & 1.35 & $57 \%$ & 3.81 & 5.98 & 2.17 & $57 \%$ \\
\hline RCT. & 2.188 & 0.261 & -0.202 & -0.101 & 4.06 & 3.10 & 1.50 & 1.18 & 1.98 & 2.18 & 0.21 & $10 \%$ & 0.89 & 0.38 & -0.51 & $-57 \%$ \\
\hline
\end{tabular}


(continued)

\begin{tabular}{|c|c|c|c|c|c|c|c|c|c|c|c|c|c|c|c|c|}
\hline \multirow{2}{*}{$\begin{array}{l}\text { IV } \\
\mathrm{M} \\
\end{array}$} & & & & & & & & & \multicolumn{2}{|c|}{ Configuration } & & & \multicolumn{2}{|c|}{ Configuration } & & \\
\hline & $b_{0}$ & $b_{1}$ & $b_{2}$ & $b_{3}$ & IV & $M$ & IV & $M$ & DV & DV & \multicolumn{2}{|c|}{$\triangle \mathrm{DV}$} & DV & DV & \multicolumn{2}{|c|}{$\triangle \mathrm{DV}$} \\
\hline TC. & 1.708 & 0.100 & 0.149 & -0.056 & 3.08 & 4.19 & 1.74 & 1.60 & 2.04 & 1.88 & -0.15 & $-8 \%$ & 2.27 & 1.50 & -0.77 & $-34 \%$ \\
\hline TD. & 1.884 & 0.123 & 0.146 & -0.047 & 3.07 & 2.68 & 1.74 & 1.45 & 2.15 & 2.37 & 0.22 & $10 \%$ & 2.39 & 2.14 & -0.26 & $-11 \%$ \\
\hline TCT. & 1.793 & 0.132 & 0.145 & -0.001 & 3.08 & 3.04 & 1.73 & 1.30 & 2.22 & 2.67 & 0.45 & $20 \%$ & 2.60 & 3.03 & 0.44 & $17 \%$ \\
\hline SCT. & 1.784 & 0.130 & 0.128 & 0.027 & 3.08 & 3.36 & 1.73 & 1.15 & 2.32 & 2.98 & 0.66 & $28 \%$ & 2.70 & 3.58 & 0.88 & $32 \%$ \\
\hline $\mathrm{RC}$. & 1.736 & 0.092 & 0.166 & -0.109 & 3.09 & 3.94 & 1.73 & 1.38 & 1.91 & 1.26 & -0.65 & $-34 \%$ & 1.96 & 0.27 & -1.69 & $-86 \%$ \\
\hline RD. & 1.592 & 0.098 & 0.273 & -0.066 & 3.07 & 2.73 & 1.74 & 1.13 & 2.02 & 1.99 & -0.03 & $-1 \%$ & 2.44 & 1.88 & -0.55 & $-23 \%$ \\
\hline RCT. & 2.788 & 0.138 & -0.191 & -0.047 & 3.09 & 3.10 & 1.73 & 1.18 & 2.49 & 2.66 & 0.17 & $7 \%$ & 1.89 & 1.67 & -0.22 & $-11 \%$ \\
\hline \multicolumn{17}{|c|}{ PRD. Product optimisation } \\
\hline TC. & 1.221 & 0.496 & 0.001 & 0.027 & 2.79 & 4.19 & 1.57 & 1.60 & 1.91 & 3.69 & 1.78 & $93 \%$ & 2.02 & 4.08 & 2.05 & $101 \%$ \\
\hline SCT. & 0.721 & 0.525 & 0.127 & 0.157 & 2.79 & 3.36 & 1.57 & 1.15 & 2.07 & 4.81 & 2.74 & $133 \%$ & 2.80 & 6.69 & 3.89 & $139 \%$ \\
\hline $\mathrm{RC}$. & 1.046 & 0.493 & 0.050 & 0.022 & 2.79 & 3.94 & 1.57 & 1.38 & 1.85 & 3.58 & 1.73 & $94 \%$ & 2.06 & 3.99 & 1.93 & $94 \%$ \\
\hline RD. & 1.016 & 0.490 & 0.088 & 0.022 & 2.79 & 2.73 & 1.57 & 1.13 & 1.80 & 3.45 & 1.65 & $92 \%$ & 2.06 & 3.87 & 1.81 & $88 \%$ \\
\hline RCT. & 1.742 & 0.502 & -0.165 & -0.016 & 2.79 & 3.10 & 1.57 & 1.18 & 2.00 & 3.48 & 1.48 & $74 \%$ & 1.56 & 2.93 & 1.36 & $87 \%$ \\
\hline
\end{tabular}


(continued)

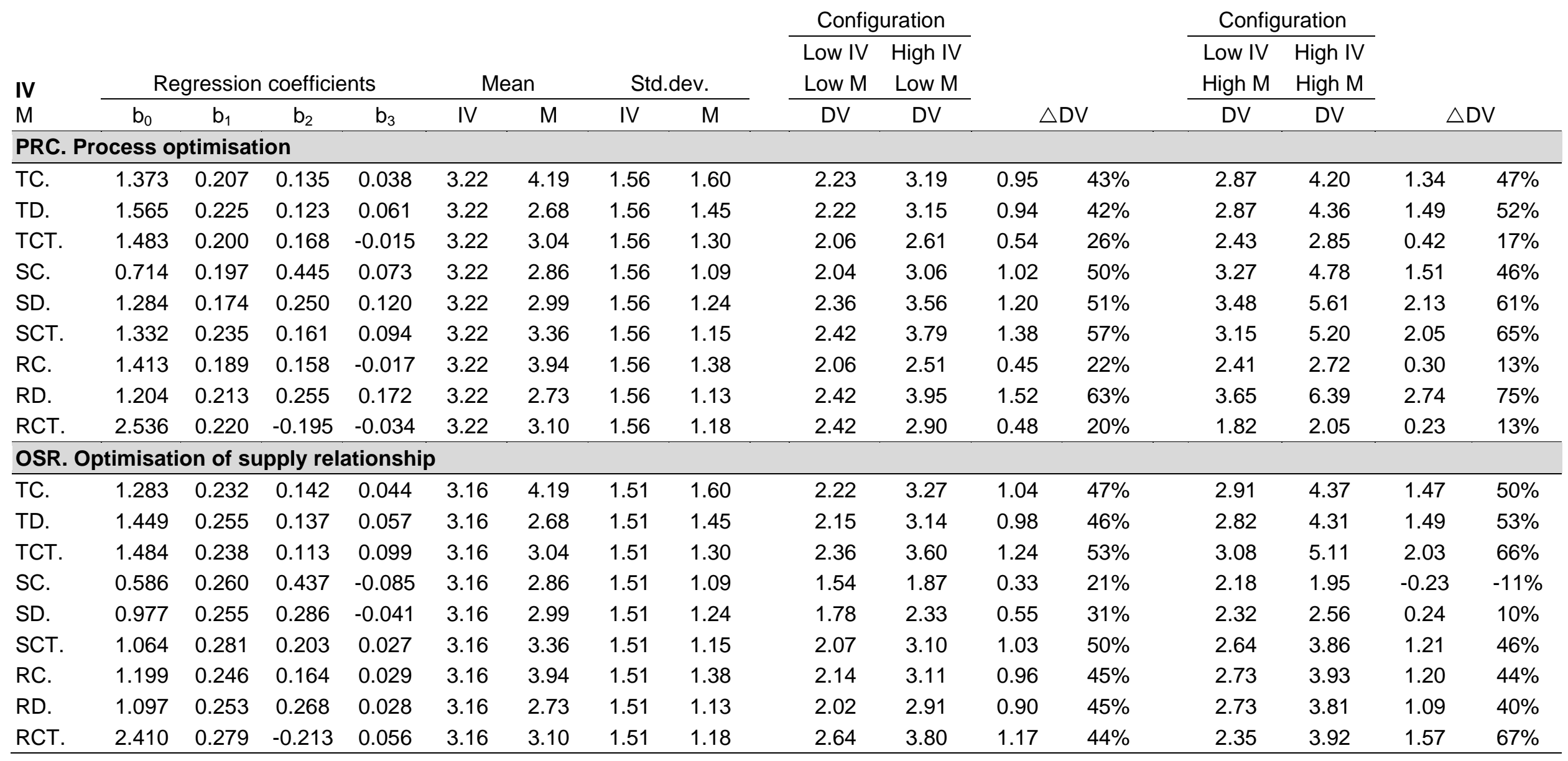


(continued)

\begin{tabular}{|c|c|c|c|c|c|c|c|c|c|c|c|c|c|c|c|c|}
\hline \multirow{3}{*}{$\begin{array}{l}\text { IV } \\
\text { M }\end{array}$} & & & & & & & & & \multicolumn{2}{|c|}{ Configuration } & & & \multicolumn{2}{|c|}{ Configuration } & & \\
\hline & \multicolumn{4}{|c|}{ Regression coefficients } & \multicolumn{2}{|c|}{ Mean } & \multicolumn{2}{|c|}{ Std.dev. } & Low IV & High IV & \multirow{2}{*}{\multicolumn{2}{|c|}{$\triangle D V$}} & Low IV & High IV & \multirow{2}{*}{\multicolumn{2}{|c|}{$\triangle \mathrm{DV}$}} \\
\hline & $\mathrm{b}_{0}$ & $b_{1}$ & $\mathrm{~b}_{2}$ & $b_{3}$ & IV & $\mathrm{M}$ & IV & $\mathrm{M}$ & DV & DV & & & DV & DV & & \\
\hline TC. & 1.530 & 0.187 & 0.168 & -0.052 & 2.15 & 4.19 & 1.57 & 1.60 & 2.00 & 2.15 & 0.16 & $8 \%$ & 2.43 & 2.07 & -0.37 & $-15 \%$ \\
\hline TD. & 1.930 & 0.170 & 0.125 & -0.002 & 2.15 & 2.68 & 1.57 & 1.45 & 2.18 & 2.71 & 0.53 & $24 \%$ & 2.54 & 3.06 & 0.51 & $20 \%$ \\
\hline TCT. & 1.647 & 0.179 & 0.199 & -0.040 & 2.15 & 3.04 & 1.57 & 1.30 & 2.06 & 2.40 & 0.34 & $17 \%$ & 2.51 & 2.53 & 0.01 & $0 \%$ \\
\hline SCT. & 1.445 & 0.224 & 0.217 & 0.062 & 2.15 & 3.36 & 1.57 & 1.15 & 2.13 & 3.27 & 1.13 & $53 \%$ & 2.72 & 4.30 & 1.58 & $58 \%$ \\
\hline RC. & 1.446 & 0.192 & 0.198 & -0.048 & 2.15 & 3.94 & 1.57 & 1.38 & 1.99 & 2.21 & 0.22 & $11 \%$ & 2.46 & 2.27 & -0.20 & $-8 \%$ \\
\hline RD. & 1.541 & 0.158 & 0.272 & 0.041 & 2.15 & 2.73 & 1.57 & 1.13 & 2.11 & 2.81 & 0.70 & $33 \%$ & 2.78 & 3.77 & 1.00 & $36 \%$ \\
\hline RCT. & 2.683 & 0.204 & -0.156 & 0.088 & 2.15 & 3.10 & 1.57 & 1.18 & 2.60 & 3.77 & 1.17 & $45 \%$ & 2.35 & 4.18 & 1.83 & $78 \%$ \\
\hline
\end{tabular}

TC. = Technological complexity; TD. = Technological dynamism; TCT. $=$ Technological competition; SC. $=$ Supply market complexity; SD. = Supply market dynamism; SCT. = Supply market competition; RC. = Relational complexity; RD. = Relational dynamism; RCT. = Relational competition

DV (Dependent variable) $=$ Innovation performance

M (Moderator) = Contingency factors TC., TD., TCT., SC., SD., SCT., RC., RD., RCT.

IV (Independent variable) = Sourcing lever VB., PE., ESB., PRD., PRC., OSR., CS.

$\triangle \mathrm{DV}=$ Change in the DV, when IV is changed from 'low' to 'high' 



\section{REFERENCES}

Achrol, R.S., Stern, L.W., 1988. Environmental determinants of decisionmaking uncertainty in marketing channels. Journal of marketing research 25, 36-50.

Adobor, H., McMullen, R.S., 2014. Strategic purchasing and supplier partnerships - The role of a third party organization. Journal of Purchasing and Supply Management 20, 263-272.

Ageron, B., Lavastre, O., Spalanzani, A., 2013. Innovative supply chain practices: the state of French companies. Supply chain management: an international journal 18, 265-276.

Agrawal, T., Sao, A., Fernandes, K.J., Tiwari, M.K., Kim, D.Y., 2013. A hybrid model of component sharing and platform modularity for optimal product family design. International Journal of Production Research 51, 614-625.

Ahtonen, A.-K., Virolainen, V.-M., 2009. Supply strategy in the food industry value net perspective. International Journal of Logistics: Research and Applications 12, 263-279.

Akin, M., Van Raaij, E.M., Wynstra, F., 2011. The Link Between Purchasing Strategies and Purchasing Structure, 42nd Decision Sciences Institute Annual Meeting, Boston, pp. 5121-5126.

Akin, M., Van Raaij, E.M., Wynstra, J.Y.F., 2010. A typology of purchasing strategies: An analysis at the purchase category level, 19th IPSERA Conference, Lappeenranta, pp. 471-481.

Aldrich, H., 1979. Organizations and environments. Prentice-Hall, Englewood Cliffs.

Amabile, T.M., Patterson, C., Mueller, J., Wojcik, T., Odomirok, P.W., Marsh, M., Kramer, S.J., 2001. Academic-practitioner collaboration in management research: A case of cross-profession collaboration. Academy of Management Journal 44, 418-431.

Amann, M., Essig, M., 2011. Der "Strategic Fit" bei Wettbewerbs- und Beschaffungsstrategien von Unternehmen. Marketing Review St. Gallen 28, 8-13.

Anderson, J.C., Wynstra, F., 2010. Purchasing higher-value, higher-price offerings in business markets. Journal of Business-to-business Marketing 17, 29-61. 
Appelfeller, W., Buchholz, W., 2010. Supplier Relationship Management: Strategie, Organisation und IT des modernen Beschaffungsmanagements. Gabler Verlag, Wiesbaden.

Arnold, U., 1997. Beschaffungsmanagement, 2 ed. Schäffer-Poeschel, Stuttgart. Arnold, U., 2006. Strategisches Beschaffungsmanagement, In: Arnold, U., Kasulke, G. (Eds.), Praxishandbuch innovative Beschaffung: Wegweiser für den strategischen und operativen Einkauf. Wiley $\mathrm{VCH}$ Verlag $\mathrm{GmbH}$, Weinheim.

Arnold, U., Essig, M., 2000. Sourcing-Konzepte als Grundelemente der Beschaffungsstrategie. Wirtschaftswissenschaftliches Studium 29, 122-128.

Arnold, U., Kärner, H., Schnabel, M., 2005. Target-oriented use of strategic sourcing tools: A critical analysis creating process awareness for electronic reverse auctions. Journal of Purchasing and Supply Management 11, 116-128.

Ateş, M., 2014. Purchasing and Supply Management at the Purchase Category Level: strategy, structure and performance. Erasmus Research Institute of Management (ERIM).

Ateş, M.A., Wynstra, F., van Raaij, E., 2015. An exploratory analysis of the relationship between purchase category strategies and supply base structure. Journal of Purchasing and Supply Management.

Atuahene-Gima, K., 1995. Involving organizational buyers in new product development. Industrial Marketing Management 24, 215-226.

Autry, C.W., Golicic, S.L., 2010. Evaluating buyer-supplier relationshipperformance spirals: A longitudinal study. Journal of operations management $28,87-100$.

Axelsson, B., Rozemeijer, F., Wynstra, F., 2005. Developing sourcing capabilities: creating strategic change in purchasing and supply management. John Wiley \& Sons, Chichester.

Azadegan, A., Dooley, K.J., 2010. Supplier innovativeness, organizational learning styles and manufacturer performance: An empirical assessment. Journal of operations management 28, 488-505.

Azadegan, A., Patel, P.C., Zangoueinezhad, A., Linderman, K., 2013. The effect of environmental complexity and environmental dynamism on lean practices. Journal of operations management 31, 193-212.

Baier, C., 2008. The alignment performance link in purchasing and supply management: Performance implications of fit between business strategy, purchasing strategy, and purchasing practices. Gabler Verlag, Wiesbaden.

Baier, C., Hartmann, E., Moser, R., 2008. Strategic alignment and purchasing efficacy: an exploratory analysis of their impact on financial performance. Journal of Supply Chain Management 44, 36-52.

Baily, P., Farmer, D., Crocker, B., Jessop, D., Jones, D., 2008. Procurement principles and management, 10 ed. Prentice Hall Financial Times, Harlow.

Bandyopadhyay, S., 2009. A dynamic model of cross-category competition: theory, tests and applications. Journal of Retailing 85, 468-479. 
Baud-Lavigne, B., Agard, B., Penz, B., 2012. Mutual impacts of product standardization and supply chain design. International Journal of Production Economics 135, 50-60.

Baxter, R., 2012. How can business buyers attract sellers' resources?: Empirical evidence for preferred customer treatment from suppliers. Industrial Marketing Management 41, 1249-1258.

Ben-Arieh, D., Qian, L., 2003. Activity-based cost management for design and development stage. International Journal of Production Economics 83, 169183.

Bengtsson, L., Von Haartman, R., Dabhilkar, M., 2009. Low-cost versus innovation: Contrasting outsourcing and integration strategies in manufacturing. Creativity and Innovation Management 18, 35-47.

Bensaou, M., 1999. Portfolios of buyer-supplier relationships. Sloan management review 40, 35-44.

Benton, W.C., 2009. Purchasing and Supply Chain Management, 2 ed. McGraw-Hill Education, Irwin.

Bezawada, R., Balachander, S., Kannan, P., Shankar, V., 2009. Cross-category effects of aisle and display placements: A spatial modeling approach and insights. Journal of Marketing 73, 99-117.

Bhutta, K.S., Huq, F., 2002. Supplier selection problem: a comparison of the total cost of ownership and analytic hierarchy process approaches. Supply chain management: an international journal 7, 126-135.

Birkinshaw, J., Morrison, A., Hulland, J., 1995. Structural and competitive determinants of a global integration strategy. Strategic Management Journal 16, 637-655.

Birou, L., Fawcett, S.E., Magnan, G.M., 1997. Integrating product life cycle and purchasing strategies. Journal of Supply Chain Management 33, 23-31.

Blonska, A., Storey, C., Rozemeijer, F., Wetzels, M., de Ruyter, K., 2013. Decomposing the effect of supplier development on relationship benefits: The role of relational capital. Industrial Marketing Management 42, 1295-1306.

Bourgeois, L.J., 1980. Strategy and Environment: A Conceptual Integration. Academy of management review 5, 25-39.

Boutellier, R., Wagner, S.M., 2003. Sourcing concepts: Matching product architecture, task interface, supplier competence and supplier relationship, Business engineering. Springer, pp. 223-248.

Boutellier, R., Zagler, M., 2000. Materialgruppenmanagement und Einkaufskooperationen. Hanser Verlag, München.

Boyd, B.K., Dess, G.G., Rasheed, A.M.A., 1993. Divergence between archival and perceptual measures of the environment: Causes and consequences. Academy of management review 18, 204-226.

Bozarth, C., Handfield, R.B., Das, A., 1998. Stages of global sourcing strategy evolution: An exploratory study. Journal of operations management 16, 241255. 
Bozarth, C.C., Warsing, D.P., Flynn, B.B., Flynn, E.J., 2009. The impact of supply chain complexity on manufacturing plant performance. Journal of operations management 27, 78-93.

Bräkling, E., Oidtmann, K., 2012. Power in Procurement: Erfolgreich einkaufen - Wettbewerbsvorteile sichern - Gewinne steigern. Gabler Verlag, Wiesbaden.

Brandes, H., 1994. Strategic changes in purchasing: Two main tracks. European Journal of Purchasing \& Supply Management 1, 77-87.

Brown, J., Isaacs, D., 2005. The world café: Shaping our futures through conversations that matter. Berrett-Koehler, San Francisco.

Burgelman, R.A., Grove, A.S., 1996. Strategie dissonance. California Management Review 38, 8-28.

Burns, T., Stalker, G.M., 1961. The management of innovation. University of Illinois at Urbana-Champaign's Academy for Entrepreneurial Leadership Historical Research Reference in Entrepreneurship 17, 143-144.

Burt, D., Petcavage, S., Pinkerton, R., 2011. Proactive purchasing in the supply chain: The key to world-class procurement. McGraw-Hill Education, Irwin.

Burt, D.N., Dobler, D.W., Starling, S.L., 2003. World class supply management: The key to supply chain management, 7 ed. McGraw-Hill, New York.

Büsch, M., 2011. Praxishandbuch Strategischer Einkauf: Methoden, Verfahren, Arbeitsblätter für professionelles Beschaffungsmanagement, 2 ed. Gabler Verlag, Wiesbaden.

Cachon, G.P., Kök, A.G., 2007. Category management and coordination in retail assortment planning in the presence of basket shopping consumers. Management Science 53, 934-951.

Caddick, J., Dale, B., 1987. The determination of purchasing objectives and strategies: some key influences. International Journal of Physical Distribution \& Logistics Management 17, 5-16.

Calantone, R., Garcia, R., Dröge, C., 2003. The effects of environmental turbulence on new product development strategy planning. Journal of Product Innovation Management 20, 90-103.

Cammish, R., Keough, M., 1991. A strategic role for purchasing. The McKinsey Quarterly 3, 22-39.

Caniato, F., Luzzini, D., Ronchi, S., 2014. Purchasing performance management systems: an empirical investigation. Production Planning \& Control 25, 616635.

Canièls, M.C.J., Gelderman, C.J., 2005. Purchasing strategies in the Kraljic matrix: A power and dependence perspective. Journal of Purchasing and Supply Management 11, 141-155.

Caniëls, M.C.J., Gelderman, C.J., 2007. Power and interdependence in buyer supplier relationships: A purchasing portfolio approach. Industrial Marketing Management 36, 219-229.

Cannon, J.P., Homburg, C., 2001. Buyer-supplier relationships and customer firm costs. Journal of Marketing 65, 29-43. 
Cannon, J.P., Perreault Jr, W.D., 1999. Buyer-seller relationships in business markets. Journal of marketing research, 439-460.

Cao, M., Zhang, Q., 2011. Supply chain collaboration: impact on collaborative advantage and firm performance. Journal of operations management 29, 163180.

Carey, S., Lawson, B., Krause, D.R., 2011. Social capital configuration, legal bonds and performance in buyer-supplier relationships. Journal of operations management 29, 277-288.

Carr, A.S., Pearson, J.N., 1999. Strategically managed buyer-supplier relationships and performance outcomes. Journal of operations management 17, 497-519.

Carr, A.S., Pearson, J.N., 2002. The impact of purchasing and supplier involvement on strategic purchasing and its impact on firm's performance. International Journal of Operations \& Production Management 22, 10321053.

Carr, A.S., Smeltzer, L.R., 1997. An empirically based operational definition of strategic purchasing. European Journal of Purchasing \& Supply Management 3, 199-207.

Carr, A.S., Smeltzer, L.R., 2000. An empirical study of the relationships among purchasing skills and strategic purchasing, financial performance, and supplier responsiveness. Journal of Supply Chain Management 36, 40-54.

Carter, J.R., 2006. Development of supply strategies, In: Cavinato, J.L. (Ed.), The supply mangement handbook, 7 ed. McGraw-Hill, New York.

Carter, J.R., Maltz, A., Yan, T., Maltz, E., 2008. How procurement managers view low cost countries and geographies: a perceptual mapping approach. International Journal of Physical Distribution \& Logistics Management 38, 224-243.

Carter, J.R., Narasimhan, R., 1996. Is purchasing really strategic? Journal of Supply Chain Management 32, 20-28.

Castaldo, S., Zerbini, F., Grosso, M., 2009. Integration of third parties within existing dyads: An exploratory study of category management programs (CMPs). Industrial Marketing Management 38, 946-959.

Castrogiovanni, G.J., 1991. Environmental munificence: A theoretical assessment. Academy of management review 16, 542-565.

Castrogiovanni, G.J., 2002. Organization task environments: Have they changed fundamentally over time? Journal of Management 28, 129-150.

Cavinato, J., 2006. The Supply Mangement Handbook, 7th Ed. McGraw-Hill Education.

Cavusgil, S.T., Yaprak, A., Yeoh, P.L., 1993. A decision-making framework for global sourcing. International Business Review 2, 143-156.

Cenfetelli, R.T., Bassellier, G., 2009. Interpretation of formative measurement in information systems research. Management Information Systems Quarterly 33,7 . 
Chatterjee, S.C., Hyvönen, S., Anderson, E., 1995. Concentrated vs. balanced sourcing: An examination of retailer purchasing decisions in closed markets. Journal of Retailing 71, 23-46.

Chen, I.J., Paulraj, A., 2004. Towards a theory of supply chain management: the constructs and measurements. Journal of operations management 22, 119150.

Chen, I.J., Paulraj, A., Lado, A.A., 2004. Strategic purchasing, supply management, and firm performance. Journal of operations management 22, 505-523.

Chesley, J.A., Wenger, M.S., 1999. Transforming an organization: using models to foster a strategic conversation. California Management Review 41, 54.

Chicksand, D., Watson, G., Walker, H., Radnor, Z., Johnston, R., 2012. Theoretical perspectives in purchasing and supply chain management: an analysis of the literature. Supply chain management: an international journal $17,454-472$.

Child, J., 1972. Organizational structure, environment and performance: The role of strategic choice. Sociology 6, 1-22.

Chin, W.W., 1998. The partial least squares approach to structural equation modeling. Modern methods for business research 295, 295-336.

Chintagunta, P.K., Haldar, S., 1998. Investigating purchase timing behavior in two related product categories. Journal of marketing research 35, 43-53.

Choffray, J.M., Lilien, G.L., 1980. Industrial market segmentation by the structure of the purchasing process. Industrial Marketing Management 9, 331342.

Choi, T.Y., Hartley, J.L., 1996. An exploration of supplier selection practices across the supply chain. Journal of operations management 14, 333-343.

Choi, T.Y., Krause, D.R., 2006. The supply base and its complexity: Implications for transaction costs, risks, responsiveness, and innovation. Journal of operations management 24, 637-652.

Churchill, G.A.J., 1979. A paradigm for developing better measures of marketing constructs. Journal of marketing research 16, 64-73.

Cohen, J., 1983. The cost of dichotomization. Applied Psychological Measurement 7, 247-253.

Cohen, J., Cohen, P., West, S.G., Aiken, L.S., 2013. Applied Multiple Regression/Correlation Analysis for the Behavioral Sciences. Taylor \& Francis.

Coltman, T., Devinney, T.M., Midgley, D.F., Venaik, S., 2008. Formative versus reflective measurement models: Two applications of formative measurement. Journal of Business Research 61, 1250-1262.

Cooper, R., Yoshikawa, T., 1994. Inter-organizational cost management systems: The case of the Tokyo-Yokohama-Kamakura supplier chain. International Journal of Production Economics 37, 51-62. 
Costantino, N., Pellegrino, R., 2010. Choosing between single and multiple sourcing based on supplier default risk: A real options approach. Journal of Purchasing and Supply Management 16, 27-40.

Cousins, P.D., 2005. The alignment of appropriate firm and supply strategies for competitive advantage. International Journal of Operations \& Production Management 25, 403-428.

Cousins, P.D., Lawson, B., 2007. Sourcing strategy, supplier relationships and firm performance: An empirical investigation of UK organizations. British Journal of Management 18, 123-137.

Cousins, P.D., Lawson, B., Squire, B., 2008a. Performance measurement in strategic buyer-supplier relationships: The mediating role of socialization mechanisms. International Journal of Operations \& Production Management 28, 238-258.

Cousins, P.M., Lamming, R., Lawson, B., Squire, B., 2008b. Strategic supply management: Principles, theories and practice. Prentice Hall, Harlow.

Cox, A., 1996. Relational competence and strategic procurement management: Towards an entrepreneurial and contractual theory of the firm. European Journal of Purchasing \& Supply Management 2, 57-70.

Cox, A., 2004. The art of the possible: relationship management in power regimes and supply chains. Supply chain management: an international journal 9, 346-356.

Cox, A., 2014. Sourcing Portfolio Analysis. Earlsgate Press, London.

Cox, A., Chicksand, D., Ireland, P., Davies, T., 2005. Sourcing Indirect Spend: A Survey of Current Internal and External Strategies for Non-RevenueGenerating Goods and Services. Journal of Supply Chain Management 41, 39-51.

Cox, A., Ireland, P., Lonsdale, C., Sanderson, J., Watson, G., 2003. Supply Chains, Markets and Power: Managing Buyer and Supplier Power Regimes. Taylor \& Francis.

Cox, A., Sanderson, J., Watson, G., 2001. Supply chains and power regimes: toward an analytic framework for managing extended networks of buyer and supplier relationships. Journal of Supply Chain Management 37, 28-35.

Cuervo-Cazurra, A., Caligiuri, P., Andersson, U., Brannen, M.Y., 2013. From the Editors: How to write articles that are relevant to practice. Journal of International Business Studies 44, 285-289.

Daly, S.P., Nath, P., 2005. Reverse auctions for relationship marketers. Industrial Marketing Management 34, 157-166.

Danese, P., Filippini, R., 2010. Modularity and the impact on new product development time performance: Investigating the moderating effects of supplier involvement and interfunctional integration. International Journal of Operations \& Production Management 30, 1191-1209.

Dankbaar, B., 2007. Global sourcing and innovation: the consequences of losing both organizational and geographical proximity. European Planning Studies $15,271-288$. 
Dawson, J.F., 2014. Moderation in management research: What, why, when, and how. Journal of Business and Psychology 29, 1-19.

Day, M., Magnan, G.M., Moeller, M.M., 2010. Evaluating the bases of supplier segmentation: A review and taxonomy. Industrial Marketing Management 39, 625-639.

Day, M., Purchasing, C.I.o., Supply, Company, G.P., 2002. Gower Handbook of Purchasing Management. Gower.

De Boer, L., Labro, E., Morlacchi, P., 2001. A review of methods supporting supplier selection. European Journal of Purchasing \& Supply Management 7, 75-89.

de Quervain, M.A., Wagner, S.M., 2003. Von der Strategiefindung zur Strategieumsetzung, In: Boutellier, R., Wagner, S.M., Wehrli, H.P. (Eds.), Handbuch Beschaffung: Strategien - Methoden - Umsetzung. Carl Hanser Verlag, München.

DeCoster, J., Iselin, A.-M.R., Gallucci, M., 2009. A conceptual and empirical examination of justifications for dichotomization. Psychological methods 14, 349.

Dekkers, R., 2002. Strategic capacity management: meeting technological demands and performance criteria. International Journal of Production Research 40, 3895-3911.

Dess, G.G., Beard, D.W., 1984. Dimensions of organizational task environments. Administrative science quarterly 29, 52-73.

Diamantopoulos, A., Riefler, P., Roth, K.P., 2008. Advancing formative measurement models. Journal of Business Research 61, 1203-1218.

Diamantopoulos, A., Siguaw, J.A., 2006. Formative versus reflective indicators in organizational measure development: a comparison and empirical illustration. British Journal of Management 17, 263-282.

Diamantopoulos, A., Winklhofer, H.M., 2001. Index construction with formative indicators: an alternative to scale development. Journal of marketing research 38, 269-277.

Dobler, D., Burt, D., Lee Jr, L., 1990. Purchasing and materials management: Text and cases. McGraw-Hill, New York.

Downey, H.K., Hellriegel, D., Slocum Jr, J.W., 1975. Environmental uncertainty: the construct and its application. Administrative science quarterly 20, 613-629.

Drake, P.R., Lee, D.M., Hussain, M., 2013. The lean and agile purchasing portfolio model. Supply chain management: an international journal 18, 3-20.

Driedonks, B.A., Gevers, J.M., van Weele, A.J., 2013. Success factors for sourcing teams: How to foster sourcing team effectiveness. European Management Journal 32, 288-304.

Driedonks, B.A., J.M.P.; Van Weele, A.J., 2010. Managing sourcing team effectiveness: The need for a team perspective in purchasing organizations. Journal of Purchasing and Supply Management 16, 109-117. 
Droege, 1998. Gewinne einkaufen: Best practices im Beschaffungsmanagement. Gabler Verlag, Wiesbaden.

Dubois, A., Fredriksson, P., 2008. Cooperating and competing in supply networks: Making sense of a triadic sourcing strategy. Journal of Purchasing and Supply Management 14, 170-179.

Dubois, A., Pedersen, A.C., 2002. Why relationships do not fit into purchasing portfolio models - A comparison between the portfolio and industrial network approaches. European Journal of Purchasing \& Supply Management 8, 35-42.

Dubois, A., Wynstra, F., 2005. Developing the supply base by changing supplier relations, In: Axelsson, B., Rozemeijer, F., Wynstra, F. (Eds.), Developing sourcing capabilities: Creating strategic change in purchasing and supply management, John Wiley \& Sons.

Dyer, J.H., Cho, D.S., Chu, W., 1998. Strategic supplier segmentation: The next 'best practice' in supply chain managment. California Management Review 40, 55-77.

Eckhaus, E., Kogan, K., Perlman, Y., 2013. Enhancing Strategic Supply Decisions by Estimating Suppliers' Marginal Costs. Journal of Supply Chain Management 49, 96-107.

Edwards, J.R., Lambert, L.S., 2007. Methods for integrating moderation and mediation: a general analytical framework using moderated path analysis. Psychological methods 12, 1 .

Elliott-Shircore, T., Steele, P., 1985. Procurement positioning overview. Purchasing and Supply Management, December 23, 26.

Ellis, S.C., Henke Jr, J.W., Kull, T.J., 2012. The effect of buyer behaviors on preferred customer status and access to supplier technological innovation: An empirical study of supplier perceptions. Industrial Marketing Management 41, 1259-1269.

Ellis, S.C., Henry, R.M., Shockley, J., 2010. Buyer perceptions of supply disruption risk: a behavioral view and empirical assessment. Journal of operations management 28, 34-46.

Ellram, L.M., 1996. A structured method for applying purchasing cost management tools. Journal of Supply Chain Management 32, 11-19.

Ellram, L.M., Carr, A., 1994. Strategic purchasing: A history and review of the literature. Journal of Supply Chain Management 30, 9-19.

Ellram, L.M., Perrott Siferd, S., 1993. Purchasing: the cornerstone of the total cost of ownership concept. Journal of Business Logistics 14, 163-163.

Ellram, L.M., Zsidisin, G.A., Perrott Siferd, S., Stanly, M.J., 2002. The impact of purchasing and supply management activities on corporate success. Journal of Supply Chain Management 38, 4-17.

Emiliani, M.L., 2000. Business-to-business online auctions: key issues for purchasing process improvement. Supply chain management: an international journal 5, 176-186. 
Englyst, L., Jørgensen, F., Johansen, J., Mikkelsen, O.S., 2008. Commodity team motivation and performance. Journal of Purchasing and Supply Management 14, 15-27.

Essig, M., 2000. Purchasing consortia as symbiotic relationships: developing the concept of "consortium sourcing". European Journal of Purchasing \& Supply Management 6, 13-22.

Essig, M., 2011. Book reviews - Purchasing and supply chain management: Analysis, strategy, planning and practice, 5th ed., Arjan van Weele. Cengage Learning, Andover, UK (2010). ISBN: 978-1-4080-1896-5. Journal of Purchasing and Supply Management 17, 143-144.

Essig, M., Wagner, S.M., 2003. Strategien in der Beschaffung. Zeitschrift für Planung und Unternehmenssteuerung 14, 279-296.

Faes, W., Matthyssens, P., 2009. Insights into the process of changing sourcing strategies. The Journal of Business and Industrial Marketing 24, 245-255.

Ferguson, W.C., Hartley, M.F., Turner, G.B., Pierce, E.M., 1996. Purchasing's role in corporate strategic planning. International Journal of Physical Distribution \& Logistics Management 26, 51-62.

Fernández, I., Kekäle, T., 2005. The influence of modularity and industry clockspeed on reverse logistics strategy: implications for the purchasing function. Journal of Purchasing and Supply Management 11, 193-205.

Fliess, S., Becker, U., 2006. Supplier integration-Controlling of codevelopment processes. Industrial Marketing Management 35, 28-44.

Forker, L.B., 1997. Factors affecting supplier quality performance. Journal of operations management 15, 243-269.

Foster Jr, S.T., Wallin, C., Ogden, J., 2011. Towards a better understanding of supply chain quality management practices. International Journal of Production Research 49, 2285-2300.

Fuchs, A., Kaufmann, L., 2008. Von Zielen zu Erfolgen: Strategische Lieferantenbeziehungen gestalten, In: BME (Ed.), Best Practice in Einkauf und Logistik. Gabler Verlag, Wiesbaden.

Gadde, L.-E., Snehota, I., 2000. Making the most of supplier relationships. Industrial Marketing Management 29, 305-316.

Gadde, L.E., Hakansson, H., 1994. The changing role of purchasing: Reconsidering three strategic issues. European Journal of Purchasing \& Supply Management 1, 27-35.

Gadde, L.E., Hakansson, H., Persson, G., 2010. Supply network strategies. John Wiley \& Sons, Chichester.

Gelderman, C.J., Semeijn, J., 2006. Managing the global supply base through purchasing portfolio management. Journal of Purchasing and Supply Management 12, 209-217.

Gelderman, C.J., Van Weele, A.J., 2002. Strategic direction through purchasing portfolio management: A case study. Journal of Supply Chain Management $38,30-37$. 
Gelderman, C.J., Van Weele, A.J., 2003. Handling measurement issues and strategic directions in Kraljic's purchasing portfolio model. Journal of Purchasing and Supply Management 9, 207-216.

Gelderman, C.J., Van Weele, A.J., 2005. Purchasing portfolio models: A critique and update. Journal of Supply Chain Management 41, 19-28.

Ghijsen, P.W.T., Semeijn, J., Ernstson, S., 2010. Supplier satisfaction and commitment: The role of influence strategies and supplier development. Journal of Purchasing and Supply Management 16, 17-26.

Glock, C., Hochrein, S., 2011. Purchasing Organization and Design: a literature review. BuR Business Research Journal 4, 149-191.

Gnyawali, D.R., Madhavan, R., 2001. Cooperative networks and competitive dynamics: A structural embeddedness perspective. Academy of management review 26, 431-445.

Goh, M., Lau, G.T., Neo, L., 1999. Strategic role and contribution of purchasing in Singapore: A survey of CEOs. Journal of Supply Chain Management 35, 12-22.

González-Benito, J., 2007. A theory of purchasing's contribution to business performance. Journal of operations management 25, 901-917.

González-Benito, J., 2010. Supply strategy and business performance: An analysis based on the relative importance assigned to generic competitive objectives. International Journal of Operations \& Production Management 30, 774-797.

González-Benito, J., Reis da Rocha, D., Queiruga, D., 2010. The environment as a determining factor of purchasing and supply strategy: An empirical analysis of Brazilian firms. International Journal of Production Economics 124, 1-10.

Göpfert, I., Grünert, M., 2010. Die optimale Ausgestaltung der beschaffungsseitigen Beziehungen bei Automobilherstellern: Ein transaktionskostenbasierter Erklärungsansatz, In: Schönberger, R., Elbert, R. (Eds.), Dimensionen der Logistik: Funktionen, Institutionen und Handlungsebenen. Gabler Verlag, Wiesbaden, pp. 47-70.

Gottfredson, M., Phillips, S., 2005. A sourcing strategy for enhancing core capabilities. Strategy and Leadership 33, 48-49.

Gunasekaran, A., Patel, C., Tirtiroglu, E., 2001. Performance measures and metrics in a supply chain environment. International Journal of Operations \& Production Management 21, 71-87.

Hadeler, B., Evans, J., 1994. Supply strategy: Capturing the value. Industrial Management 36, 3-4.

Hair, J.F., Black, W.C., Babin, B.J., Anderson, R.E., Tatham, R.L., 2010. Multivariate data analysis. Prentice Hall New Jersey.

Hair Jr., J.F., Hult, G.T.M., Ringle, C., Sarstedt, M., 2013. A primer on partial least squares structural equation modeling (PLS-SEM). SAGE Publications, Inc., London. 
Hallikas, J., Karvonen, I., Pulkkinen, U., Virolainen, V.-M., Tuominen, M., 2004. Risk management processes in supplier networks. International Journal of Production Economics 90, 47-58.

Handfield, R.B., Krause, D.R., Scannell, T.V., Monczka, R.M., 2000. Avoid pitfalls in supplier development. Sloan management review 42, 37-49.

Handfield, R.B., Monczka, R., Giunipero, L., Patterson, J.L., 2009. Sourcing and supply chain management. South-Western, Newgen.

Handfield, R.B., Ragatz, G.L., Peterson, K., Monczka, R.M., 1999. Involving suppliers in new product development? California Management Review 42, 59-82.

Harland, C.M., Lamming, R.C., Cousins, P.D., 1999. Developing the concept of supply strategy. International Journal of Operations \& Production Management 19, 650-674.

Hartley, J.L., 2000. Collaborative value analysis: experiences from the automotive industry. Journal of Supply Chain Management 36, 27-32.

Hartmann, E., Kerkfeld, D., Henke, M., 2012. Top and bottom line relevance of purchasing and supply management. Journal of Purchasing and Supply Management 18, 22-34.

Heikkilä, J., Kaipa, R., 2009. Purchasing Category Management - From Reactive to Proactive Management Practice, 19th IPSERA Conference, Oestrich-Winkel.

Hesping, F.H., Schiele, H., 2015. Purchasing strategy development: A multilevel review. Journal of Purchasing and Supply Management 21, 138-150.

Hess, G., 2010. Supply-Strategien in Einkauf und Beschaffung: Systematischer Ansatz und Praxisfälle, 2 ed. Gabler Verlag, Wiesbaden.

Hillman, A.J., Hitt, M.A., 1999. Corporate political strategy formulation: A model of approach, participation, and strategy decisions. Academy of management review 24, 825-842.

Hines, P., Rich, N., 1997. The seven value stream mapping tools. International Journal of Operations \& Production Management 17, 46-64.

Hoffmann, P., 2012. Innovative Supply Risk Management, In: Bogaschewsky, R., Essig, M., Lasch, R., Stoelzle, W. (Eds.), Supply Management Research. Springer, Wiesbaden, pp. 79-104.

Hoffmann, P., Schiele, H., Krabbendam, K., 2013. Uncertainty, supply risk management and their impact on performance. Journal of Purchasing and Supply Management 19, 199-211.

Hollander, M., Wolfe, D.A., Chicken, E., 2013. Nonparametric statistical methods. John Wiley \& Sons, Chichester.

Holweg, M., Reichhart, A., Hong, E., 2011. On risk and cost in global sourcing. International Journal of Production Economics 131, 333-341.

Hong, Y., Hartley, J.L., 2011. Managing the supplier-supplier interface in product development: The moderating role of technological newness. Journal of Supply Chain Management 47, 43-62. 
Horn, P., Schiele, H., Werner, W., 2013. The "ugly twins": Failed low-wagecountry sourcing projects and their expensive replacements. Journal of Purchasing and Supply Management 19, 27-38.

Hough, J.R., White, M.A., 2003. Environmental dynamism and strategic decision-making rationality: an examination at the decision level. Strategic Management Journal 24, 481-489.

Hult, G.T.M., Hurley, R.F., Knight, G.A., 2004. Innovativeness: Its antecedents and impact on business performance. Industrial Marketing Management 33, 429-438.

Hultman, J., Johnsen, T., Johnsen, R., Hertz, S., 2011. An interaction Approach to global sourcing: A case study of IKEA. Journal of Purchasing and Supply Management 18, 9-21.

Hunter, G.K., Bunn, M.D., Perreault, W.D., 2006. Interrelationships among key aspects of the organizational procurement process. International Journal of Research in Marketing 23, 155-170.

Hüttinger, L., Schiele, H., Veldman, J., 2012. The drivers of customer attractiveness, supplier satisfaction and preferred customer status: A literature review. Industrial Marketing Management 41, 1194-1205.

IBM, 2013. IBM SPSS Statistics for Windows, Version 22.0

Inemek, A., Matthyssens, P., 2013. The impact of buyer-supplier relationships on supplier innovativeness: An empirical study in cross-border supply networks. Industrial Marketing Management 42, 580-594.

Jahns, C., 2005. Supply Management: Neue Perspektiven eines Managementansatzes für Einkauf und Supply. Verlag Wiss. und Praxis, München.

Jap, S.D., 1999. Pie-expansion efforts: collaboration processes in buyer-supplier relationships. Journal of marketing research 36, 461-475.

Jarvis, C.B., MacKenzie, S.B., Podsakoff, P.M., 2003. A critical review of construct indicators and measurement model misspecification in marketing and consumer research. Journal of consumer research 30, 199-218.

Jarzabkowski, P., Kaplan, S., 2008. Using strategy tools in practice: an exploration of "technologies of rationality" in use, Academy of Management Proceedings. Academy of Management, pp. 1-6.

Jayaram, J., 2008. Supplier involvement in new product development projects: dimensionality and contingency effects. International Journal of Production Research 46, 3717-3735.

Jia, F., Lamming, R., Sartor, M., Orzes, G., Nassimbeni, G., 2014a. Global purchasing strategy and International Purchasing Offices: Evidence from case studies. International Journal of Production Economics 154, 284-298.

Jia, F., Lamming, R., Sartor, M., Orzes, G., Nassimbeni, G., 2014b. International purchasing offices in China: A dynamic evolution model. International Business Review 23, 580-593. 
Johnsen, T.E., 2009. Supplier involvement in new product development and innovation: Taking stock and looking to the future. Journal of Purchasing and Supply Management 15, 187-197.

Johnson, P.F., Leenders, M., Flynn, A., 2010. Purchasing and Supply Management, 14 ed. McGraw-Hill, Boston.

Johnson, P.F., Leenders, M.R., Flynn, A.E., 2011. Purchasing and Supply Management. McGraw-Hill.

Juha, M., Pentti, J., 2008. Managing risks in organizational purchasing through adaptation of buying centre structure and the buying process. Journal of Purchasing and Supply Management 14, 253-262.

Jurkovich, R., 1974. A core typology of organizational environments. Administrative science quarterly 19, 380-394.

Kähkönen, A.K., Lintukangas, K., 2012. The underlying potential of supply management in value creation. Journal of Purchasing and Supply Management.

Kaicker, A., Bearden, W.O., Manning, K.C., 1995. Component versus bundle pricing: the role of selling price deviations from price expectations. Journal of Business Research 33, 231-239.

Kakabadse, A., Kakabadse, N., 2002. Trends in Outsourcing: Contrasting USA and Europe. European Management Journal 20, 189-198.

Kamakura, W.A., Kang, W., 2007. Chain-wide and store-level analysis for cross-category management. Journal of Retailing 83, 159-170.

Kamann, D.J.F., 2000. Adding an extra dimension to the Kraljic portfolio, IPSERA Conference, London.

Kannan, V.R., Tan, K.C., 2002. Supplier selection and assessment: Their impact on business performance. Journal of Supply Chain Management 38, 11-21.

Karjalainen, K., 2011. Estimating the cost effects of purchasing centralizationEmpirical evidence from framework agreements in the public sector. Journal of Purchasing and Supply Management 17, 87-97.

Karjalainen, K., Salmi, A., 2013. Continental differences in purchasing strategies and tools. International Business Review 22, 112-125.

Karjalainen, K., van Raaij, E., 2011. An empirical test of contributing factors to different forms of maverick buying. Journal of Purchasing and Supply Management 17, 185-197.

Kaufmann, L., 2002. Purchasing and supply management-a conceptual framework, In: Hahn, D., Kaufmann, L. (Eds.), Handbuch industrielles Beschaffungsmanagement. Gabler Verlag, Wiesbaden, pp. 3-33.

Kaufmann, L., Kreft, S., Ehrgott, M., Reimann, F., 2012. Rationality in supplier selection decisions: The effect of the buyer's national task environment. Journal of Purchasing and Supply Management 18, 76-91.

Ketokivi, M.A., Schroeder, R.G., 2004. Perceptual measures of performance: fact or fiction? Journal of operations management 22, 247-264. 
Khan, O., Christopher, M., Burnes, B., 2008. The impact of product design on supply chain risk: a case study. International Journal of Physical Distribution \& Logistics Management 38, 412-432.

Khandwalla, P.N., 1972. Environment and its impact on the organization. International Studies of Management \& Organization 2, 297-313.

Kidd, P.S., Parshall, M.B., 2000. Getting the focus and the group: enhancing analytical rigor in focus group research. Qualitative health research 10, 293308.

Kieser, A., Kubicek, H., 1977. Organisation. de Gruyter, Berlin.

Kitzinger, J., 1995. Qualitative research. Introducing focus groups. British Medical Journal 311, 299.

Knight, L., Tu, Y.-H., Preston, J., 2014. Integrating skills profiling and purchasing portfolio management: An opportunity for building purchasing capability. International Journal of Production Economics 147, 271-283.

Knudsen, D., 2003. Aligning corporate strategy, procurement strategy and eprocurement tools. International Journal of Physical Distribution \& Logistics Management 33, 720-734.

Koppelmann, U., 2000. Beschaffungsmarketing, 3 ed. Springer, Berlin.

Kotabe, M., Murray, J.Y., 2004. Global sourcing strategy and sustainable competitive advantage. Industrial Marketing Management 33, 7-14.

Kraljič, P., 1977. Neue Wege im Beschaffungsmarketing. Manager Magazin 11, 72-80.

Kraljič, P., 1983. Purchasing must become supply management. Harvard business review 61, 109-117.

Kraljič, P., 1988. Zukunftsorientierte Beschaffungs- und Versorgungsstrategie als Element der Unternehmensstrategie, In: Henzler, H.A. (Ed.), Handbuch Strategische Führung Gabler Verlag, Wiesbaden, pp. 477-497.

Krause, D.R., 1999. The antecedents of buying firms' efforts to improve suppliers. Journal of operations management 17, 205-224.

Krause, D.R., Ellram, L.M., 1997. Success factors in supplier development. International Journal of Physical Distribution \& Logistics Management 27, 39-52.

Krause, D.R., Handfield, R.B., Scannell, T.V., 1998. An empirical investigation of supplier development: reactive and strategic processes. Journal of operations management 17, 39-58.

Krause, D.R., Handfield, R.B., Tyler, B.B., 2007. The relationships between supplier development, commitment, social capital accumulation and performance improvement. Journal of operations management 25, 528-545.

Krause, D.R., Pagell, M., Curkovic, S., 2001. Toward a measure of competitive priorities for purchasing. Journal of operations management 19, 497-512.

Krause, D.R., Scannell, T.V., 2002. Supplier Development Practices: Productand Service-Based Industry Comparisons. Journal of Supply Chain Management 38, 13-21. 
Krause, D.R., Vachon, S., Klassen, R.D., 2009. Special Topic Forum on Sustainable Supply Chain Management: Introduction and Reflections on the Role of Purchasing Management*. Journal of Supply Chain Management 45, 18-25.

Kreiser, P., Marino, L., 2002.analysing the historical development of the environmental uncertainty construct. Management decision 40, 895-905.

Kroes, J.R., Ghosh, S., 2010. Outsourcing congruence with competitive priorities: Impact on supply chain and firm performance. Journal of operations management 28, 124-143.

Kulmala, H.I., 2004. Developing cost management in customer-supplier relationships: three case studies. Journal of Purchasing and Supply Management 10, 65-77.

Labro, E., 2006. Is a focus on collaborative product development warranted from a cost commitment perspective? Supply chain management: an international journal 11, 503-509.

Lagrosen, Y., Lagrosen, S., 2013. The Quality Café as a Method for Organisational learning and Quality Development, International Conference on Management, Leadership and Governance, Bangkok, pp. 203-209.

Lakemond, N., Echtelt, F., Wynstra, F., 2001. A configuration typology for involving purchasing specialists in product development. Journal of Supply Chain Management 37, 11-20.

Large, R., 2009. Strategisches Beschaffungsmanagement: Eine praxisorientierte Einführung. Mit Fallstudien, 4 ed. Gabler Verlag, Wiesbaden.

Laseter, T.M., 1998. Balanced sourcing: cooperation and competition in supplier relationships. Jossey-Bass Publishers, San Francisco.

Lau, G.-T., Goh, M., Phua, S.L., 1999. Purchase-related factors and buying center structure: an empirical assessment. Industrial Marketing Management 28, 573-587.

Lawrence, P.R., Lorsch, J.W., 1967. Differentiation and integration in complex organizations. Administrative science quarterly 12, 1-47.

Lawrence, P.R., Lorsch, J.W., 1969. Organization and Environment: Managing Differentiation and Integration. Homewood, Boston.

Lawson, B., Cousins, P.D., Handfield, R.B., Petersen, K.J., 2009. Strategic purchasing, supply management practices and buyer performance improvement: An empirical study of UK manufacturing organisations. International Journal of Production Research 47, 2649-2667.

Lee, D.M., Drake, P.R., 2010. A portfolio model for component purchasing strategy and the case study of two South Korean elevator manufacturers. International Journal of Production Research 48, 6651-6682.

Leeflang, P.S., Parreño-Selva, J., 2012. Cross-category demand effects of price promotions. Journal of the Academy of Marketing Science 40, 572-586.

Leenders, M.R., Blenkhorn, D.L., 1988. Reverse marketing: the new buyersupplier relationship. Free Press, New York. 
Lepak, D.P., Takeuchi, R., Snell, S.A., 2003. Employment flexibility and firm performance: Examining the interaction effects of employment mode, environmental dynamism, and technological intensity. Journal of Management 29, 681-703.

Li, C., 2013. Sourcing for supplier effort and competition: Design of the supply base and pricing mechanism. Management Science 59, 1389-1406.

Li, W., Humphreys, P.K., Yeung, A.C., Cheng, T., 2012a. The impact of supplier development on buyer competitive advantage: A path analytic model. International Journal of Production Economics 135, 353-366.

Li, X., Olorunniwo, F., Jolayemi, J., Fan, C., 2014. Re-examining the structure of supplier stratification matrix: a focus on differential value and relationship. International Journal of Procurement Management 7, 219-237.

Li, Y., Wei, Z., Zhao, J., Zhang, C., Liu, Y., 2012b. Ambidextrous Organizational Learning, Environmental Munificence and New Product Performance: Moderating Effect of Managerial Ties in China. International Journal of Production Economics 146, 95-105.

Lin, N., 1999. Building a network theory of social capital. Connections 22, 2851.

Lindblom, A., Olkkonen, R., Ollila, P., Hyvönen, S., 2009. Suppliers' roles in category management: A study of supplier-retailer relationships in Finland and Sweden. Industrial Marketing Management 38, 1006-1013.

Lintukangas, K., Peltola, S., Virolainen, V.M., 2009. Some issues of supply management integration. Journal of Purchasing and Supply Management 15, 240-248.

Liu, Z., Wong, Y.S., Lee, K.S., 2010. Modularity analysis and commonality design: a framework for the top-down platform and product family design. International Journal of Production Research 48, 3657-3680.

Lonsdale, C., 2001. Locked-ln to Supplier Dominance: On the Dangers of Asset Specificity for the Outsourcing Decision. Journal of Supply Chain Management 37, 22-27.

Loppacher, J.S., Cagliano, R., Spina, G., 2011. Key drivers of buyer-supplier relationships in global sourcing strategies. International Journal of Procurement Management 4, 156-180.

Loppacher, J.S., Luchi, R., Cagliano, R., Spina, G., 2006. Global sourcing and procurement strategy: a model of interrelated decisions. Supply Chain Forum: International Journal 7, 34-46.

Lorange, P., 1980. Corporate planning: An executive viewpoint. Prentice-Hall, Englewood Cliffs.

Lui, S.S., Ngo, H.y., 2012. Drivers and Outcomes of Long-term Orientation in Cooperative Relationships. British Journal of Management 23, 80-95.

Lumpkin, G.T., Dess, G.G., 2001. Linking two dimensions of entrepreneurial orientation to firm performance: The moderating role of environment and industry life cycle. Journal of business venturing 16, 429-451. 
Luo, X., Kwong, C., Tang, J., Deng, S., Gong, J., 2011. Integrating supplier selection in optimal product family design. International Journal of Production Research 49, 4195-4222.

Luzzini, D., Caniato, F., Ronchi, S., Spina, G., 2012. A transaction costs approach to purchasing portfolio management. International Journal of Operations \& Production Management 32, 1015-1042.

Luzzini, D., Ronchi, S., 2011. Organizing the purchasing department for innovation. Operations Management Research 4, 14-27.

Lysons, K., Farrington, B., 2012. Purchasing and Supply Chain Management, 8 ed. Peason Education, Harlow.

MacCallum, R.C., Zhang, S., Preacher, K.J., Rucker, D.D., 2002. On the practice of dichotomization of quantitative variables. Psychological methods $7,19$.

MacKenzie, S.B., Podsakoff, P.M., Podsakoff, N.P., 2011. Construct measurement and validation procedures in MIS and behavioral research: Integrating new and existing techniques. MIS Quarterly 35, 293-334.

Maffin, D., Braiden, P., 2001. Manufacturing and supplier roles in product development. International Journal of Production Economics 69, 205-213.

Manrodt, K.B., Vitasek, K., 2004. Global process standardization: a case study. Journal of Business Logistics 25, 1-23.

Masi, D., Micheli, G.J.L., Cango, E., 2013. A meta-model for choosing a supplier selection technique within an EPC company. Journal of Purchasing and Supply Management 19, 5-15.

Matthyssens, P., Toole, R.J., Favre, D.J., 2006. The future of purchasing and supply, In: Cavinato, J.L. (Ed.), The supply mangement handbook, 7 ed. McGraw-Hill, New York.

Mayring, P., 2003. Qualitative Inhaltsanalyse: Grundlagen und Techniken, 8 ed. Beltz Verlag, Weinheim.

McAlister, L., 2006. Introduction to the Marketing Science Institute Special Section on Academic and Practitioner Collaborative Research. Journal of marketing research 43, 515-517.

McGinnis, M.A., Vallopra, R.M., 1999. Purchasing and supplier involvement in process improvement: a source of competitive advantage. Journal of Supply Chain Management 35, 42-50.

McMillan, J., 1990. Managing suppliers: Incentive systems in japanese and u.s. industry. California Management Review 32, 38-55.

Melander, L., Lakemond, N., 2014. Variation of purchasing's involvement: case studies of supplier collaborations in new product development. International Journal of Procurement Management 7, 103-118.

Meredith, J., 1993. Theory building through conceptual methods. International Journal of Operations \& Production Management 13, 3-11.

Merton, R.K., 1990. Focused interview, 2 ed. The Free Press, New York. 
Miles, R.E., Snow, C.C., Pfeffer, J., 1974. Organization-Environment: Concepts and Issues. Industrial Relations: A Journal of Economy and Society 13, 244264.

Miller, D., Friesen, P.H., 1983. Strategy-making and environment: The third link. Strategic Management Journal 4, 221-235.

Miller, P.A., Kelle, P., 1998. Quantitative support for buyer-supplier negotiation in just-in-time purchasing. International Journal of Purchasing and Materials Management 34, 25-30.

Min, H., LaTour, M.S., Williams, A., 1994. Positioning against foreign supply sources in an international purchasing environment. Industrial Marketing Management 23, 371-382.

Mintzberg, H., 1979. The structuring of organizations. Prentice-Hall, Englewood Cliffs.

Mintzberg, H., 1994. Rise and fall of strategic planning. The Free Press, New York.

Modi, S.B., Mabert, V.A., 2007. Supplier development: improving supplier performance through knowledge transfer. Journal of operations management $25,42-64$.

Mol, M.J., 2003. Purchasing's strategic relevance. Journal of Purchasing and Supply Management 9, 43-50.

Mol, M.J., Van Tulder, R.J., Beije, P.R., 2005. Antecedents and performance consequences of international outsourcing. International Business Review 14, 599-617.

Monczka, R., Handfield, R.B., Giunipero, L., Patterson, J., 2011. Purchasing and Supply Chain Management, 5 ed. Cengage Learning, Mason.

Monczka, R.M., Handfield, R.B., Giunipero, L., 2008. Purchasing and supply chain management. Cengage Learning, Mason.

Monczka, R.M., Markham, W.J., 2007. Category strategies and supplier management. Supply Chain Management Review 11, 24-30.

Monczka, R.M., Trent, R.J., 1991. Evolving sourcing strategies for the 1990s. International Journal of Physical Distribution \& Logistics Management 21, 412.

Monczka, R.M., Trent, R.J., Callahan, T.J., 1993. Supply base strategies to maximize supplier performance. International Journal of Physical Distribution \& Logistics Management 23, 42-54.

Morgan, D.L., 1997. Focus groups as qualitative research, 2 ed. Sage Publications, London.

Morrison, D.E., 1998. The Search for a Method: Focus Groups and the Development of Mass Communication Research. University of Luton, Luton.

Morssinkhof, S., Wouters, M., Warlop, L., 2011. Effects of providing total cost of ownership information on attribute weights in purchasing decisions. Journal of Purchasing and Supply Management 17, 132-142.

Moser, R., 2007. Strategic Purchasing and Supply Management: A StrategyBased Selection of Suppliers. Deutscher Universitätsverlag, Wiesbaden. 
Mukhopadhyay, T., Kekre, S., 2002. Strategic and operational benefits of electronic integration in B2B procurement processes. Management Science 48, 1301-1313.

Nagashima, M., Wehrle, F.T., Kerbache, L., Lassagne, M., Wagner, B., 2015. Impacts of adaptive collaboration on demand forecasting accuracy of different product categories throughout the product life cycle. Supply chain management: an international journal 20, 415 - 433.

Nagati, H., Rebolledo, C., 2013. Supplier development efforts: The suppliers' point of view. Industrial Marketing Management.

Nakano, M., 2009. Collaborative forecasting and planning in supply chains: The impact on performance in Japanese manufacturers. International Journal of Physical Distribution \& Logistics Management 39, 84-105.

Nandakumar, M., Ghobadian, A., O'Regan, N., 2010. Business-level strategy and performance: The moderating effects of environment and structure. Management decision 48, 907-939.

Narasimhan, R., Carter, J.R., 1998. Linking business unit and material sourcing strategies. Journal of Business Logistics 19, 155-171.

Narasimhan, R., Das, A., 2001. The impact of purchasing integration and practices on manufacturing performance. Journal of operations management 19, 593-609.

Nassimbeni, G., 2006. International sourcing: Empirical evidence from a sample of Italian firms. International Journal of Production Economics 103, 694-706.

Nellore, R., Söderquist, K., 2000. Portfolio approaches to procurement: Analysing the missing link to specifications. Long Range Planning 33, 245267.

Nellore, R., Taylor, J.E., 2000. Using portfolio approaches to manage engineering-purchasing-supplier interaction. Production and Inventory Management Journal 41, 6-12.

Newbert, S.L., 2007. Empirical research on the resource-based view of the firm: An assessment and suggestions for future research. Strategic Management Journal 28, 121-146.

Newman, W., Krehbiel, T.C., 2007. Linear performance pricing: A collaborative tool for focused supply cost reduction. Journal of Purchasing and Supply Management 13, 152-165.

Nicolini, D., Tomkins, C., Holti, R., Oldman, A., Smalley, M., 2000. Can target costing and whole life costing be applied in the construction industry?: Evidence from two case studies. British Journal of Management 11, 303-324.

Nollet, J., Beaulieu, M., 2005. Should an organisation join a purchasing group? Supply chain management: an international journal 10, 11-17.

Nollet, J., Calvi, R., Audet, E., Côté, M., 2008. When excessive cost savings measurement drowns the objectives. Journal of Purchasing and Supply Management 14, 125-135. 
Nollet, J., Ponce, S., Campbell, M., 2005. About "strategy" and "strategies" in supply management. Journal of Purchasing and Supply Management 11, 129140.

Nollet, J., Rebolledo, C., Popel, V., 2012. Becoming a preferred customer one step at a time. Industrial Marketing Management 41, 1186-1193.

Nyaga, G.N., Whipple, J.M., Lynch, D.F., 2010. Examining supply chain relationships: do buyer and supplier perspectives on collaborative relationships differ? Journal of operations management 28, 101-114.

O'Brien, J., 2012. Category management in purchasing: A strategic approach to maximize business profitability, 2 ed. Kogan Page, London.

O'Keeffe, M., Fearne, A., 2002. From commodity marketing to category management: insights from the Waitrose category leadership program in fresh produce. Supply chain management: an international journal 7, 296-301.

Ogden, J.A., Petersen, K.J., Carter, J.R., Monczka, R.M., 2005. Supply management strategies for the future: A Delphi study. Journal of Supply Chain Management 41, 29-48.

Olsen, R.F., Ellram, L.M., 1997. A portfolio approach to supplier relationships. Industrial Marketing Management 26, 101-113.

Pagell, M., Krause, D.R., 2004. Re-exploring the relationship between flexibility and the external environment. Journal of operations management 21, 629649.

Pagell, M., Wu, Z., Wasserman, M.E., 2010. Thinking differently about purchasing portfolios: an assessment of sustainable sourcing. Journal of Supply Chain Management 46, 57-73.

Pandit, K., Marmanis, H., 2008. Spend Analysis: The Window Into Strategic Sourcing. J. Ross Pub., Fort Lauderdale.

Parente, R.C., Baack, D.W., Hahn, E.D., 2011. The effect of supply chain integration, modular production, and cultural distance on new product development: A dynamic capabilities approach. Journal of International Management 17, 278-290.

Parker, D.B., Zsidisin, G.A., Ragatz, G.L., 2008. Timing and extent of supplier integration in new product development: a contingency approach. Journal of Supply Chain Management 44, 71-83.

Patala, S., Jalkala, A., Soukka, R., 2014. Methods for reducing buyer perceived risk related to the adoption of technological innovations. International Journal of Procurement Management 7, 71-84.

Paulraj, A., Chen, I.J., Flynn, J., 2006. Levels of strategic purchasing: Impact on supply integration and performance. Journal of Purchasing and Supply Management 12, 107-122.

Pazirandeh, A., Norrman, A., 2014. An interrelation model of power and purchasing strategies: A study of vaccine purchase for developing countries. Journal of Purchasing and Supply Management 20, 41-53.

Pearson, J.N., Gritzmacher, K.J., 1990. Integrating purchasing into strategic management. Long Range Planning 23, 91-99. 
Pelham, A.M., 1999. Influence of environment, strategy, and market orientation on performance in small manufacturing firms. Journal of Business Research 45, 33-46.

Perdue, B.C., Summers, J.O., 1991. Purchasing agents' use of negotiation strategies. Journal of marketing research 28, 175-189.

Petersen, K.J., Prayer, D.J., Scannell, T.V., 2000. An empirical investigation of global sourcing strategy effectiveness. Journal of Supply Chain Management 36, 29-38.

Petersen, K.J., Ragatz, G.L., Monczka, R.M., 2005. An examination of collaborative planning effectiveness and supply chain performance. Journal of Supply Chain Management 41, 14-25.

Petter, S., Straub, D., Rai, A., 2007. Specifying formative constructs in information systems research. MIS Quarterly 31, 623-656.

Pettigrew, A.M., 1997. The double hurdles for management research, In: Clarke, T. (Ed.), Advancement in Organizational Behaviour: Essays in Honour of D. S. Pugh. Darthmouth Press, London, pp. 277-296.

Pettigrew, A.M., 2001. Management research after modernism. British Journal of Management 12, 61-70.

Pfohl, H.-C., Large, R.O., 2003. Beschaffungsstrategien und strategisches Management, In: Boutellier, R., Wagner, S.M., Wehrli, H.P. (Eds.), Handbuch Beschaffung: Strategien, Methoden, Umsetzung. Carl Hanser Verlag, München, Wien.

Pohl, M., 2011. Achieving purchasing competence through purchasing performance measurement system design: A multiple-case study analysis. Journal of Purchasing and Supply Management 17, 231-245.

Porter, M.E., 1980. Competitive strategy. Free Press, New York.

Pradhan, S.K., Routroy, S., 2014. Development of supply chain risk mitigation strategy: a case study. International Journal of Procurement Management 7, 359-375.

Prahalad, C.K., Hamel, G., 1994. Strategy as a field of study: Why search for a new paradigm? Strategic Management Journal 15, 5-16.

Pramatari, K., 2007. Collaborative supply chain practices and evolving technological approaches. Supply chain management: an international journal $12,210-220$.

Prewitt, V., 2011. Working in the cafe: Lessons in group dialogue. The Learning Organization 18, 189-202.

Priem, R.L., Rasheed, A.M., Kotulic, A.G., 1995. Rationality in strategic decision processes, environmental dynamism and firm performance. Journal of Management 21, 913-929.

Prince, M., Geunes, J., Smith, J.C., 2013. Procurement allocation planning with multiple suppliers under competition. International Journal of Production Research 51, 6900-6922. 
Pulles, N.J., Veldman, J., Schiele, H., 2014. Identifying innovative suppliers in business networks: An empirical study. Industrial Marketing Management 43, 409-418.

Puschmann, T., Alt, R., 2005. Successful use of e-procurement in supply chains. Supply chain management: an international journal 10, 122-133.

Quayle, M., 2006. Purchasing and supply chain management: Strategies and realities. Idea Group Publishing, Hershey.

Quintens, L., Pauwels, P., Matthyssens, P., 2006a. Global purchasing strategy: Conceptualization and measurement. Industrial Marketing Management 35, 881-891.

Quintens, L., Pauwels, P., Matthyssens, P., 2006b. Global purchasing: State of the art and research directions. Journal of Purchasing and Supply Management 12, 170-181.

Ragatz, G.L., Handfield, R.B., Petersen, K.J., 2002. Benefits associated with supplier integration into new product development under conditions of technology uncertainty. Journal of Business Research 55, 389-400.

Rajagopal, S., Bernard, K.N., 1993a. Cost containment strategies: Challenges for strategic purchasing in the 1990s. Journal of Supply Chain Management 29, 17-24.

Rajagopal, S., Bernard, K.N., 1993b. Strategic procurement and competitive advantage. Journal of Supply Chain Management 29, 12-20.

Rajagopal, S., Bernard, K.N., 1994. Creating strategic change in procurement orientation: A strategy for improving competitiveness. European Journal of Purchasing \& Supply Management 1, 149-160.

Ramanathan, U., Gunasekaran, A., 2014. Supply chain collaboration: Impact of success in long-term partnerships. International Journal of Production Economics 147, 252-259.

Ramsay, J., 2001a. Purchasing's strategic irrelevance. European Journal of Purchasing \& Supply Management 7, 257-263.

Ramsay, J., 2001b. The resource based perspective, rents, and purchasing's contribution to sustainable competitive advantage. Journal of Supply Chain Management 37, 38-47.

Ramsay, J., Croom, S., 2008. The impact of evolutionary and developmental metaphors on Purchasing and Supply Management: A critique. Journal of Purchasing and Supply Management 14, 192-204.

Ramsay, J., Wilson, I., 1990. Sourcing/contracting strategy selection. International Journal of Operations \& Production Management 10, 19-28.

Randolph, W.A., Dess, G.G., 1984. The congruence perspective of organization design: a conceptual model and multivariate research approach. Academy of management review 9, 114-127.

Ratha, P.C., 2014. Towards concurrent product and supply chain designing: a review of concepts and practices. International Journal of Procurement Management 7, 391-406. 
Reinartz, W., Haenlein, M., Henseler, J., 2009. An empirical comparison of the efficacy of covariance-based and variance-based SEM. International Journal of Research in Marketing 26, 332-344.

Rendon, R., 2005. Commodity sourcing strategies: Processes, best practices, and defense initiatives. Journal of Contract Management 3, 7-21.

Rese, M., 2006. Successful and sustainable business partnerships: How to select the right partners. Industrial Marketing Management 35, 72-82.

Ringle, C., Wende, S., Becker, J.-M., 2015. SmartPLS 3. SmartPLS. Retrieved from http://www.smartpls.com.

Ringle, C., Wende, S., Will, A., 2005. SmartPLS 2. SmartPLS. Retrieved from http://www.smartpls.com.

Rink, D.R., 1976. The product life cycle in formulating purchasing strategy. Industrial Marketing Management 5, 231-242.

Rink, D.R., David, R., HFox, H.W., 2003. Using the product life cycle concept to formulate actionable purchasing strategies. Singapore Management Review $25,73-89$.

Rogers, K.W., Purdy, L., Safayeni, F., Duimering, P.R., 2007. A supplier development program: rational process or institutional image construction? Journal of operations management 25, 556-572.

Romano, P., Formentini, M., 2012. Designing and implementing open book accounting in buyer-supplier dyads: A framework for supplier selection and motivation. International Journal of Production Economics 137, 68-83.

Rossetti, C., Choi, T.Y., 2005. On the dark side of strategic sourcing: Experiences from the aerospace industry. The Academy of Management Executive 19, 46-60.

Rossiter, J.R., 2002. The C-OAR-SE procedure for scale development in marketing. International Journal of Research in Marketing 19, 305-335.

Rowe, G., Wright, G., 2001. Expert opinions in forecasting: the role of the Delphi technique, In: Armstrong, J. (Ed.), Principles of forecasting. Kluwer Academic, Boston, pp. 125-144.

Rozemeijer, F., 2000. How to manage corporate purchasing synergy in a decentralised company? Towards design rules for managing and organising purchasing synergy in decentralised companies. European Journal of Purchasing \& Supply Management 6, 5-12.

Rozemeijer, F., 2008. Purchasing myopia revisited again? Journal of Purchasing and Supply Management 14, 205-207.

Rüdrich, G., Kalbfuss, W., Weisser, K., 2000. Materialgruppenmanagement: Quantensprung in der Beschaffung. Gabler Verlag, Wiesbaden.

Salomon, R., Martin, X., 2008. Learning, knowledge transfer, and technology implementation performance: A study of time-to-build in the global semiconductor industry. Management Science 54, 1266-1280.

Salvador, F., Villena, V.H., 2013. Supplier Integration and NPD Outcomes: Conditional Moderation Effects of Modular Design Competence. Journal of Supply Chain Management 49, 87-113. 
Samli, A.C., Browning, J.M., Busbia, C., 1998. The status of global sourcing as a critical tool of strategic planning: Opportunistic versus strategic dichotomy. Journal of Business Research 43, 177-187.

Sanchez-Rodriguez, C., Hemsworth, D., Martínez-Lorente, Á.R., 2005. The effect of supplier development initiatives on purchasing performance: a structural model. Supply chain management: an international journal 10, 289301.

Sanderson, J., Cox, A., 2008. The challenges of supply strategy selection in a project environment: Evidence from UK naval shipbuilding. Supply chain management: an international journal 13, 16-25.

Sarstedt, M., Wilczynski, P., Melewar, T., 2013. Measuring reputation in global markets-A comparison of reputation measures' convergent and criterion validities. Journal of World Business 48, 329-339.

Sartor, M., Orzes, G., Nassimbeni, G., Jia, F., Lamming, R., 2014. International purchasing offices: Literature review and research directions. Journal of Purchasing and Supply Management 20, 1-17.

Schiele, H., 2006. How to distinguish innovative suppliers? Identifying innovative suppliers as new task for purchasing. Industrial Marketing Management 35, 925-935.

Schiele, H., 2007. Supply-management maturity, cost savings and purchasing absorptive capacity: Testing the procurement-performance link. Journal of Purchasing and Supply Management 13, 274-293.

Schiele, H., 2010. Early supplier integration: the dual role of purchasing in new product development. R\&d Management 40, 138-153.

Schiele, H., Calvi, R., Gibbert, M., 2012a. Customer attractiveness, supplier satisfaction and preferred customer status: Introduction, definitions and an overarching framework. Industrial Marketing Management 41, 1178-1185.

Schiele, H., Horn, P., Vos, B., 2011a. Estimating cost-saving potential from international sourcing and other sourcing levers: Relative importance and trade-offs. International Journal of Physical Distribution \& Logistics Management 41, 315-336.

Schiele, H., Krummaker, S., 2011. Consortium benchmarking: Collaborative academic-practitioner case study research. Journal of Business Research 64, 1137-1145.

Schiele, H., Veldman, J., Hüttinger, L., 2011b. Supplier innovativeness and supplier pricing: The role of preferred customer status. International Journal of Innovation Management 15, 1-27.

Schiele, H., Veldman, J., Hüttinger, L., Pulles, N., 2012b. Towards a social exchange theory perspective on preferred customership - concept and practice, In: Bogaschewsky, R., Essig, M., Lasch, R., Stoelzle, W. (Eds.), Supply Management Research. Gabler, Wiesbaden, pp. 133-151.

Schoenherr, T., Mabert, V.A., 2008. The use of bundling in B2B online reverse auctions. Journal of operations management 26, 81-95. 
Schoenherr, T., Mabert, V.A., 2011. A comparison of online and offline procurement in B2B markets: results from a large-scale survey. International Journal of Production Research 49, 827-846.

Schotanus, F., Telgen, J., 2007. Developing a typology of organisational forms of cooperative purchasing. Journal of Purchasing and Supply Management 13, 53-68.

Schotanus, F., Telgen, J., Boer, L., 2010. Critical success factors for managing purchasing groups. Journal of Purchasing and Supply Management 16, 51-60.

Schuh, C., Bremicker, M., 2005. Der Einkauf als Margenmotor: Methoden zur Kostensenkung: mit Fallbeispielen. Gabler Verlag, Wiesbaden.

Schuh, C., Kromoser, R., Strohmer, M., Pérez, R.R., Triplat, A., 2008. Das Einkaufsschachbrett: Mit 64 Ansätzen Materialkosten senken und Wert schaffen. Gabler Verlag, Wiesbaden.

Schuh, C., Raudabaugh, J.L., Kromoser, R., Strohmer, M.F., Triplat, A., 2011. The Purchasing Chessboard: 64 Methods to Reduce Costs and Increase Value with Suppliers. Springer, New York.

Schulze, M., Seuring, S., Ewering, C., 2012. Applying activity-based costing in a supply chain environment. International Journal of Production Economics $135,716-725$.

Schumacher, S.C., Schiele, H., Contzen, M., Zachau, T., 2008. Die 3 Faktoren des Einkaufs: Einkauf und Lieferanten strategisch positionieren. Wiley-VCH Verlag, Weinheim.

Seuring, S., Müller, M., 2008. From a literature review to a conceptual framework for sustainable supply chain management. Journal of Cleaner Production 16, 1699-1710.

Shao, J., Moser, R., Henke, M., 2011. Multidimensional supply performance framework: A conceptual development and empirical analysis. International Journal of Production Economics.

Sharfman, M.P., Dean, J.W., 1991. Conceptualizing and measuring the organizational environment: A multidimensional approach. Journal of Management 17, 681-700.

Sheth, J.N., Sharma, A., 1997. Supplier relationships: emerging issues and challenges. Industrial Marketing Management 26, 91-100.

Shou, Z., Yang, L., Zhang, Q., Su, C., 2013. Market munificence and inter-firm information sharing: The moderating effect of specific assets. Journal of Business Research 66, 2130-2138.

Sillanpää, I., Shahzad, K., Sillanpää, E., 2015. Supplier development and buyersupplier relationship strategies-a literature review. International Journal of Procurement Management 8, 227-250.

Smals, R.G., Smits, A.A., 2012. Value for value-The dynamics of supplier value in collaborative new product development. Industrial Marketing Management 41, 156-165. 
Smart, A., Dudas, A., 2007. Developing a decision-making framework for implementing purchasing synergy: a case study. International Journal of Physical Distribution \& Logistics Management 37, 64-89.

Smart, A., Harrison, A., 2003. Online reverse auctions and their role in buyersupplier relationships. Journal of Purchasing and Supply Management 9, 257268.

Smeltzer, L.R., Carr, A.S., 2003. Electronic reverse auctions: Promises, risks and conditions for success. Industrial Marketing Management 32, 481-488.

Smeltzer, L.R., Manship, J.A., Rossetti, C.L., 2003. An analysis of the integration of strategic sourcing and negotiation planning. Journal of Supply Chain Management 39, 16-25.

Smith, J.M., 1999. Item selection for global purchasing. European Journal of Purchasing \& Supply Management 5, 117-127.

Sollish, F., Semanik, J., 2011. Strategic global sourcing best practices. Wiley, Hoboken.

Song, I., Chintagunta, P.K., 2006. Measuring cross-category price effects with aggregate store data. Management Science 52, 1594-1609.

Song, M., Di Benedetto, C.A., 2008. Supplier's involvement and success of radical new product development in new ventures. Journal of operations management 26, 1-22.

Spee, A.P., Jarzabkowski, P., 2009. Strategy tools as boundary objects. Strategic Organization 7, 223-232.

Speed, R., 1993. Maximizing the potential of strategic typologies for marketing strategy research. Journal of Strategic Marketing 1, 171-188.

Spekman, R.E., 1981. A strategic approach to procurement planning. Journal of Purchasing and Materials Management Winter, 3-9.

Spekman, R.E., 1985. Competitive procurement strategies: building strength and reducing vulnerability. Long Range Planning 18, 94-99.

Spekman, R.E., Davis, E.W., 2004. Risky business: expanding the discussion on risk and the extended enterprise. International Journal of Physical Distribution \& Logistics Management 34, 414-433.

Spekman, R.E., Johnston, W.J., 1986. Relationship management: Managing the selling and the buying interface. Journal of Business Research 14, 519-531.

Spekman, R.E., Kamauff, J.W., Salmond, D.J., 1994. At last purchasing is becoming strategic. Long Range Planning 27, 76-84.

Spina, G., Caniato, F., Luzzini, D., Ronchi, S., 2013. Past, present and future trends of purchasing and supply management: An extensive literature review. Industrial Marketing Management 42, 1202-1212.

Srinivasan, N., Ratchford, B.T., 1991. An empirical test of a model of external search for automobiles. Journal of consumer research 18, 233-242.

Stanley, L.L., 1993. Linking purchasing department structure and performance-Toward a contingency model. Journal of Strategic Marketing $1,211-219$. 
Starbuck, W.H., 1976. Organizations and their environments, In: Dunette, M.D. (Ed.), Handbook of industrial and organizational psychology. Rand McNally, Chicago, pp. 1069-1123.

Steinle, C., Schiele, H., 2008. Limits to global sourcing? Strategic consequences of dependency on international suppliers: Cluster theory, resource-based view and case studies. Journal of Purchasing and Supply Management 14, 3-14.

Stolle, M.A., 2008. From Purchasing to Supply Management. Gabler, Wiesbaden.

Stollenwerk, A., 2012. Wertschöpfungsmanagement im Einkauf: AnalysenStrategien- Methoden- Kennzahlen. Gabler Verlag, Wiesbaden.

Stremersch, S., Tellis, G.J., 2002. Strategic bundling of products and prices: a new synthesis for marketing. Journal of Marketing 66, 55-72.

Stump, R.L., 1995. Antecedents of purchasing concentration: A transaction cost explanation. Journal of Business Research 34, 145-157.

Su, Q., Song, Y.-t., Li, Z., Dang, J.-x., 2008. The impact of supply chain relationship quality on cooperative strategy. Journal of Purchasing and Supply Management 14, 263-272.

Sucky, E., Durst, S.M., 2013. Supplier development: current status of empirical research. International Journal of Procurement Management 6, 92-127.

Sundtoft, H.K., Sigurbjornsson, T., 2013. How Do Category Managers Manage? - A network perspective, IPSERA 2013 Conference, Nantes.

Susman, G.I., Evered, R.D., 1978. An assessment of the scientific merits of action research. Administrative science quarterly 23, 582-603.

Sutton, B., 1989. Procurement and its role in corporate strategy: an overview of the wine and spirit industry. International Journal of Wine Marketing 1, 4959.

Svahn, S., Westerlund, M., 2009. Purchasing strategies in supply relationships. Journal of Business \& Industrial Marketing 24, 173-181.

Svensson, G., 2004. Supplier segmentation in the automotive industry: a dyadic approach of a managerial model. International Journal of Physical Distribution \& Logistics Management 34, 12-38.

Tai, Y.-M., Ho, C.-F., Wu, W.-H., 2010. The performance impact of implementing web-based e-procurement systems. International Journal of Production Research 48, 5397-5414.

Talluri, S., Narasimhan, R., 2004. A methodology for strategic sourcing. European Journal of Operational Research 154, 236-250.

Tan, S., Brown, J., 2005. The World Café in Singapore Creating a Learning Culture Through Dialogue. The Journal of Applied Behavioral Science 41, 83-90.

Taylor, M., Taylor, A., 2008. Operations management research in the automotive sector: Some contemporary issues and future directions. International Journal of Operations \& Production Management 28, 480-489.

Tella, E., Virolainen, V.-M., 2005. Motives behind purchasing consortia. International Journal of Production Economics 93, 161-168. 
Terpend, R., Krause, D.R., Dooley, K.J., 2011. Managing buyer-supplier relationships: empirical patterns of strategy formulation in industrial purchasing. Journal of Supply Chain Management 47, 73-94.

Thomas, E., 2013. Supplier integration in new product development: Computer mediated communication, knowledge exchange and buyer performance. Industrial Marketing Management 42, 890-899.

Thomas, L., Autio, E., Gann, D., 2014. Architectural leverage: Putting platforms in context. The Academy of Management Perspectives 28, 198-219.

Thomas, R., 1994. Purchasing and technological change: Exploring the links between company technology strategy and supplier relationships. European Journal of Purchasing \& Supply Management 1, 161-168.

Thompson, J.D., 1967. Organizations in action: Social science bases of administrative theory. McGráw-Hill, New York.

Tornberg, K., Jämsen, M., Paranko, J., 2002. Activity-based costing and process modeling for cost-conscious product design: A case study in a manufacturing company. International Journal of Production Economics 79, 75-82.

Tracey, M., Neuhaus, R., 2013. Purchasing's role in global new product-process development projects. Journal of Purchasing and Supply Management 19, 98105.

Tranfield, D., Denyer, D., Marcos, J., Burr, M., 2004. Co-producing management knowledge. Management decision 42, 375-386.

Trautmann, G., Bals, L., Hartmann, E., 2009a. Global sourcing in integrated network structures: The case of hybrid purchasing organizations. Journal of International Management 15, 194-208.

Trautmann, G., Turkulainen, V., Hartmann, E., Bals, L., 2009b. Integration in the global sourcing organization: An information processing perspective. Journal of Supply Chain Management 45, 57-74.

Trent, R.J., Monczka, R.M., 2003. International Purchasing and Global Sourcing - What are the Differences? Journal of Supply Chain Management 39, 26-36.

Trim, P.R.J., Lee, Y., 2004. A reflection on theory building and the development of management knowledge. Management decision 42, 473-480.

Trkman, P., McCormack, K., 2009. Supply chain risk in turbulent environments-A conceptual model for managing supply chain network risk. International Journal of Production Economics 119, 247-258.

Tsai, W., Ghoshal, S., 1998. Social capital and value creation: The role of intrafirm networks. Academy of Management Journal 41, 464-476.

Tuten, T.L., Urban, D.J., 2001. An expanded model of business-to-business partnership formation and success. Industrial Marketing Management 30, 149-164.

Van Hoek, R., Chapman, P., 2007. How to move supply chain beyond cleaning up after new product development. Supply chain management: an international journal 12, 239-244.

Van Weele, A.J., 2010. Purchasing and supply chain management: Analysis, strategy, planning and practice, 5 ed. Cengage Learning EMEA, Hampshire. 
Villena, V.H., Revilla, E., Choi, T.Y., 2011. The dark side of buyer-supplier relationships: A social capital perspective. Journal of operations management 29, 561-576.

Virolainen, V.M., 1998. A survey of procurement strategy development in industrial companies. International Journal of Production Economics 56, 677688.

Vrat, P., 2014. Value Analysis for Material Cost Reduction, Materials Management. Springer, pp. 339-356.

Wacker, J.G., 1998. A definition of theory: research guidelines for different theory-building research methods in operations management. Journal of operations management 16, 361-385.

Wagner, B.A., Macbeth, D.K., Boddy, D., 2002. Improving supply chain relations: an empirical case study. Supply chain management: an international journal 7, 253-264.

Wagner, S.M., 2008. Cost management practices for supply chain management: an exploratory analysis. International Journal of Services and Operations Management 4, 296-320.

Wagner, S.M., 2011. Supplier development and the relationship life-cycle. International Journal of Production Economics 129, 277-283.

Wagner, S.M., 2012. Tapping supplier innovation. Journal of Supply Chain Management 48, 37-52.

Wagner, S.M., Bode, C., 2006. An empirical investigation into supply chain vulnerability. Journal of Purchasing and Supply Management 12, 301-312.

Wagner, S.M., Johnson, J.L., 2004. Configuring and managing strategic supplier portfolios. Industrial Marketing Management 33, 717-730.

Wang, S., Archer, N., 2007. Business-to-business collaboration through electronic marketplaces: an exploratory study. Journal of Purchasing and Supply Management 13, 113-126.

Ward, P.T., Duray, R., Keong Leong, G., Sum, C.-C., 1995. Business environment, operations strategy, and performance: an empirical study of Singapore manufacturers. Journal of operations management 13, 99-115.

Watts, C.A., Kim, K.Y., Hahn, C.K., 1992. Linking purchasing to corporate competitive strategy. International Journal of Purchasing and Materials Management 28, 2-8.

Weber, M., Hiete, M., Lauer, L., Rentz, O., 2010. Low cost country sourcing and its effects on the total cost of ownership structure for a medical devices manufacturer. Journal of Purchasing and Supply Management 16, 4-16.

Wee, H.-M., Lee, M.-C., Yu, J.C., Edward Wang, C., 2011. Optimal replenishment policy for a deteriorating green product: Life cycle costing analysis. International Journal of Production Economics 133, 603-611.

Weick, K.E., 1995. What theory is not, theorizing is. Administrative science quarterly 40, 385-390. 
Whipple, J., Wiedmer, R., Boyer, K., 2015. A Dyadic Investigation of Collaborative Competence, Social Capital, and Performance in BuyerSupplier Relationships. Journal of Supply Chain Management 51, 3-21.

White, P., Hanmer-Lloyd, S., 1999. Managing the input market: the strategic challenge. European Journal of Purchasing \& Supply Management 5, 23-31.

Whitney, D., Luo, J., Heller, D.A., 2014. The Benefits and Constraints of Temporary Sourcing Diversification in Supply Chain Disruption and Recovery. Journal of Purchasing and Supply Management 20, 238-250.

Wiersema, M.F., Bantel, K.A., 1993. Top management team turnover as an adaptation mechanism: The role of the environment. Strategic Management Journal 14, 485-504.

Wilding, R., Wagner, B., Chicksand, D., Watson, G., Walker, H., Radnor, Z., Johnston, R., 2012. Theoretical perspectives in purchasing and supply chain management: an analysis of the literature. Supply chain management: an international journal 17, 454-472.

Williams, A.J., Smith, W.C., 1990. Involving purchasing in product development. Industrial Marketing Management 19, 315-319.

Wynstra, F., Weggeman, M., Van Weele, A., 2003. Exploring purchasing integration in product development. Industrial Marketing Management 32, 69-83.

Yang, Z., Aydin, G., Babich, V., Beil, D.R., 2009. Supply disruptions, asymmetric information, and a backup production option. Management Science 55, 192-209.

Yeniyurt, S., Henke Jr, J.W., Yalcinkaya, G., 2014. A longitudinal analysis of supplier involvement in buyers' new product development: working relations, inter-dependence, co-innovation, and performance outcomes. Journal of the Academy of Marketing Science 42, 291-308.

Yeung, K., Lee, P.K., Yeung, A.C., Cheng, T., 2013. Supplier partnership and cost performance: The moderating roles of specific investments and environmental uncertainty. International Journal of Production Economics $144,546-559$.

Ylimäki, J., 2014. A dynamic model of supplier-customer product development collaboration strategies. Industrial Marketing Management 43, 996-1004.

Yoshikawa, T., Innes, J., Mitchell, F., 1994. Applying functional cost analysis in a manufacturing environment. International Journal of Production Economics 36, 53-64.

Zengin, Y., Ada, E., 2010. Cost management through product design: target costing approach. International Journal of Production Research 48, 55935611.

Zheng, J., Knight, L., Harland, C., Humby, S., James, K., 2007. An analysis of research into the future of purchasing and supply management. Journal of Purchasing and Supply Management 13, 69-83. 
Zhou, K.Z., Zhang, Q., Sheng, S., Xie, E., Bao, Y., 2014. Are relational ties always good for knowledge acquisition? Buyer-supplier exchanges in China. Journal of operations management 32, 88-98.

Zsidisin, G.A., Panelli, A., Upton, R., 2000. Purchasing organization involvement in risk assessments, contingency plans, and risk management: An exploratory study. Supply chain management: an international journal 5, 187-198. 


\section{SAMENVATTING (SUMMARY IN DUTCH)}

Er zijn vraagtekens gezet bij de stelling dat generieke best practices voor inkoop valide zijn voor het hele scala aan uitgaven en leveranciersrelaties van bedrijven. Wat betreft de operationele inkoopmedewerker is duidelijk dat niet alle productcategorieën en leveranciersrelaties op dezelfde manier benaderd dienen te worden. Integendeel, in een moderne Categoriemanagement- aanpak groeperen bedrijven materialen of diensten met vergelijkbare kenmerken in 'materiaalgroepen' om een samenhangende aanbodmarkt te vormen (bijv. 'metalen platen', 'leer', 'schermen', 'kabels' etc.). Voor kostenreductie, innovatie en andere doelstellingen kiezen en implementeren operationele inkoopmedewerkers voor elke materiaalgroep een toegesneden set tactieken, ook wel 'inkooptactieken'. Verrassend genoeg bood de hedendaagse literatuur nauwelijks enige inzichten in welke inkoop- tactieken voor elke materiaalgroep de meeste potentie hebben bij specifieke kenmerken van de aanbodmarkt. Om deze leemte te vullen is de centrale doelstelling van deze scriptie het beantwoorden van de volgende onderzoekshoofdvraag: Wat zijn de effecten van tactische inkooptactieken op kosten- en innovatieprestaties, en op welke manier kunnen kenmerken van de materiaalgroep het succes van inkoop vergroten of belemmeren? Het doel is om praktische aanbevelingen te doen met betrekking tot welke tactische inkooptactieken gekozen dienen te worden, rekening houdend met de kenmerken van de materiaalgroep. Om de onderzoeksdoelstelling te bereiken volgt de scriptie meerdere stappen:

(1) Tot nu toe heeft een uiteenlopende set aan inzichten (inclusief misvattingen) over de reikwijdte van inkoopstrategie en -tactiek er met verschillende analyseniveau's toe geleid dat een diepgaande discussie over tactische inkooptactieken moeilijk is. Daarom wordt in Hoofdstuk 2 de volgende subvraag behandeld: Is het redelijk om te spreken van 'de' inkoopstrategie, of dient er onderscheid te worden gemaakt tussen 
verschillende hiërarchische analyseniveau's? In een gestructureerd literatuuronderzoek worden 2.321 Duitse en Engelse publicaties uit de afgelopen 42 jaar gescreend. De bevindingen laten zien dat er een hiërarchie van stappen ontstaat wanneer de algemene strategie wordt uitgesplitst in uitvoerbare en controleerbare activiteiten: (1) bedrijfsstrategie, (2) inkoopstrategie als een specifieke functionele strategie, (3) categorie-strategieën voor de meerderheid van de aanbodmarkten, (4) totstandkoming door een set tactische inkooptactieken en (5) strategieën voor elke leverancier binnen een materiaalgroep. Bestaande stappen bij de ontwikkeling van inkoopstrategieën worden voor de eerste keer uitgebreid met een volledige integratie van materiaalgroepen en inkooptactieken als analyseniveau's. De hiërarchische structuur biedt een samenhangende, stapsgewijze praktische aanpak voor strategie-ontwikkeling.

(2) In het vorige hoofdstuk werd een gebrek aan theoretische inzichten vastgesteld over wat tactische inkooptactieken zijn, of niet zijn. Om in de volgende hoofdstukken empirisch onderzoek mogelijk te maken, behandelt Hoofdstuk 3 de volgende subvraag: Wat definieert de conceptuele inhoud binnen het concept van inkooptactieken, en met welke maatstaven kan dit worden gevat? Hiervoor is een formatieve meetmethode voor inkooptactieken ontwikkeld. Tijdens het ontwikkelingsproces van deze index, vormde een literatuuronderzoek de basis voor zeer interactieve world café discussies met zakelijke professionals. De hierop gebaseerde maatstaven zijn vervolgens getest in 107 inkoopprojecten binnen een grote Europese automobielindustrie OEM. Voor het eerst is een breed scala aan inkooptactieken geaggregeerd tot maatstaven die bij toekomstig onderzoek helpen om relevante onderzoeksvragen over tactische inkooptactieken te beantwoorden. Het hoofdstuk onthult een breed scala aan specifieke, uitvoerbare kostenbesparingsmethodes die voor praktijkmensen kunnen dienen als 'instrumentarium' of 'checklist' bij het plannen van toekomstige inkoopactiviteiten.

(3) Inkoopportfolio's zijn op grote schaal aangepast om inkopen te categoriseren en om hieruit passende inkooptactieken af te leiden. De Kraljič-matrix en varianten hierop stellen voor elk portfoliokwadrant generieke inkooptactieken voor, Er is echter weinig gedaan om empirisch te verifiëren of conceptuele en normatieve aanbevelingen uit leerboeken 
ook in de praktijk kloppen. Daarom wordt in Hoofdstuk 4 de volgende subvraag behandeld: Verschilt de toepassing van tactische inkooptactieken afhankelijk van 'strategisch belang' en 'aanbodrisico' zoals gesuggereerd door Kraljič en zo ja, hoe? Gegevens uit een grootschalig onderzoek zijn gebruikt om 107 inkoopprojecten te classificeren in het 'routine', 'hefboom', 'knelpunt' en 'strategische' kwadrant van de Kraljič-matrix en om het profiel van toegepaste inkooptactieken tegen elkaar af te zetten. De bevindingen wijzen erop dat leerboeken mogelijk dienen te worden herzien. Leerboeken nemen aan dat bepaalde tactische inkooptactieken zich exclusief beperken tot een enkele portfolio-cel; bijv. efficiënte verwerking enkel voor routineinkopen en nauwe samenwerking enkel voor strategische inkopen. Analyses in dit hoofdstuk laten echter zien dat inkopers een mix van alle inkooptactieken in alle portfoliokwadranten gebruiken. In plaats van als alternatieven worden inkooptactieken gebruikt op een additieve manier.

(4) $\mathrm{Na}$ het leggen van de theoretische fundatie van deze scriptie wordt in Hoofdstuk 5 de directe invloed van de toepassing van inkooptactieken op kosten- en innovatieprestaties empirisch getest. De eerder ontwikkelde indices voor inkooptactieken worden gebruikt om de volgende subvraag te behandelen: Verklaart de toepassing van tactische inkooptactieken verschillen in de kosten- en innovatieprestaties van een inkoopproject? Partial least squares structural equation modelling (PLS-SEM) wordt gebruikt op de gegevens van 107 inkoopprojecten om te testen of inkooptactieken invloed hebben op prestaties. De bevindingen bieden bewijs voor het positieve effect van de 'prijs-evaluatie'-tactiek op innovatie. Dit bevestigt recente bevindingen die pleiten voor een vroegtijdige value analysis-aanpak voor inkoop om een vruchtbare basis te leggen voor discussies met leveranciers over waardeproposities, productontwerp en -functionaliteit van de aangeboden concepten.

(5) Om de onderzoekshoofdvraag volledig te behandelen worden in Hoofdstuk 6 kenmerken van de materiaalgroep gekoppeld aan de toepassing van inkooptactieken en prestatie-uitkomsten: Verklaren kenmerken van de materiaalgroep verschillen in de bijdrage van een tactische inkooptactiek aan kosten- of innovatieprestaties? Moderation analyse is gebruikt om voor 107 inkoopprojecten de prestaties onder verschillende configuraties van inkooptactieken, en gemodereerd door contextfactoren, te onderzoeken. Het hoofdstuk koppelt contingency 
theory en het concept van inkooptactieken, en biedt praktische richtlijnen met betrekking tot welke inkooptactieken leiden tot betere of slechtere kosten- of innovatieprestaties onder verschillende materiaalgroepomstandigheden. Bevindingen in Hoofdstuk 6 laten zien dat 'extension of supply base' en 'volume bundling', niet per se een 'condition sine qua non' zijn voor betere prestaties. Onder sommige omstandigheden kan het besteden van meer aandacht aan deze tactieken prestaties zelfs verminderen. Verder wijzen de bevindingen op potentiële afruilen tussen inkooptactieken. Onder zeer complexe omstandigheden kan de 'extension of supply base' tactiek bijvoorbeeld worden geïntensiveerd om extra kostenvoordelen te bewerkstelligen. Onder vergelijkbare omstandigheden vermindert dit echter innovatieprestaties. Het hoofdstuk biedt praktische richtlijnen voor operationale inkoopmedewerkers om te verifiëren of de beoogde inkooptactieken daadwerkelijk gunstig zijn bij de geldende inkoopomstandigheden.

Concluderend draagt deze scriptie bij aan de literatuur over inkoop- en supply management door bij te dragen aan de kennis over de relaties tussen tactische inkooptactieken, kenmerken van materiaalgroepen, en prestaties, bij analyses op het categorie-niveau. Een belangrijk sterk punt is dat deze scriptie stoelt op een intensieve samenwerking met operationele inkoopmedewerkers. Eerdere studies richtten zich op de meningen van het hogere management. Operationele inkoopmedewerkers en hun ervaringen op het gebied van inkopen zijn tot dusverre grotendeels verontachtzaamd op categorieniveau. De bevindingen in deze scriptie adresseren niet alleen bestaande hiaten in onderzoek, maar zijn ook praktisch gezien erg relevant, omdat ze direct de acties behandelen die operationele inkoop medewerkers kunnen nemen om de prestatie van een inkoopcategorie te verbeteren. 

Frank Henrik Hesping

Tactics at the CATEgory LeVel of Purchasing and Supply

MANAGEMENT: SOURCING LEVERS, CONTINGENCIES AND PERFORMANCE

For the 'front-line' purchasing agent, it is obvious that not all categories of products and supplier relationships should be managed in the same way. Rather, in a modern category management approach, firms group similar products into 'sourcing categories' forming coherent supply markets (e.g., 'metal sheets', 'leather', 'displays', 'cables', etc.). Thus, to achieve cost reduction targets, a tailored mix of tactical sourcing levers for each sourcing category may be required. The fundamental question is: Which tactical sourcing levers and activities, under which conditions, yield the highest cost savings? This study provides practical recommendations regarding what sourcing activities should be selected with respect to the characteristics of a particular sourcing category. The research builds on strong collaboration with 'front-line' purchasing agents and provides guidelines that can be adopted to verify whether the targeted tactical sourcing levers are actually beneficial for the sourcing conditions faced.

Frank Henrik Hesping is a research associate at the University of Twente, in Enschede, The Netherlands. At the Chair of Technology Management - Innovation of Operations, he focused his research on strategic purchasing planning. In 2011, he was awarded a University Diploma in Industrial Engineering and Management from the Karlsruhe Institute of Technology (KIT), the former University of Karlsruhe, Germany. In 2010, he graduated from the Australian School of Business and holds a Master in Technology Management from the University of New South Wales (UNSW), Australia. Besides academia, he has worked for several years in the Automotive industry.

ISBN: 978-90-365-4002-5 